\title{
THE EFFECTS OF APPLIED STRAIN AND HEAT TREATMENT ON THE PROPERTIES OF NiTi WIRE DURING SHAPE SETTING
}

\author{
A Thesis \\ presented to \\ the Faculty of the Department of Materials Engineering \\ California Polytechnic State University San Luis Obispo
}

\author{
In Partial Fulfillment \\ of the Requirements for the Degree \\ Master of Science in Engineering \\ With a specialization in Materials Engineering
}

Frank Zapoticla

June 2010 
This thesis is dedicated to my family

for their love, endless support

and encouragement 
(C) 2010

Frank Zapoticla

ALL RIGHTS RESERVED 


\section{SIGNATURE PAGE}

THESIS:

AUTHOR:

DATE SUBMITTED:

Dr. Kathy Chen

Professor

Materials Engineering

Dr. Alan R. Pelton

Nitinol Devices Components

Fremont, California

Dr. Linda Vanasupa

Materials Engineering see attached pdf see attached pdf see attached pdf
June 2010

Department of Materials Engineering

THE EFFECTS OF APPLIED STRAIN AND HEAT

TREATMENT ON THE PROPERTIES OF NiTi WIRE DURING SHAPE SETTING

Frank Zapoticla 


\section{ABSTRACT \\ THE EFFECTS OF APPLIED STRAIN AND HEAT TREATMENT ON THE PROPERTIES OF NiTi WIRE DURING SHAPE SETTING Frank Zapoticla}

NiTi components are commonly subjected to thermo-mechanical heat treatments during production and fabrication. This study investigates the effects of applied strain of $0-10 \%$ and heat treatments of $300-600^{\circ} \mathrm{C}$ for times of $2-30$ minutes during shape-setting of Ti-50.8 at $\%$ Ni wire with a nominal diameter of $0.495 \mathrm{~mm}$ and an initial transition temperature, $\mathrm{A}_{\mathrm{f}}$, of $12^{\circ} \mathrm{C}$. Strain was applied prior to heat treatments by coiling NiTi wire, essentially producing coiled springs, around different diameter steel mandrels to obtain different strain levels. The samples of NiTi wire under applied strain were heat treated in a salt bath, followed by a rapid quench. Transformation temperatures and mechanical properties were characterized using the differential scanning calorimeter and tensile tests. Changes in the $A_{f}$, UTS, and elastic modulus due to ageing processes and applied strain were observed. Following theory, precipitation rates of Ni-rich phases generally increased with increased temperature (up to a certain point), time and applied strain levels. Reaction rates to achieve a particular $\mathrm{A}_{\mathrm{f}}$ might be faster than expected if the sample is under strain during the shape-setting process. Due to precipitation strengthening, an increase in UTS with increased heat treatment time was observed between $300-450^{\circ} \mathrm{C}$; annealing processes dominate at higher temperatures, resulting in a decrease in UTS above $500^{\circ} \mathrm{C}$. A decrease in UTS with increasing level of applied strain was observed. Trends in elastic modulus were highly inconsistent in this study. As shown by this study, applied strain in NiTi during heat treatment affects the $A_{f}$ and mechanical properties.

KEYWORDS: Materials Engineering, nickel titanium, NiTi, applied strain, transformation temperature, $\mathrm{A}_{\mathrm{f}}$, precipitation rates, TTT-like diagram, DSC, tensile testing, wire, precipitation strengthening, UTS, annealing 


\section{ACKNOWLEDGEMENTS}

Throughout my journey at Cal Poly I have been blessed by God, who has guided me toward a path which has led to invaluable advisors, friendships, and opportunities. For this, I am forever grateful. Throughout my five years at Cal Poly, I have encountered numerous individuals who have inspired, encouraged, and provided financial assistance. Without their support, this achievement would not have been possible.

I would first like to thank my advisor, Dr. Katherine Chen, for her continuous support and assistance in my project. Thank you for accepting my application and becoming my advisor given such short notice. Your constructive feedback on my project has helped me become a better researcher and will continue to guide me in the future. Thank you for your persistence and determination to finish this project in two years. Most of all, thank you for introducing me to NiTi and for sparking my interest in the medical device industry.

I would next like to thank Dr. Alan Pelton and NDC for their financial support and technical assistance throughout my project. In many ways, this research would not have been possible without the support of NDC. Thank you for giving me the opportunity to work with such an interesting material. Also, thank you for providing the experience of an SMST conference. It was a memorable experience that I will always cherish. 
I would next like to thank those closest to me whose love and support have made my academic journey possible. I would first like to thank my parents, Francisco and Concepcion Zapoticla, for their personal sacrifices in order for me to have this opportunity. Thank you for guiding me in the right direction and for always encouraging me to pursue my dreams. I am truly blessed to have you as my parents. I would next like to thank my fiancé, Maricela Contreras, for her love and patience throughout our five year long distance relationship. You have always been there for me and I look forward to sharing our lives together. I would also like to thank my two sisters, Sylvia and Monica, for their unconditional love and support. Most of all, thank you for always believing in me. To everyone in my family, this thesis is dedicated to you. 


\section{TABLE OF CONTENTS}

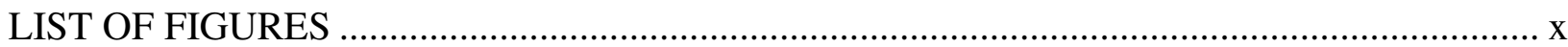

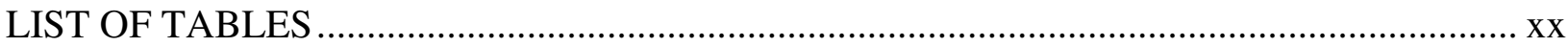

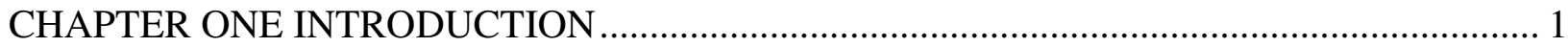

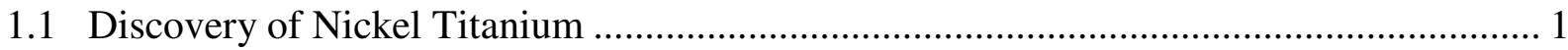

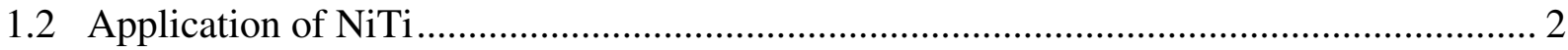

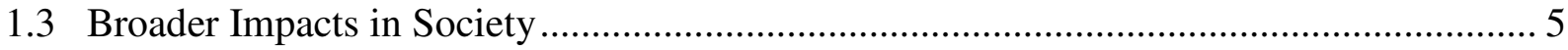

CHAPTER TWO LITERATURE REVIEW …................................................................ 7

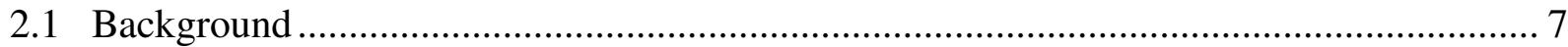

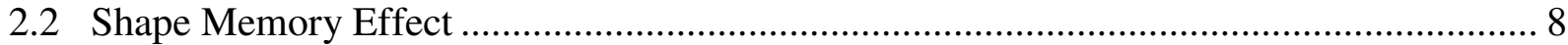

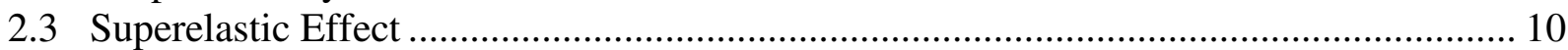

2.4 Effects of Composition ..................................................................................... 12

2.5 Precipitation Process in NiTi ........................................................................... 13

2.6 Effects of Thermal-Mechanical Treatments ......................................................... 17

CHAPTER THREE RESEARCH OBJECTIVES ............................................................. 25

CHAPTER FOUR MATERIALS AND EXPERIMENTAL METHODS ................................ 26

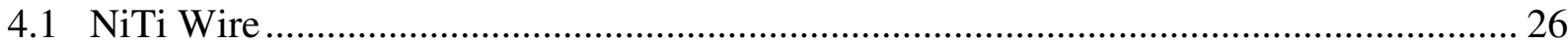

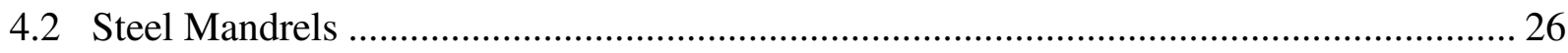

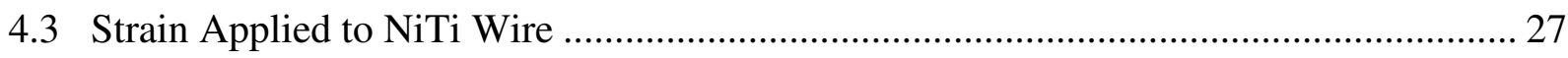

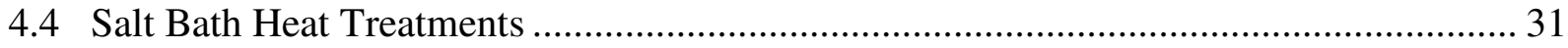

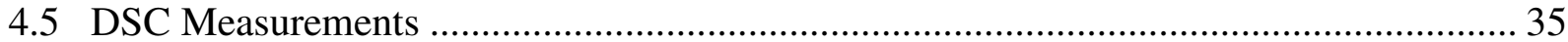

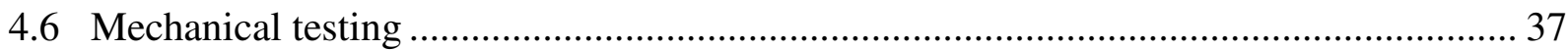

4.7 Three Dimensional TTT-like Diagram ................................................................ 43

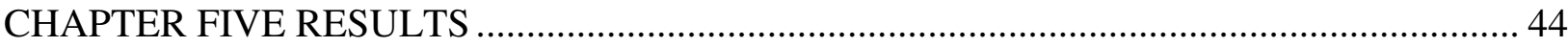

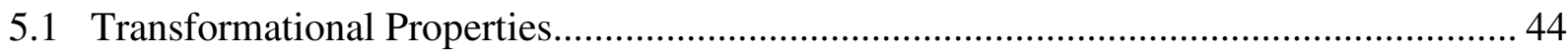

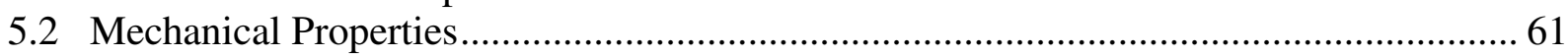

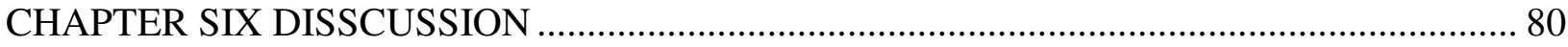

6.1 Transformation Properties ............................................................................... 80

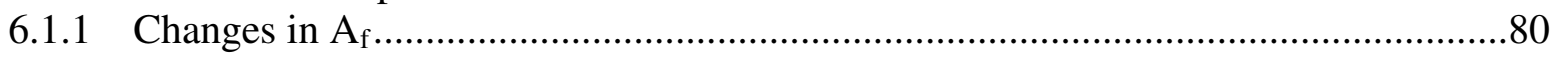

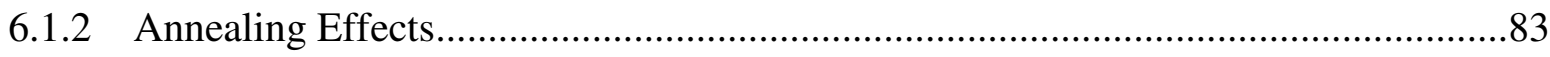




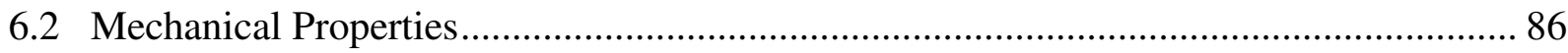

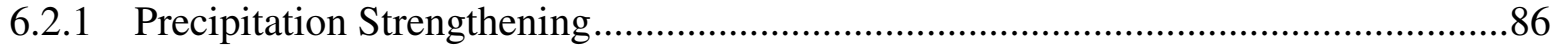

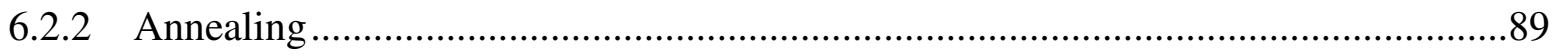

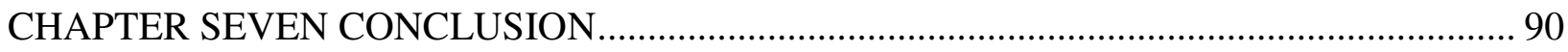

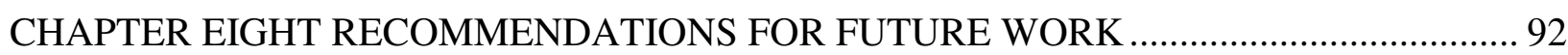

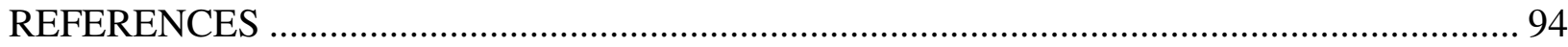

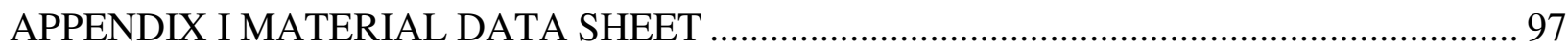

APPENDIX II EFFECT OF APPLIED STRAIN AND HEAT TREATMENT ON $\mathrm{A}_{\mathrm{f}} \mathrm{AT}$

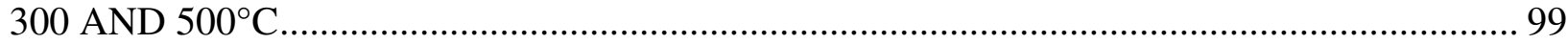

APPENDIX III EFFECT OF HEAT TREATMENT ON A A AT APPLIED STRAINS OF

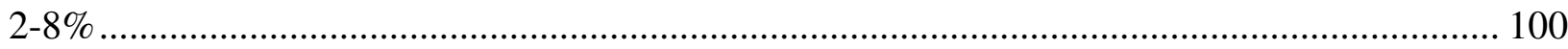

APPPENDIX IV TTT-LIKE DIAGRAMS FOR APPLIED STRAINS OF 2-8\% …………..... 102

APPENDIX V TENSILE RESPONSE AT 400 ${ }^{\circ} \mathrm{C}$ FOR 2 AND 30 MINUTES ......................... 104

APPENDIX VI EFFECT OF APPLIED STRAIN HEAT TREATMENT ON UTS AT 5

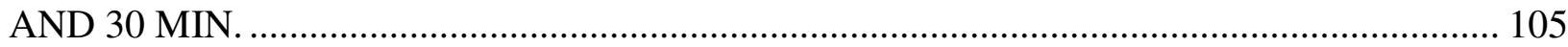

APPENDIX VII EFFECT OF HEAT TREATMENT TIME AT APPLIED STRAINS OF

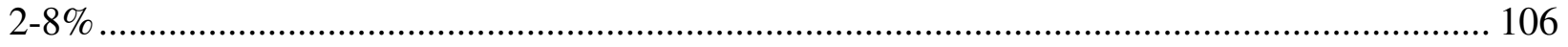

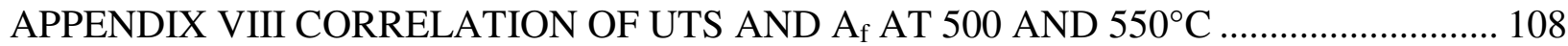

APPENDIX IX EFFECT OF TEMEPRATURE ON ELASTIC MODULUS AT 5 AND

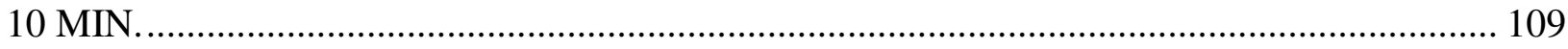

APPENDIX X EFFECT OF HEAT TREATMENT ON ELASTIC MODULUS

APPLIED STRAINS OF 2-8\% 


\section{LIST OF FIGURES}

Figure 1 - (a) A compressed NiTi stent will (b) completely recover its original shape upon the release of an applied load due to superelasticity [3].

Figure 2 - Simon vena cava filter employs the shape memory and superelastic effect. The progression as the device expands to the designed shape is shown. Once expanded, a constant stress against the vessel walls is provided by the superelastic properties [4]. 4

Figure 3 - Superelastic NiTi archwire retains a curved shape and provides a low continuous force that effectively corrects mal-occluded teeth. NiTi arch-wires can be thermally activated once placed inside the mouth or superelastic at room temperature [5] .5

Figure 4 - (a) A crystallographic schematic of a cubic $\mathrm{CsCl}$ crystal structure observed in the austenite phase, and (b) a B19' monoclinic crystal structure observed in the martensite phase of NiTi. The change in crystal structure results from a solid state, diffusion less phase transformation [9]. .8

Figure 5 -A generic thermal hysteresis for NiTi illustrates the temperature induced phase transformation. Note that a physical change in shape occurs during the phase transformation from martensite to austenite [11].

Figure 6 - Typical stress-strain behavior illustrated for two temperature ranges. Note the large amount of recoverable strain in superelastic NiTi [8].

Figure 7 - A general trend illustrating the effect of nickel concentration in NiTi on the transformation temperature. Small variations in alloy composition results in a significant change in $\mathrm{A}_{\mathrm{f}}$. Typical alloy compositions used in superelastic applications are represented by the shaded section [14].

Figure 8 - Phase diagram for NiTi illustrating the narrow compositional range where superelastic NiTi exists. Slight variations in nickel or titanium concentration will vary the phases formed at equilibrium [16].

Figure 9 - TTT-like diagram presented by Pelton illustrating the effect of ageing temperature and time on the transformation temperature of Ti-50.8 at.\% $\mathrm{Ni}$. The maximum precipitation of $\mathrm{Ni}_{4} \mathrm{Ti}_{3}$ occurs at $450{ }^{\circ} \mathrm{C}$. Precipitates re-solutionize between $500-600^{\circ} \mathrm{C}$ followed by an increase in $\mathrm{A}_{\mathrm{f}}$ represented by the nose at approximately $575^{\circ} \mathrm{C}$ [1].

Figure 10 - A schematic of two common methods used to manufacture endovascular stents. Method 1 involves a series of cutting and expansion to achieve the desired size, resulting in inhomogeneous mechanical and thermal properties. Method 2 consists of a 
single heat treatment on a larger tube, typically near the size the vessel wall, and results in uniform mechanical and thermal properties [18]

Figure 11 - According to finite elemental simulation presented by Favier, the maximum strain experienced by a NiTi stent undergoing a series of expansion during shape setting is approximately $10 \%$ in compression. Note the shift in neutral axis resulting from a high radius of curvature at the curved segments of a stent [20].

Figure 12 - A clear increase in ageing kinetics with increasing heat treatment time is evident under an applied stress of $50 \mathrm{MPa}$. An applied stress influences the shape and growth of $\mathrm{Ni}_{4} \mathrm{Ti}_{3}$ precipitates [22].....

Figure 13 - Effect of applied strain and heat treatment on the $\left(\sigma_{\mathrm{A}-\mathrm{M}}\right)$ upper and $\left(\sigma_{\mathrm{M}-\mathrm{A}}\right)$ lower plateau of aged Ti-50.7 at.\% Ni alloy. Constrained samples were taken from the curved segments of a shape-set stent and compared to the straight segments. Note a systematic decrease in plateau stress with increasing ageing time [28].

Figure 14 - The effect of heat treatment and cold work on the ultimate tensile stress of Ti50.8 at. \% Ni presented by Drexel. Note annealing effects dominate at high temperatures for a) $30 \%$ cold work and for any heat treatment temperature for b) $50 \%$ cold work [3].

Figure 15 - Phase transformation behavior for (a) an unconstrained sample, (b) a sample under 5\% strain, and (c) a sample under $7.5 \%$ strain. The R-phase transformation peak converges with the austenite phase transformation peak and is more pronounced during constrained ageing [29].

Figure 16 - The larger mandrel, approximately 1 inch in diameter, corresponds to $2 \%$ strain. Conversely, the smaller mandrel of approximately 0.18 inches in diameter corresponds to $10 \%$. Note that the larger mandrel is hollow with a wall thickness of 0.03 inches to have a similar volume to a $6 \%$ strain mandrel.

Figure 17 - Schematic of the coiling system used to apply strain on the NiTi wire. The wire first constrained on each mandrel followed by using the steel bar (circled in yellow) as a leverage to apply and maintain tension on the wire. The spool of wire was held in place using a polymer disc.

Figure 18 - Samples of NiTi wire in order of increasing strain level from left to right, $2 \%$, $4 \%, 6 \%, 8 \%$, and $10 \%$. Straight wire taken directly from the spool was used as the control sample, $0 \%$ strain.

Figure 19 - Samples under applied strain, including the control sample, were randomly chosen and placed inside a wire basket. The wire basket, including all six samples, was then placed inside the salt bath under a certain heat treatment condition. 
Figure 20 - Schematic of a split plot design used in this study. All samples of NiTi of various applied strain were placed inside the salt bath. This method significantly minimizes the amount of time required to conduct the heat treatments while detecting differences within each salt pot condition.

Figure 21 - A representative set of NiTi samples that have been heat treated at $500^{\circ} \mathrm{C}$ for 2 minutes in order of increasing level of strain from left to right. Note that the wire has shape set to conform around each mandrel at $500^{\circ} \mathrm{C}$. Samples that were heat treated below $450^{\circ} \mathrm{C}$ for short heat treatment times and less than $6 \%$ applied strain did not shapeset to the size of the corresponding mandrel.

Figure 22 - Seiko Instruments Q100 is an automated DSC capable of testing 50 consecutive samples. Each test run takes approximately approximately one hour at a ramp rate of 5 degrees per minute.

Figure 23 - A typical DSC curve for NiTi wire. Upon cooling from $125^{\circ} \mathrm{C}$ to $-125^{\circ} \mathrm{C}$, an exothermic peak characterizes the complete transition from austenite to martensite. Upon heating to $125^{\circ} \mathrm{C}$, an endothermic peak indicates the reversible transformation from martensite to austenite.

Figure 24 - The capstan disc, with a diameter of 1.5 inches, effectively distributed the load and reduced premature failure due to high stress concentrations. $65 \%$ of the samples fractured at the center of the gauge length using this capstan grip.

Figure 25 - A semi-circular groove, with a radius of 0.02 inches, distributes the load and prevents the wire from slipping outward. Capstan grips rely primarily on friction to maintain tension on the specimen. The majority of the load is distributed around the circumference of the capstan disc....

Figure 26 - Typical stress-strain response of superelastic NiTi wire using capstan grips and crosshead displacement to measure strain. Note the large amount of strain indicating that the majority of the strain was occurring around the curvature of the capstan disc as the wire straightened during the tensile test. A clear superelastic flag is still observed using the capstan grips.

Figure 27 - Effect of applied strain during heat treatment on the shape-setting behavior of $\mathrm{NiTi}$ wire following a heat treatment of $400^{\circ} \mathrm{C}$ for 2 minutes. Applied strain during heat treatment tends to encourage the shape-setting behavior between $300-450^{\circ} \mathrm{C}$.

Figure 28 - Effect of heat treatment time on the shape setting behavior of NiTi wire heat treated at $400^{\circ} \mathrm{C}$ with $4 \%$ applied strain. The yellow bar represents the diameter of the mandrel corresponding to $4 \%$ applied strain. Wires heat treated above 5 minutes tend to shape-set more successfully. 
Figure 29 - The effects of applied strain on the shape setting behavior of NiTi wire at $500^{\circ} \mathrm{C}$ for 2 minutes. Heat treatments above $450^{\circ} \mathrm{C}$ tend to shape-set successfully around the mandrel, indicating that sufficient thermal energy has been provided to relieve strain and allow recrystallization.

Figure 30 - Endothermic DSC curve of specimen heat treated between $300-500^{\circ} \mathrm{C}$ for 2 minutes in order of increasing strain level from bottom to top. Note that all heat treatment temperatures tend to increase $\mathrm{A}_{\mathrm{f}}$ except at $500^{\circ} \mathrm{C}$.

Figure 31 - Endothermic DSC curve for specimen heat treated between $300-500^{\circ} \mathrm{C}$ for 30 minutes in order of increasing level of applied strain. Note a systematic increase in $\mathrm{A}_{\mathrm{f}}$ as level of applied strain increases at low temperatures. Applied strain has no significant effect on $\mathrm{A}_{\mathrm{f}}$ between $450-500^{\circ} \mathrm{C}$ at a heat treatment of 30 minutes.

Figure 32 - The effect of applied strain and heat treatment between $350-400^{\circ} \mathrm{C}$ for 2 and 30 minutes. Note a systematic increase in $\mathrm{A}_{\mathrm{f}}$ with increased level of applied strain and heat treatment time. At short heat treatment times, $A_{f}$ increases most rapidly at $400^{\circ} \mathrm{C}$; at longer heat treatment times, the maximum $\mathrm{A}_{\mathrm{f}}$ is obtained at $350^{\circ} \mathrm{C}$

Figure 33 - The effect of applied strain and heat treatment between $450-500^{\circ} \mathrm{C}$ for 2 and 30 minutes. At short heat treatment times, applied strain increases $\mathrm{A}_{\mathrm{f}}$ most rapidly at $450^{\circ} \mathrm{C}$; applied strain has no significant effect on $\mathrm{A}_{\mathrm{f}}$ increase at longer times. Also note that applied strain and heat treatment time have no significant effect on $\mathrm{A}_{\mathrm{f}}$ at $500^{\circ} \mathrm{C}$.

Figure 34 - Effect of applied strain and heat treatment temperature on the transformation temperature of specimen heat treated for 2 minutes. The blue horizontal dash line at $11^{\circ} \mathrm{C}$ represents the starting $A_{f}$ of as-received wire. Applied strain significantly increases $A_{f}$ between $300-350^{\circ} \mathrm{C}$. At $500^{\circ} \mathrm{C}$, applied strain has no significant effect on the transformation temperature.

Figure 35 - Effect of applied strain and heat treatment on the transformation temperature of specimen heat treated for 5 minutes. The blue horizontal dash line at $11^{\circ} \mathrm{C}$ represents the starting $\mathrm{A}_{\mathrm{f}}$ of as-received wire. Again, applied strain increases the $\mathrm{A}_{\mathrm{f}}$ more significantly between $300-400^{\circ} \mathrm{C}$. Note that the maximum $\mathrm{A}_{\mathrm{f}}$ is obtained at $400^{\circ} \mathrm{C}$ for all levels of applied strain.

Figure 36 -Effect of applied strain and heat treatment on the transformation temperature of specimen heat treated for 10 minutes. The blue horizontal dash line at $11^{\circ} \mathrm{C}$ represents the starting $\mathrm{A}_{\mathrm{f}}$ of as-received wire. Between $450-550^{\circ} \mathrm{C}$, applied strain has no significant effect on the transformation temperature. Note that the maximum $\mathrm{A}_{\mathrm{f}}$ is now obtained between $350-400^{\circ} \mathrm{C}$ for all levels of applied strain.

Figure 37 - Effect of applied strain and heat treatment on the transformation temperature of specimen heat treated for 30 minutes. The blue horizontal dash line at $11^{\circ} \mathrm{C}$ represents the starting $\mathrm{A}_{\mathrm{f}}$ of as-received wire. Between $450-550^{\circ} \mathrm{C}$, applied strain has no significant 
effect on the transformation temperature. Note that the maximum $\mathrm{A}_{\mathrm{f}}$ is obtained through heat treatments between $300-350^{\circ} \mathrm{C}$.

Figure 38 - Effect of applied strain and temperature on the transformation temperature for all heat treatment times. Applied strain significantly increases $\mathrm{A}_{\mathrm{f}}$ between $300-350^{\circ} \mathrm{C}$; reaction rates have significantly decreased with increasing level of applied strain and heat treatment. Between $500-550^{\circ} \mathrm{C}$, applied strain and heat treatment temperature have no significant effect on $\mathrm{A}_{\mathrm{f}}$ increase.

Figure 39 - Effect of heat treatment temperature and time on the transformation temperature of specimen heat treated under $0 \%$ strain with a starting $\mathrm{A}_{\mathrm{f}}$ of $11^{\circ} \mathrm{C}$, represented by the blue horizontal dash line. Note that all heat treatment temperatures from $300-450^{\circ} \mathrm{C}$ tend to increase $\mathrm{A}_{\mathrm{f}}$.

Figure 40 - Effect of heat treatment temperature and time on the transformation temperature of specimen heat treated under a strain of $10 \%$ with a starting $\mathrm{Af}$ of $11^{\circ} \mathrm{C}$. A rapid increase at short times, followed no significant increase in $\mathrm{A}_{\mathrm{f}}$ at longer times, is observed; the exception to this trend occurs between $300-350^{\circ} \mathrm{C}$ where a gradual increase in $A_{\mathrm{f}}$ with increasing time is observed.

Figure 41 - TTT-like diagram illustrating the effects of heat treatment temperature and time for specimen heat treated at $0 \%$ strain. The maximum precipitation rate occurs at approximately $400^{\circ} \mathrm{C}$

Figure 42 - TTT-like diagram illustrating the effects of heat treatment temperature and time for specimen heat treated at $10 \%$ strain. The maximum precipitation rate occurs at approximately $400^{\circ} \mathrm{C}$.

Figure 43 - A three-dimensional TTT-like diagram illustrating the effect of applied strain and heat treatment on the transformation temperature. Note a systematic shift of $A_{f}$ contours to the left, indicating faster reaction times, with increasing level of applied strain occurs.

Figure 44 - Tensile response of as-received wire with an initial $\mathrm{A}_{\mathrm{f}}$ of $11^{\circ} \mathrm{C}$ prior to heat treatment. A reversible phase transformation from austenite to martensite is clearly observed.

Figure 45 - Tensile response of specimen heat treated at $300^{\circ} \mathrm{C}$ for 2 minutes illustrated for all levels of applied strain. A superelastic flag is observed for specimen heat treated at strain levels of $0-4 \%$; higher strain levels tend to distort the superelastic flag. Also note a systematic decrease in UTS as applied strain increases.

Figure 46 - Tensile response of specimen heat treated at $400^{\circ} \mathrm{C}$ for 30 minutes illustrated for all levels of applied strain. A superelastic flag is not observed for specimen heat 
treated at applied strains of $0-4 \%$ due to such a high unloading stress of $60 \mathrm{MPa}$ used in the tensile test

Figure 47 - Tensile response of specimen heat treated at $500^{\circ} \mathrm{C}$ for 2 minutes illustrated for all levels of applied strain. A superelastic flag is only observed for specimen heat treated at 0 and 2\%; higher levels of applied strain tend to distort the superelastic flag. A systematic decrease in UTS occurs as applied strain during heat treatment increases.

Figure 48 -Tensile response of specimen heat treated at $500^{\circ} \mathrm{C}$ for 2 minutes illustrated for all levels of applied strain. Superelastic behavior is lost for specimen heat treated at strain levels between 6-10\%. A systematic decrease in UTS occurs with increasing level of applied strain during heat treatment.

Figure 49 - Tensile response for specimen heat treated at $550^{\circ} \mathrm{C}$ and 2 minutes illustrated for all levels of applied strain. The superelastic flag is retained for specimen heat treated at strain levels between 0 and $2 \%$; higher strain levels tend to distort the superelastic flag.

Figure 50 - Tensile response of specimen heat treated at $550^{\circ} \mathrm{C}$ for 30 minutes illustrated for all levels of applied strain. The superelastic flag is retained for specimen heat treated at strain levels between 0-4\%. Note an upper plateau stress at approximately $1050 \mathrm{MPa}$ for all levels of applied strain.

Figure 51 - Tensile response for specimen heat treated at $550^{\circ} \mathrm{C}$ for 30 minutes and $300^{\circ} \mathrm{C}$ for 2 minutes. The wire heat treated at $300^{\circ} \mathrm{C}$ for 2 minutes was chosen since the $\mathrm{A}_{\mathrm{f}}$ temperature is similar to the $\mathrm{A}_{\mathrm{f}}$ at $550^{\circ} \mathrm{C}$; different Ni-rich precipitates are formed at these temperature extremes. Though the unusual upper plateau is not observed at $300^{\circ} \mathrm{C}$, in retrospect, this was not a wise choice to investigate the upper plateau seen at approximately $1050 \mathrm{MPa}$ at $550^{\circ} \mathrm{C}$

Figure 52 - Effect of applied strain and heat treatment temperature for specimen heat treated for 2 minutes. The blue dash line at $1116 \mathrm{MPa}$ represents the UTS of the asreceived wire. The maximum UTS is obtained between heat treatments temperatures of $400-450^{\circ} \mathrm{C}$; above $450^{\circ} \mathrm{C}$, annealing effects dominate. Note that a decrease in UTS is observed with increasing level of applied strain....

Figure 53 - Effects of applied strain and heat treatment temperature for specimen heat treated for 30 minutes. The blue dash line at $1116 \mathrm{MPa}$ represents the UTS of the asreceived wire. The maximum UTS is obtained between heat treatments temperatures of $400-450^{\circ} \mathrm{C}$. Note that heat treatments of $550^{\circ} \mathrm{C}$ for 30 minutes a significant decrease in UTS, approximately $60 \mathrm{MPa}$ lower than the as-received wire.

Figure 54 - Effect of applied strain and temperatuer on the ultimate tensile strength for all heat treatment times. Applied strain tends to decrease UTS for all heat treatments; applied strain has no significant effect following a heat treatment of $550^{\circ} \mathrm{C}$ for 30 minutes. 
Figure 55 - Effect of time and temperature on the UTS for specimen heat treated at $0 \%$ strain. Heat treatment at $300^{\circ} \mathrm{C}$ does not significantly increase the UTS. The blue dash line at $1116 \mathrm{MPa}$ represents the UTS of the as-received wire. Heat treatments between $350-450^{\circ} \mathrm{C}$ tend to increase UTS; heat treatments at $500^{\circ} \mathrm{C}$ and above tend to decrease UTS.

Figure 56 - Effects of time and temperature on the UTS for specimen heat treated at $6 \%$ strain. The blue dash line at $1116 \mathrm{MPa}$ represents the UTS of the as-received wire. An increase in UTS is observed for heat treatments between $350-450^{\circ} \mathrm{C}$. Note heat treatments at $6 \%$ strain results in lower overall UTS as compared to a sample heat treated at lower levels of applied strain.

Figure 57 -Effects of time and temperature on the UTS of specimen heat treated at $10 \%$ strain. The blue dash line at $1116 \mathrm{MPa}$ represents the UTS of the as-received wire. Heat treatments between $350-450^{\circ} \mathrm{C}$ tend to increase UTS; note the significant decrease in UTS following a heat treatment at $550^{\circ} \mathrm{C}$.

Figure 58 - Effect of transformation temperature on the ultimate tensile strength for all levels of applied strain at $350^{\circ} \mathrm{C}$. An increase in $\mathrm{A}_{\mathrm{f}}$ results in a decrease in UTS. Also note that higher levels of applied strain result in lower UTS values. Compared to the asreceived wire, all treatments at $350^{\circ} \mathrm{C}$ have resulted in a decrease in UTS.

Figure 59 - Effect of transformation temperature on the ultimate tensile strength for all levels of applied strain at $400^{\circ} \mathrm{C}$. Higher UTS are obtained at lower $\mathrm{A}_{\mathrm{f}}$ values. Compared to the as-received wire, all treatments at $400^{\circ} \mathrm{C}$ have resulted in an increase in UTS

Figure 60 - Correlation between UTS and $\mathrm{A}_{\mathrm{f}}$ for all levels of applied strain and heat treatment temperature. The maximum UTS is obtained through heat treatments between $400-450^{\circ} \mathrm{C}$. The smallest spread in $\mathrm{A}_{\mathrm{f}}$ is obtained at $500^{\circ} \mathrm{C}$.

Figure 61 - Effect of applied strain and heat treatment temperature on the elastic modulus of specimen heat treated for 2 minutes. Higher levels of applied strain during heat treatment tend to decrease the elastic modulus; this trend is not consistent between heat treatment temperatures of $400-550^{\circ} \mathrm{C}$.

Figure 62 - Effect of applied strain and heat treatment temperature on the elastic modulus for specimen heat treated for 30 minutes. High levels of applied strain during heat treatment tend to decrease elastic modulus: note that this trend is not observed between heat treatment temperatures of $400-550^{\circ} \mathrm{C}$.

Figure 63 - Effect of heat treatment time and temperature on the elastic modulus for specimen heat treated at $0 \%$ applied strain. The blue dash line at $66 \mathrm{GPa}$ represents the elastic modulus of the as-received wire. After a rapid increase in $\mathrm{E}$ at short times, all heat 
treatment temperatures tend to decrease elastic modulus with increasing heat treatment time.

Figure 64 - Effect of heat treatment time and temperature on the elastic modulus of specimen heat treated at $6 \%$ applied strain. The blue dash line at $66 \mathrm{GPa}$ represents the elastic modulus of the as-received wire. A rapid decrease at short times followed by a rapid increase between 2-10 minutes occurs between $450-550^{\circ} \mathrm{C}$. A rapid decrease in elastic modulus occurs between $300-400^{\circ} \mathrm{C}$.

Figure 65 - Effect of time and temperature on the elastic modulus of specimen heat treated at $10 \%$ applied strain. The blue dash line at $66 \mathrm{GPa}$ represents the elastic modulus of the as-received wire. A rapid decrease in elastic modulus occurs at temperature between $300-400^{\circ} \mathrm{C}$

Figure 66 - Schematic of a lenticular precipitate, including an anisotropic stress field with a compressive stress in the normal direction, formed during stress-assisted aging. These lenticular precipitates form preferentially aligned to the external tensile stress and perpendicular to the external compressive stress. As the anisotropic stress field increases due to formation of $\mathrm{Ni}_{4} \mathrm{Ti}_{3}$ precipitates, an increase in aging kinetics occurs to relax the internal stresses.

Figure 67 - Effect of applied strain and heat treatment $300550^{\circ} \mathrm{C}$ for 2 and 30 minutes. A systematic increase in $\mathrm{A}_{\mathrm{f}}$ with increased level of applied strain and heat treatment time occurs at $350^{\circ} \mathrm{C}$. Applied strain and heat treatment time have no significant effect on $A_{f}$ increase at $550^{\circ} \mathrm{C}$.

Figure 68 - Effect of heat treatment temperature and time on the transformation temperature of NiTi wire under a strain of $2 \%$ with a starting $\mathrm{A}_{\mathrm{f}}$ of $11^{\circ} \mathrm{C}$. Note that all heat treatment temperatures tend to increase the $\mathrm{A}_{\mathrm{f}}$ with increasing time.

Figure 69 - Effect of heat treatment temperature and time on the transformation temperature of NiTi wire under a strain of $4 \%$ with a starting Af of $11^{\circ} \mathrm{C}$. Note that all heat treatment temperatures tend

Figure 70 - Effect of heat treatment temperature and time on the transformation temperature of NiTi wire under a strain of $6 \%$ with a starting Af of $11^{\circ} \mathrm{C}$. Note that all heat treatment temperatures tend

Figure 71 - Effect of heat treatment temperature and time on the transformation temperature of NiTi wire under a strain of $8 \%$ with a starting Af of $11^{\circ} \mathrm{C}$. Note that all heat treatment temperatures tend to increase the Af with increasing time.

Figure 72 - TTT-like diagram illustrating the effects of heat treatment temperature and time for specimen heat treated at $2 \%$ strain. The maximum precipitation rate occurs at 
approximately $400^{\circ} \mathrm{C}$. A systematic shift to the left, indicating faster reaction times, is observed as compared to a specimen heat treated at $0 \%$ applied strain.

Figure 73 - TTT-like diagram illustrating the effects of heat treatment temperature and time for specimen heat treated at $4 \%$ strain. The maximum precipitation rate occurs at approximately $400^{\circ} \mathrm{C}$. Faster reaction times are observed to achieve an $\mathrm{A}_{\mathrm{f}}$ of $40^{\circ} \mathrm{C}$.

Figure 74 - TTT-like diagram illustrating the effects of heat treatment temperature and time for specimen heat treated at $6 \%$ strain. The maximum precipitation rate occurs at approximately $400^{\circ} \mathrm{C}$. All three c-curves has significantly shifted to the left, indication increased kinetics during heat treatment under an applied strain.

Figure 75 - TTT-like diagram illustrating the effects of heat treatment temperature and time for specimen heat treated at $8 \%$ strain. The maximum precipitation rate occurs at approximately $400^{\circ} \mathrm{C}$.

Figure 76 - Tensile response of specimen heat treated at $400^{\circ} \mathrm{C}$ for 2 minutes illustrated for all levels of applied strain. A superelastic flag is observed for specimen heat treated at strain levels of $0-4 \%$; higher strain levels tend to distort the superelastic flag. Also note a systematic decrease in UTS as applied strain increases.

Figure 77 - Tensile response of specimen heat treated at $400^{\circ} \mathrm{C}$ for 30 minutes illustrated for all levels of applied strain. A superelastic flag is observed for specimen heat treated at strain levels of $0-4 \%$; higher strain levels tend to distort the superelastic flag. A decrease in UTS is observed with increasing level of applied strain.

Figure 78 - Effect of applied strain and heat treatment temperature for specimen heat treated for 5 minutes. The blue dash line at $1116 \mathrm{MPa}$ represents the UTS of the asreceived wire. The maximum UTS is obtained between heat treatments temperatures of $400-450^{\circ} \mathrm{C}$;

Figure 79 - Effects of applied strain and heat treatment temperature for specimen heat treated for 10 minutes. The blue dash line at $1116 \mathrm{MPa}$ represents the UTS of the asreceived wire. The maximum UTS is obtained between heat treatments temperatures of $400-450^{\circ} \mathrm{C}$

Figure 80 - Effect of time and temperature on the UTS for specimen heat treated at $2 \%$ strain. Heat treatment at $300^{\circ} \mathrm{C}$ does not significantly increase the UTS. Heat treatments between $350-450^{\circ} \mathrm{C}$ tend to increase UTS; heat treatments at $500^{\circ} \mathrm{C}$ and above tend to decrease UTS.

Figure 81 -Effect of time and temperature on the UTS for specimen heat treated at $4 \%$ strain. Heat treatment at $300^{\circ} \mathrm{C}$ does not significantly increase the UTS. A rapid increase in UTS at short times followed by a slower increase at longer times is observed between $300-500^{\circ} \mathrm{C}$. 
Figure 82 - Effects of time and temperature on the UTS for specimen heat treated at $8 \%$ strain. An increase in UTS is observed for heat treatments between $350-450^{\circ} \mathrm{C}$. Note, heat treatments at $8 \%$ strain results in lower overall UTS as compared to a sample heat treated at lower levels of applied strain.

Figure 83 - Effect of transformation temperature on the ultimate tensile strength for all levels of applied strain at $500^{\circ} \mathrm{C}$. The spread in $\mathrm{A}_{\mathrm{f}}$ values decreases at $500^{\circ} \mathrm{C}$. Compared to the as-received wire, all treatments at $400^{\circ} \mathrm{C}$ have resulted in an increase in UTS 108

Figure 84 - Effect of transformation temperature on the ultimate tensile strength for all levels of applied strain at $550^{\circ} \mathrm{C}$. No general correlation exists between UTS and $\mathrm{A}_{\mathrm{f}}$ at $550^{\circ} \mathrm{C}$.

Figure 85 -Effect of applied strain and heat treatment temperature on the elastic modulus of specimen heat treated for 5 minutes. Higher levels of applied strain during heat treatment tend to decrease the elastic modulus; this trend is not consistent between heat treatment temperatures of $400-550^{\circ} \mathrm{C}$

Figure 86 - Effect of applied strain and heat treatment temperature on the elastic modulus of specimen heat treated for 10 minutes. Higher levels of applied strain during heat treatment tend to decrease the elastic modulus; this trend is not consistent between heat treatment temperatures of $400-550^{\circ} \mathrm{C}$.

Figure 87 - Effect of heat treatment time and temperature on the elastic modulus for specimen heat treated at $2 \%$ applied strain. After a rapid increase in $\mathrm{E}$ at short times, all heat treatment temperatures tend to decrease $\mathrm{E}$ with increasing heat treatment time.

Figure 88 - Effect of heat treatment time and temperature on the elastic modulus for specimen heat treated at $4 \%$ applied strain. After a rapid increase in $\mathrm{E}$ at short heat treatment times, all heat treatment temperatures tend to decrease $\mathrm{E}$ with increasing heat treatment time.

Figure 89 - Effect of heat treatment time and temperature on the elastic modulus of specimen heat treated at $8 \%$ applied strain. A decrease at short times followed by a rapid increase between $2-10$ minutes occurs between $450-550^{\circ} \mathrm{C}$. A rapid decrease occurs between $300-400^{\circ} \mathrm{C}$ 


\section{LIST OF TABLES}

Table I: Diameter of cylindrical rods with corresponding strain levels, using a wire

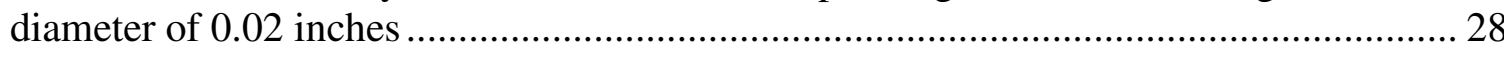

Table II: Heat treatment conditions used in this study ............................................ 32 


\section{CHAPTER ONE \\ INTRODUCTION}

\subsection{Discovery of Nickel Titanium}

Some of the greatest inventions in science and engineering were stumbled upon by serendipitous discovery. The discovery of nickel titanium (NiTi) and its unique properties certainly falls into this category. NiTi refers to a family of near equiatomic nickeltitanium alloys. Its discovery in 1959 is credited to William J. Buehler, a metallurgist at the United States Naval Ordinance Laboratory (NOL). While working at the NOL, Buehler investigated nickel-titanium alloys as possible candidates for the nose cone of the U.S. Navy Polaris reentry vehicle. He decided to concentrate on the equiatomic nickeltitanium composition alloys due to their simpler stoichiometric proportions. After melting and arc-casting several nickel-titanium bars, Buehler tested the near room temperature samples for their damping characteristics by dropping the bars on the concrete floor. Buehler often used this method as a quick test to determine the damping capacity of an alloy. He noticed the room temperature samples produced a "thud" sound, similar to that of a lead sample of the same size. This unexpected sound suggested the possibility of micro-cracks due to the arc-casting process. With this possible discouraging development in mind, he dropped more bars onto the concrete floor. However, these bars were slightly warmer and produced a high pitched sound, completely different from the bars at room temperature. To understand this phenomenon, he quickly water cooled the warmer bars and discovered that the bars again produced the same lead-like, damped acoustic response at room temperature. After verifying that the bars were of the same 
composition, Buehler theorized that the difference in acoustic response of the nickel titanium alloy was due to an atomic structural change present at even minor variations of temperature. Although the discovery of the unique damping characteristics of NiTi was never used in the Polaris project, further research by Buehler and his associate Dr. Fredrick Wang, lead to a beginning understanding of the atomic re-arrangement that occurs at the microstructure [1].

Initially, NiTi received small interest commercially due to the inconsistencies produced during the manufacturing process. Researchers noted that small variations in composition and temperature significantly altered the properties of NiTi. From a design prospective, inconsistencies in the properties of NiTi among batches hindered potential engineering applications. However, with further experimentation, researchers focused on specific compositions and heat treatments of nickel-titanium to achieve reproducible properties. Engineers were then able to design applications that exploited the unique properties of NiTi [1].

\subsection{Application of NiTi}

NiTi has gained interest in the medical device industry, primarily due to its biocompatibility and superelastic properties. The superelastic property, also known as pseudoelasticity, describes a nonlinear behavior and recoverable deformation exhibited by NiTi in the austenite phase. The most classic example that takes advantage of the superelastic property of NiTi is a self-expanding stent. The main function of a stent is to 
stabilize and prop open narrow or weakened blood vessels. NiTi stents are designed to self-expand slightly below body temperature. NiTi stents are manufactured to a size slightly larger than the diameter of the vessel and constrained upon delivery. Upon deployment, the NiTi stents self-expand to the desired shape and provide a constant, low outward force against the artery or vein. The superior spring-back capability due to the high recoverable strain is essential for endovascular stents located in superficial regions, such as the carotid and femoral arteries, as these areas may encounter impact or deformation [2]. The high recoverable strain exhibited by a NiTi stent is illustrated in Figure $1[3]$.

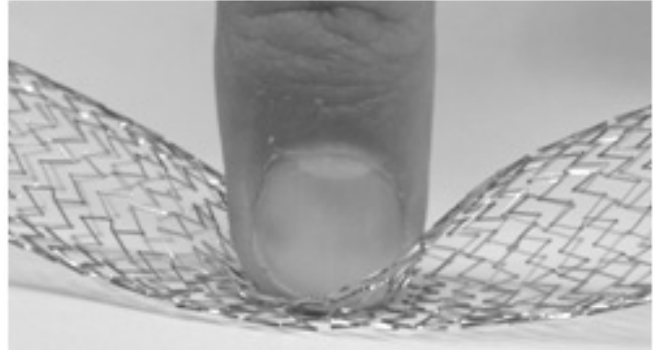

(a)

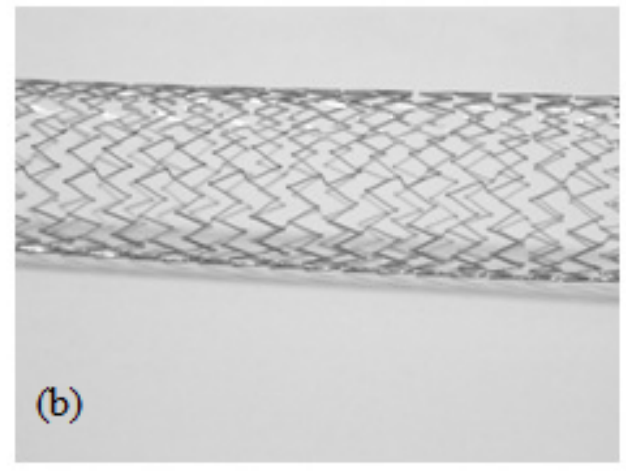

(b)

Figure 1 - (a) A compressed NiTi stent will (b) completely recover its original shape upon the release of an applied load due to superelasticity [3].

NiTi is also used in the endovascular medical device industry as a vena cava filter to capture blood clots and prevent pulmonary embolism. Vena cava filters, such as the Simon Nitinol Filter shown in Figure 2, is constrained within a catheter to the intended deployment location followed by removing the catheter and allowing the filter to expand to the designed shape. The transition temperature is designed to be martensitic at room 
temperature but superelastic once deployed inside the body. The cone-shaped design, in conjunction with a thin polyurethane film, allows for large blood clots to be filtered by the first level of NiTi wires (top conical section) followed by further filtration of smaller blood clots by the second level (bottom section) [4].
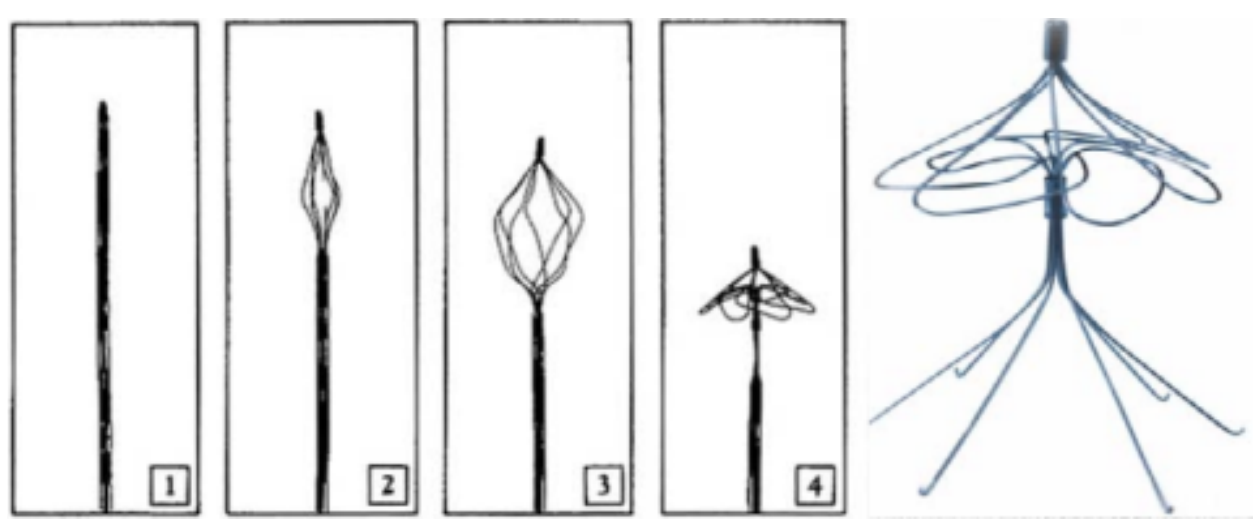

Figure 2 - Simon vena cava filter employs the shape memory and superelastic effect. The progression as the device expands to the designed shape is shown. Once expanded, a constant stress against the vessel walls is provided by the superelastic properties [4].

In 1988, NiTi was first introduced into the field of dentistry as an orthodontic arch-wire. NiTi is an ideal material for orthodontic arch wires due to its high recoverable strain, up to ten times that of stainless steel, and lower elastic modulus. An orthodontic arch-wire, shown in Figure 3, is designed to have a curved shape conforming to the dental arch and can be used with braces to provide a force to correct mal-occluded teeth. Strains of up to $8 \%$ can be completely recovered upon release of an applied stress [5]. Due to the superelastic property of $\mathrm{NiTi}$, the number of wires required to align mal-occluded teeth is significantly reduced. The superelastic property is also exploited in endodontic instruments, such as root canal files, and other dentistry applications. 


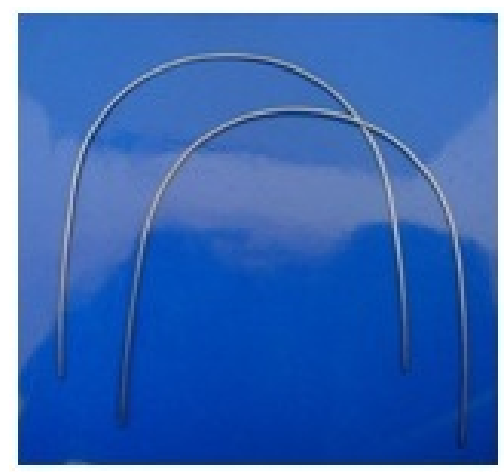

Figure 3 - Superelastic NiTi archwire retains a curved shape and provides a low continuous force that effectively corrects mal-occluded teeth. NiTi arch-wires can be thermally activated once placed inside the mouth or superelastic at room temperature [5].

\subsection{Broader Impacts in Society}

Applications for shape memory alloys (SMA) are growing at a strong pace and will continue to grow into the foreseeable future. SMA falls under the category of smart materials due to the ability to retain shape or perform actuation in response to changes in temperature. In 2005, smart materials represented $\$ 8.1$ billion of the global market. It is projected that this number will rise to $\$ 12.3$ billion by 2010 [6]. Although SMAs such as NiTi represents only $15 \%$ percent of smart materials, the production and utilization will continue to grow primarily due to the use of NiTi stents in the biomedical industry [6].

As interest in SMAs increases, this industry may have the potential to create job opportunities and stimulate the economy. Manufacturers that produce SMAs, such as Nitinol Devices and Components, Wah Chang, Johnson-Mattheys, Memory-Metalle $\mathrm{GmbH}$, and Memry Corporation, have increased in size due to the promising revenue. For example, Memry Corporation reported revenue growth due to SMA averaging $4.4 \%$ per year from 2000 to 2005 (adjusted for inflation) [6]. However, manufacturers of SMAs 
must produce products with consistent and reproducible properties to sustain the increased interest in SMA.

To ensure the quality and consistency of SMA, manufacturers must understand the fabrication process and their effects on the final properties and performance. Certain applications, such as in the biomedical industry, require high tolerances for specific reasons. For example, the deployment of a NiTi stent is designed to self-expand at a temperature slightly below body temperature. Inconsistencies during the manufacturing process may cause the stent to deploy at a different temperature than what was designed. In such cases, the manufacture of NiTi requires compositional tolerances of between one tenth and one hundredth of a percent [7]. Several variables, including composition, time, temperature, initial amount of cold work and the presence of applied strain during the shape setting process can alter the final properties of NiTi. From a manufacturer's point of view, these variables must be fully understood to obtain consistent properties. 


\section{CHAPTER TWO \\ LITERATURE REVIEW}

\subsection{Background}

The shape memory and superelastic property of NiTi is due to a reversible and diffusionless solid-state phase transformation. The phase transformation occurs between a higher temperature austenite phase and a lower temperature martensite phase. The temperature at which martensite completely transforms into austenite is called the austenite finish temperature $\left(\mathrm{A}_{\mathrm{f}}\right)$. At temperatures above the $\mathrm{A}_{\mathrm{f}}$, NiTi exists in the austenite, or parent phase. The atomic lattice of the austenite phase is a cubic $\mathrm{B} 2 \mathrm{CsCl}$ crystal structure. A schematic crystallographic representation of the $\mathrm{B} 2 \mathrm{CsCl}$ crystal structure is shown in Figure 4a [8]. The mechanical properties, such as the ultimate tensile strength, are higher when NiTi is in the austenite phase. At temperatures below the $\mathrm{M}_{\mathrm{f}}$, NiTi exists in the martensite, or daughter phase. The atomic lattice of the martensite phase forms in a B19' monoclinic crystal structure. A schematic of the B19' monoclinic crystal structure is shown in Figure 4b [8]. This microstructure is composed of different twin variants. The transformation temperature is determined primarily by the composition of the NiTi alloy. However, the processing history also has a significant effect on the transformation temperature [7]. 


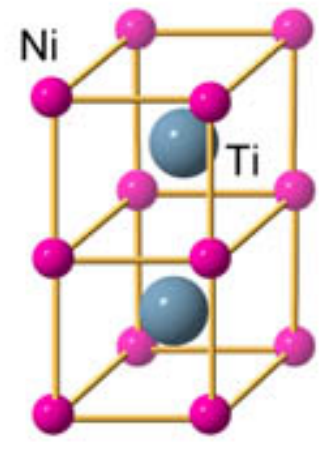

(a)

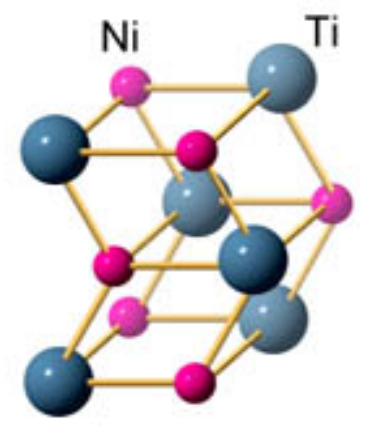

(b)

Figure 4 - (a) A crystallographic schematic of a cubic $\mathrm{CsCl}$ crystal structure observed in the austenite phase, and (b) a B19' monoclinic crystal structure observed in the martensite phase of NiTi. The change in crystal structure results from a solid state, diffusion less phase transformation [9].

\subsection{Shape Memory Effect}

NiTi has the ability to restore to a previously defined shape after deformation by heating the alloy to a certain temperature. This unique property is referred to as 'shape memory'. The shape memory effect in NiTi is due to a temperature induced solid-state phase transformation. A generic thermal hysteresis for NiTi under a constant load is shown in Figure 5. The hysteresis loop illustrates the phase transformations that occur upon heating and cooling. At temperatures above the $\mathrm{A}_{\mathrm{f}} \mathrm{NiTi}$ exists in the austenite phase as illustrated in Figure 5. Once the temperature is cooled down to the martensite start temperature, $\mathrm{M}_{\mathrm{s}}$, the phase transformation from austenite to martensite begins. Once cooled below the martensite finish temperature, $\mathrm{M}_{\mathrm{f}}$, all austenite has completely transformed to twinned martensite. If a stress is applied to NiTi at a temperature below $\mathrm{M}_{\mathrm{f}}$, deformation occurs through twinning. Twinning is a dislocation mechanism that involves a shear-like rearrangement of several martensite variants; upon deformation, different twin-variants grow at the expense of others to accommodate the strain, which is in contrast to 
dislocation movement in conventional metals. Martensitic NiTi has 24 possible twin orientations, making deformation by twinning easier than by dislocation movement [9].. Upon heating to the austenite start temperature, $\mathrm{A}_{\mathrm{s}}$, sufficient thermal energy is provided to initiate the phase transformation from martensite to austenite. Further heating above the $A_{f}$ results in complete phase transformation from martensite to austenite. Above the $\mathrm{A}_{\mathrm{f}}$, sufficient thermal energy has been applied to drive the reversible reaction and restore to its previously defined shape in the austenite phase. In addition, the maximum strain has been recovered. Upon cooling, the austenite returns to twinned martensite. At this point, if no load has been applied, the bulk shape is still retained but an atomic re-arrangement has occurred. Deformation in the martensite phase can be applied and the process can be cycled once again [10].

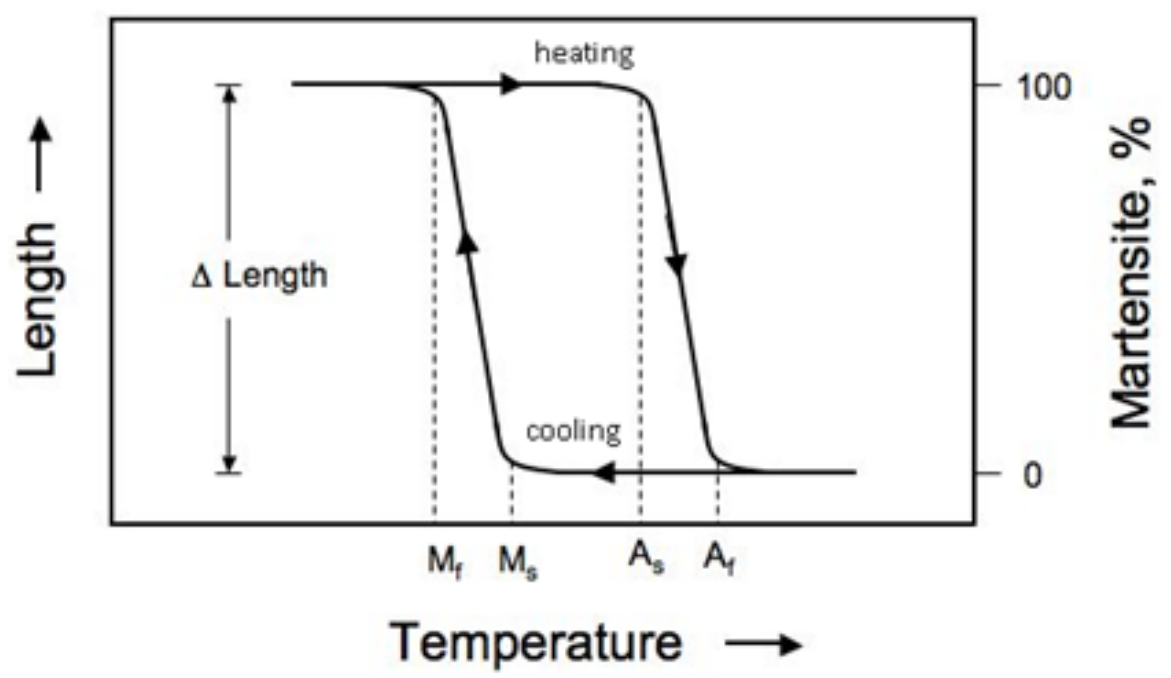

Figure 5 -A generic thermal hysteresis for NiTi illustrates the temperature induced phase transformation. Note that a physical change in shape occurs during the phase transformation from martensite to austenite [11]. 
The thermal hysteresis in Figure 5 also shows the change in length associated with martensite-austenite transformation that corresponds to the change in mechanical properties. Under a constant load, NiTi will increase in length upon cooling below $\mathrm{M}_{\mathrm{f}}$ as a result of the alloy's decrease in stiffness in the martensite phase. Conversely, NiTi will shorten in length upon heating above $A_{\mathrm{f}}$ as a result of the alloy's increase in stiffness in the austenite phase [8]. The modulus of elasticity of NiTi in the martensite phase is 40 GPa. In the austenite phase, the modulus of elasticity is $75 \mathrm{GPa}$. Therefore, the shape memory effect exhibited by NiTi not only physically changes the alloy, but also significantly changes the mechanical properties [12].

\subsection{Superelastic Effect}

NiTi also has the ability to undergo large deformations and return to its original shape without the onset of plastic deformation. This unique property is known as superelastic, or 'pseudoelastic', due to such high recoverable strains (up to 8\%) [5]. This is ten times greater than the recoverable strain from metals such as stainless steel. Unlike conventional metals, NiTi exhibits a non-linear elastic behavior, which results from a stress-induced phase transformation. A typical stress-strain curve for NiTi is shown in Figure $6[8]$ at two different temperatures. At a temperature range greater than the $A_{f}$, NiTi will exist in the austenite phase. In the austenite phase, the stress-strain curve of NiTi will initially behave according to Hooke's law with linear elastic deformation. However as the load increases, the phase transformation from austenite to martensite will begin. The onset of stress-induced martensitic phase transformation or $\mathrm{M}_{\mathrm{s}}$ corresponds to point A in Figure 6. If loading continues, austenite will completely transform into 
martensite. The final phase transformation from austenite to martensite or $\mathrm{M}_{\mathrm{f}}$ corresponds to point B in Figure 6. If the load is released at point B, martensite will begin the reverse transformation to austenite. The onset of the reverse phase transformation or $\mathrm{A}_{\mathrm{s}}$ corresponds to point $\mathrm{C}$ in Figure 6. Once the load is entirely removed, any remaining martensite will transform back into austenite as illustrated at point D in Figure 6. In addition, the elastic strain is recovered. At temperatures greater than the martensite deformation temperature, $M_{d}$, the phase transformation from austenite to martensite can no longer be stress-induced. In addition, further deformation at temperatures greater than $\mathrm{M}_{\mathrm{d}}$ will eventually result in plastic deformation until fracture as illustrated by the top curve in Figure 6 [13]. The energy dissipation exhibited by NiTi in the superelastic phase is illustrated by the hysteresis loop in Figure 6.

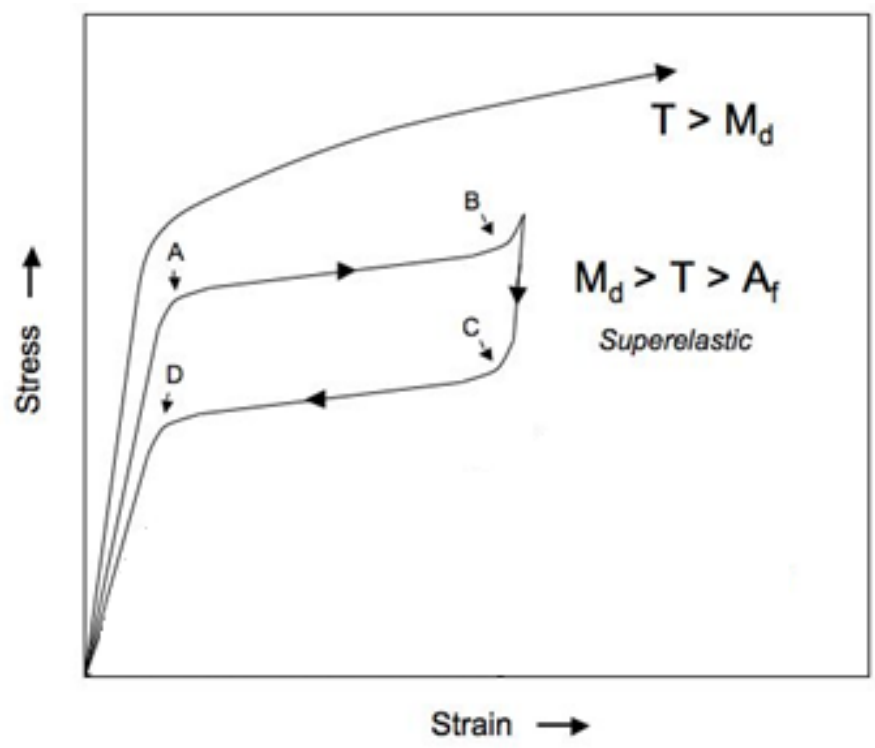

Figure 6 - Typical stress-strain behavior illustrated for two temperature ranges. Note the large amount of recoverable strain in superelastic NiTi [8]. 


\subsection{Effects of Composition}

The $\mathrm{A}_{\mathrm{f}}$ temperature in NiTi is considered one of the most important material properties since it dictates the transition between shape memory and superelastic properties. Altering the composition of the NiTi phase significantly changes the transformation temperature. Researchers have conducted several studies to determine the effect in varying the composition of NiTi. A general trend was found showing that an increase in titanium concentration results in an increase in transformation temperature. Russell et al. [14], have published data supporting this general trend. Russell has constructed a plot, shown in Figure 7, illustrating the effect of nickel composition in NiTi on the transformation temperature. Russell reports that a $1 \%$ shift in the amount of nickel or titanium will result in a $100^{\circ} \mathrm{C}$ change in transformation temperature. Therefore, small deviations in composition will significantly change the transformation temperature and resulting properties. The shaded region in Figure 7 illustrates the narrow range in composition where superelastic NiTi is commonly used, typically around 51 at.\% $\mathrm{Ni}$. 


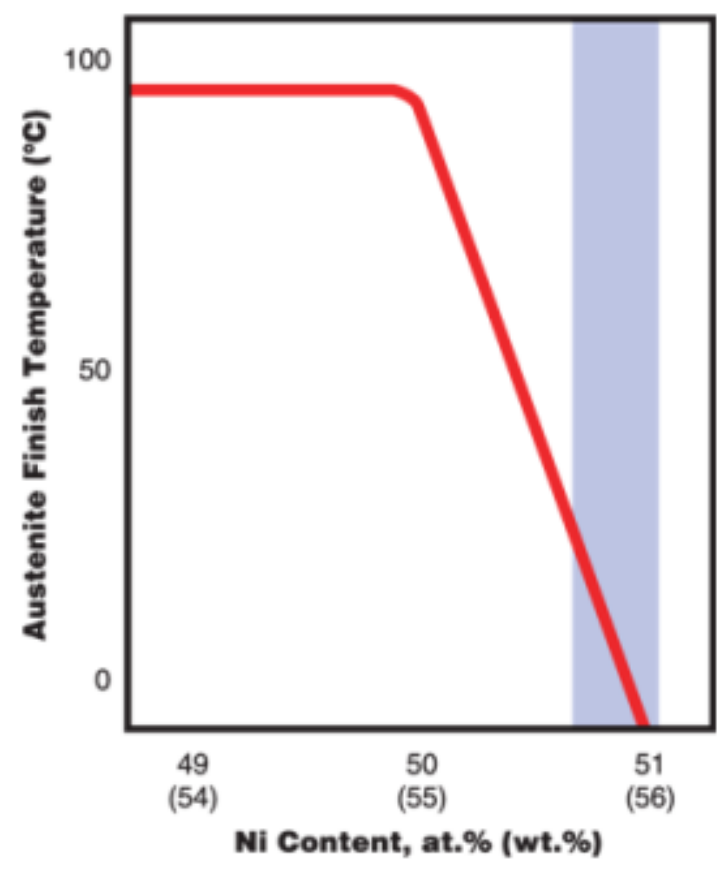

Figure 7 - A general trend illustrating the effect of nickel concentration in NiTi on the transformation temperature. Small variations in alloy composition results in a significant change in $A_{\mathrm{f}}$. Typical alloy compositions used in superelastic applications are represented by the shaded section [14].

\subsection{Precipitation Process in NiTi}

The transformation temperature can be gradually altered by precipitating nickel-rich phases from the surrounding matrix starting from a single alloy composition. Nishida et al. [15], have established the precipitation processes of Ti-52 at.\% Ni and Ti-50 at.\% Ni through a Time-Temperature-Transformation (TTT) diagram that illustrates the formation of a series of nickel-rich precipitates over a range of heat treatment conditions. The precipitation process occurring at a temperature range below $680^{\circ} \mathrm{C} \pm 10^{\circ} \mathrm{C}$ is described by the following sequence in Equation 1:

$$
\beta_{0} \rightarrow \beta_{1}+\mathrm{Ni}_{14} \mathrm{Ti}_{11} \rightarrow \beta_{2}+\mathrm{Ni}_{3} \mathrm{Ti}_{2} \rightarrow \beta_{3}+\mathrm{Ni}_{3} \mathrm{Ti}
$$


Where $\beta_{0}$ is the initial matrix composition of the alloy, $\beta_{1}$ is the matrix composition in equilibrium with $\mathrm{Ni}_{14} \mathrm{Ti}_{11} ; \beta_{2}$ is the matrix composition in equilibrium with $\mathrm{Ni}_{3} \mathrm{Ti}_{2}$ and $\beta_{3}$ is the matrix composition in equilibrium with $\mathrm{Ni}_{3} \mathrm{Ti}$. The equilibrium phase diagram for NiTi is shown in Figure 8. Note the narrow range in composition, shaded yellow, where NiTi alloys exist. The phase diagram indicates an excess of nickel will result in $\mathrm{Ni}_{3} \mathrm{Ti}$. Conversely, a slight excess of titanium concentration results in formation of $\mathrm{NiTi}_{2}$ [16].

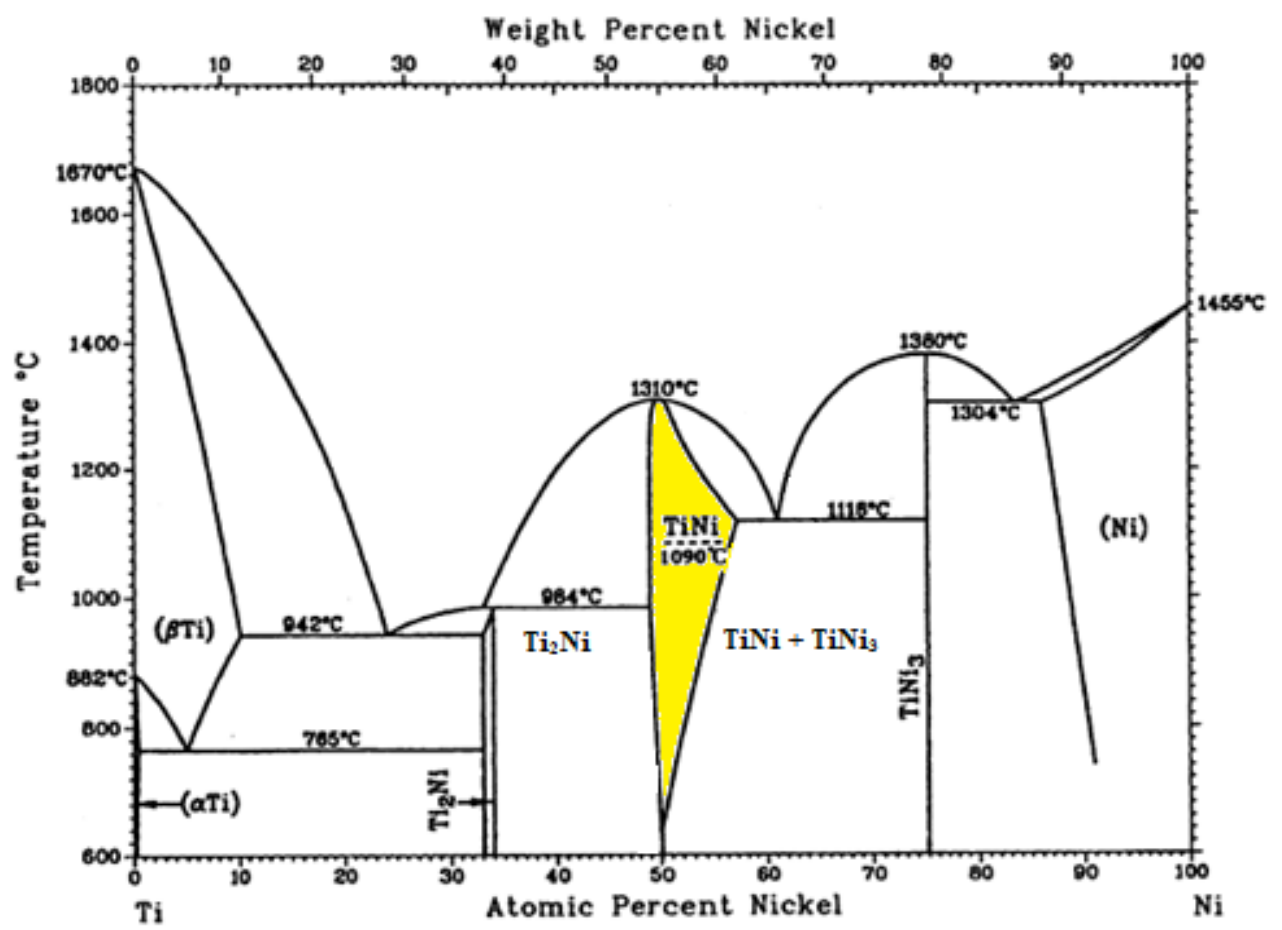

Figure 8 - Phase diagram for NiTi illustrating the narrow compositional range where superelastic NiTi exists. Slight variations in nickel or titanium concentration will vary the phases formed at equilibrium [16].

The phase diagram only shows the equilibrium phase diagram and not the metastable phases that form during the precipitation process. Several metastable phases including, $\mathrm{Ni}_{4} \mathrm{Ti}_{3}$ and $\mathrm{Ni}_{3} \mathrm{Ti}_{2}$, form as nickel precipitates from the NiTi phase during the 
precipitation process. Nickel-rich phases precipitate from within the surrounding NiTi matrix, forming coherent lenticular precipitates between heat treatments of $300-450^{\circ} \mathrm{C}$. As nickel is depleted from the NiTi phase, the concentration of titanium in the NiTi phase increases. This precipitation process results in an increase in transformation temperature [15]. According to Melton et al. [13], a change in $\mathrm{A}_{\mathrm{s}}$ of $150^{\circ} \mathrm{C}$ has been reported during ageing of Ti-51.5 at. $\% \mathrm{Ni}$ at $400^{\circ} \mathrm{C}$.

The precipitation process of Ti-50.8 at.\% Ni has been extensively studied by Pelton et al. [17] and presented in the form of a TTT-like diagram that illustrates the trends in $\mathrm{A}_{\mathrm{f}}$ as a function of heat treatment temperature and time. The TTT-like diagram, shown in Figure 9, illustrates the reaction time at different temperatures to achieve a particular $\mathrm{A}_{\mathrm{f}}$. Each $\mathrm{C}$ curve on the TTT-like diagram represents contours of constant $\mathrm{A}_{\mathrm{f}}$. The maximum precipitation rate is represented by the two 'noses' seen in the TTT diagram presented by Pelton. The first nose, located at $450^{\circ} \mathrm{C}$, is the temperature at which $\mathrm{A}_{\mathrm{f}}$ increases most rapidly with heat treatment time. The second nose, located at approximately $575^{\circ} \mathrm{C}$, represents the maximum precipitation rate at higher temperatures where annealing dominates and different precipitates are formed. 


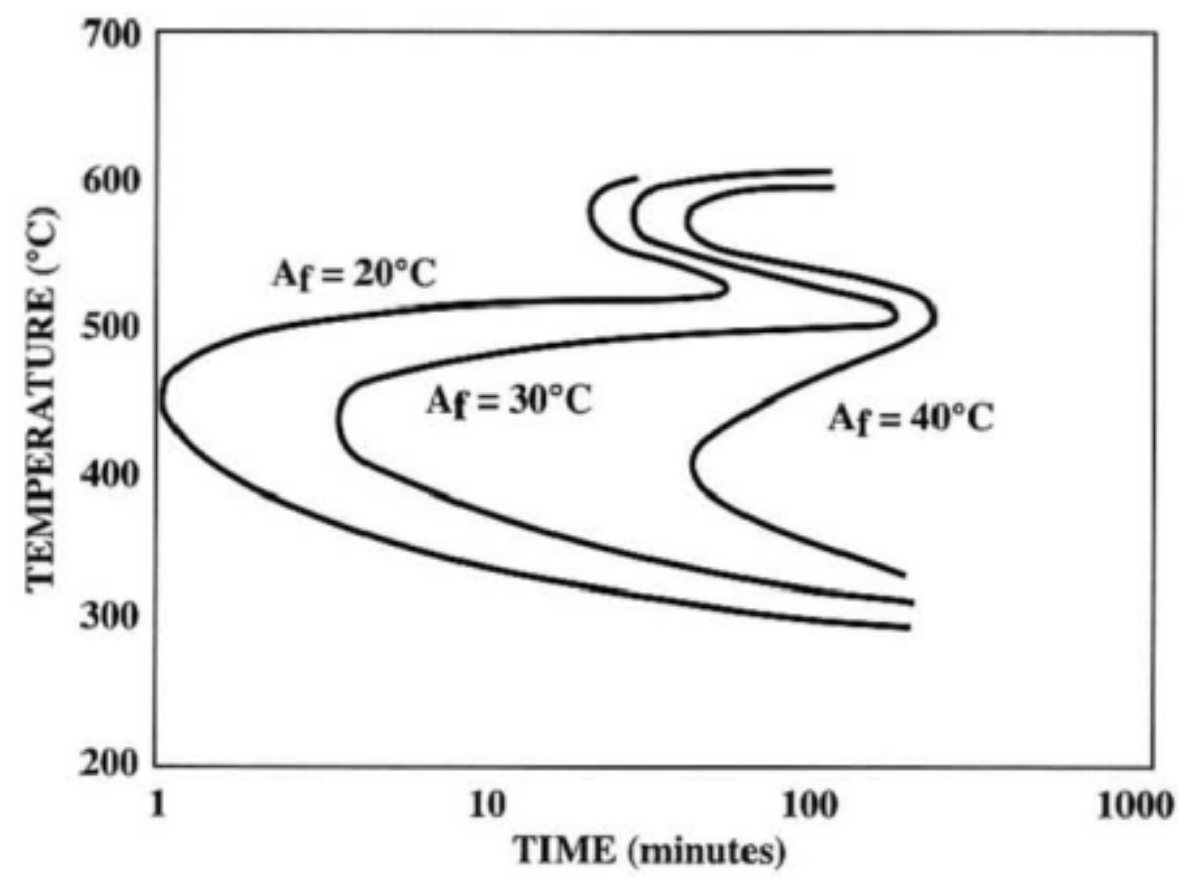

Figure 9 - TTT-like diagram presented by Pelton illustrating the effect of ageing temperature and time on the transformation temperature of Ti-50.8 at.\% $\mathrm{Ni}$. The maximum precipitation of $\mathrm{Ni}_{4} \mathrm{Ti}_{3}$ occurs at $450{ }^{\circ} \mathrm{C}$. Precipitates re-solutionize between $500-600^{\circ} \mathrm{C}$ followed by an increase in $A_{f}$ represented by the nose at approximately $575^{\circ} \mathrm{C}[1]$.

The locations of maximum increase in transformation temperature rate are due to nucleation and growth processes involved in the precipitation of Ni-rich phases. At high temperatures the atomic mobility is high, resulting in an increase in the precipitation growth rate. However, the critical size of a stable nucleus is large due to lower thermodynamic driving force. This results in a low nucleation rates. At lower temperatures, the atomic mobility is low. This decreases the precipitation growth rate. However, the critical size of a stable nucleus is smaller. This increases the driving force and results in a higher nucleation rate forming in coherent metastable precipitates. A balance between nucleation and growth results in the maximum amount of precipitation occurring between the two extremes, around $450^{\circ} \mathrm{C}$. The nose at $450^{\circ} \mathrm{C}$ 
corresponds to the maximum precipitation of $\mathrm{Ni}_{4} \mathrm{Ti}_{3}$, while the second nose at approximately $575^{\circ} \mathrm{C}$ corresponds to the maximum precipitation of $\mathrm{Ni}_{3} \mathrm{Ti}_{2}$. An initial decrease in $\mathrm{A}_{\mathrm{f}}$ was observed above $500^{\circ} \mathrm{C}$, resulting from the dissolution of $\mathrm{Ni}_{4} \mathrm{Ti}_{3}$ into the matrix. $\mathrm{As} \mathrm{Ni}_{4} \mathrm{Ti}_{3}$ precipitates dissolve into the matrix, the transformation temperature of NiTi decreases. At longer times above $500{ }^{\circ} \mathrm{C}$, the $\mathrm{Ni}_{3} \mathrm{Ti}_{2}$ phase precipitates, resulting in a gradual increase in $\mathrm{A}_{\mathrm{f}}[7]$.

\subsection{Effects of Thermal-Mechanical Treatments}

NiTi components are commonly subjected to a series of thermal-mechanical treatments during its production and fabrication process. Stents, for instance, are manufactured by two common methods as illustrated in Figure 10. Method 1 involves expansion of a pattern cut from a small tube requiring a series of post-cutting, expansion, and heat treatments. Method 2 involves cutting the deployed design on a tube of a larger diameter and requires a single heat treatment that follows a simple ageing process. Consequently, applying a single heat treatment without apply mechanical a stress during shape -setting (Method 2) results in uniform properties throughout the stent. However, stents that undergo a series of expansion (Method 1) contain regions of inhomogeneous stress and strain states, specifically between the straight and curved segments of the struts [18]. 


\section{METHOD 1}

\section{Expansion on a small tube $\mathrm{inh}$ inomogeneous properties}

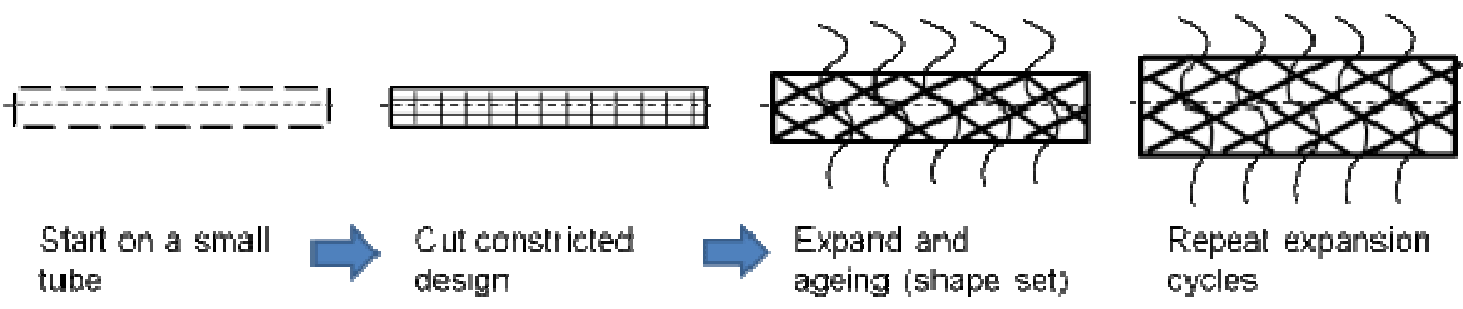

\section{METHOD 2}

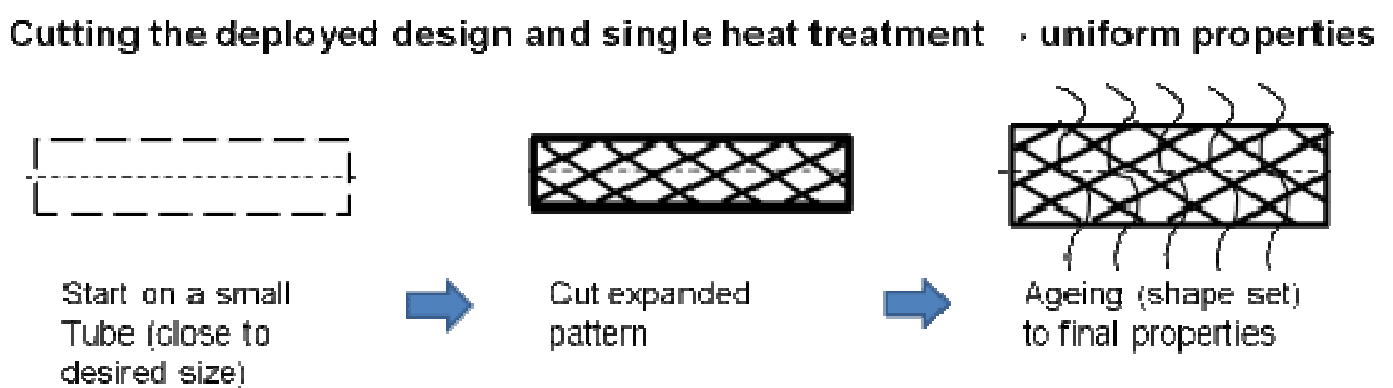

Figure 10 - A schematic of two common methods used to manufacture endovascular stents. Method 1 involves a series of cutting and expansion to achieve the desired size, resulting in inhomogeneous mechanical and thermal properties. Method 2 consists of a single heat treatment on a larger tube, typically near the size the vessel wall, and results in uniform mechanical and thermal properties [18].

Finite element simulation has been conducted by Favier et al. [19], to estimate the stress and strain fields experienced during the shape setting of a stent that undergoes a series of expansion. A simple stent, consisting of an array of $\mathrm{v}$-shaped structures rotated $90^{\circ}$, was used to model the forces experienced during shape setting. Due to the high radius of curvature in the vertex region of the v-shaped strut, the neutral axis was estimated to be closer to the compression side, as illustrated in Figure 11. Therefore, the majority of the NiTi material is in tension as the tube is expanded at the curved segment. Simulation shows that, during the expansion of a stent, the straight segments experience negligible strains and stresses. However, the maximum strain for the curved segment of a stent that 
undergoes a series of expansion is estimated to be approximately $12 \%$ in compression and $10 \%$ in tension [19].

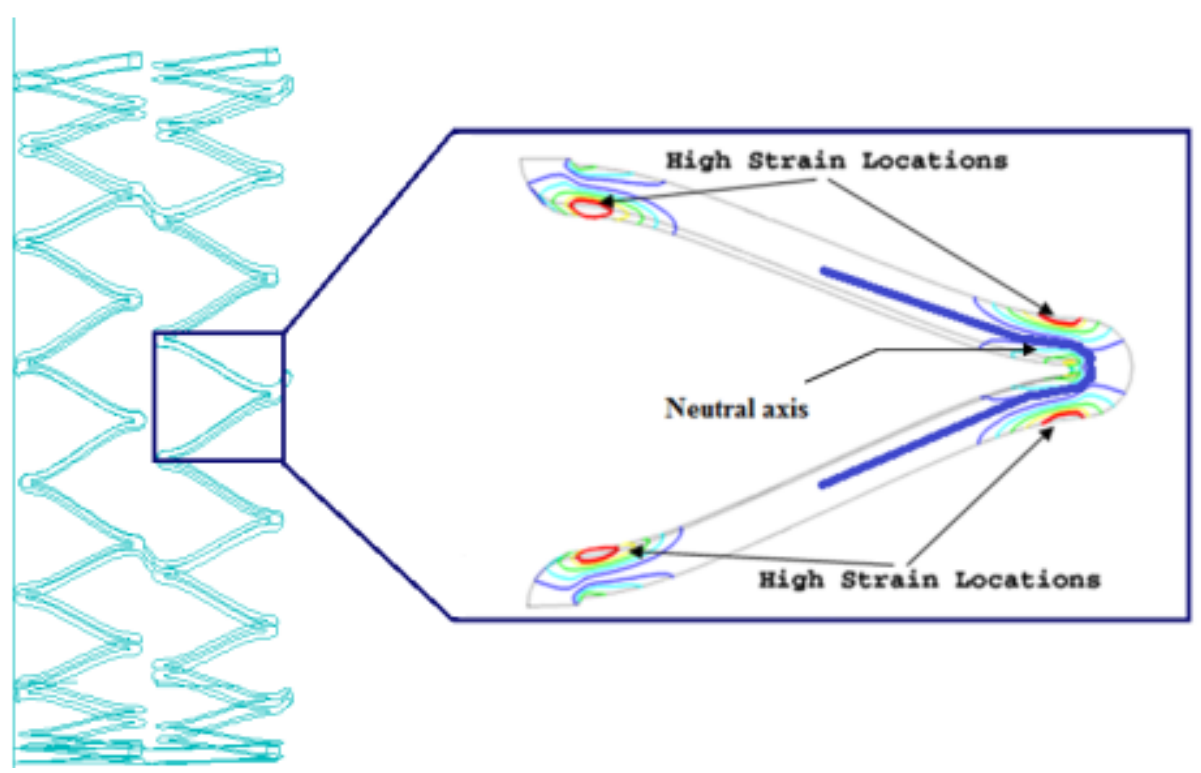

Figure 11 - According to finite elemental simulation presented by Favier, the maximum strain experienced by a NiTi stent undergoing a series of expansion during shape setting is approximately $10 \%$ in compression. Note the shift in neutral axis resulting from a high radius of curvature at the curved segments of a stent [20].

Poncin et al. [21], have demonstrated the influence of constrained ageing on the transformational behavior of NiTi tubing. In this study, stents were manufactured using Method 1, where the stent undergoes a series of expansion. The curved segments on the stent corresponded to the constrained sample, while the straight segments of the stent were used as the unconstrained samples. An increase in ageing kinetics and a decrease in upper and lower plateau strength were observed for the constrained samples.

According to Poncin, the increase in ageing kinetics is attributed to the formation of $\mathrm{Ni}_{4} \mathrm{Ti}_{3}$ rich precipitates preferentially aligned to the external tensile stress of the curved 
segment during constrained ageing. During the precipitation process, coherent $\mathrm{Ni}_{4} \mathrm{Ti}_{3}$ precipitates are formed in lenticular shapes and exert an anisotropic stress field within its vicinity [22-24]. It has been reported Honma et al. [25-27] that during constrained ageing, the external stress can affect the formation and shape of the lenticular precipitates. An applied stress tends to increase the size of the precipitates, specifically the major axis of the lenticular discs with increasing ageing time as illustrated in Figure 12. According to Michutta [22], an applied stress will encourage the formation of elongated $\mathrm{Ni}_{4} \mathrm{Ti}_{3}$ precipitates to relax the internal stresses created by the anisotropic stress fields.
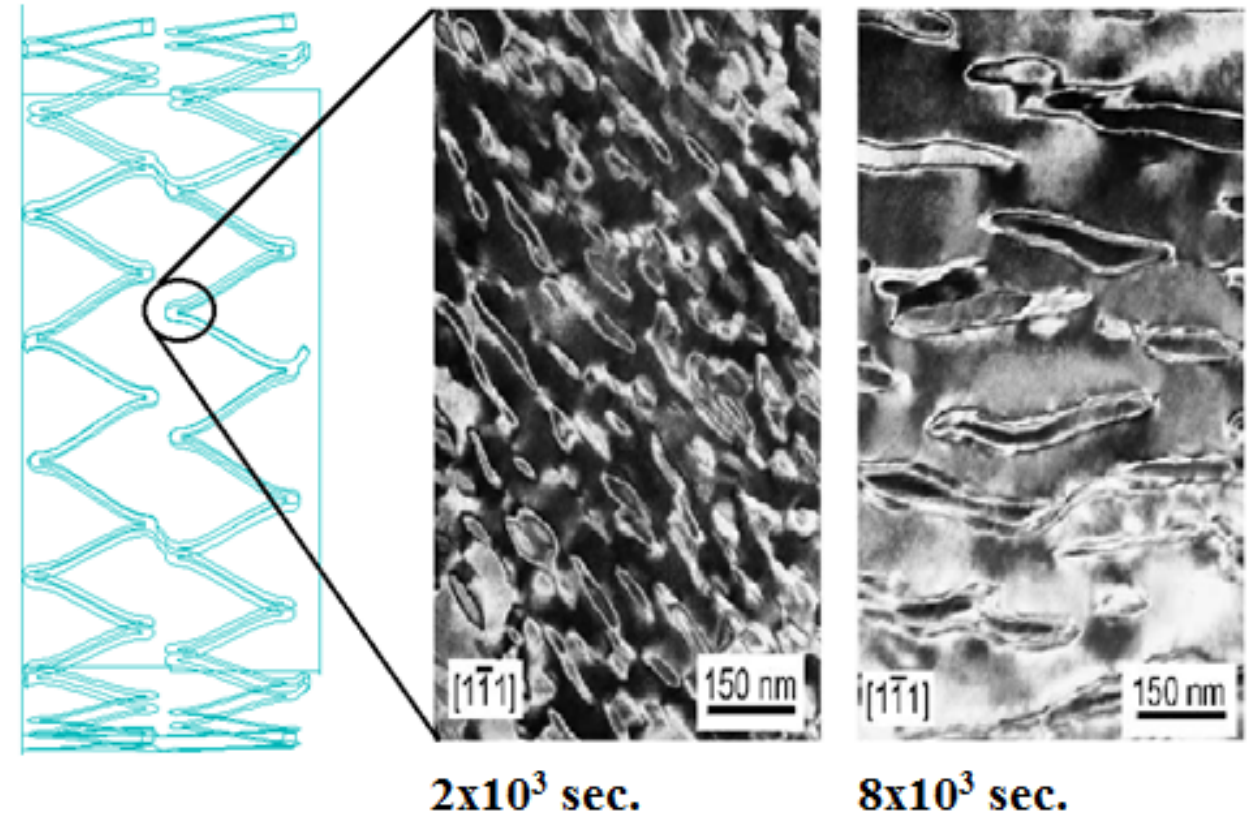

Figure 12 - A clear increase in ageing kinetics with increasing heat treatment time is evident under an applied stress of $50 \mathrm{MPa}$. An applied stress influences the shape and growth of $\mathrm{Ni}_{4} \mathrm{Ti}_{3}$ precipitates [22].

Lui et al.[28], have reported a decrease in upper and lower plateau stress after short heat treatment times for constrained ageing of Ti-50.7 at.\% Ni, as shown in Figure 13. At 
short times heat treatment times of less than 2 minutes, the upper and lower plateau stress increase due to precipitation strengthening. At longer heat treatment times, annealing processes dominate and tend to decrease the upper and lower plateau stress more rapidly. Both Favier [18] and Lui [28] attribute the decrease in upper and lower plateau stress to an increase in transformation temperature. As the transformation temperature increases above room temperature due the formation of nickel rich precipitates influenced by an applied strain, the NiTi sample is predominantly in the martensite phase. Martensite has lower mechanical properties due to its atomic structure.

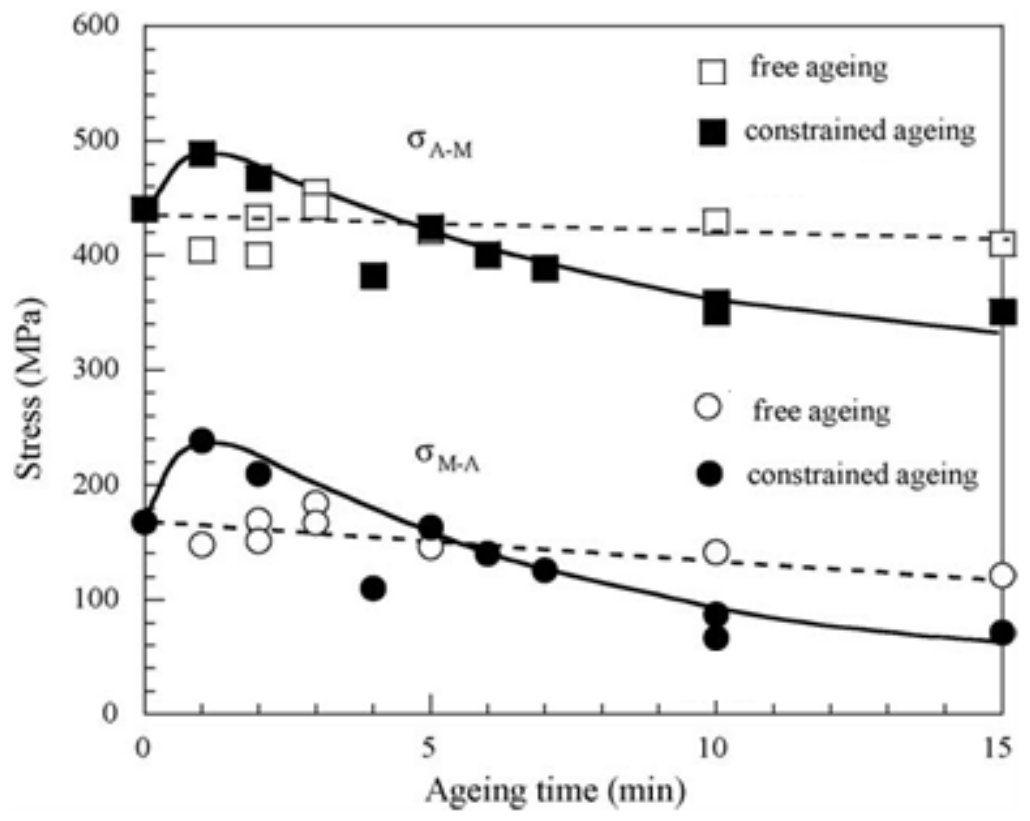

Figure 13 - Effect of applied strain and heat treatment on the $\left(\sigma_{\mathrm{A}-\mathrm{M}}\right)$ upper and $\left(\sigma_{\mathrm{M}-\mathrm{A}}\right)$ lower plateau of aged Ti-50.7 at.\% Ni alloy. Constrained samples were taken from the curved segments of a shapeset stent and compared to the straight segments. Note a systematic decrease in plateau stress with increasing ageing time [28].

The effect of constrained ageing on the ultimate tensile stress of NiTi is not richly published in literature. However, the effect of cold work and heat treatment on the 
ultimate tensile stress of Ti-50.8 at.\% Ni has been investigated [3]. Drexel presented the trends in UTS as a function of heat treatment time for $30 \%$ and $50 \%$ initial cold work as shown in Figure 14. An increase in tensile strength due to precipitation hardening occurs between 350 and $450^{\circ} \mathrm{C}$ at $30 \%$ initial cold work. At higher temperatures, between 500 and $600^{\circ} \mathrm{C}$, annealing effects dominate and lower the tensile strength. At $50 \%$ cold work, a decrease in ultimate tensile strength is observed for all heat treatment temperatures.
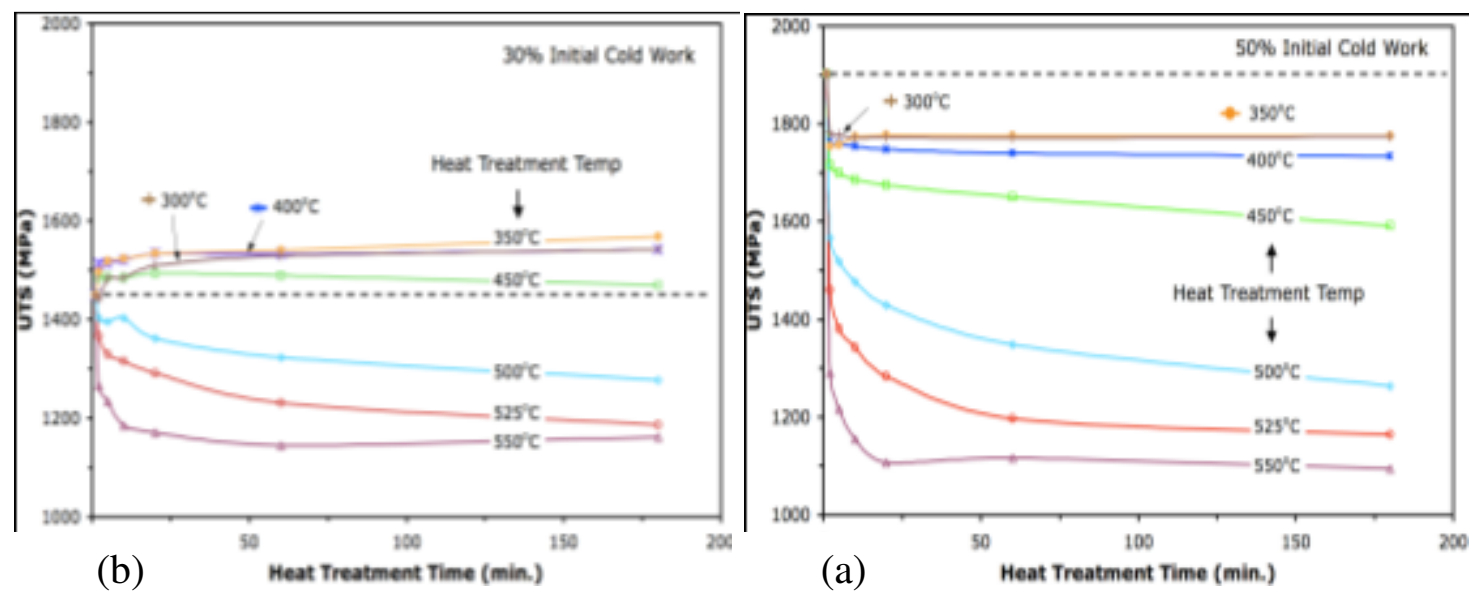

Figure 14 - The effect of heat treatment and cold work on the ultimate tensile stress of Ti-50.8 at.\% Ni presented by Drexel. Note annealing effects dominate at high temperatures for a) $30 \%$ cold work and for any heat treatment temperature for b) $50 \%$ cold work [3].

Kim et al.[29], have reported pronounced phase transformation behavior occurs for constrained ageing as illustrated in Figure 15. Depending on the amount of cold work within the NiTi sample, typical phase transformation upon cooling involves austenite to martensite followed by martensite to austenite upon heating. As an applied stress is introduced during shape setting, this two-stage transformation is disrupted by the appearance of the R-phase. The R-phase transformation upon heating tends to converge with the austenite transformation for a sample under constrained ageing, as shown in 
Figure 15. Otsaka [30] reported that the R-phase can be stabilized by the following methods:

1) The presence of rearranged dislocations due to cold work followed by heat treatments at $400-500^{\circ} \mathrm{C}$

2) Fine dispersion of $\mathrm{Ti}_{2} \mathrm{Ni}_{3}$ precipitates at temperatures between $400-500^{\circ} \mathrm{C}$ occurring in alloys of Ti-50.8 at.\% Ni or greater

3) Adding a third alloying element such as Fe and Al

The stabilization of the R-phase through heat treatments was investigated in great detail by Ren et al.[31]. Heat treatments between $400-500^{\circ} \mathrm{C}$ tend to encourage the formation of fine precipitates; these precipitates exert an anisotropic stress field to the lattice. As a result of an elastically strained lattice, the transformation from austenite to martensite is suppressed. The R-phase can then be stabilized through the assist of an elastically strained lattice [29]. 


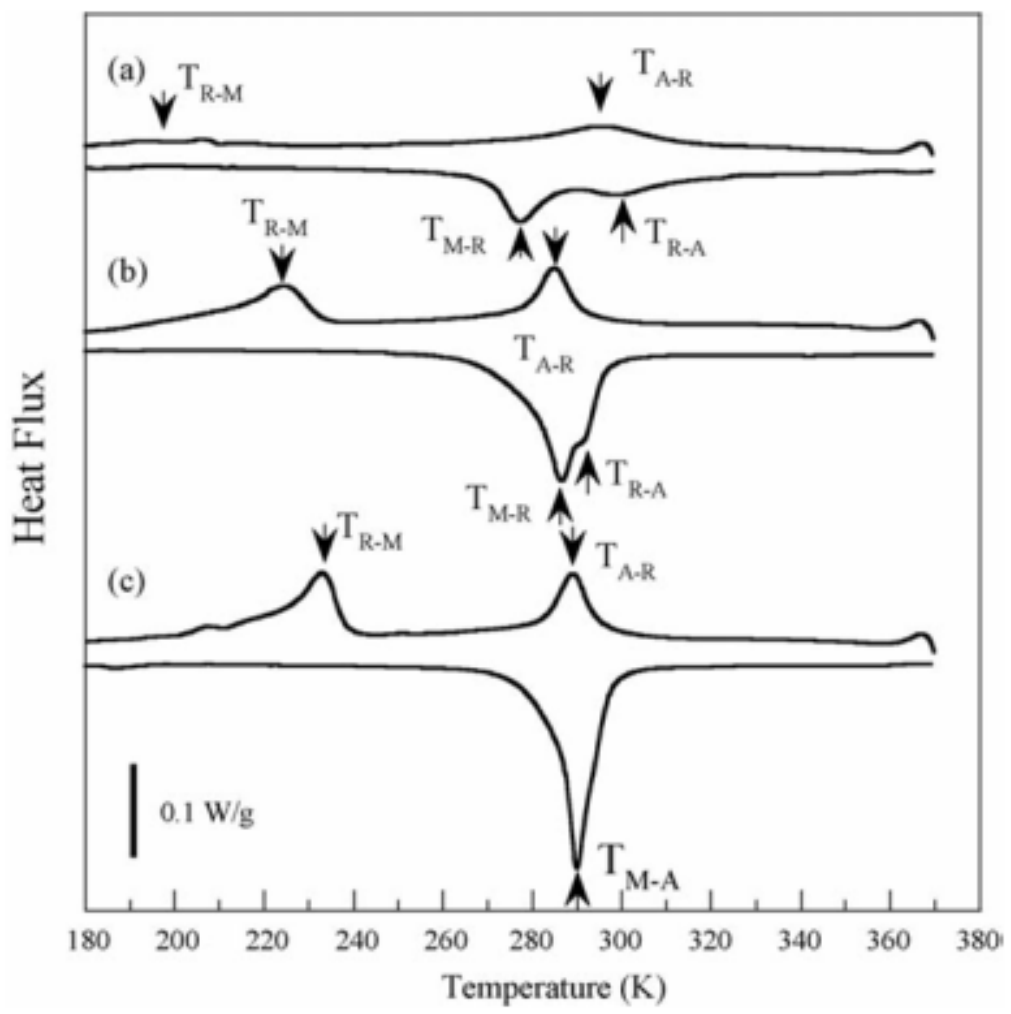

Figure 15 - Phase transformation behavior for (a) an unconstrained sample, (b) a sample under 5\% strain, and (c) a sample under $7.5 \%$ strain. The R-phase transformation peak converges with the austenite phase transformation peak and is more pronounced during constrained ageing [29]. 


\section{CHAPTER THREE RESEARCH OBJECTIVES}

The objectives of this study is to characterize the trends in thermal and mechanical properties due to applied strain levels of $2-10 \%$ and heat treatments of $300-550^{\circ} \mathrm{C}$ for times of 2-30 minutes during the shape setting of NiTi wire. The transformation properties will be summarized in six diagrams of $A_{f}$ versus heat treatment time, one for each level of applied strain. A control sample under no strain will be used as comparison to determine the effects of applied strain on $\mathrm{A}_{\mathrm{f}}$ during shape setting. A three-dimensional TTT-like diagram will be constructed to illustrate the general trends in $A_{f}$ due to applied strain and heat treatment. A shift to the left of $\mathrm{A}_{\mathrm{f}}$ contours, indicating faster reaction rates, is expected for specimens heat treated with an applied strain. The mechanical properties, including ultimate tensile strength (UTS) and elastic modulus, will be summarized in several diagrams illustrating the effects of precipitation and annealing processes. A decrease in mechanical properties with increasing level of applied strain is expected if annealing processes dominate, but an increase in mechanical properties is expected if precipitation strengthening is dominant. In addition, the influence of an applied strain during heat treatment on the shape-setting behavior of NiTi will be investigated. 


\section{CHAPTER FOUR \\ MATERIALS AND EXPERIMENTAL METHODS}

\subsection{NiTi Wire}

Ti-50.8 at.\% Ni wire, supplied by Nitinol Devices and Components (NDC), Fremont, California, with a diameter of 0.02 inches $(0.495 \mathrm{~mm})$ and an initial $\mathrm{A}_{\mathrm{f}}$ of $12^{\circ} \mathrm{C}$ was used in this study. All samples used in this study came from the same spool of wire. The material data sheet for superelastic wire including the lot number is included in Appendix I. The wire used in this research meets the compositional specifications of wire used in the medical device industry per ASTM 2063.

\subsection{Steel Mandrels}

Tool steel W1 (TSW1) mandrels were used in this study to constrain the NiTi wire. TSW1 was selected as the material for the mandrels due to its similar coefficient of thermal expansion (CTE) to NiTi in the austenite phase of approximately $11 \times 10^{-6}{ }^{\circ} \mathrm{C}^{-1}$ [32]. In the martensite phase, NiTi has a CTE of approximately $6.6 \times 10^{-6 \circ} \mathrm{C}^{-1}$. For $\mathrm{TSW} 1$, this value of $11 \times 10^{-6}{ }^{\circ} \mathrm{C}^{-1}$ holds for temperature ranges of $0-200^{\circ} \mathrm{C}$. At temperatures greater than $200^{\circ} \mathrm{C}$, the CTE of TSW1 increases to approximately $14.2 \times 10^{-}$ ${ }^{6} \mathrm{C}^{-1}$ at $600^{\circ} \mathrm{C}$ [33]. However, austenite is stable at higher temperatures and has the same CTE as TSW1 in the austenite phase. Therefore, the CTE of NiTi and TSW1 was assumed to be similar at higher temperatures due to comparable properties such as CTE, density, and specific heat at $200^{\circ} \mathrm{C}$ in the austenite phase. 
The thermal conductivity of TSW1 and NiTi were investigated to determine the ability of each material to conduct heat. Since the NiTi wire and TSW1 mandrel are submerged entirely inside the salt bath, heat transfer occurs primarily by conduction. In theory, the ideal material for the mandrel should have a similar thermal conductivity as NiTi to ensure that the heat transfer occurs primarily between the NiTi wire and the salt bath solution. Investigating the thermal conductivity of both materials reveals a maximum difference of $22 \mathrm{Wm}^{-10} \mathrm{C}^{-1}$ in the austenite phase for NiTi. For example, at $300^{\circ} \mathrm{C}$ for TSW 1 , the thermal conductivity is approximately $40.2 \mathrm{Wm}^{-1} \mathrm{C}^{-1}$ and approximately 30.4 $\mathrm{Wm}^{-1 \circ} \mathrm{C}^{-1}$ at $600^{\circ} \mathrm{C}[33]$. For NiTi in the austenite phase, the published thermal conductivity is $18 \mathrm{Wm}^{-1} \mathrm{C}^{-1}$ [32]. Note, the thermal conductivity for NiTi is not published for a range of temperatures. Therefore, the difference in thermal conductivity between TSW1 and NiTi is expected to increase linearly with temperature.

\subsection{Strain Applied to NiTi Wire}

Strain was applied prior to conducting the heat treatments by coiling the NiTi wire around steel mandrels of different diameters to obtain strain levels of 2-10\%. The maximum strain level of $10 \%$ was chosen based on the results of the finite element simulation conducted by Favier [20]. Equation 2 estimates the maximum tensile strain, $\mathcal{E}_{\max }$, of a bending wire around a cylindrical mandrel where $\mathrm{D}$ is the diameter of the mandrel and $\mathrm{d}$ is the diameter of the wire [34].

$$
\varepsilon_{\max }=\frac{1}{\left(1+\frac{D}{d}\right)}
$$


Using a constant diameter of 0.02 inches for the NiTi wire, the amount of applied strain was varied based on the diameter of the steel mandrel. Table I summarizes the diameter of the mandrels used in this study and the corresponding strain levels.

Table I: Diameter of cylindrical rods with corresponding strain levels, using a wire diameter of 0.02 inches

\begin{tabular}{|c|c|}
\hline Diameter of Steel Rod (in.) & Resulting Strain (\%) \\
\hline- & 0 \\
\hline 0.98 & 2 \\
\hline 0.48 & 4 \\
\hline 0.31 & 6 \\
\hline 0.23 & 8 \\
\hline 0.18 & 10 \\
\hline
\end{tabular}

As the size of the steel mandrel decreases, the resulting strain increases. The steel mandrels corresponding to strain levels of $2 \%$ and $10 \%$ are shown in Figure 16. The steel mandrels were cut into lengths of three inches. Using a CNC mill, four holes were machined through the entire thickness of each steel mandrel. The largest mandrel was reamed hollow with a wall thickness of 0.03 inches to account for the large volume difference between the smallest and largest mandrel. The holes located near the edge of the steel mandrel served to constrain the NiTi wire using steel threaded hex bolts. The two center holes, separated by approximately 0.3 inches, allowed for a total of 15 active coils and served to reduce the amount of slack and increase the tension during the coiling process. 


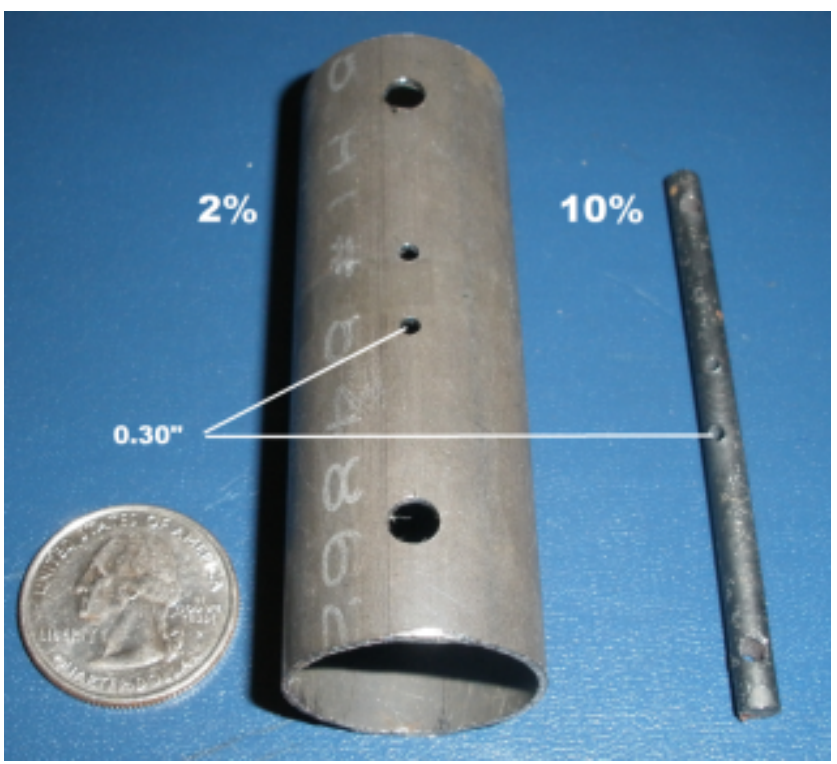

Figure 16 - The larger mandrel, approximately 1 inch in diameter, corresponds to $2 \%$ strain. Conversely, the smaller mandrel of approximately 0.18 inches in diameter corresponds to $10 \%$. Note that the larger mandrel is hollow with a wall thickness of 0.03 inches to have a similar volume to a $6 \%$ strain mandrel.

The NiTi wires were manually coiled at room temperature directly from the spool of wire. The wire was first guided through one of the center holes followed by constraining the wire through one of the holes located near the edge of the mandrel using a hex threaded bolt. The wire was then guided around the steel bar circled yellow in Figure 17 to apply tension during the coiling process. The spool of wire was held in place using a flat polymer disc and a threaded bolt as shown in Figure 17. After obtaining 15 coils between the two center holes, the wire was cut and guided through the second center hole. Using wire grips to maintain tension, the wire was guided through the final hole and constrained using a threaded hex bolt. 


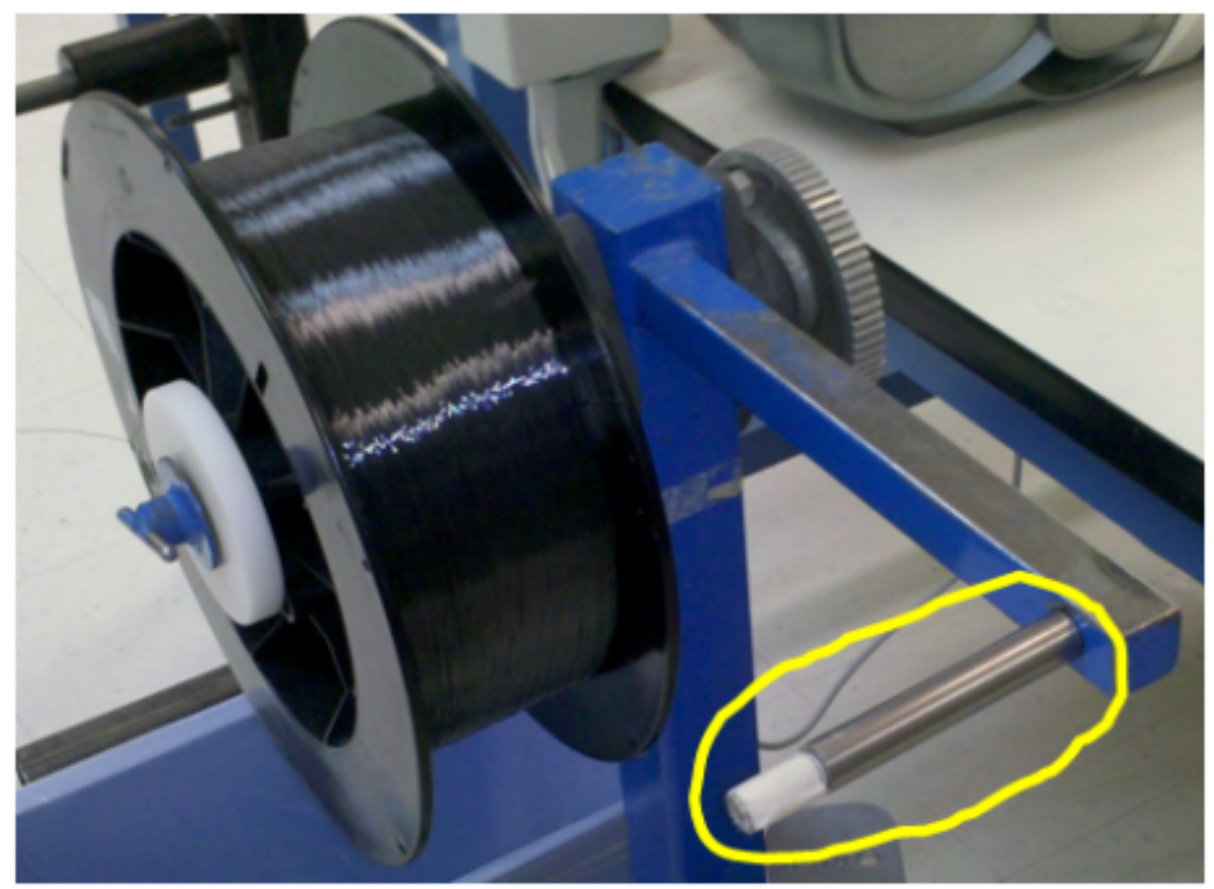

Figure 17 - Schematic of the coiling system used to apply strain on the NiTi wire. The wire first constrained on each mandrel followed by using the steel bar (circled in yellow) as a leverage to apply and maintain tension on the wire. The spool of wire was held in place using a polymer disc.

Though the maximum amount of strain was based on Equation 2, the actual amount of tension applied to the wire was not controlled during the coiling process. Based on preliminary studies, a difference in $\mathrm{A}_{\mathrm{f}}$ was observable between samples under strain within each heat treatment time. Therefore, the addition of radial strain due to thermal expansion was not quantified aside from using Equation 2. Each mandrel and strain condition was randomly selected during the coiling process to minimize the variance due to operator fatigue. For instance, the wires under higher levels of applied strain require greater force to maintain tension during the coiling process. All wires were coiled in a single day, causing the samples that were coiled near the end of the day to be less tightly coiled. By randomizing the selection of the mandrels, each strain condition has a higher 
probability of being coiled with the same tension. A representative set of NiTi wire under applied strain is shown in Figure 18 in order of increasing strain level.

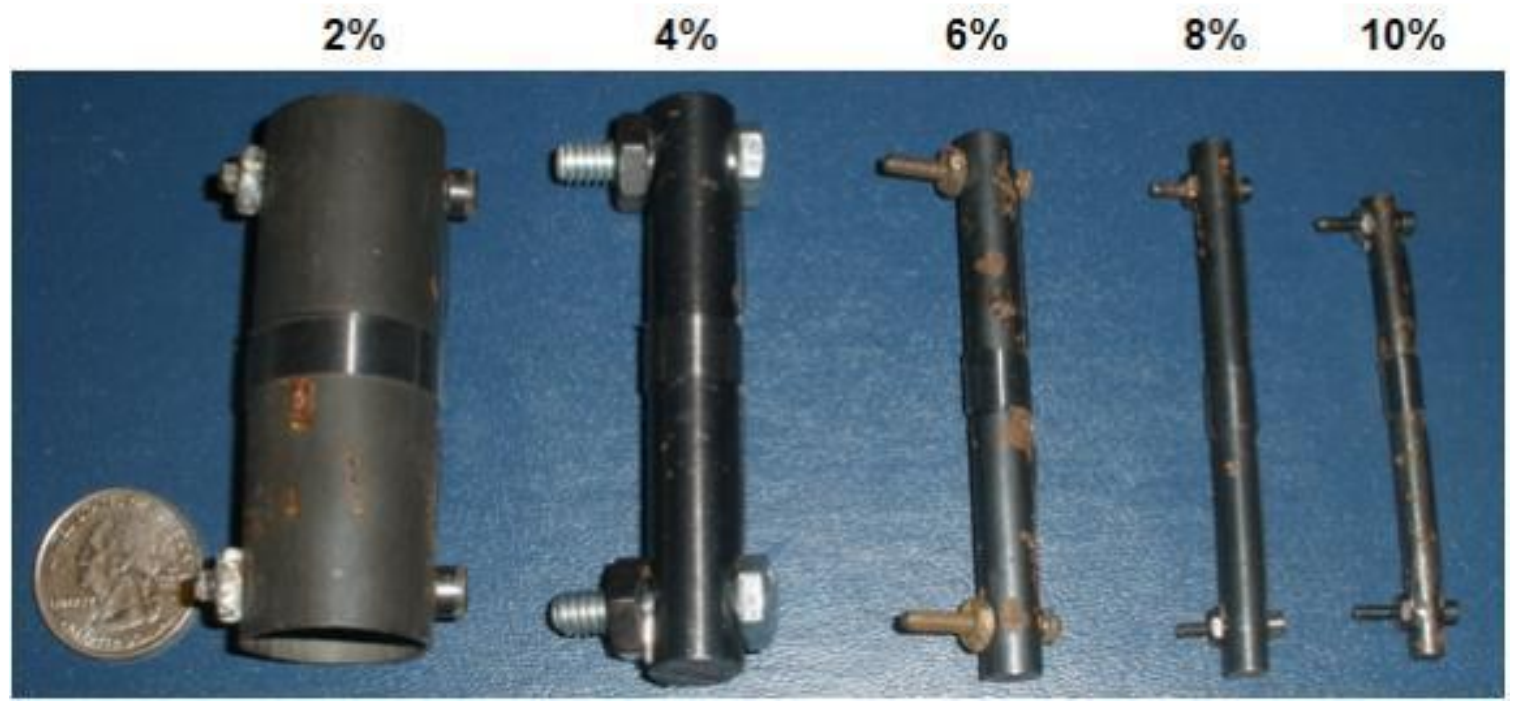

Figure 18 - Samples of NiTi wire in order of increasing strain level from left to right, $2 \%, 4 \%, 6 \%$, $8 \%$, and $10 \%$. Straight wire taken directly from the spool was used as the control sample, $0 \%$ strain.

\subsection{Salt Bath Heat Treatments}

Heat treatments of the NiTi samples under applied strain were performed using salt baths at NDC. Thermocouples, calibrated by Micro Precision, Inc, were used to monitor and ensure a constant heat flow. Table II summarizes the strain levels and heat treatment conditions used in this study. Sixty heat treatment conditions, two for each heat treatment time, were selected to replicate based on the trends observed for the first data set. Therefore, only half of the entire heat treatment conditions were replicated. The heat treatment temperatures of $300-550^{\circ} \mathrm{C}$ were chosen to characterize the maximum precipitation rate, which Pelton [7] found to be centered near $450^{\circ} \mathrm{C}$. In addition, small time intervals were chosen to capture the rapid increase in $A_{f}$ previously reported by 
Pelton. Each set of NiTi samples under applied strain was quenched in a water bath following the heat treatment.

Table II: Heat treatment conditions used in this study

\begin{tabular}{|c|c|c|c|}
\hline Applied Strain (\%) & $\begin{array}{c}\text { Heat Treatment } \\
\text { Temperature }\left({ }^{\circ} \mathbf{C}\right)\end{array}$ & $\begin{array}{c}\text { Heat Treatment } \\
\text { Time (min.) }\end{array}$ & $\begin{array}{c}\text { Total Number } \\
\text { of Specimen }\end{array}$ \\
\hline $0,2,4$, & $300,350,400$, & 2,5, & 120 \\
$6,8,10$ & 450,550 & 10,30 & \\
\hline
\end{tabular}

A split-plot design, commonly used in industry when one of the factors is difficult to adjust, was effectively used to reduce the total amount of time required to complete the heat treatments. For instance, the salt bath takes approximately one hour to reach equilibrium following a temperature change of $50^{\circ} \mathrm{C}$. In this study, adjusting the heat treatment temperature was a nuisance factor. Therefore, a set of six NiTi samples under applied strain (0-10\%) were placed inside a steel wire mesh basket shown in Figure 19 and into a salt bath at a specified heat treatment temperature and time. This results in a split-plot design using a combination of temperature and time as the whole-plot factor and level of applied strain as the split-plot factor. This method is an effective way to detect differences within the variable used as the split-plot factor, in this case, level of applied strain. A schematic of a split plot design is shown in Figure 20, where each box represents an individual run. 


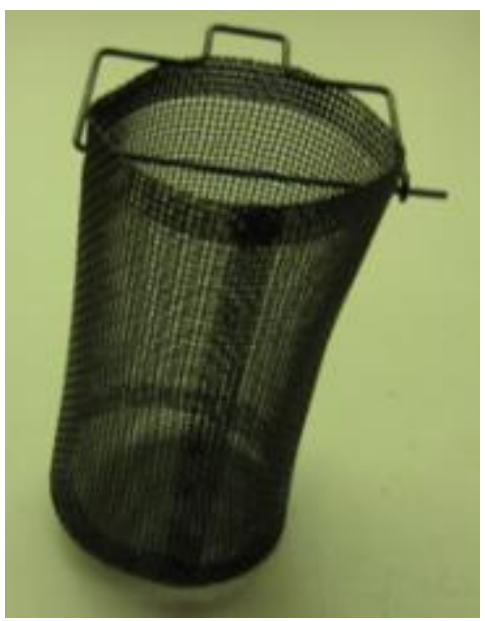

Figure 19 - Samples under applied strain, including the control sample, were randomly chosen and placed inside a wire basket. The wire basket, including all six samples, was then placed inside the salt bath under a certain heat treatment condition.
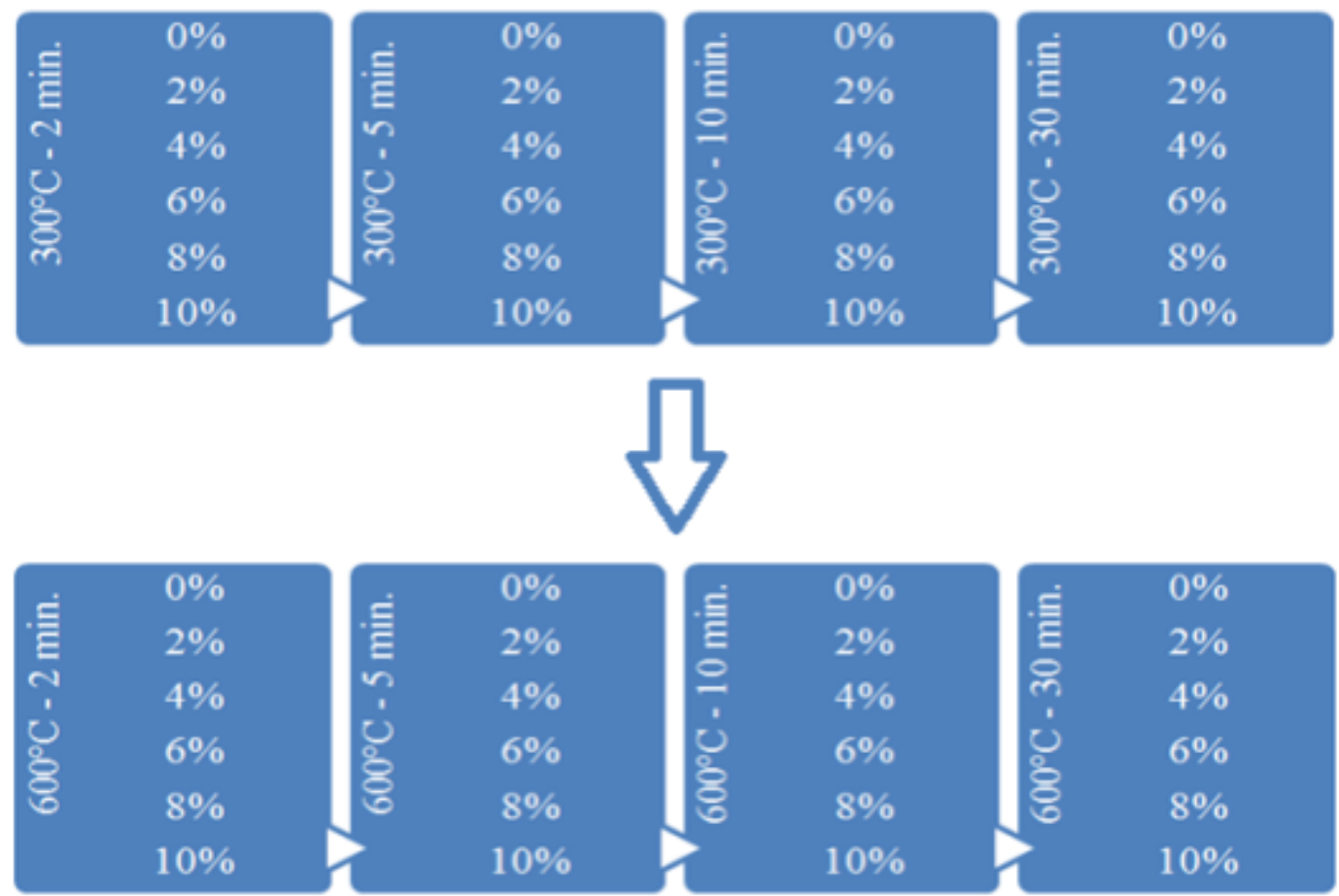

Figure 20 - Schematic of a split plot design used in this study. All samples of NiTi of various applied strain were placed inside the salt bath. This method significantly minimizes the amount of time required to conduct the heat treatments while detecting differences within each salt pot condition. 
Salt baths were chosen to heat the NiTi samples because of fast heat up times (up to six times faster than a convection furnace), resulting from high thermal conduction between the salt bath solution and the NiTi wire [35]. A salt bath process is especially advantageous when heating samples for short times, as the time for the sample to reach the desired temperature may constitute for a significant portion of the heat up time. A thin layer of salt film adheres to the surface of the sample and continues to provide a uniform heat flow while the sample is transferred to the quenching station. Since the NiTi wire and steel mandrel are in direct contact with the salt bath solution, heat is transferred by conduction [35] versus a typical oven furnace where heat is transferred by convection. Due to the proprietary configuration of the salt bath process, images are not provided. A representative image of the coiled NiTi samples once removed from the salt bath and steel mandrel is shown in Figure 21. 

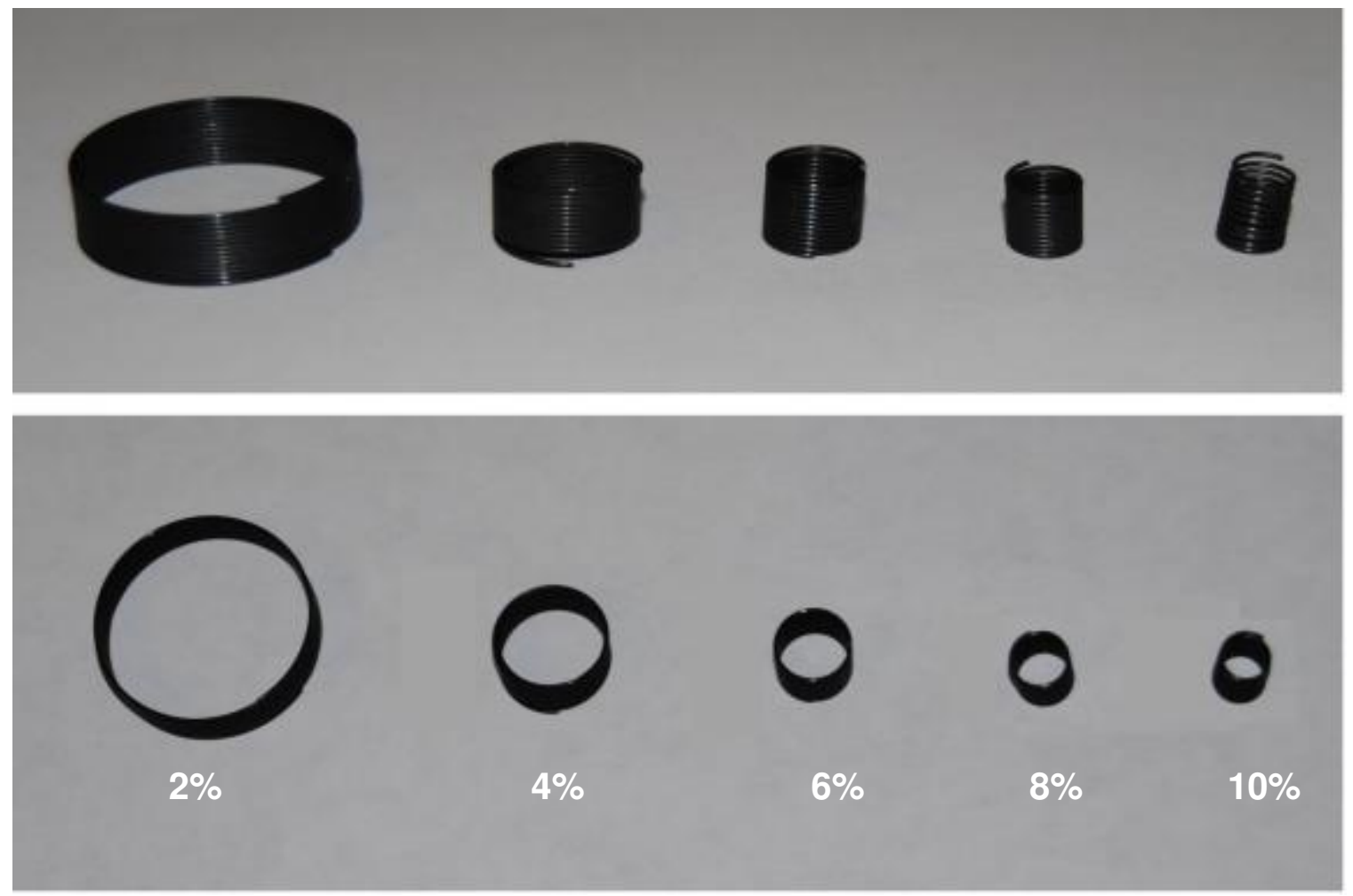

Figure 21 - A representative set of NiTi samples that have been heat treated at $500^{\circ} \mathrm{C}$ for 2 minutes in order of increasing level of strain from left to right. Note that the wire has shape set to conform around each mandrel at $500^{\circ} \mathrm{C}$. Samples that were heat treated below $450^{\circ} \mathrm{C}$ for short heat treatment times and less than $6 \%$ applied strain did not shape-set to the size of the corresponding mandrel.

\subsection{DSC Measurements}

Transformational properties were characterized using a Seiko Instruments Q100 DSC, shown in Figure 22, in accordance with American Society of Testing Materials (ASTM) standard F 2004-05 [36]. This test method involves heating and cooling a sample of the NiTi wire inside an encapsulated aluminum pan through the temperature intervals that include the phase transformation. The difference in heat flow between the NiTi sample and a reference aluminum pan due to changes in energy is continuously monitored and recorded. 


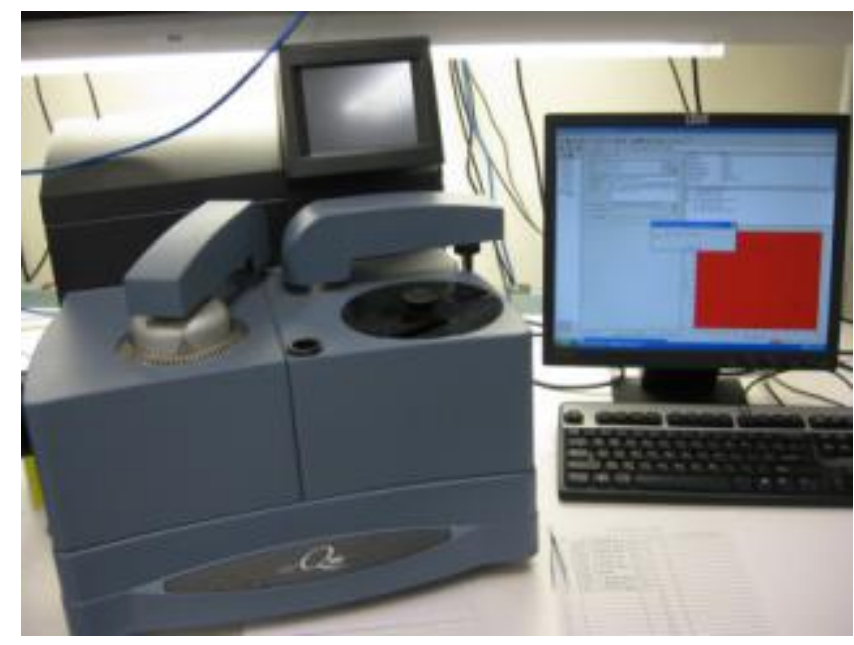

Figure 22 - Seiko Instruments Q100 is an automated DSC capable of testing 50 consecutive samples. Each test run takes approximately approximately one hour at a ramp rate of 5 degrees per minute.

For each scan, the sample was first heated to $125^{\circ} \mathrm{C}$ to drive off water vapor. Data was then collected as the sample was cooled from $125^{\circ} \mathrm{C}$ to $-125^{\circ} \mathrm{C}$ and re-heated to $125^{\circ} \mathrm{C}$ at a rate of 5 degrees per minute. $A_{\mathrm{f}}$ temperatures were determined using Universal Thermal Analysis software in accordance to ASTM 2004-05. Two intersection lines were selected using the software between the baseline and the maximum slope of the endothermic $A_{f}$ peak. A typical DSC curve for NiTi, shown in Figure 23, illustrates the endothermic and exothermic peaks corresponding to the reversible solid state phase transformation between martensite and austenite. 


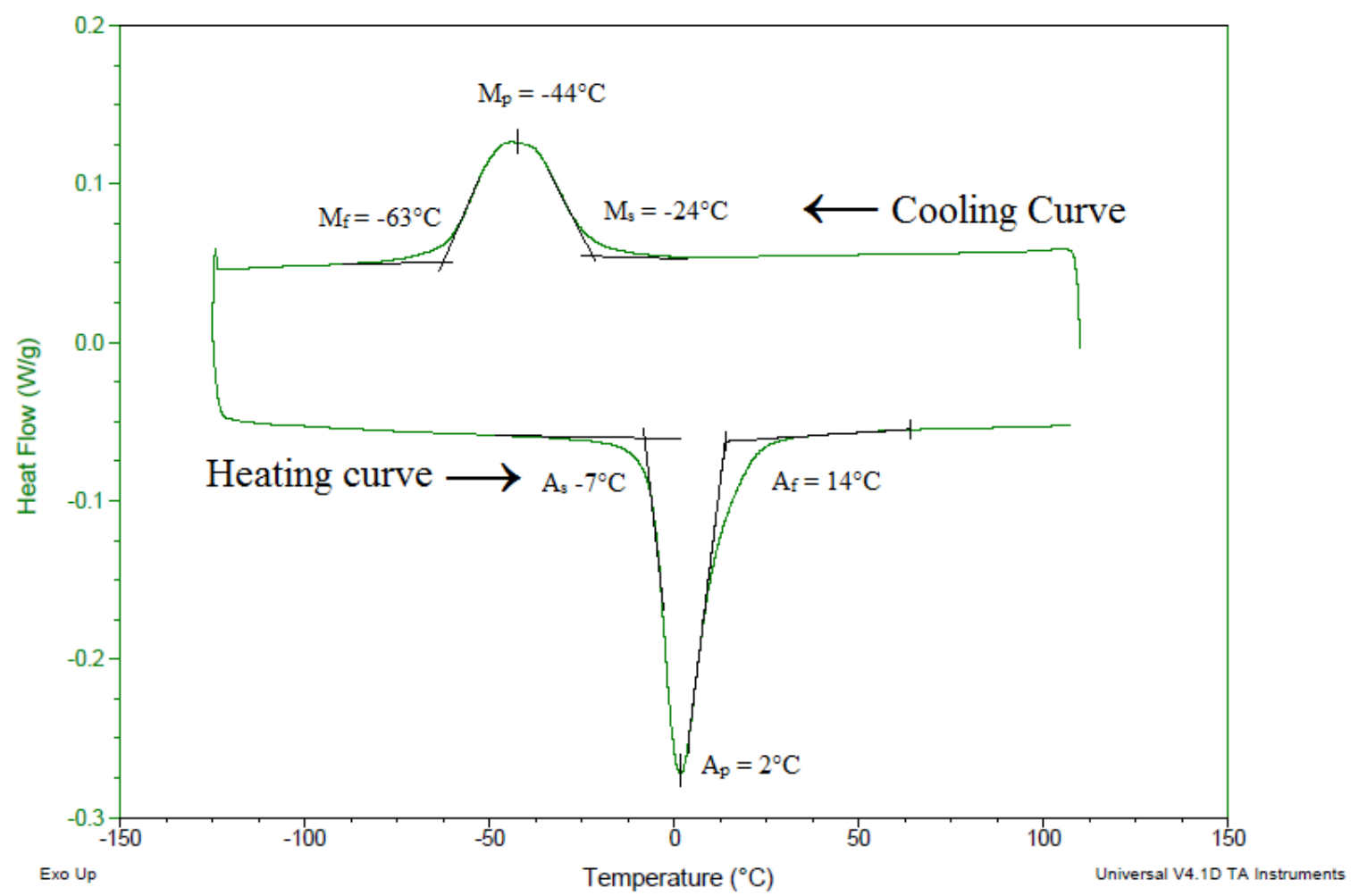

Figure 23 - A typical DSC curve for NiTi wire. Upon cooling from $125^{\circ} \mathrm{C}$ to $-125^{\circ} \mathrm{C}$, an exothermic peak characterizes the complete transition from austenite to martensite. Upon heating to $125^{\circ} \mathrm{C}$, an endothermic peak indicates the reversible transformation from martensite to austenite.

\subsection{Mechanical testing}

The shape-set coils were initially to be characterized by measuring the spring constant of each heat treated wire. The spring constant can be calculated by using a tensile tester and measuring the deflection of each coil due to an applied load. Using a constant diameter of $0.5 \mathrm{~mm}$ for the wire and a total number of 15 active coils ${ }^{1}$ on each spring, the shear modulus of each heat treated wire can then be determined using Equation 3.

Eq. 3

\footnotetext{
${ }^{1}$ Active coils - coils in a spring that are free to deflect under an applied load
} 
In Equation 3, $\mathrm{K}$ is the spring constant of each shape-set coil and $\mathrm{D}$ is the diameter of each coil. Wires that were heat treated below $450^{\circ} \mathrm{C}$ for short times shape-set less to the corresponding mandrel size, resulting in coils that were shape-set on the same size mandrel to have different diameters. This added variability and difficulty in relating the spring constant of each coil to the shear modulus based on heat treatment and applied strain. The spring constant was measured on each coil that was shape-set into a spring. However, the load cell (250 and $500 \mathrm{lb})$ of the tensile tester was too large to detect differences in displacement due an applied force. Therefore, the mechanical properties were characterized using a uniaxial tensile test.

Uniaxial tensile testing of the shape-set coiled wires was conducted at Cal Poly using the Materials Engineering department's Instron tensile tester equipped with custom capstan grips and a $500 \mathrm{lb}$ load cell at room temperature. Due to the available resources, crosshead displacement, as opposed to using a class $\mathrm{C}$ or better extensometer, was used to measure strain. Tensile tests were attempted in accordance with ASTM F2516-05 [37], the standard test method for superelastic NiTi. However, inconsistencies in UTS and elastic modulus using the custom capstan grips led to the development of a standard operating procedure (SOP), adhering to ASTM F2516 when possible. A uniaxial tensile test is not an ideal test method for characterizing coiled wires. By uncoiling the wires and conducting a uniaxial tensile test, each specimen is pre-strained due the potential energy stored in each coiled sample. In effect, this test method may lead to dramatic inconsistencies and perhaps incorrect correlations. Therefore, the results from the 
mechanical testing may be better interpreted as data for pre-strained wires, rather than a direct correlation of mechanical properties for wires heat treated under an applied strain.

According to ASTM F2516-05, a loading and unloading cycle is required to outline the stress hysteresis created by the austenite to martensite phase transformation. The wire specimen is loaded to $6 \%$ strain, unloaded to a stress less than $7 \mathrm{MPa}$, followed by the loading the sample to failure. As prescribed by ASTM F2516, the recommended strain rate for specimens of $0.5-2.5 \mathrm{~mm}$ diameter is 0.02 inches per minute per inch of gauge length. In this study, a gauge length of three inches was used, dictating a strain rate of 0.06 inches per minute.

Several issues were encountered during the mechanical testing of the NiTi wire following ASTM F2516. Initially, the wire consistently fractured at the grip interface due to high stress concentrations and poor design using typical vice-like grips. Using a split capstan design, similar to wire grips provided by Instron [38] and Wyoming Test Fixtures Inc.[39], the tensile load is distributed around the circumference of the capstan disc. This reduces the stress concentration at the grip interface and prevents premature failure [38]. Capstan grips rely primarily on friction to provide tension on the specimen. During the loading cycle, maintaining tension using the capstan grips is not an issue. Upon unloading to a stress of less than7 $\mathrm{MPa}$, the wire lost tension; this introduced variability in values obtained for the UTS. The elastic values were relatively similar regardless of the variability seen in UTS. Within heat treatment condition, the UTS was not reproducible (standard deviation of $45 \mathrm{MPa}$ ) following ASTM F2516. 
The following SOP was developed to obtain reproducible UTS using the fabricated capstan grips and crosshead displacement to measure strain. The SOP was based on a wire in the austenite phase heat treated at $550^{\circ} \mathrm{C}$ with an applied strain of $10 \%$. However, the strain due to unwinding each individual coil was not accounted for. Similar to the split plot design shown in Figure 20, tensile testing was randomized based on strain level within each heat treatment condition. Due to time constraints, each wire specimen was tested once at each heat treatment and level of applied strain; no replicates of each condition were conducted. Each coiled specimen was manually uncoiled and loaded clockwise onto the capstan grip as shown in Figure 24. A steel bolt was used to grip the wire and prevent slippage during the unloading cycle.
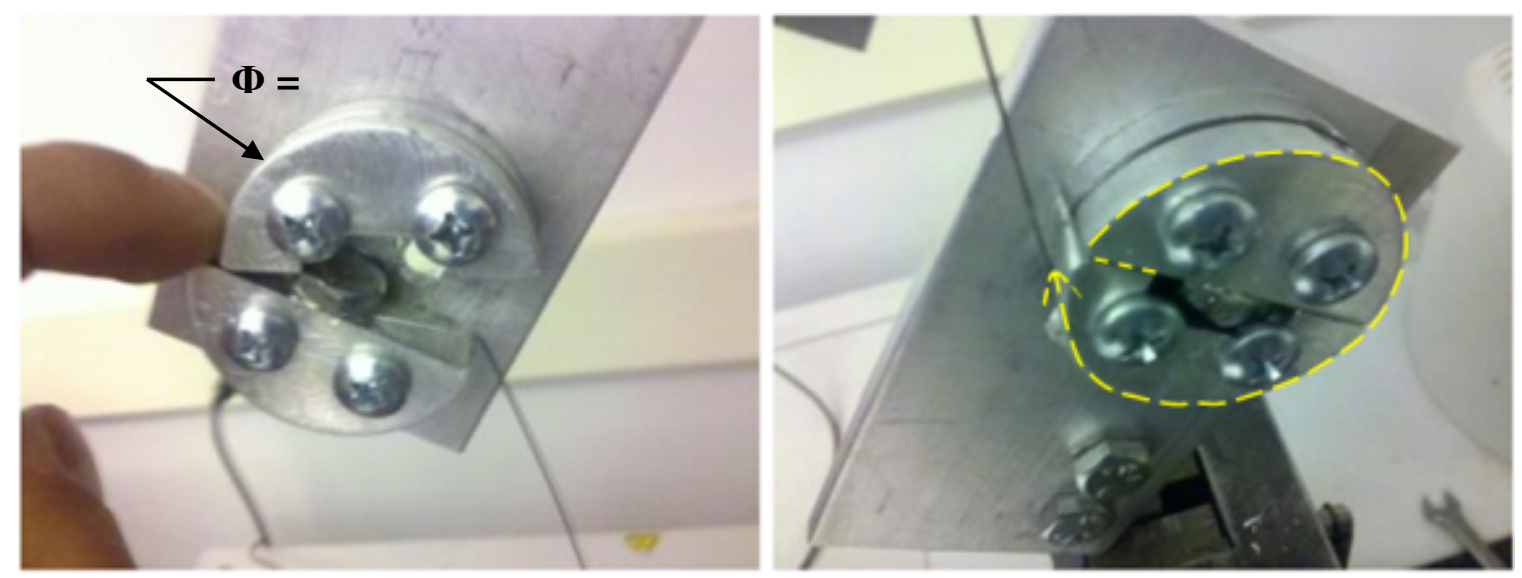

Figure 24 - The capstan disc, with a diameter of 1.5 inches, effectively distributed the load and reduced premature failure due to high stress concentrations. $65 \%$ of the samples fractured at the center of the gauge length using this capstan grip.

A semi-circular groove, as shown in Figure 25, was manufactured to guide the wire around the capstan disc and prevent the wire from slipping outward during the loading 
cycle. Each wire specimen was preloaded to $30 \mathrm{~N}$ prior to the tensile test followed by zeroing the crosshead displacement. The crosshead displacement was balanced prior to each test to ensure that each wire sample was loaded to the same strain during the loading cycle. For each tensile test, the specimen was loaded to $10 \%$ strain, unloaded to $60 \mathrm{MPa}$, and then loaded to failure. Elastic modulus was determined from the linear elastic region from the stress-strain curve. A strain rate of 0.06 inches per minute, as prescribed by ASTM F2516 for specimens of 0.5-2.5 mm diameter wire and a gauge length of 3 inches, was used for the loading cycle in this study. A slow strain rate is necessary during the tensile test due to the stress-induced phase transformation and the significant amount of heating and cooling during loading and unloading. Small changes in temperature during the tensile test can significantly alter the mechanical properties of NiTi. Therefore, a slow strain rate is required to allow heat transfer between the specimen and its surroundings thus, minimizing temperature variations in the wire.

A representative stress-strain curve for NiTi following the SOP used in this study is shown in Figure 26. Note the large strain values obtained using the devised SOP and custom grips, higher than $40 \%$, indicating that the net strain is not occurring at the gauge length. A designed experiment was conducted to investigate the location where the majority of the strain in the wire was occurring; at the center of the gauge length or around the circumference of the aluminum capstan discs. Two markers were placed near the top and bottom of the wire once mounted on the capstan grips, as illustrated in Figure 25. Initially, as the wire is subjected to a stress of up to $100 \mathrm{MPa}$, the majority of the strain occurs as the wire conforms to the circumference of the aluminum capstan grips. 
As the stress during the tensile testing increases past $100 \mathrm{MPa}$, the majority of the strain occurs at the gauge center, indicating that the load is focused at the center at higher loads. Also note that using crosshead displacement, rather than an external extensometer, to measure engineering strain may have contributed to the large strain values obtained in this study.
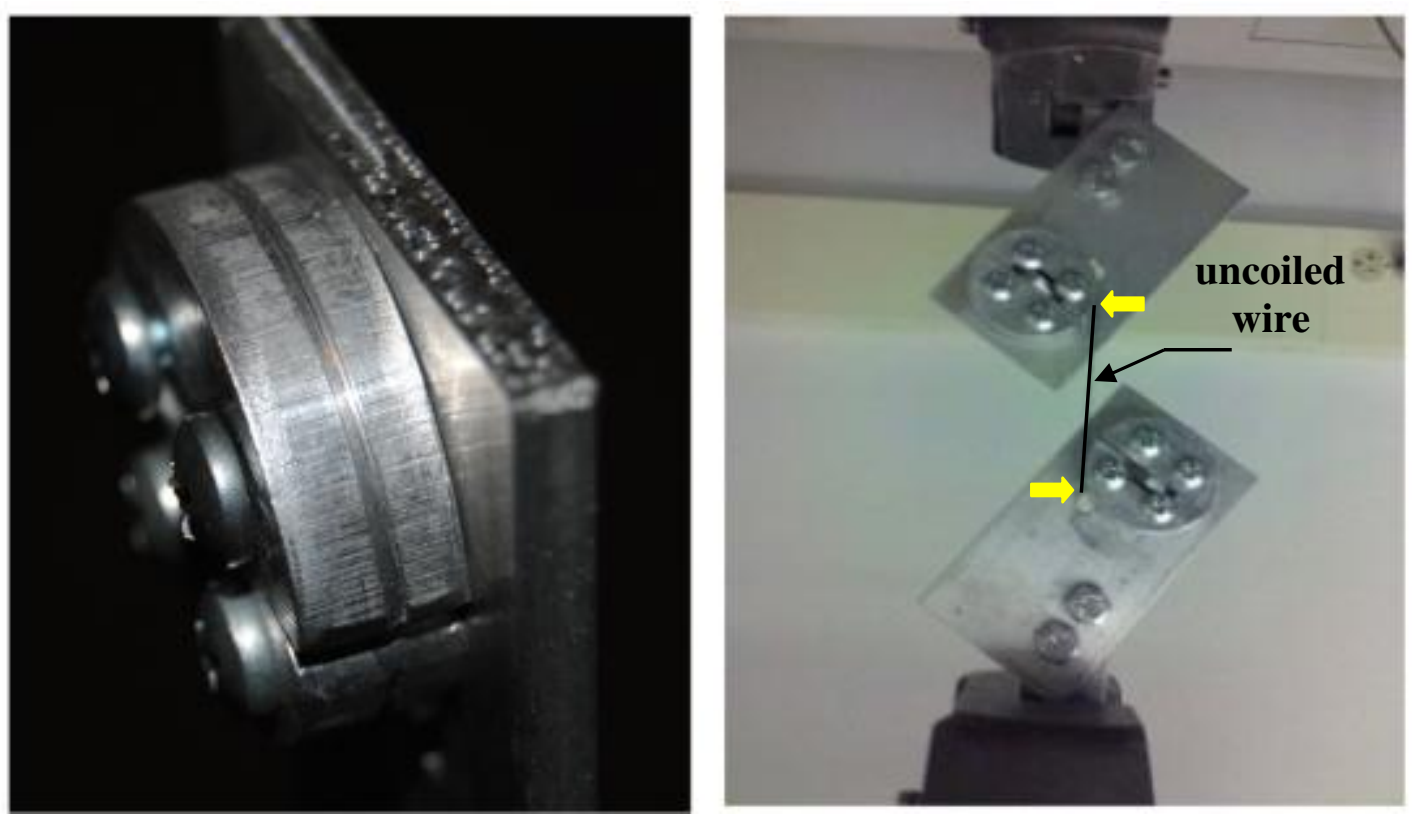

Figure 25 - A semi-circular groove, with a radius of 0.02 inches, distributes the load and prevents the wire from slipping outward. Capstan grips rely primarily on friction to maintain tension on the specimen. The majority of the load is distributed around the circumference of the capstan disc. 


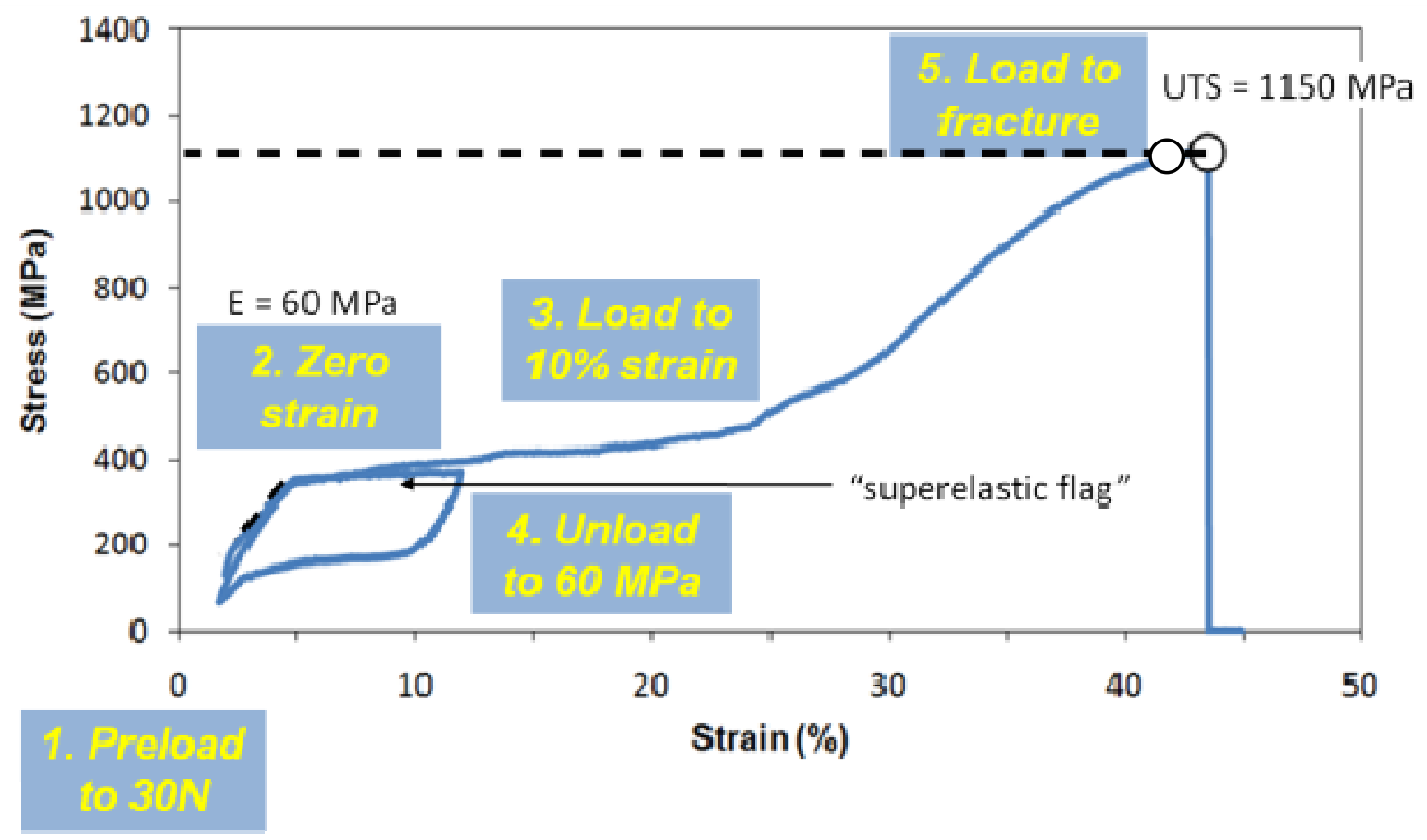

Figure 26 - Typical stress-strain response of superelastic NiTi wire using capstan grips and crosshead displacement to measure strain. Note the large amount of strain indicating that the majority of the strain was occurring around the curvature of the capstan disc as the wire straightened during the tensile test. A clear superelastic flag is still observed using the capstan grips.

\subsection{Three Dimensional TTT-like Diagram}

$A_{f}$ values were compiled from each DSC curve to construct diagrams of $A_{f}$ versus heat treatment time for each level of applied stain. Lines were drawn at 20,30 , and $40^{\circ} \mathrm{C}$ on the $A_{f}$ versus heat treatment time plots, using the intersection of the horizontal lines and the $\mathrm{A}_{\mathrm{f}}$ trend lines to construct the points on the TTT-like diagram. Points that did not match to an experimental $A_{f}$ value were then drawn accordingly between experimental values to obtain contours of constant $\mathrm{A}_{\mathrm{f}}$. The TTT-like diagrams were compiled into a three dimensional plot, with applied strain in the z-axis. 


\section{CHAPTER FIVE \\ RESULTS}

\subsection{Transformational Properties}

A representative set of wires heat treated between applied strains of $2-10 \%$ at $400^{\circ} \mathrm{C}$ for 2 minutes is shown in Figure 27 . Wires that were heat treated below $450^{\circ} \mathrm{C}$ and less than 5 minutes tend to conform less to the shape of the corresponding mandrel, indicating that the onset of recrystallization occurs at temperatures above $450^{\circ} \mathrm{C}$. As illustrated in Figure 27, applied strain during heat treatment tends to encourage shape-setting behavior follow a heat treatment at $400^{\circ} \mathrm{C}$ for 2 minutes. This trend of increased shape-setting behavior with increasing level of applied strain is observed following heat treatments between 300$400^{\circ} \mathrm{C}$.
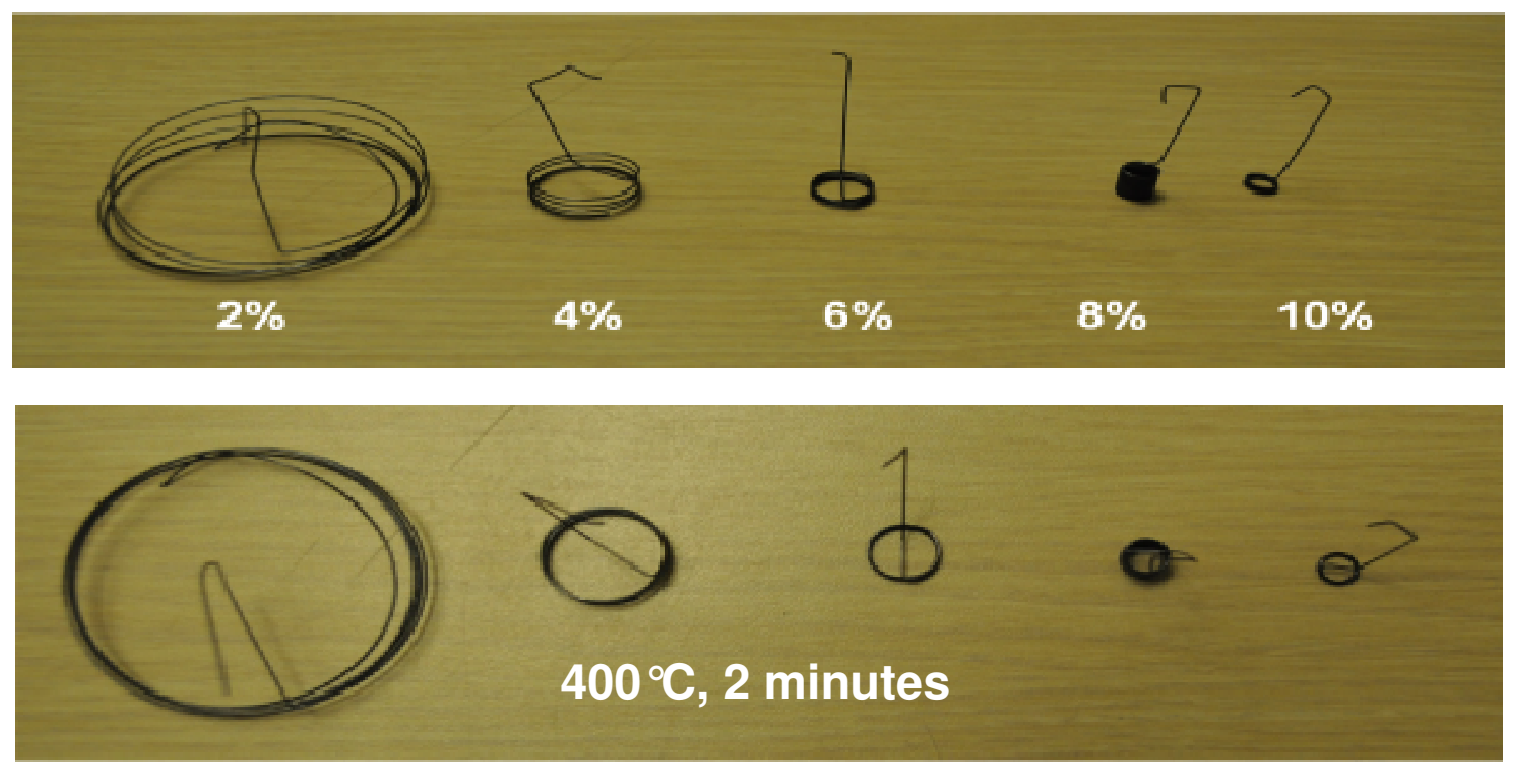

Figure 27 - Effect of applied strain during heat treatment on the shape-setting behavior of NiTi wire following a heat treatment of $400^{\circ} \mathrm{C}$ for 2 minutes. Applied strain during heat treatment tends to encourage the shape-setting behavior between $300-450^{\circ} \mathrm{C}$. 
Heat treatment time influences shape-setting behavior between $300-450^{\circ} \mathrm{C}$, as illustrated in Figure 28 for wires heat treated at $400^{\circ} \mathrm{C}$ with $4 \%$ applied strain. Wires heat treated for times longer than 5 minutes tend to shape-set around the mandrel more successfully, indicating that recrystallization occurs at low temperatures given enough time. Note that there is no visible difference on the shape-setting behavior for wire heat treated for 10 and 30 minutes. As a reference, the size of the mandrel corresponding to $4 \%$ applied strain is approximately 0.5 inches as illustrated by the yellow bars below each sample in Figure 28 .

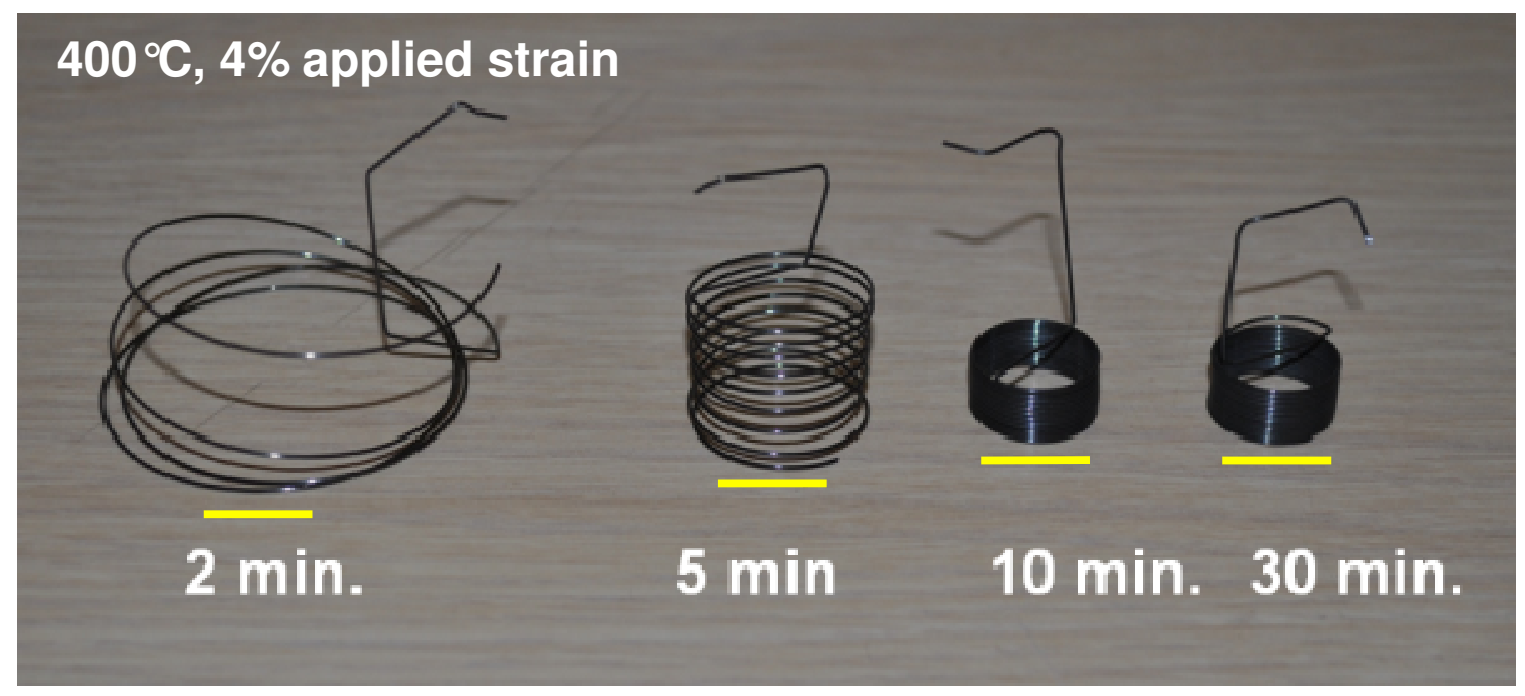

Figure 28 - Effect of heat treatment time on the shape setting behavior of NiTi wire heat treated at $400{ }^{\circ} \mathrm{C}$ with $4 \%$ applied strain. The yellow bar represents the diameter of the mandrel corresponding to $4 \%$ applied strain. Wires heat treated above 5 minutes tend to shape-set more successfully.

Heat treatments above $450^{\circ} \mathrm{C}$ tend to provide sufficient thermal energy to relieve the tensile and compressive strains caused by coiling the wire around the mandrel and allow recrystallization to occur. Applied strain has no visible effect on the shape-setting behavior for wires heat treated above $450^{\circ} \mathrm{C}$, as illustrated in Figure 29 for wires heat 
treated at $550^{\circ} \mathrm{C}$ for 2 minutes. Note that shape-setting occurs for all levels of applied strain following a heat treatment of $550^{\circ} \mathrm{C}$ for just 2 minutes. Based on the shape-setting behavior for wires heat treated between $300-550^{\circ} \mathrm{C}$, the onset of recrystallization must occur between $450-500^{\circ} \mathrm{C}$. Due to the heat treatment temperature increment of $50^{\circ} \mathrm{C}$ that was used in this experiment, the onset of recrystallization could not be verified.

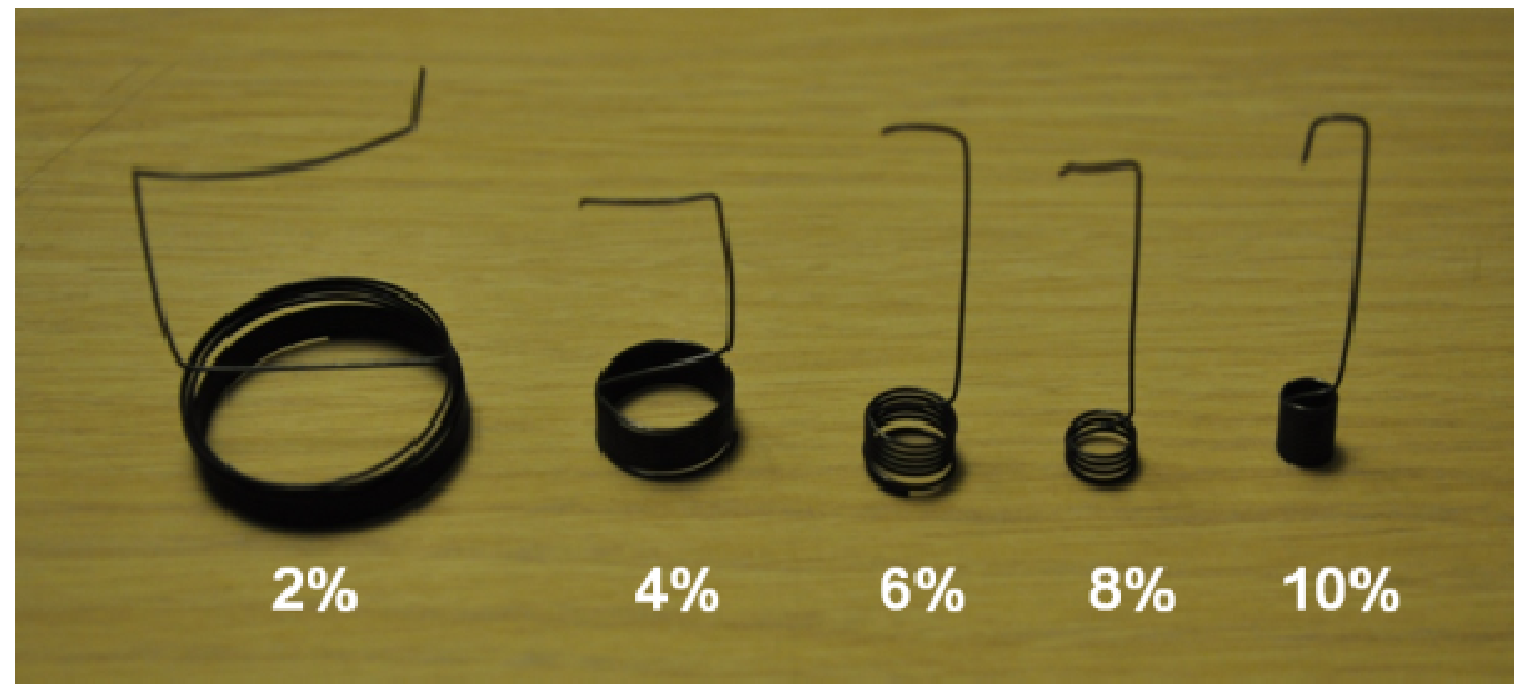

Figure 29 - The effects of applied strain on the shape setting behavior of NiTi wire at $500^{\circ} \mathrm{C}$ for 2 minutes. Heat treatments above $450^{\circ} \mathrm{C}$ tend to shape-set successfully around the mandrel, indicating that sufficient thermal energy has been provided to relieve strain and allow recrystallization.

A representative endothermic DSC curve of a specimen heat treated between $300-500^{\circ} \mathrm{C}$ for times of 2 and 30 minutes with increasing levels of applied strain is shown in Figure 30 and 31 , respectively. The temperature range of $300-500^{\circ} \mathrm{C}$ and heat treatment times of 2 and 30 minutes were selected to represent the overall trend in transformation temperatures illustrated by the endothermic DSC curves. The DSC curves have been offset on the heat flow axis to avoid overlap. The DSC curve illustrating the trend at $350^{\circ} \mathrm{C}$ is not presented but is similar to the trend seen at $300^{\circ} \mathrm{C}$. 

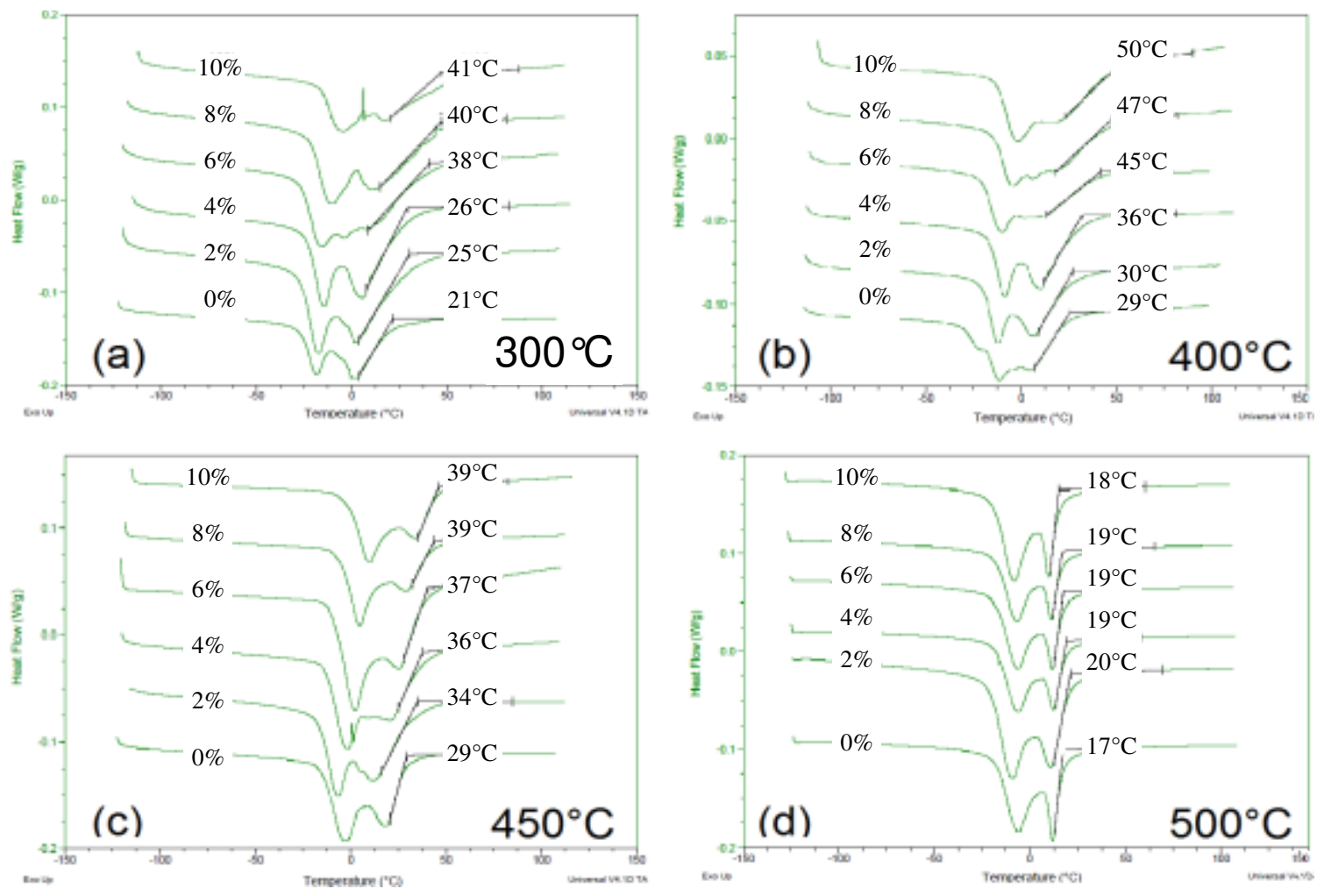

Figure 30 - Endothermic DSC curve of specimen heat treated between $300-500{ }^{\circ} \mathrm{C}$ for 2 minutes in order of increasing strain level from bottom to top. Note that all heat treatment temperatures tend to increase $A_{f}$ except at $500^{\circ} \mathrm{C}$. 

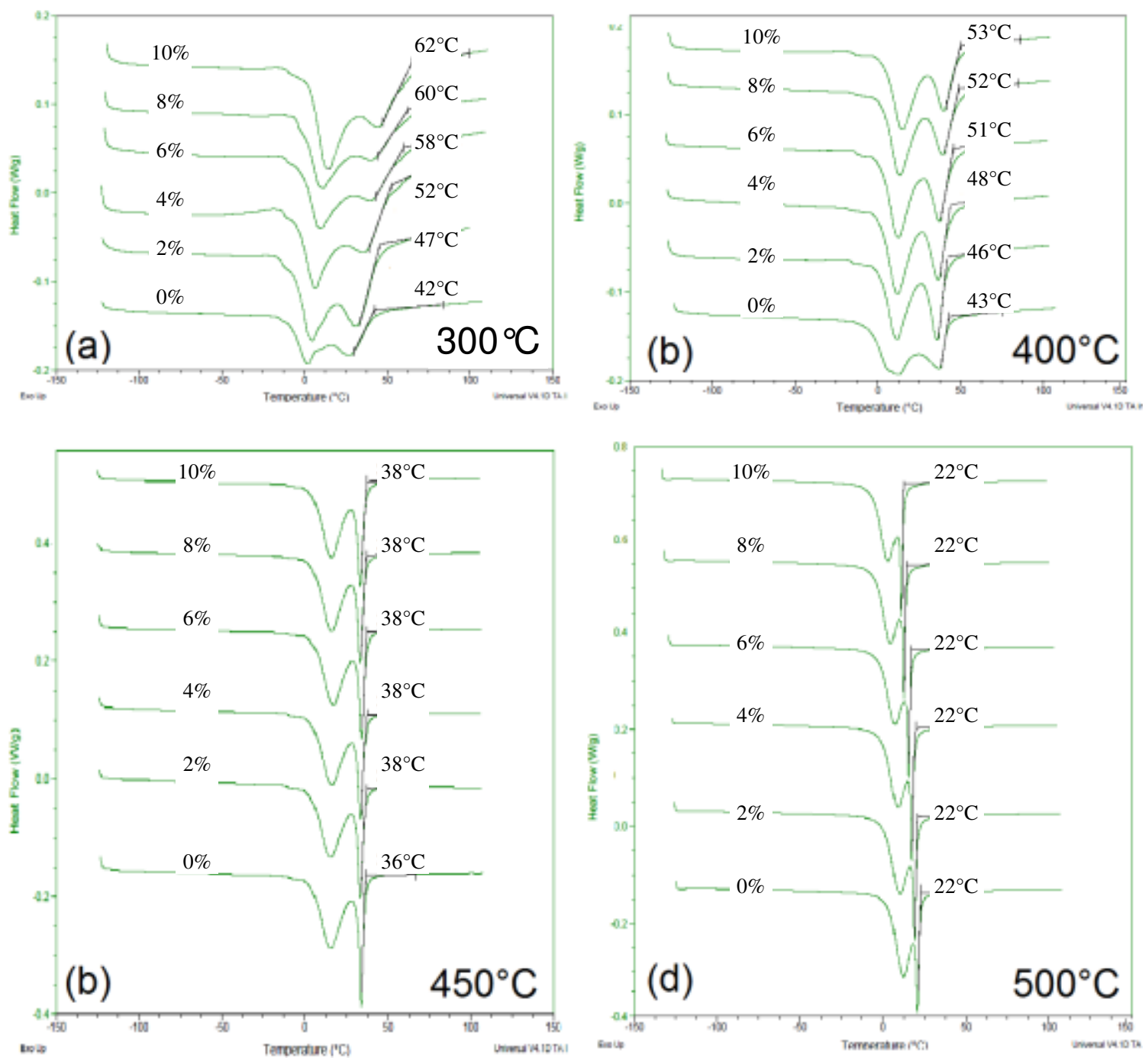

Figure 31 - Endothermic DSC curve for specimen heat treated between $300-500^{\circ} \mathrm{C}$ for 30 minutes in order of increasing level of applied strain. Note a systematic increase in $A_{f}$ as level of applied strain increases at low temperatures. Applied strain has no significant effect on $\mathrm{A}_{\mathrm{f}}$ between $450-500^{\circ} \mathrm{C}$ at a heat treatment of 30 minutes.

Figures 30 and 31 illustrate an increase in $\mathrm{A}_{\mathrm{f}}$ with increasing level of applied strain and heat treatment time. Applied strain increases $A_{\mathrm{f}}$ significantly at lower temperatures, specifically between 300 and $350^{\circ} \mathrm{C}$. This is illustrated by a shift to the right in the position of the endothermic peak as the level of applied strain increases between 300 and $350^{\circ} \mathrm{C}$. At the intermediate temperatures of $400-450^{\circ} \mathrm{C}$, applied strain has less of an effect 
on the resulting $\mathrm{A}_{\mathrm{f}}$. At higher heat treatment temperatures of $500-550^{\circ} \mathrm{C}$, applied strain and heat treatment time has no significant effect on $A_{f}$. Note that at $500^{\circ} \mathrm{C}$, the $A_{f}$ is approximately $20^{\circ} \mathrm{C}$ regardless of level of applied strain or heat treatment time.

Also illustrated in both figures is a two-stage martensite to R-phase to austenite $(\mathrm{M} \rightarrow \mathrm{R} \rightarrow \mathrm{A})$ transformation on heating for all temperature regimes and strain levels, including the sample under no strain. The two-stage transformation, illustrated in Figures 30 and 31, indicates the appearance of the R-phase. The R-phase was observed for all heat treatment conditions and strain levels. However, the R-phase and $A_{f}$ peak is more narrow and defined as the heat treatment time and temperature increases. Note that the $\mathrm{A}_{\mathrm{f}}$ peak at $500^{\circ} \mathrm{C}$ and 30 minutes tends to become more narrow and increases in height as compared to the $\mathrm{A}_{\mathrm{f}}$ peak at $500^{\circ} \mathrm{C}$ and 2 minutes. However, the average area under the $\mathrm{A}_{\mathrm{f}}$ peak, also known as the heat of enthalpy, does not significantly change. Note that as applied strain increases in both figures, the appearance of the R-phase and overall shape of the endothermic DSC curves do not significantly change holding heat treatment time and temperature constant.

Plots of $A_{f}$ versus applied strain were generated, each comparing two consecutive heat treatment temperatures. Figures 32 and 33 are diagrams comparing 350 and $400^{\circ} \mathrm{C}$ and 450 and $500^{\circ} \mathrm{C}$, respectively. Error bars of one standard deviation for the two samples that were replicated are shown. The diagram comparing the effects of applied strain and heat treatment at 300 and $550^{\circ} \mathrm{C}$ is provided in Appendix II. The blue horizontal dash line at $11^{\circ} \mathrm{C}$ represents the starting $\mathrm{A}_{\mathrm{f}}$ of as-received wire. Comparison of Figures 32 and 33 
illustrates an increase in $\mathrm{A}_{\mathrm{f}}$ with increasing level of applied strain and heat treatment time. At short heat treatment times, $\mathrm{A}_{\mathrm{f}}$ increases most rapidly at $400^{\circ} \mathrm{C}$ and $10 \%$ applied strain; at longer heat treatment times, the maximum $\mathrm{A}_{\mathrm{f}}$ is obtained at $350^{\circ} \mathrm{C}$ and $10 \%$ applied strain. The reaction rates have significantly decreases between $450-500^{\circ} \mathrm{C}$; an increase in $\mathrm{A}_{\mathrm{f}}$ with increased level of applied strain is only observed at $450^{\circ} \mathrm{C}$ and 2 minutes between $450-500^{\circ} \mathrm{C}$. Note that applied strain and heat treatment time have no significant effect on $\mathrm{A}_{\mathrm{f}}$ increase for specimen heat treated at $500^{\circ} \mathrm{C}$.

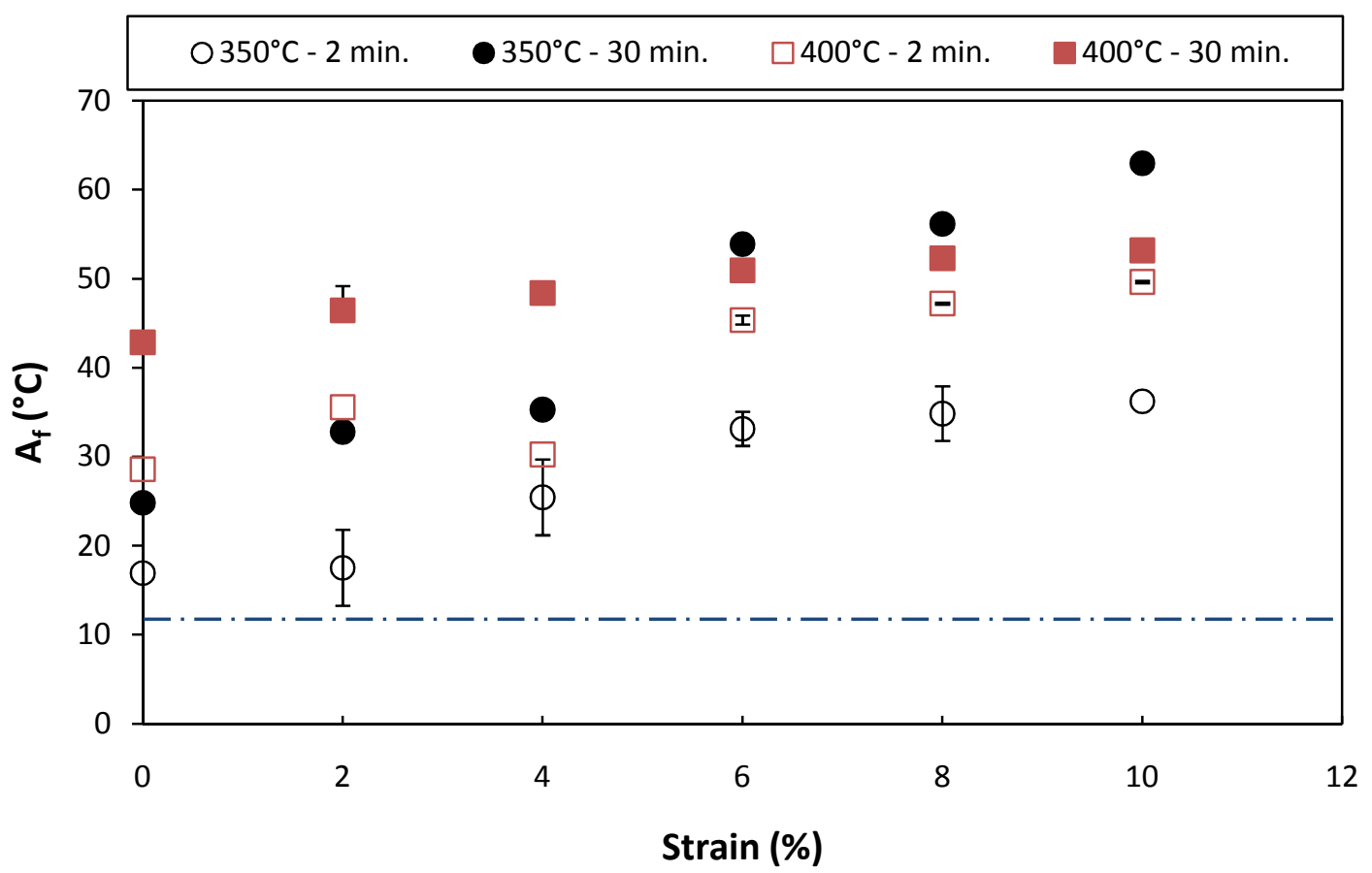

Figure 32 - The effect of applied strain and heat treatment between $350-400^{\circ} \mathrm{C}$ for 2 and 30 minutes. Note a systematic increase in $A_{f}$ with increased level of applied strain and heat treatment time. At short heat treatment times, $A_{f}$ increases most rapidly at $400^{\circ} \mathrm{C}$; at longer heat treatment times, the maximum $A_{f}$ is obtained at $350^{\circ} \mathrm{C}$. 


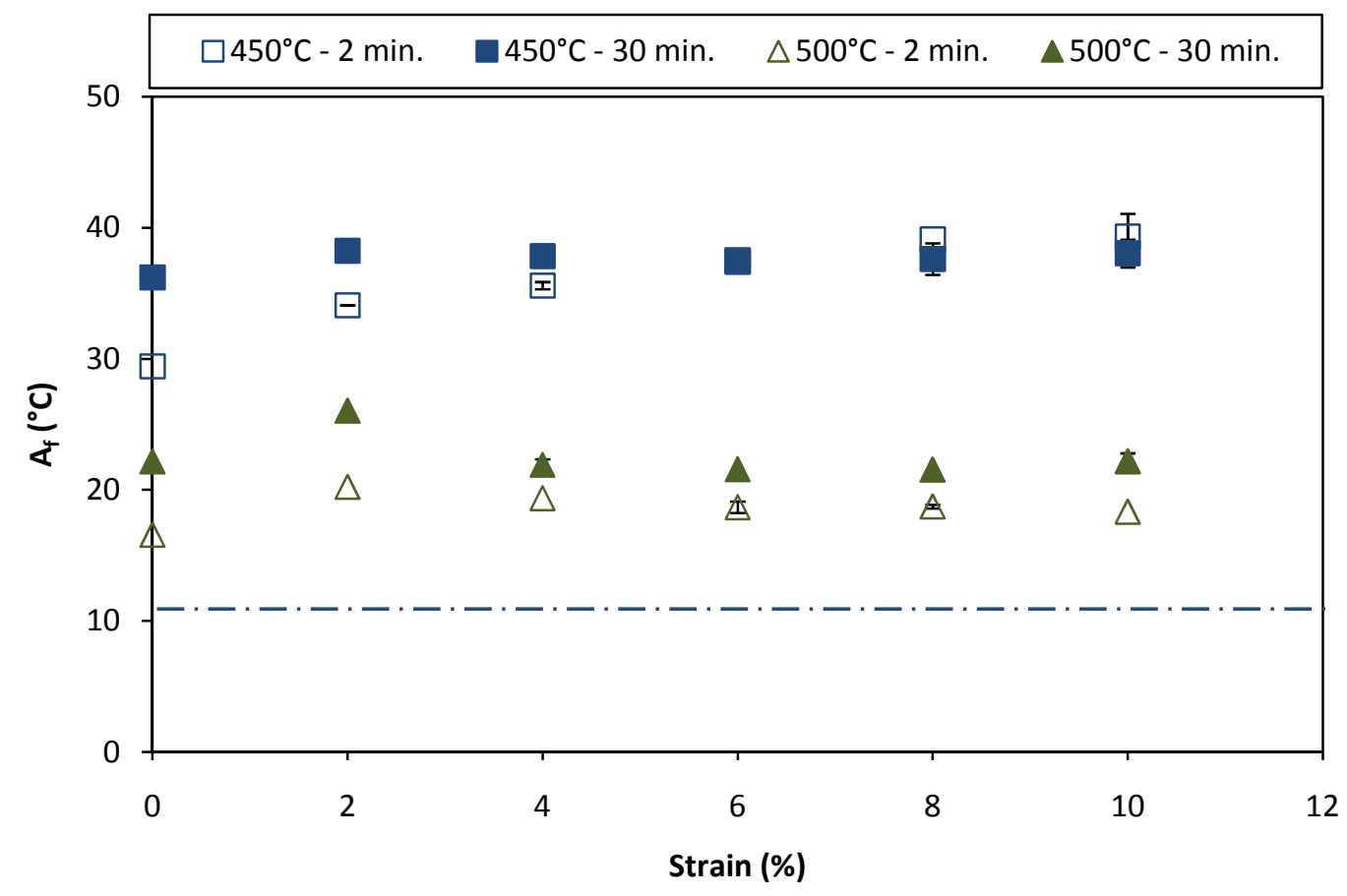

Figure 33 - The effect of applied strain and heat treatment between $450-500{ }^{\circ} \mathrm{C}$ for 2 and 30 minutes. At short heat treatment times, applied strain increases $A_{\mathrm{f}}$ most rapidly at $450^{\circ} \mathrm{C}$; applied strain has no significant effect on $A_{f}$ increase at longer times. Also note that applied strain and heat treatment time have no significant effect on $A_{f}$ at $500^{\circ} \mathrm{C}$.

Plots of $\mathrm{A}_{\mathrm{f}}$ versus heat treatment temperature were generated for each heat treatment time. Figures 34-37 are diagrams of specimen heat treated at 2, 5, 10, and 30 minutes, respectively. Error bars of one standard deviation for the samples that were replicated are shown. Comparison of Figures 34-37 illustrates an increase in $\mathrm{A}_{\mathrm{f}}$ with increasing level of applied strain for a particular heat treatment, as indicated by the endothermic DSC curves. All four plots illustrate that applied strain significantly increases $A_{f}$ between 300 $350^{\circ} \mathrm{C}$. Also note that the maximum $\mathrm{A}_{\mathrm{f}}$ at short heat treatment times is obtained at $400^{\circ} \mathrm{C}$ for all levels of applied strain. At heat treatments of $450^{\circ} \mathrm{C}$ for 2 and 5 minutes, applied strain has less of an effect on $\mathrm{A}_{\mathrm{f}}$ increase. As heat treatment time increases at $450^{\circ} \mathrm{C}$, applied strain has no significant effect on $\mathrm{A}_{\mathrm{f}}$. Also seen in Figures 34-37, applied strain 
has no significant effect at $500^{\circ} \mathrm{C}$. This is illustrated by the reduced scatter of data points at $500^{\circ} \mathrm{C}$ as level of applied strain increases. At $550^{\circ} \mathrm{C}$, there is an initial decrease in $\mathrm{A}_{\mathrm{f}}$ at short heat treatment times followed by a gradual increase in $\mathrm{A}_{\mathrm{f}}$ after a heat treatment time of 30 minutes.

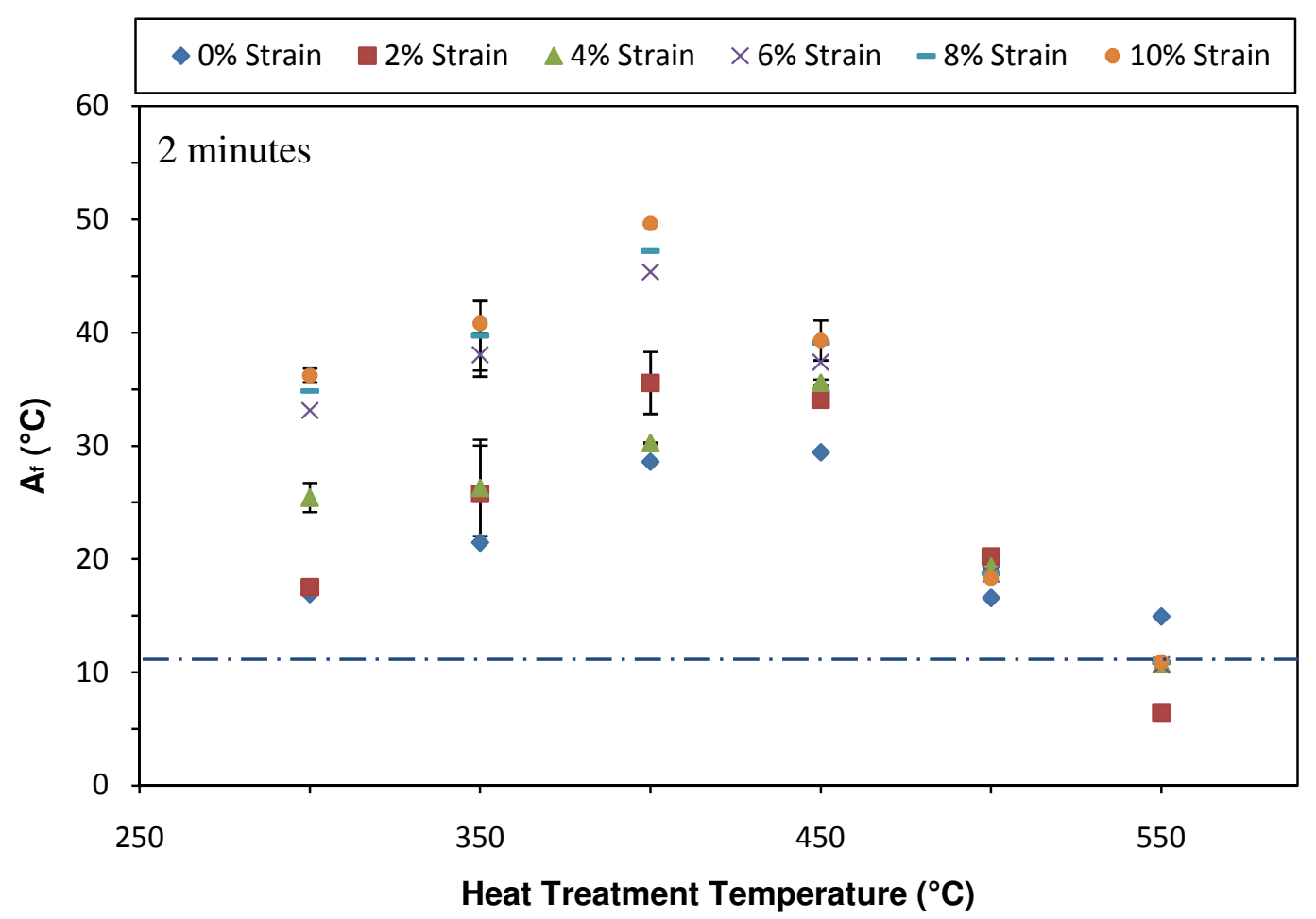

Figure 34 - Effect of applied strain and heat treatment temperature on the transformation temperature of specimen heat treated for 2 minutes. The blue horizontal dash line at $11^{\circ} \mathrm{C}$ represents the starting $A_{f}$ of as-received wire. Applied strain significantly increases $A_{f}$ between $300-350{ }^{\circ} \mathrm{C}$. At $\mathbf{5 0 0}^{\circ} \mathrm{C}$, applied strain has no significant effect on the transformation temperature. 


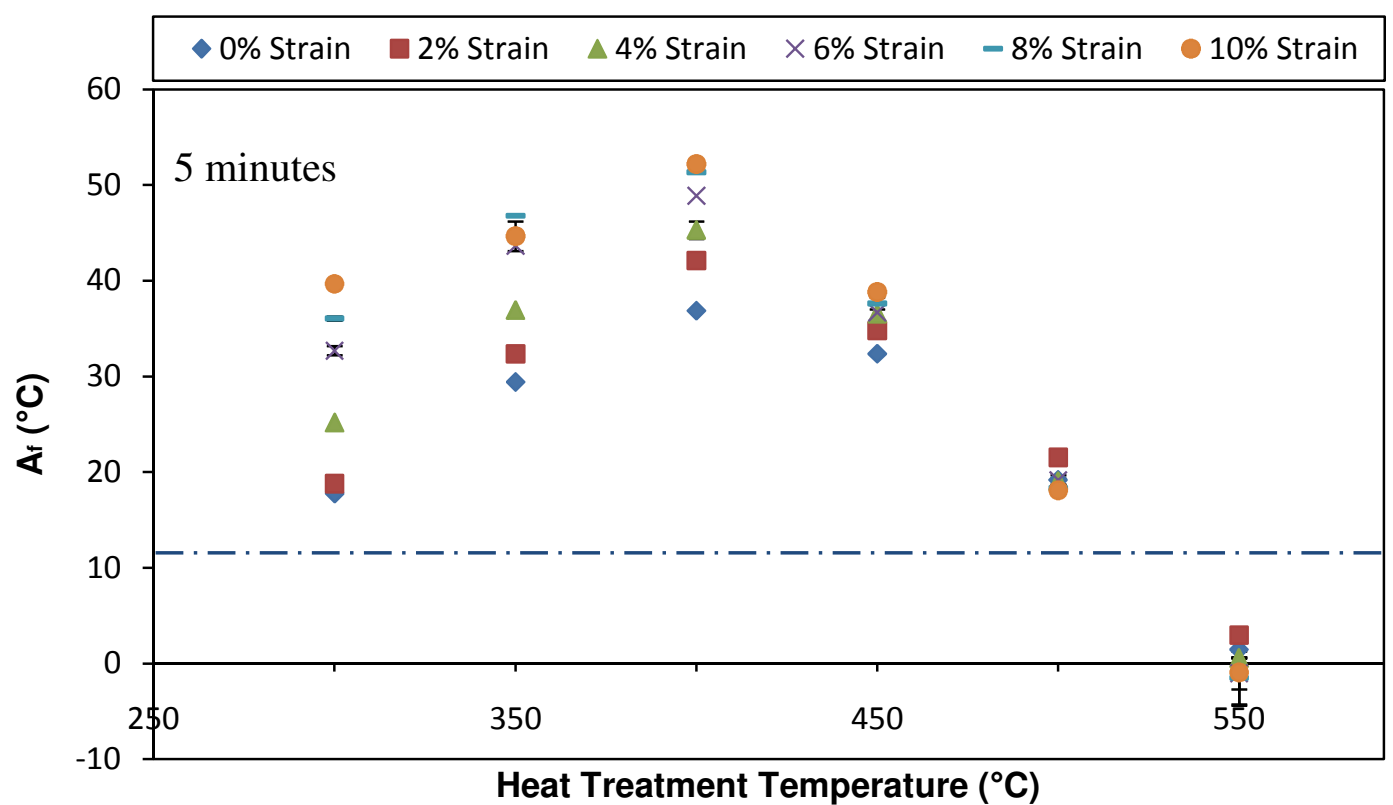

Figure 35 - Effect of applied strain and heat treatment on the transformation temperature of specimen heat treated for 5 minutes. The blue horizontal dash line at $11^{\circ} \mathrm{C}$ represents the starting $A_{f}$ of as-received wire. Again, applied strain increases the $A_{\mathrm{f}}$ more significantly between $300-400{ }^{\circ} \mathrm{C}$. Note that the maximum $A_{f}$ is obtained at $400^{\circ} \mathrm{C}$ for all levels of applied strain.

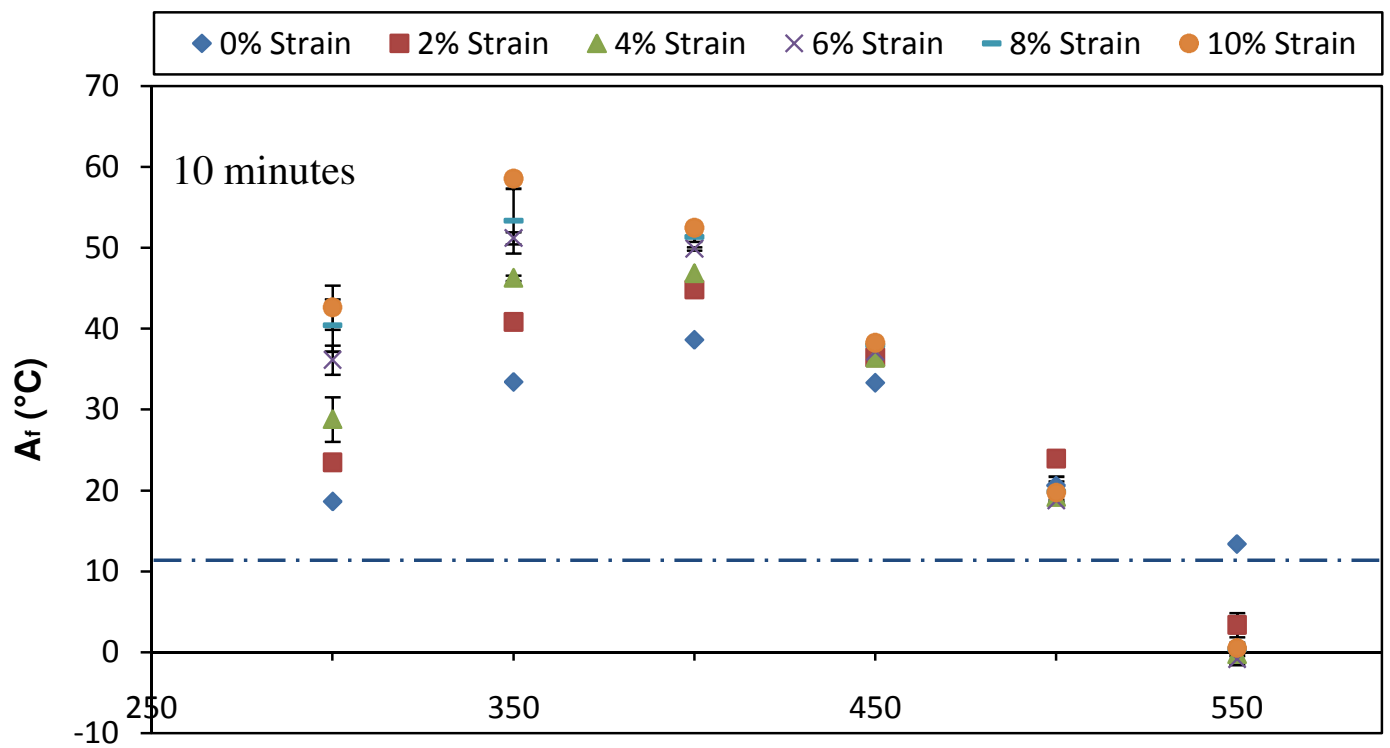

Heat Treatment Temperature $\left({ }^{\circ} \mathrm{C}\right)$

Figure 36 -Effect of applied strain and heat treatment on the transformation temperature of specimen heat treated for 10 minutes. The blue horizontal dash line at $11^{\circ} \mathrm{C}$ represents the starting $A_{f}$ of as-received wire. Between $450-550^{\circ} \mathrm{C}$, applied strain has no significant effect on the transformation temperature. Note that the maximum $A_{f}$ is now obtained between $350-400{ }^{\circ} \mathrm{C}$ for all levels of applied strain. 


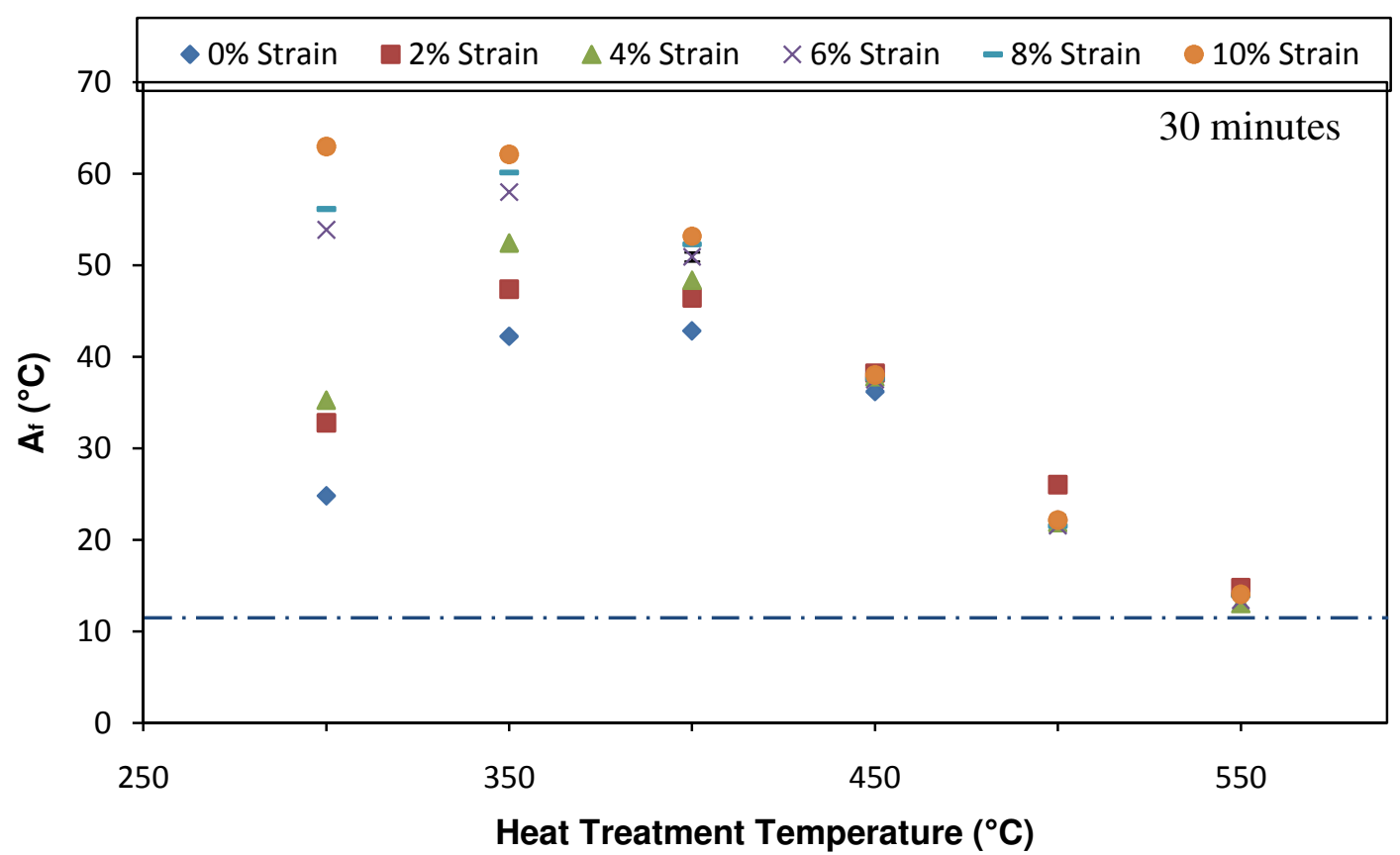

Figure 37 - Effect of applied strain and heat treatment on the transformation temperature of specimen heat treated for 30 minutes. The blue horizontal dash line at $11^{\circ} \mathrm{C}$ represents the starting $A_{f}$ of as-received wire. Between $450-550^{\circ} \mathrm{C}$, applied strain has no significant effect on the transformation temperature. Note that the maximum $A_{f}$ is obtained through heat treatments between $300-350^{\circ} \mathrm{C}$.

The trend in $\mathrm{A}_{\mathrm{f}}$ due to applied strain and temperature for all heat treatment times is summarized in Figure 38. The trend of increasing $\mathrm{A}_{\mathrm{f}}$ with increasing level of applied strain is observed between heat treatments of $300-450^{\circ} \mathrm{C}$; applied strain increases $\mathrm{A}_{\mathrm{f}}$ significantly with increased heat treatment time between $300-350^{\circ} \mathrm{C}$. Reaction rates with increasing level of applied strain and heat treatment time have significantly decreased between $450^{\circ} \mathrm{C}$. Between $500-550^{\circ} \mathrm{C}$, applied strain and heat treatment time have no significant effect on $\mathrm{A}_{\mathrm{f}}$ increase, as observed in Figure 33. 


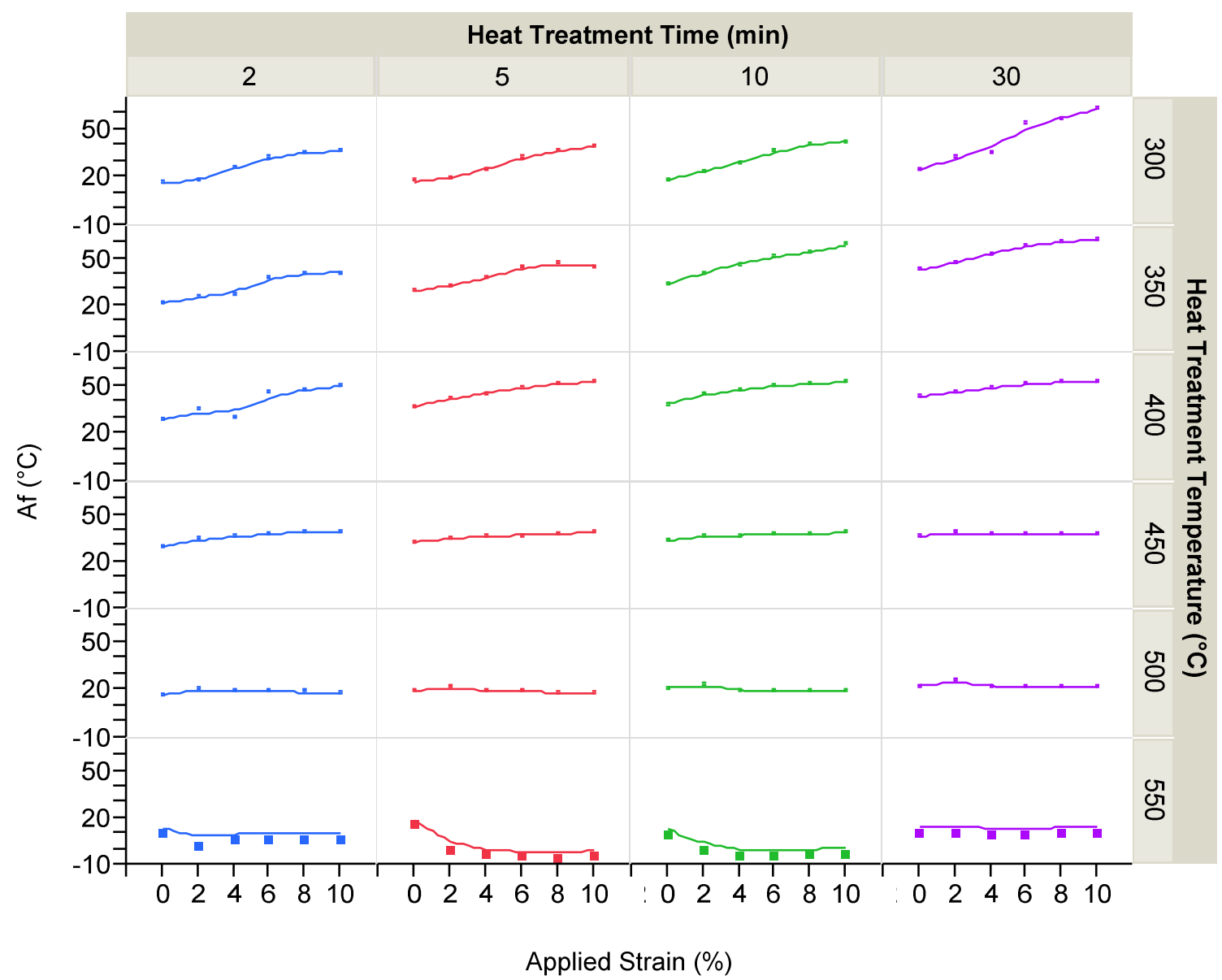

Figure 38 - Effect of applied strain and temperature on the transformation temperature for all heat treatment times. Applied strain significantly increases $\mathbf{A}_{\mathrm{f}}$ between $300-350{ }^{\circ} \mathrm{C}$; reaction rates have significantly decreased with increasing level of applied strain and heat treatment. Between 500$550^{\circ} \mathrm{C}$, applied strain and heat treatment temperature have no significant effect on $\mathrm{A}_{\mathrm{f}}$ increase.

Plots of $A_{f}$ versus heat treatment time were generated for each level of applied strain.

Figures 39 and 40 are diagrams of specimen heat treated under 0 and $10 \%$ strain, respectively. Error bars of one standard deviation for the samples that were replicated are shown. Plots of $A_{f}$ versus heat treatment time for specimen heat treated under an applied strain of 2, 4, 6, and $8 \%$ are provided in Appendix III. Comparison of the $A_{f}$ versus heat treatment time plots illustrates that the overall trend in $\mathrm{A}_{\mathrm{f}}$ during heat treatment is similar for each level of applied strain. All heat treatment temperatures, with the exception of 
$550^{\circ} \mathrm{C}$, tend to increase $\mathrm{A}_{\mathrm{f}}$; increases in $\mathrm{A}_{\mathrm{f}}$ at $500^{\circ} \mathrm{C}$ and $10 \%$ strain are not significant. Heat treatments under an applied strain (4-10\%) result in a rapid increase at short times followed no significant increase in $\mathrm{A}_{\mathrm{f}}$ at longer times, illustrated in Figure 40 for wire heat treated with $10 \%$ applied strain. Note that $A_{f}$ does not significantly change with increasing heat treatment time at $300^{\circ} \mathrm{C}$ and $0 \%$ strain. However, $\mathrm{A}_{\mathrm{f}}$ significantly increases at $300^{\circ} \mathrm{C}$ and $10 \%$ strain. The maximum $A_{f}$ at short heat treatment times is obtained through heat treatments at 400 and $450^{\circ} \mathrm{C}$ for all levels of applied strain. At $500^{\circ} \mathrm{C}$, applied strain has no significant effect on $\mathrm{A}_{\mathrm{f}}$. Heat treatment at $550^{\circ} \mathrm{C}$ results in an initial decrease in $\mathrm{A}_{\mathrm{f}}$ followed by a gradual increase for all levels of applied strain.

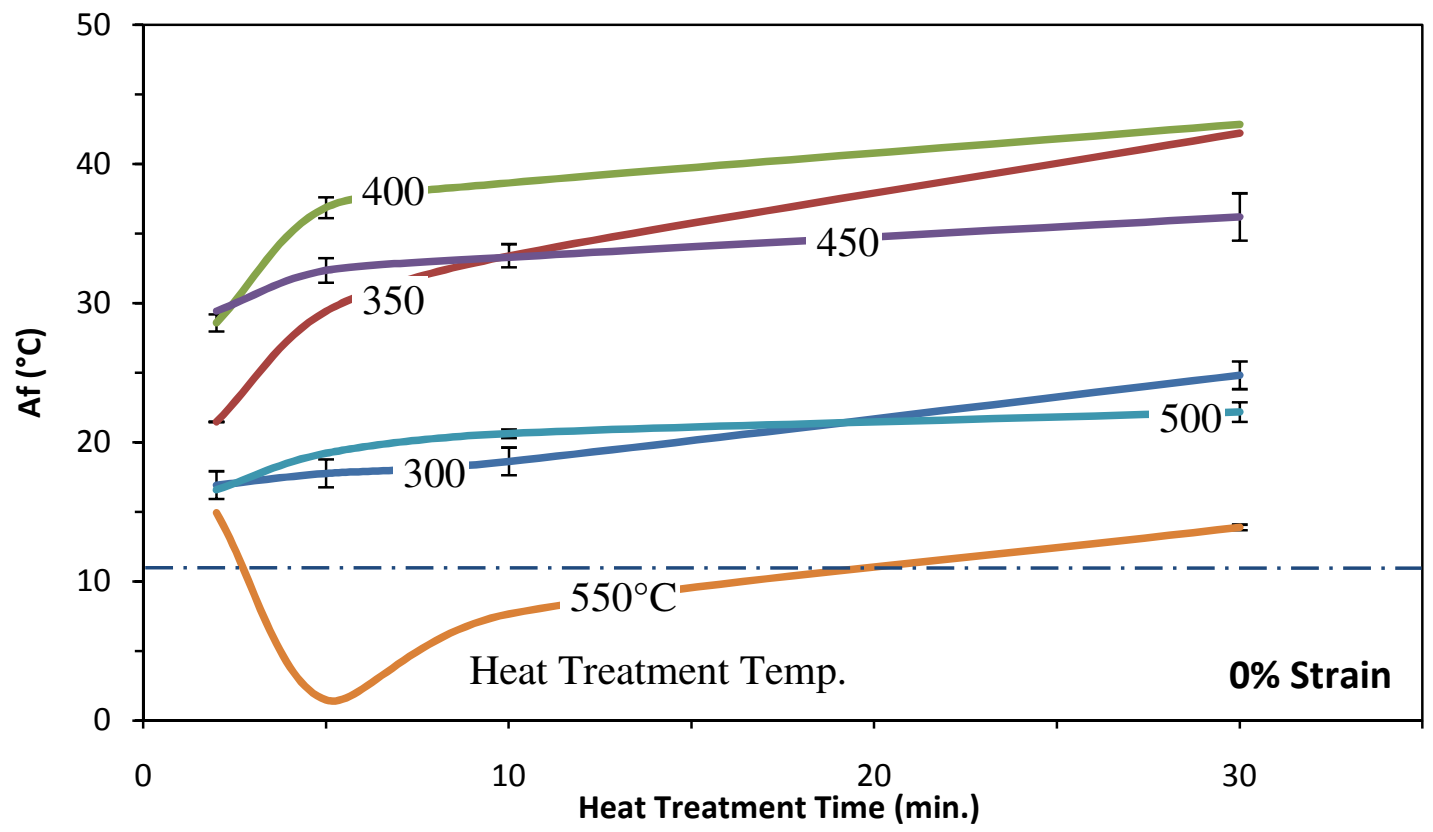

Figure 39 - Effect of heat treatment temperature and time on the transformation temperature of specimen heat treated under $0 \%$ strain with a starting $A_{f}$ of $11^{\circ} \mathrm{C}$, represented by the blue horizontal dash line. Note that all heat treatment temperatures from $300-450{ }^{\circ} \mathrm{C}$ tend to increase $A_{\mathrm{f}}$. 


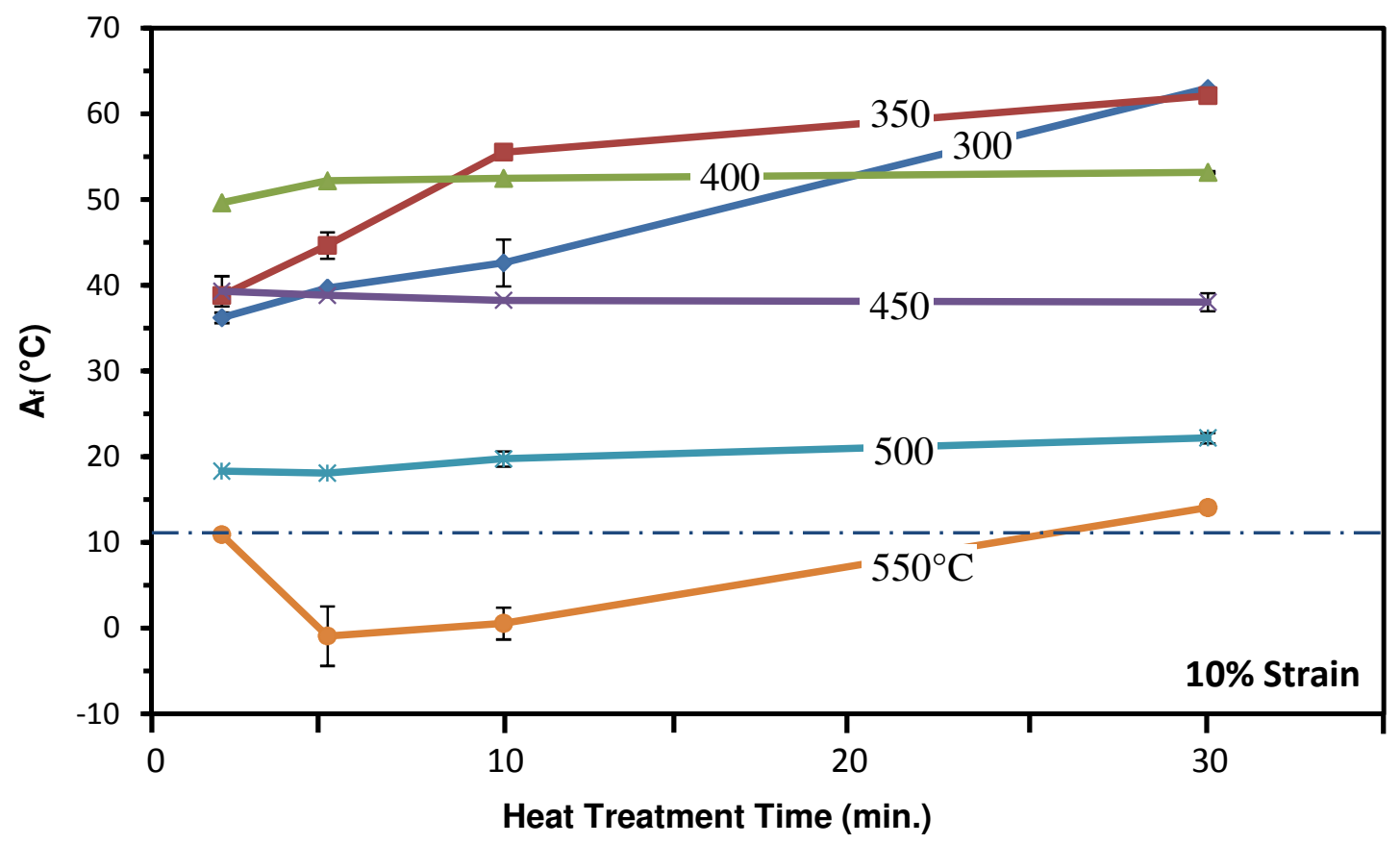

Figure 40 - Effect of heat treatment temperature and time on the transformation temperature of specimen heat treated under a strain of $10 \%$ with a starting Af of $11^{\circ} \mathrm{C}$. A rapid increase at short times, followed no significant increase in $A_{f}$ at longer times, is observed; the exception to this trend occurs between $300-350{ }^{\circ} \mathrm{C}$ where a gradual increase in $A_{f}$ with increasing time is observed.

For each level of applied strain, a TTT-like diagram consisting of constant $\mathrm{A}_{\mathrm{f}}$ contours were constructed to illustrate the trends in transformation temperature during heat treatment. TTT-like diagrams for specimen heat treated under 0 and $10 \%$ applied strain are shown in Figures 41 and 42, respectively. The TTT-like diagrams for 2, 4, 6, and 8\% applied strain are provided in Appendix IV. Comparison of each TTT-like diagram shows that the overall shape of each C-curve is similar for each level of applied strain. Each Ccurve represents the heat treatment time and temperature required to achieve constant of $\mathrm{A}_{\mathrm{f}}$ of 20,30 and $40^{\circ} \mathrm{C}$. The maximum increase in $\mathrm{A}_{\mathrm{f}}$, illustrated by the cusp or nose, is located between $400-450^{\circ} \mathrm{C}$ in all six TTT-like diagrams. A systematic shift of $A_{f}$ contours to the left, indicating faster reaction times, was observed with increasing levels 
of applied strain. A three-dimensional TTT-like diagram including all six plots is shown in Figure 43. Note the rapid shift to the left, indicating faster reaction times, to achieve an $\mathrm{A}_{\mathrm{f}}$ of $40^{\circ} \mathrm{C}$ as applied strain during heat treatment increases.

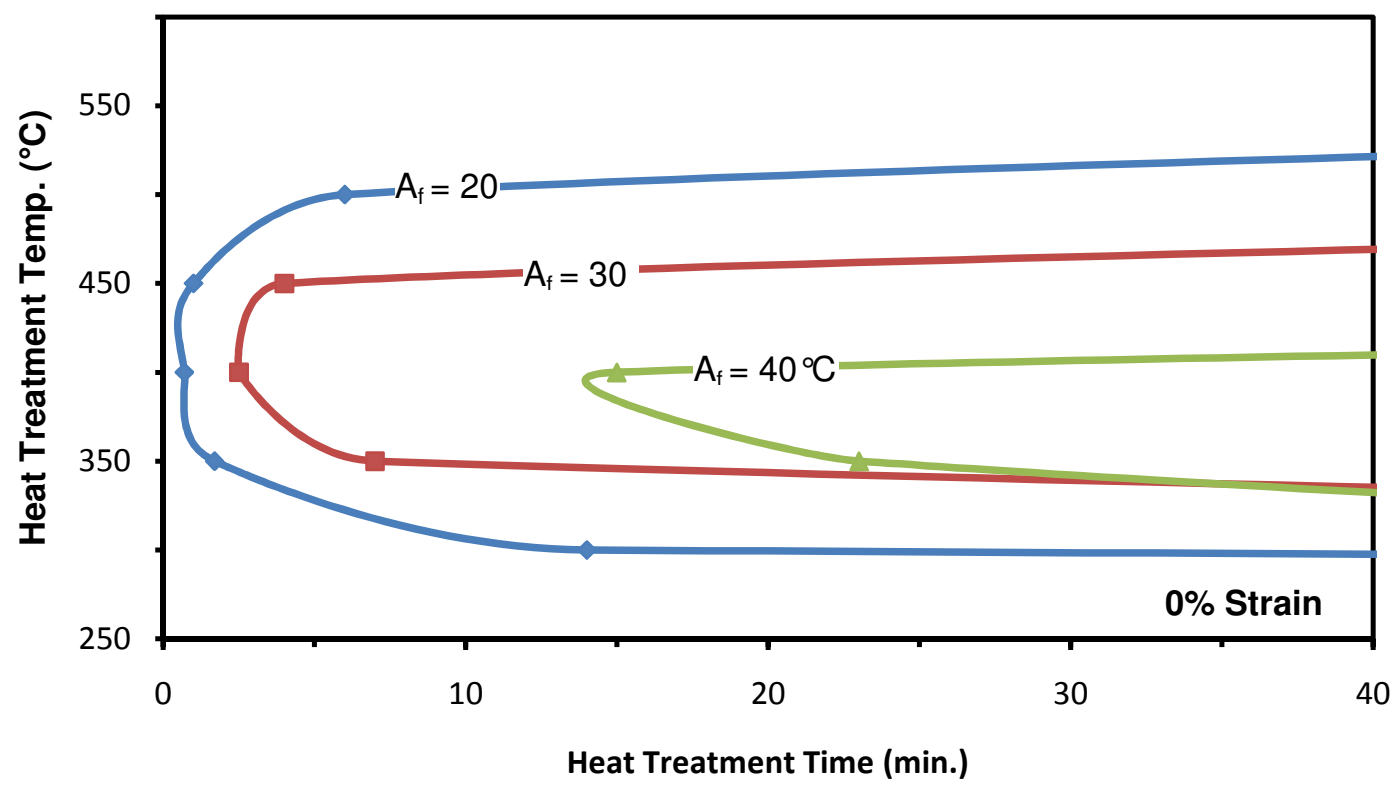

Figure 41 - TTT-like diagram illustrating the effects of heat treatment temperature and time for specimen heat treated at $0 \%$ strain. The maximum precipitation rate occurs at approximately $400^{\circ} \mathrm{C}$. 


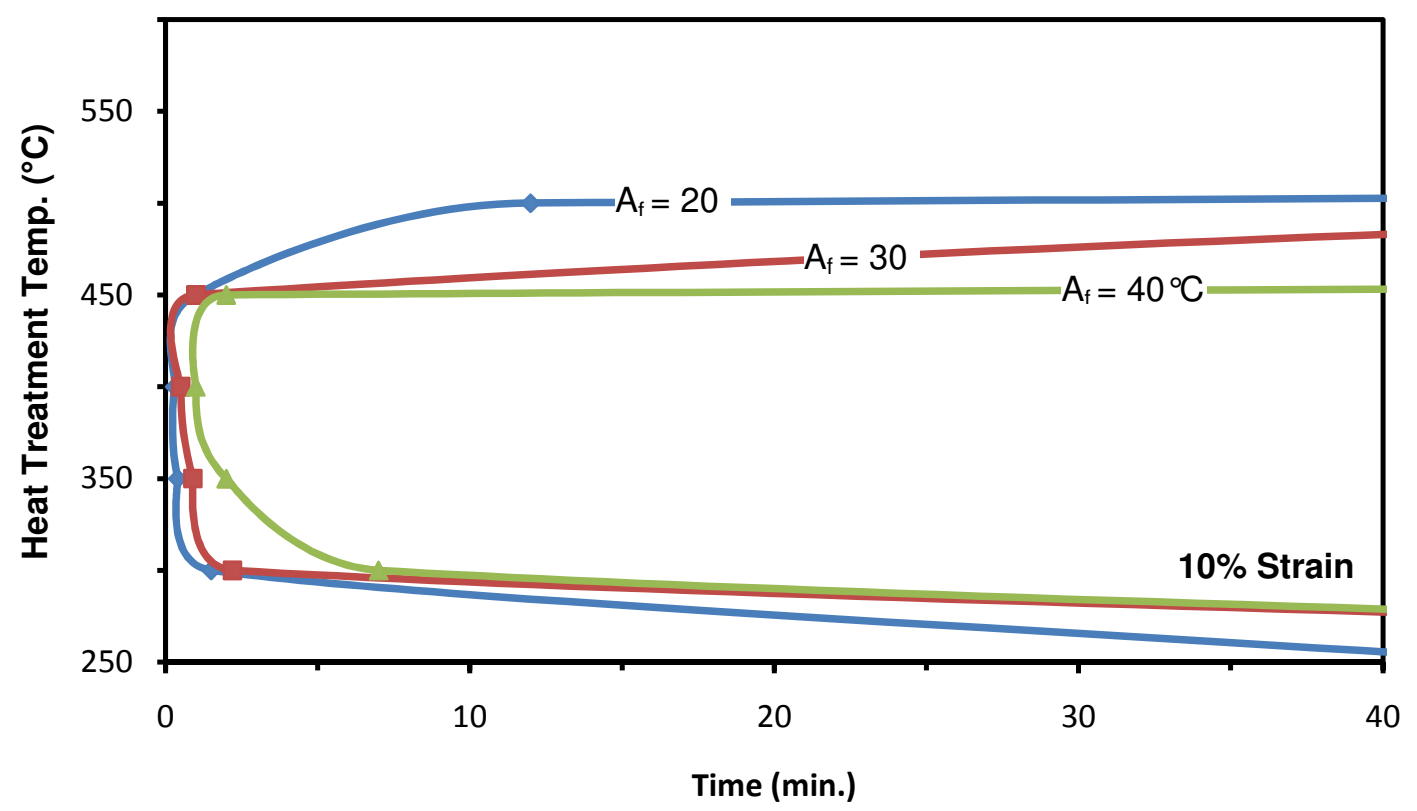

Figure 42 - TTT-like diagram illustrating the effects of heat treatment temperature and time for specimen heat treated at $10 \%$ strain. The maximum precipitation rate occurs at approximately $400^{\circ} \mathrm{C}$. 


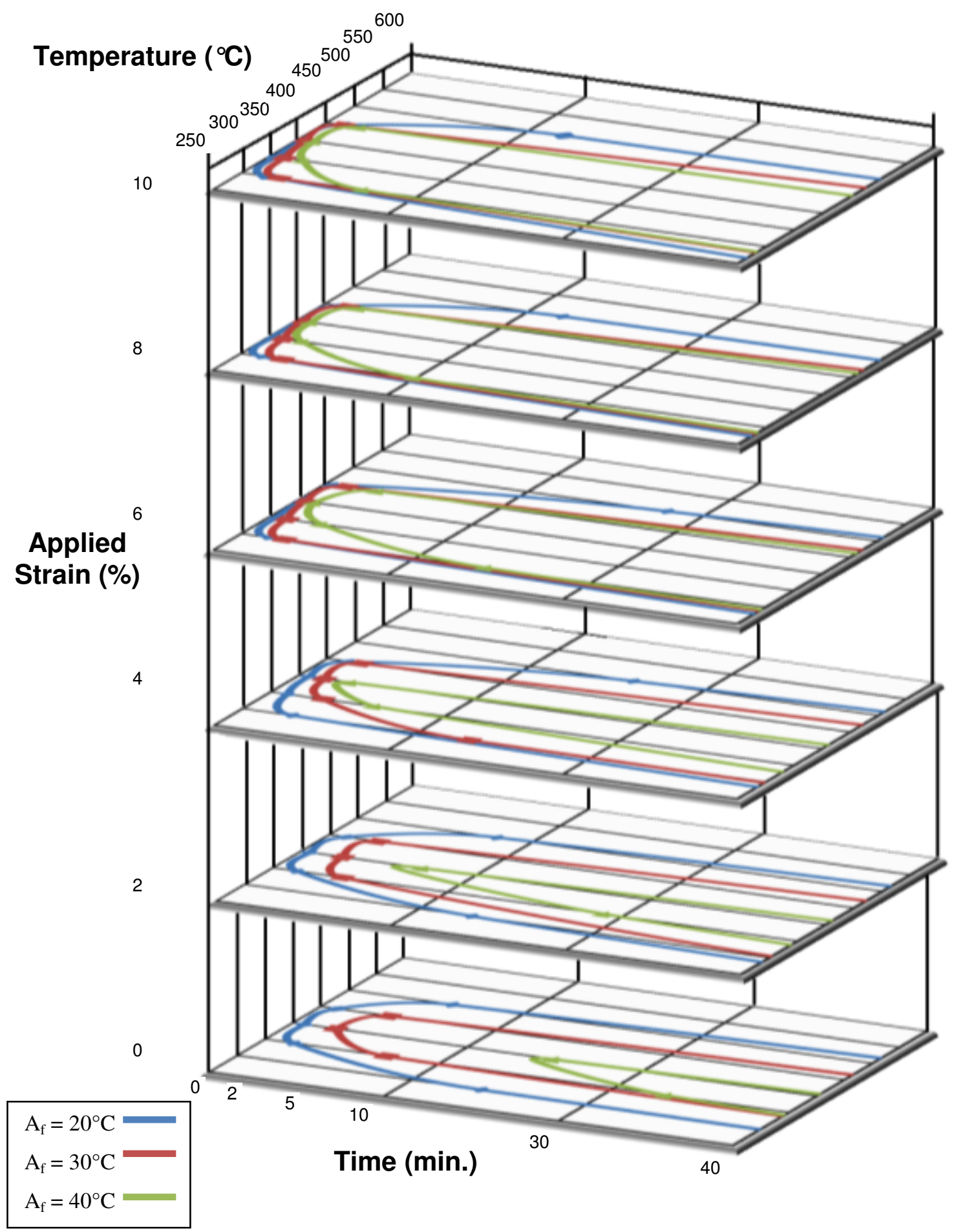

Figure 43 - A three-dimensional TTT-like diagram illustrating the effect of applied strain and heat treatment on the transformation temperature. Note a systematic shift of $A_{f}$ contours to the left, indicating faster reaction times, with increasing level of applied strain occurs. 


\subsection{Mechanical Properties}

The stress-strain response of as-received wire with a starting $\mathrm{A}_{\mathrm{f}}$ of $11^{\circ} \mathrm{C}$ prior to heat treatment is shown in Figure 44. A superelastic flag, indicating the reversible phase transformation from austenite to martensite, is shown in Figure 41. The UTS and elastic modulus of the as-received wire is $1116 \mathrm{MPa}$ and $65 \mathrm{GPa}$, respectively. These values fall within published values found in literature [40] of UTS between 1100-1150 MPa and an elastic modulus between 41-75 GPa.

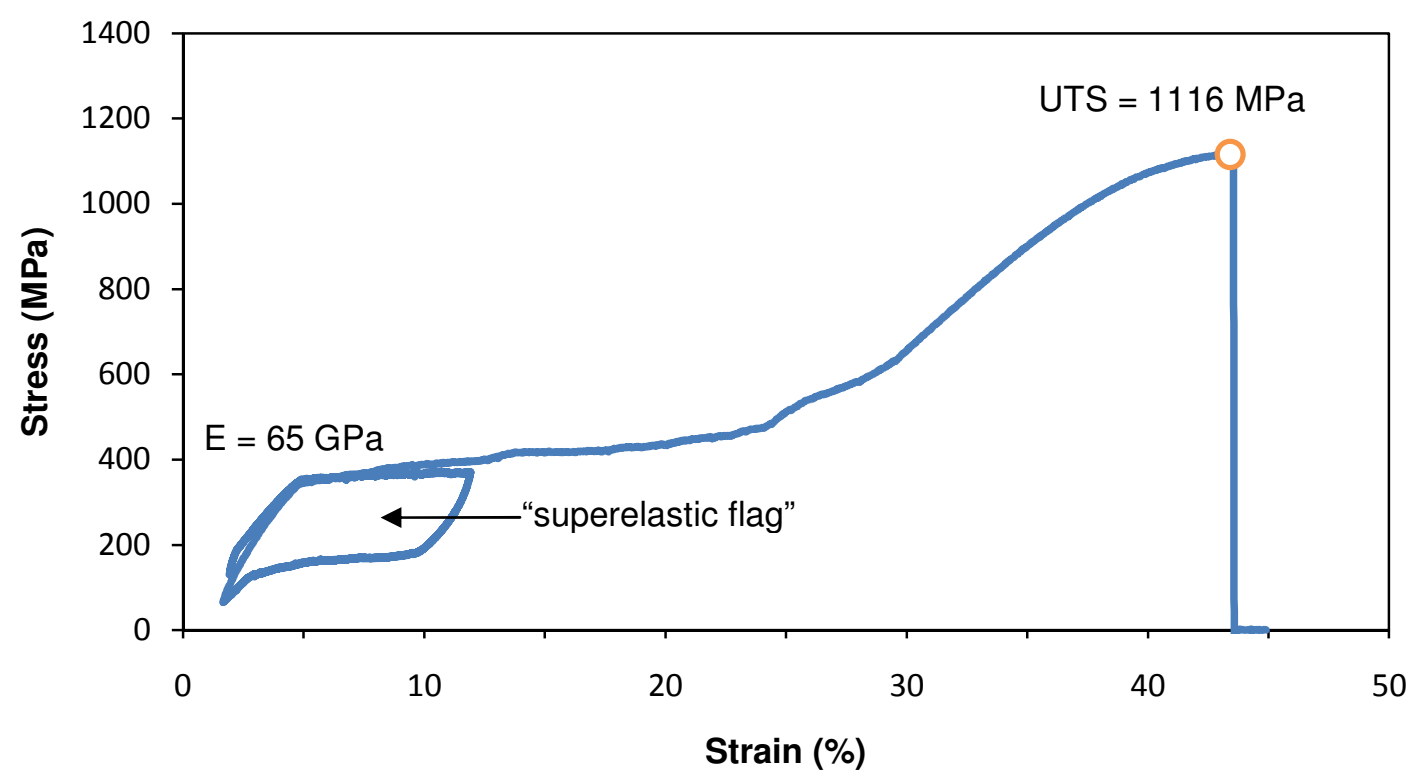

Figure 44 - Tensile response of as-received wire with an initial $A_{f}$ of $11^{\circ} \mathrm{C}$ prior to heat treatment. $A$ reversible phase transformation from austenite to martensite is clearly observed.

Following a heat treatment of $2-30$ minutes between $300-450^{\circ} \mathrm{C}$, the superelastic flag is significantly distorted for specimen heat treated at strain levels between $6-10 \%$. The stress-strain response, representative of specimen heat treated under these conditions, is shown for specimen heat treated for 2 and 30 minutes at $300^{\circ} \mathrm{C}$ for all levels of applied 
strain in Figures 45 and 46 respectively. The stress-strain response for specimens heat treated at $400^{\circ} \mathrm{C}$ is attached to Appendix V. Figures 45 and 46 illustrate that the superelastic flag is significantly distorted between strain levels of 6-10\%; the stressinduced transformation from austenite to martensite during loading is not observed. Also note the systematic decrease in UTS as the level of applied strain during heat treatment increases. The superelastic flag is not observed for specimen heat treated at strain levels of $0-4 \%$ for 30 minutes, as illustrated at $300^{\circ} \mathrm{C}$ in Figure 46 , primarily because the wire samples are predominantly in the martensite phase due to the formation of Ni-rich precipitates.

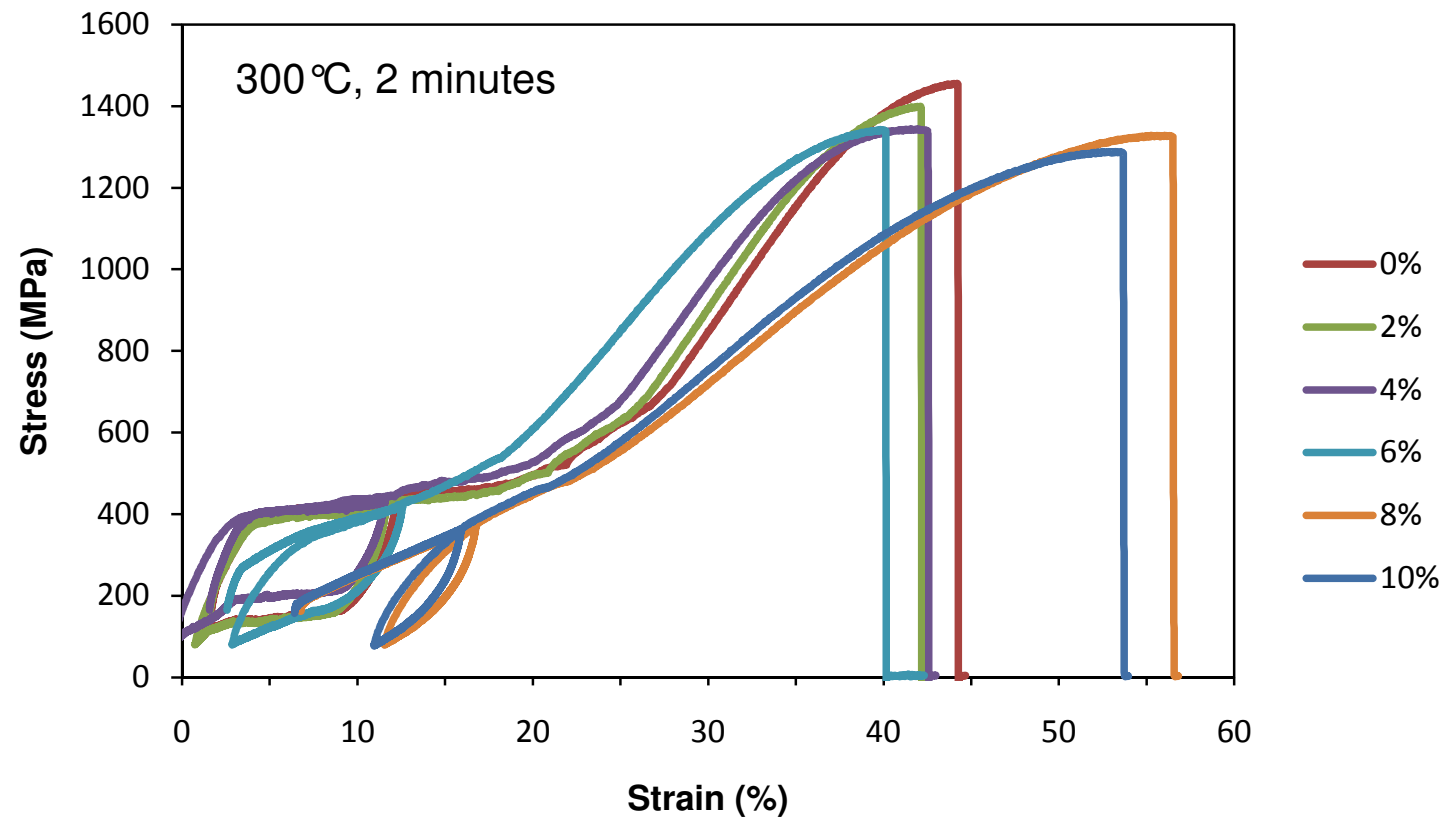

Figure 45 - Tensile response of specimen heat treated at $300^{\circ} \mathrm{C}$ for 2 minutes illustrated for all levels of applied strain. A superelastic flag is observed for specimen heat treated at strain levels of 0-4\%; higher strain levels tend to distort the superelastic flag. Also note a systematic decrease in UTS as applied strain increases. 


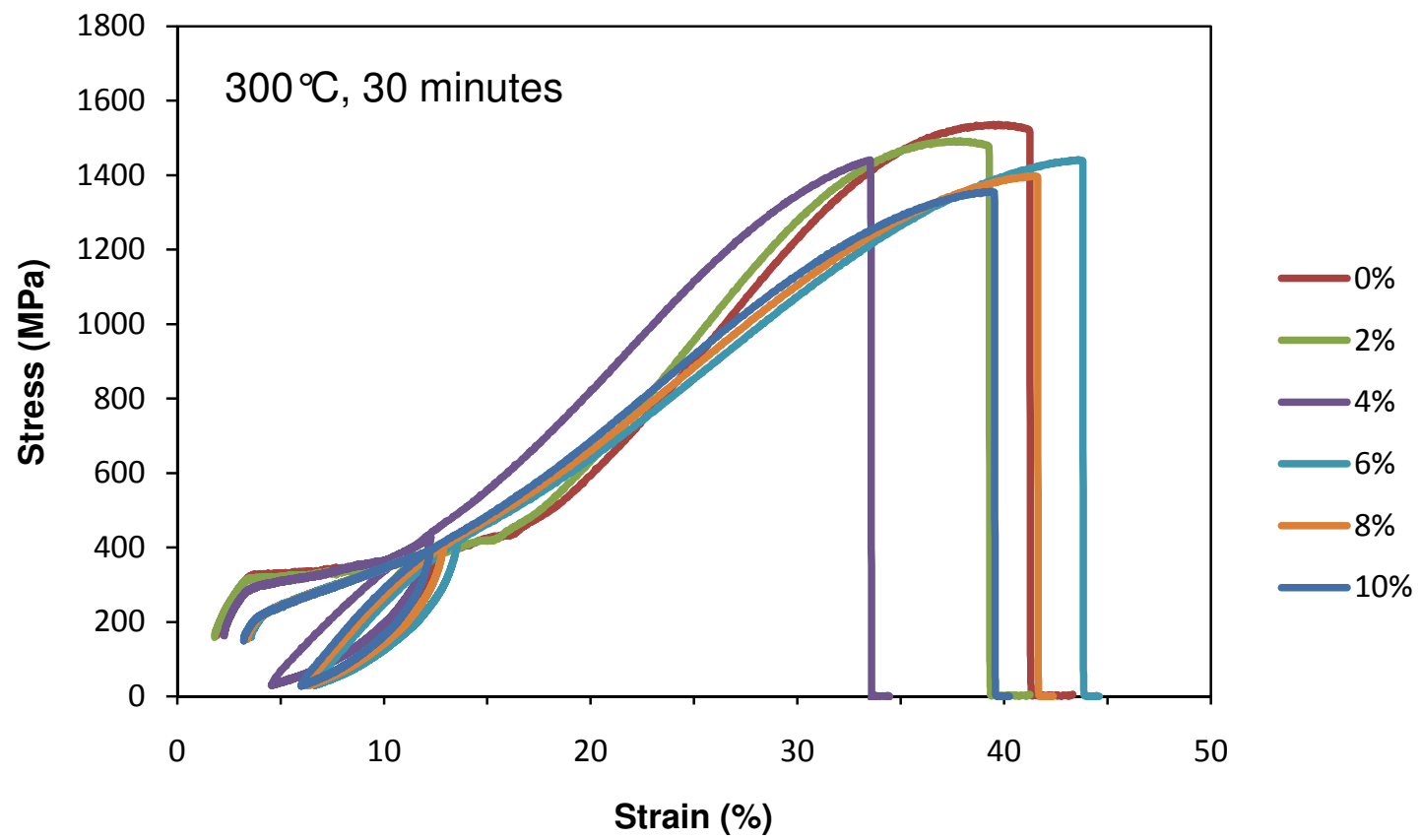

Figure 46 - Tensile response of specimen heat treated at $400^{\circ} \mathrm{C}$ for 30 minutes illustrated for all levels of applied strain. A superelastic flag is not observed for specimen heat treated at applied strains of 0 4\% due to such a high unloading stress of $60 \mathrm{MPa}$ used in the tensile test.

Heat treatments of $2-30$ minutes at $500^{\circ} \mathrm{C}$ result in similar stress-strain behavior; the only exception is that a highly distorted superelastic flag occurs for specimen heat treated with $2 \%$ applied strain. The stress-strain response for specimen heat treated for 2 and 30 minutes at $500^{\circ} \mathrm{C}$ for all levels of applied strain is shown in Figures 47 and 48 , respectively. The lower plateau of the superelastic flag is not observed for specimen heat treated at strain levels of $0-2 \%$ at $500^{\circ} \mathrm{C}$, as illustrated in Figure 47 and 48 , possibly due to the method used for the tensile tests. The unloading stress of $60 \mathrm{MPa}$ is high enough to prevent the reversible transformation from martensite to austenite. The superelastic flag would be observed if the specimens were unloaded to a stress lower than $7 \mathrm{MPa}$ during the unloading cycle, as recommended in ASTM 2516-07. A systematic decrease in UTS with increasing level of applied strain during heat treatment is observed in Figures 47 and 
48. Though the upper plateau stress was not the focus of this study due to test method used, a decrease in upper plateau was generally observed; this trend, however, is highly inconsistent and was not analyzed.

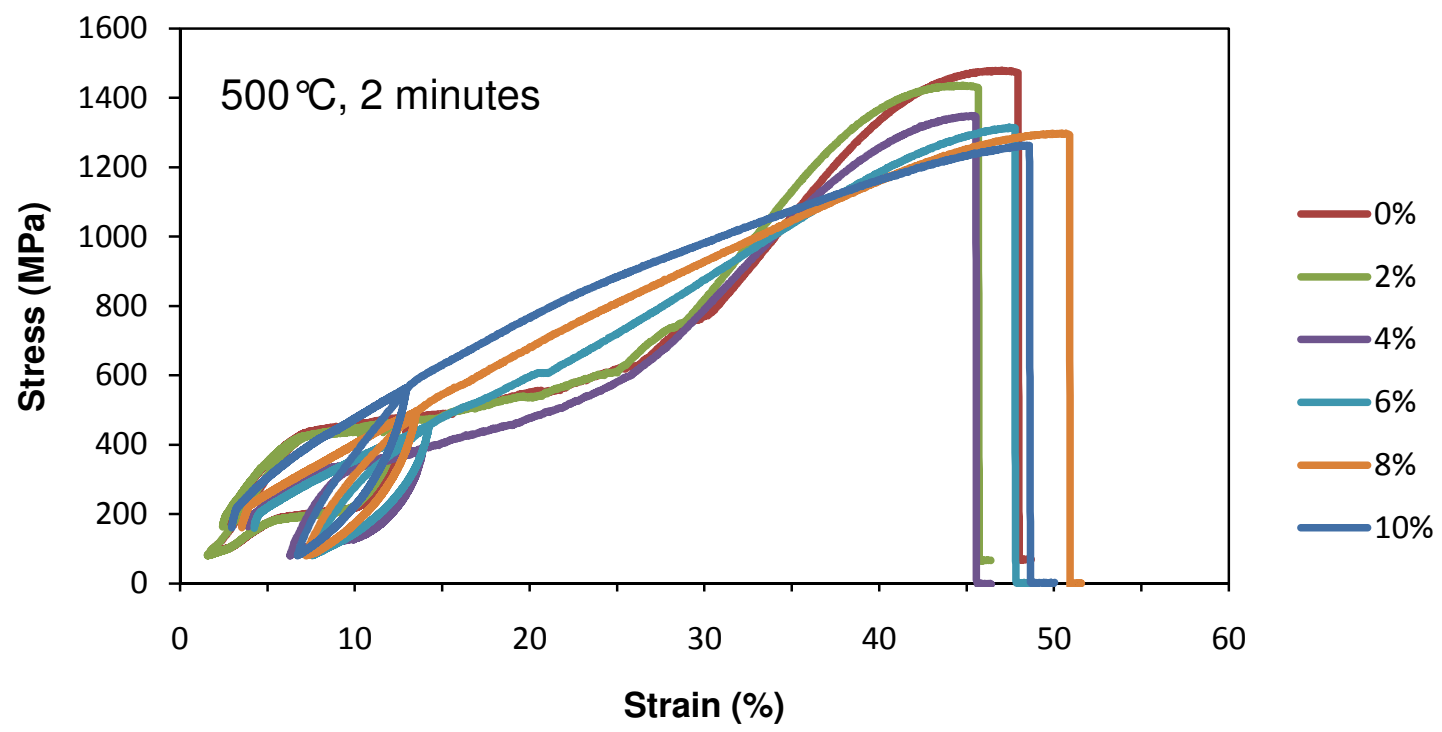

Figure 47 - Tensile response of specimen heat treated at $500^{\circ} \mathrm{C}$ for 2 minutes illustrated for all levels of applied strain. A superelastic flag is only observed for specimen heat treated at 0 and $2 \%$; higher levels of applied strain tend to distort the superelastic flag. A systematic decrease in UTS occurs as applied strain during heat treatment increases. 


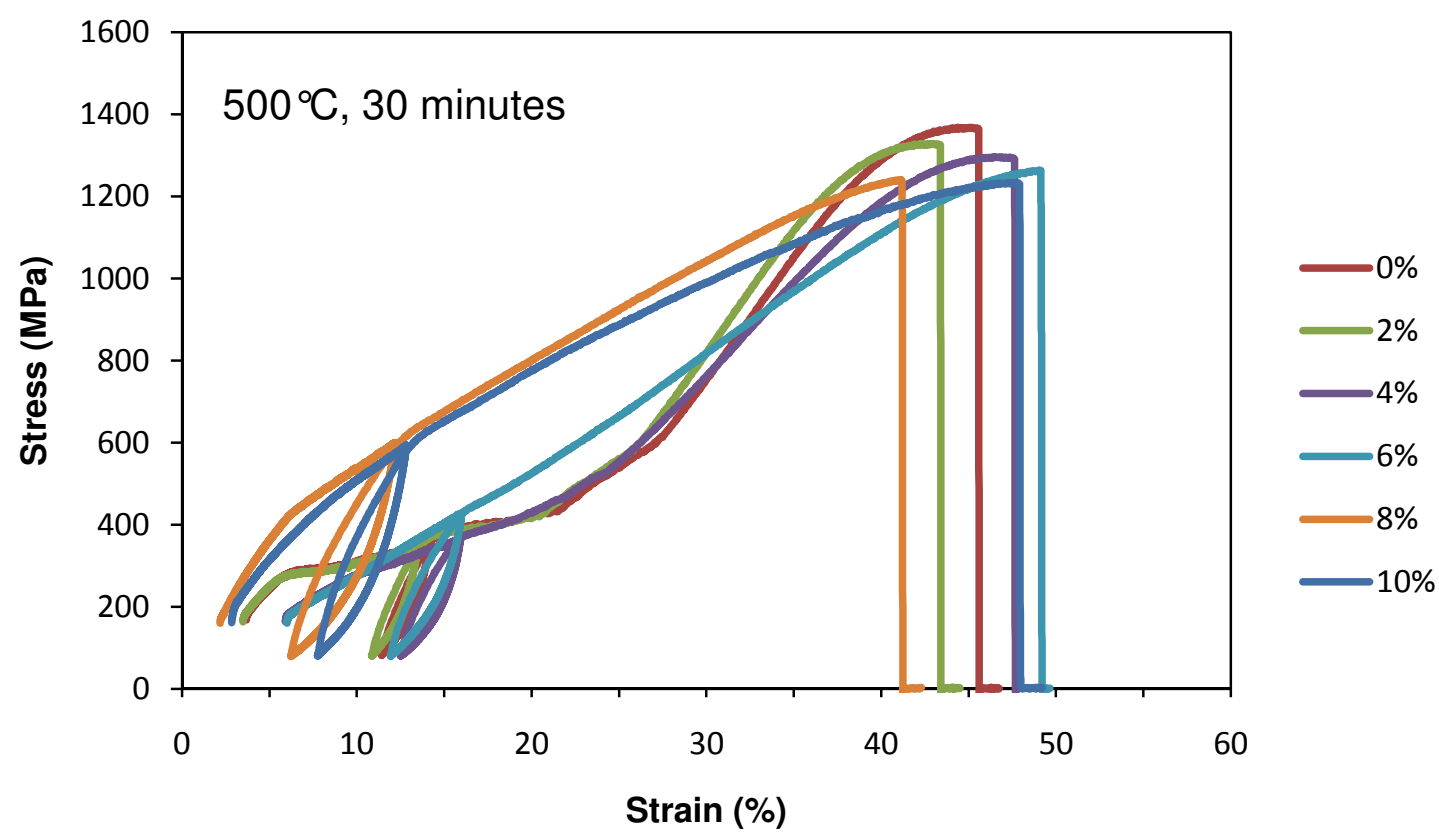

Figure 48 -Tensile response of specimen heat treated at $500^{\circ} \mathrm{C}$ for 2 minutes illustrated for all levels of applied strain. Superelastic behavior is lost for specimen heat treated at strain levels between 6$10 \%$. A systematic decrease in UTS occurs with increasing level of applied strain during heat treatment.

Heat treatments of $2-10$ minutes at $550^{\circ} \mathrm{C}$ result in similar stress-strain behavior with a highly distorted superelastic flag beginning at $4 \%$ applied strain. The stress-strain response for specimen heat treated at $550^{\circ} \mathrm{C}$ and 2 minutes for all levels of applied strain is shown in Figure 49. Heat treatments of 30 minutes at $550^{\circ} \mathrm{C}$ result in what seems to be an upper plateau stress at approximately $1050 \mathrm{MPa}$ for all levels of applied strain, as shown in Figure 50. This behavior was only observed for specimen heat treated at $550^{\circ} \mathrm{C}$ for 30 minutes. A separate test of a wire with similar $A_{f}$ was conducted to verify the appearance of the unusual upper plateau. Wire heat treated with $2 \%$ applied strain at $300^{\circ} \mathrm{C}$ for 2 minutes $\left(\mathrm{A}_{\mathrm{f}}=20^{\circ} \mathrm{C}\right)$ was retested, as shown in Figure 51; the upper plateau stress at $1050 \mathrm{MPa}$ was not seen for wire heat treated at $300^{\circ} \mathrm{C}$. However, different precipitates are formed at the two temperature extremes $\left(300\right.$ and $\left.550^{\circ} \mathrm{C}\right)$, making the 
comparison of the two tensile plots invalid. A systematic decrease in UTS occurs for specimen heat treated at $550^{\circ} \mathrm{C}$ as applied strain during heat treatment increases.

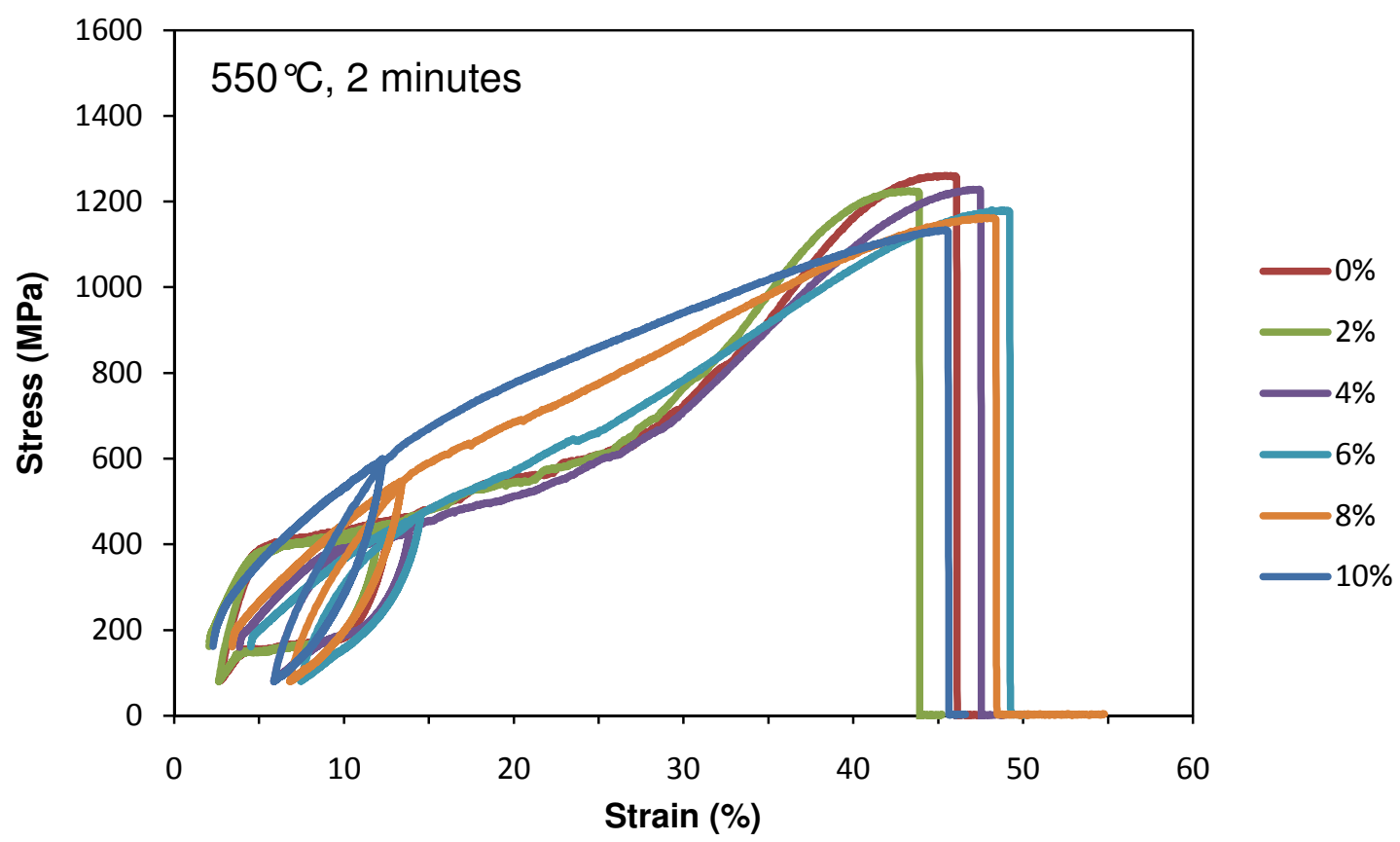

Figure 49 - Tensile response for specimen heat treated at $550^{\circ} \mathrm{C}$ and 2 minutes illustrated for all levels of applied strain. The superelastic flag is retained for specimen heat treated at strain levels between 0 and $2 \%$; higher strain levels tend to distort the superelastic flag. 


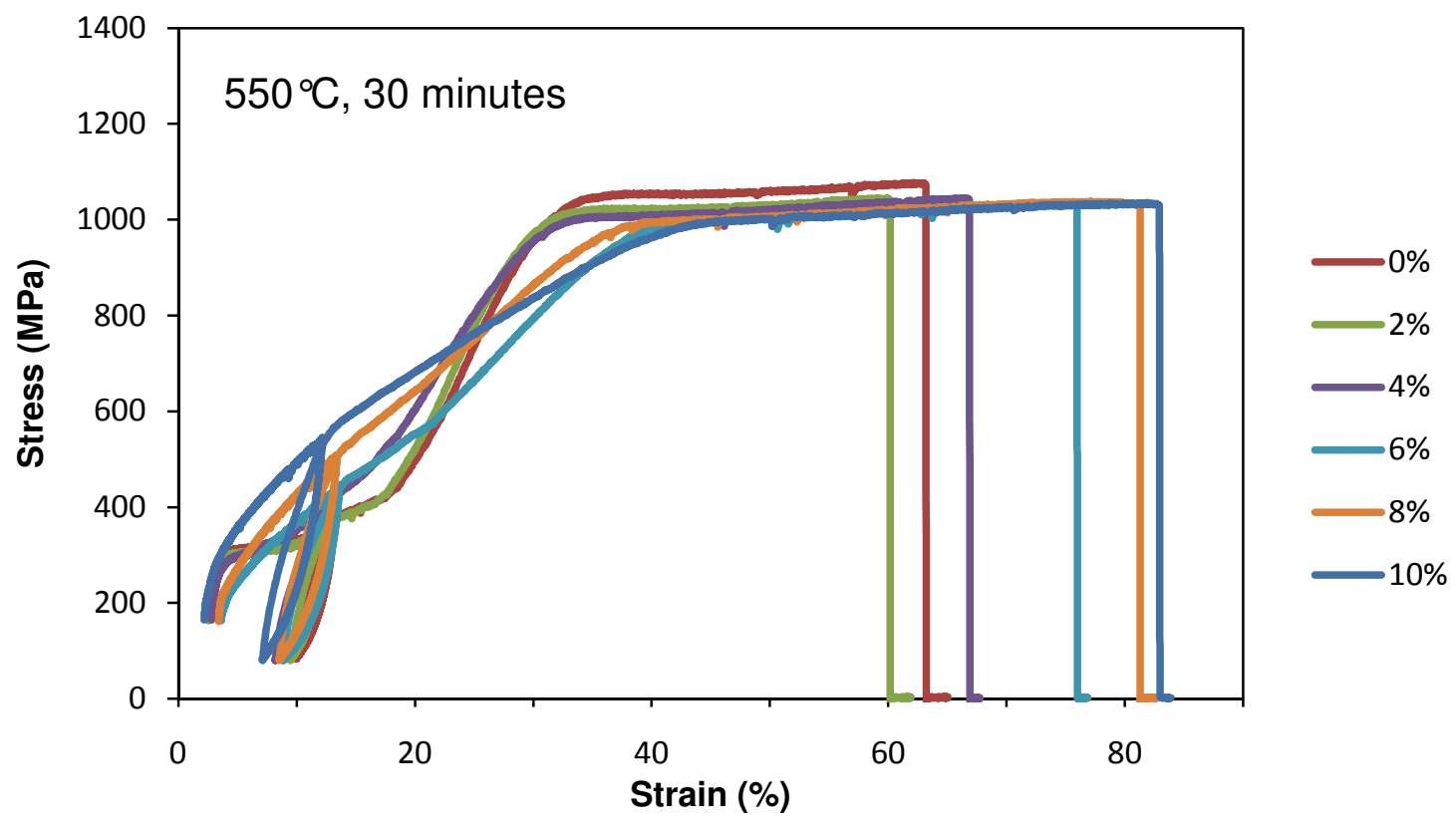

Figure 50 - Tensile response of specimen heat treated at $550{ }^{\circ} \mathrm{C}$ for 30 minutes illustrated for all levels of applied strain. The superelastic flag is retained for specimen heat treated at strain levels between 0-4\%. Note an upper plateau stress at approximately $1050 \mathrm{MPa}$ for all levels of applied strain.

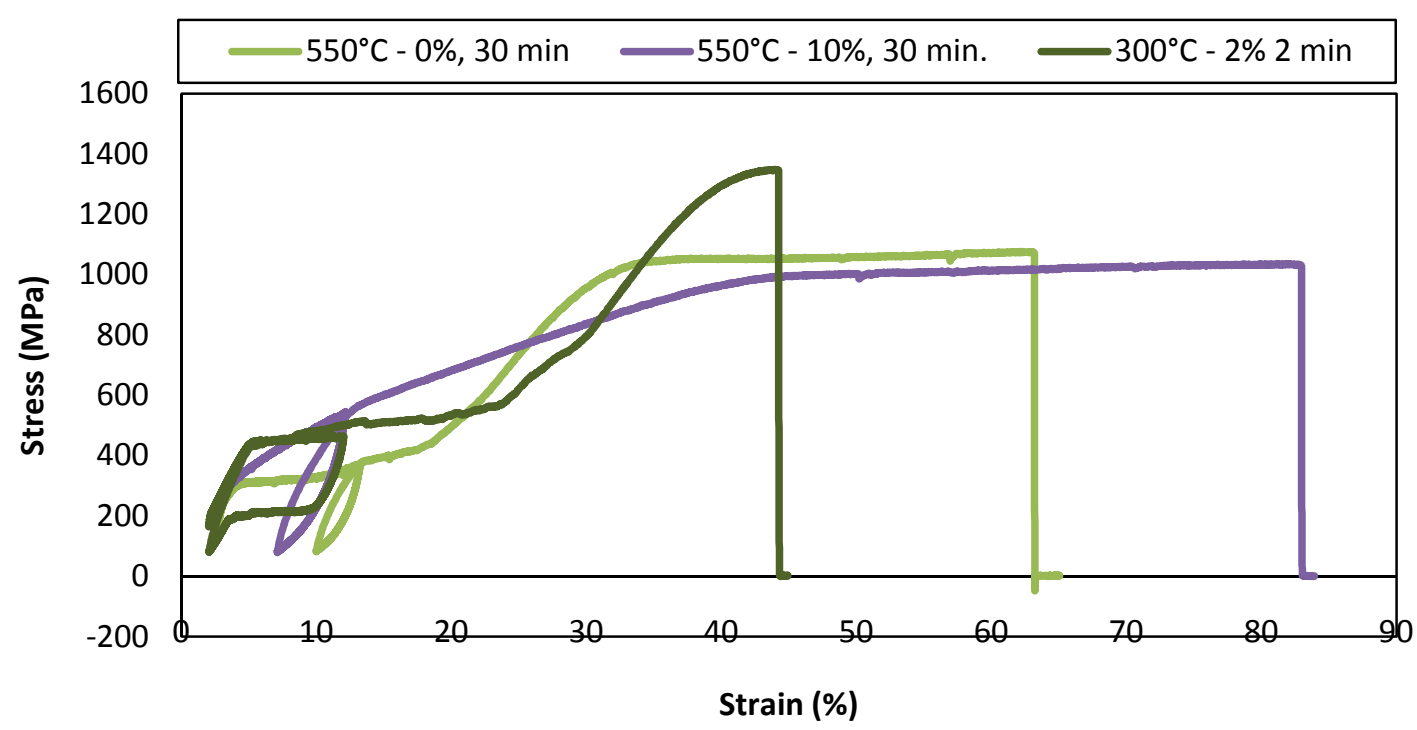

Figure 51 - Tensile response for specimen heat treated at $550^{\circ} \mathrm{C}$ for 30 minutes and $300^{\circ} \mathrm{C}$ for 2 minutes. The wire heat treated at $300^{\circ} \mathrm{C}$ for 2 minutes was chosen since the $\mathrm{A}_{\mathrm{f}}$ temperature is similar to the $\mathrm{A}_{\mathrm{f}}$ at $550^{\circ} \mathrm{C}$; different Ni-rich precipitates are formed at these temperature extremes. Though the unusual upper plateau is not observed at $300^{\circ} \mathrm{C}$, in retrospect, this was not a wise choice to investigate the upper plateau seen at approximately $1050 \mathrm{MPa}$ at $550{ }^{\circ} \mathrm{C}$. 
Graphs of UTS versus heat treatment temperature for all levels of applied strain were generated for each heat treatment time. Figures 52 and 53 are diagrams of specimen heat treated at 2 and 30 minutes, respectively. Graphs of UTS versus heat treatment temperature for specimens heat treated at 5 and 10 minutes are provided in Appendix VI. The blue horizontal dash line at $1116 \mathrm{MPa}$ represents the UTS of the as-received wire. Comparison of Figures 52 and 53 illustrate a decrease in UTS with increasing level of applied strain during heat treatment. An increase in UTS occurs with increasing heat treatment temperature between $300-450^{\circ} \mathrm{C}$. Figures 52 and 53 illustrate that the maximum UTS is obtained between $400-450^{\circ} \mathrm{C}$ for all levels of applied strain. Annealing effects tend to dominate at heat treatment temperatures above $450^{\circ} \mathrm{C}$, resulting in a decrease in UTS. The trend in UTS due to applied strain and temperature for all heat treatment times is summarized in Figure 54. Generally, all levels of applied strain tend to decrease UTS; applied strain has no significant effect on UTS following a heat treatment at $550^{\circ} \mathrm{C}$ for 30 minutes. 


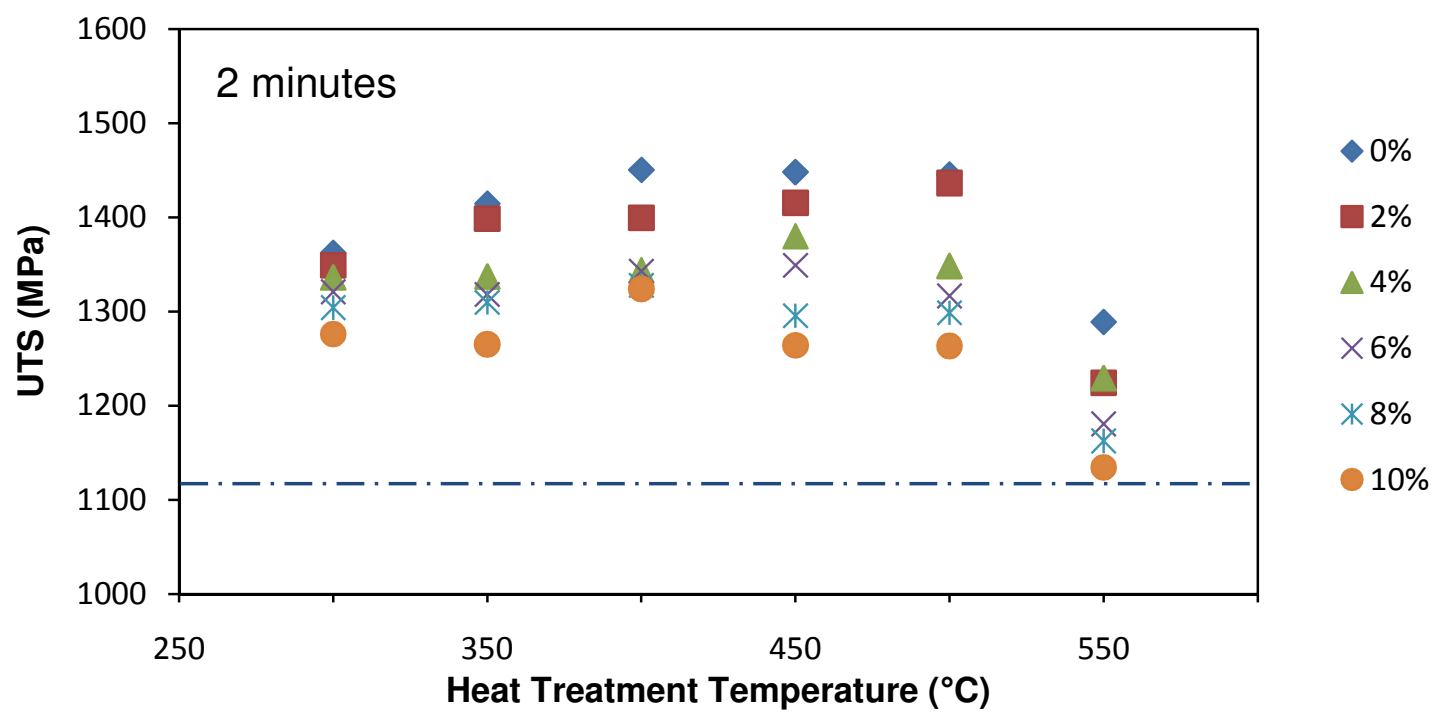

Figure 52 - Effect of applied strain and heat treatment temperature for specimen heat treated for 2 minutes. The blue dash line at 1116 MPa represents the UTS of the as-received wire. The maximum UTS is obtained between heat treatments temperatures of $400-450^{\circ} \mathrm{C}$; above $450^{\circ} \mathrm{C}$, annealing effects dominate. Note that a decrease in UTS is observed with increasing level of applied strain.

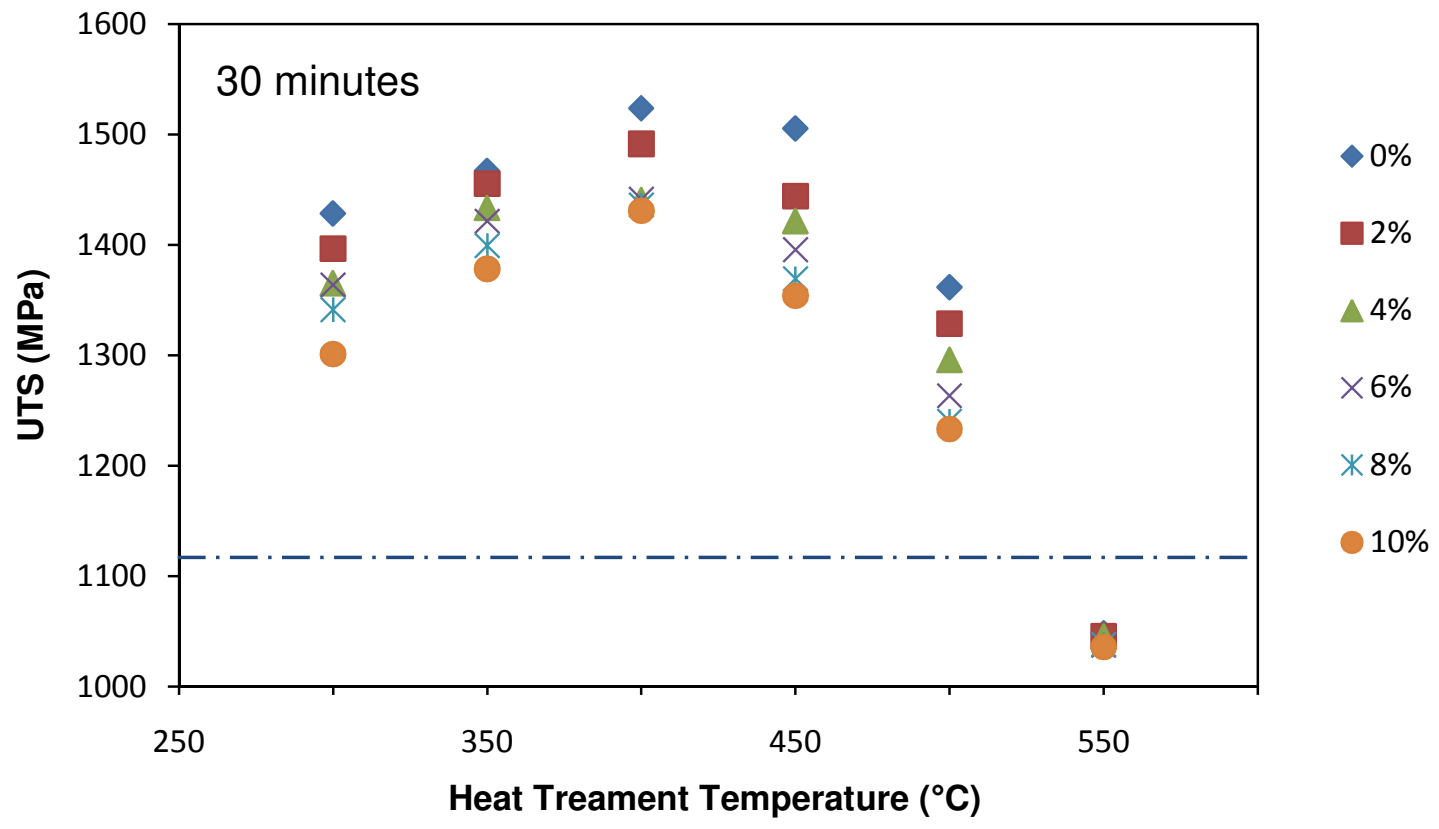

Figure 53 - Effects of applied strain and heat treatment temperature for specimen heat treated for 30 minutes. The blue dash line at 1116 MPa represents the UTS of the as-received wire. The maximum UTS is obtained between heat treatments temperatures of $400-450^{\circ} \mathrm{C}$. Note that heat treatments of $550^{\circ} \mathrm{C}$ for 30 minutes a significant decrease in UTS, approximately $60 \mathrm{MPa}$ lower than the asreceived wire. 


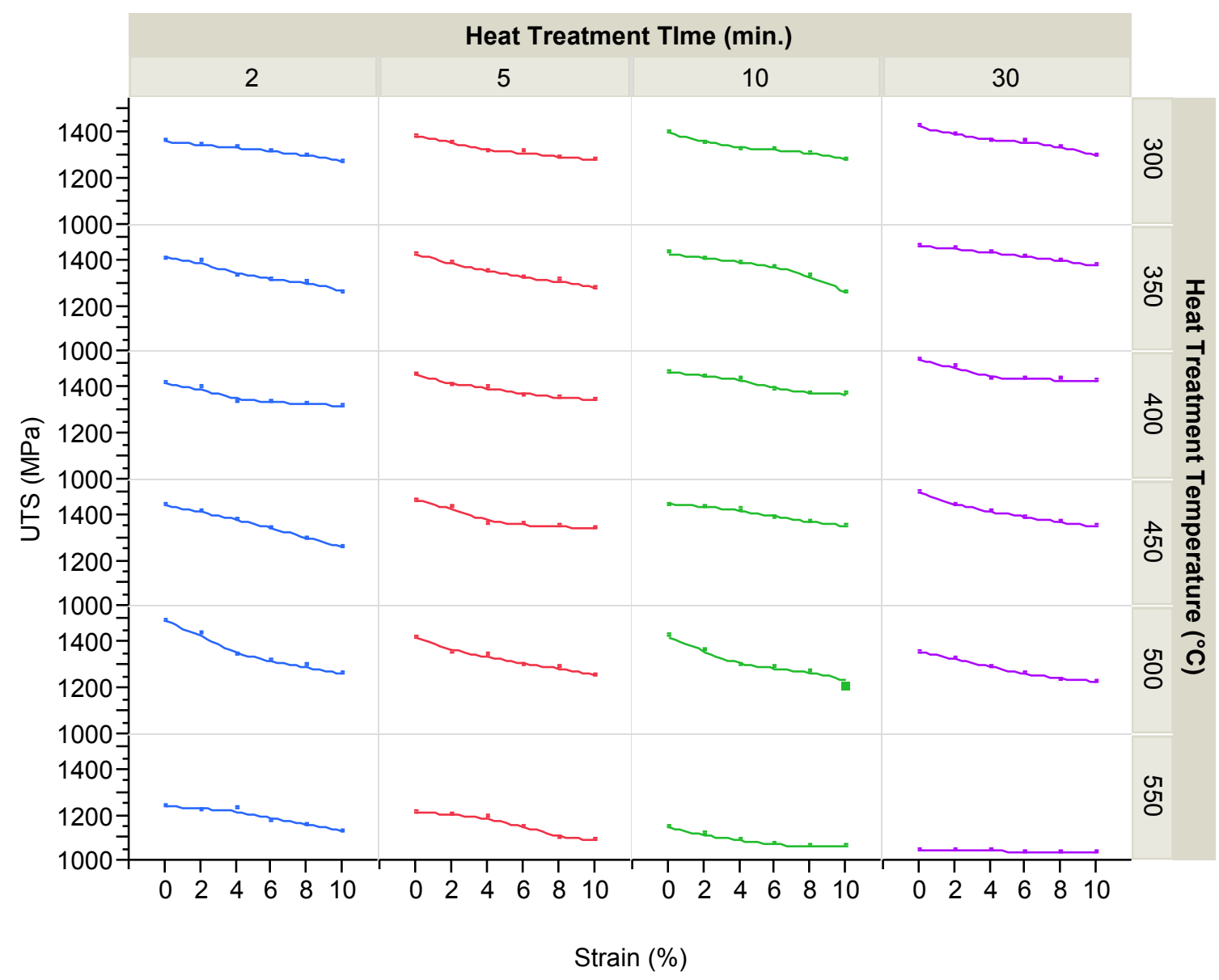

Figure 54 - Effect of applied strain and temperatuer on the ultimate tensile strength for all heat treatment times. Applied strain tends to decrease UTS for all heat treatments; applied strain has no significant effect following a heat treatment of $550^{\circ} \mathrm{C}$ for 30 minutes.

The trends in UTS as a function of heat treatment time are compiled in six plots, one for each level of applied strain. Figures 55, 56 and 57 are diagrams of UTS versus heat treatment time for specimens heat treated at 0,6 , and $10 \%$ applied strain, respectively. The trends in UTS for specimen heat treated at 2, 4, and $8 \%$ strain are provided in Appendix VII. Comparisons of Figures 55-57 illustrate an increase in UTS for specimen heat treated between $300-450^{\circ} \mathrm{C}$. Heat treatments at short times result in a rapid increase in UTS at $400^{\circ} \mathrm{C}$ for all levels of applied strain. For all levels of applied strain, the UTS increase is largest following a heat treatment of 30 minutes at $400^{\circ} \mathrm{C}$, where the 
maximum UTS of $1524 \mathrm{MPa}$ is achieved. This corresponds to an increase of $408 \mathrm{MPa}$ compared to the UTS of as-received wire. All figures illustrate a decrease in UTS following heat treatments above $500^{\circ} \mathrm{C}$. The UTS values obtained in this study, ranging from 1036-1524 MPa, fall within published values of NiTi wire undergoing heat treatments between $300-550^{\circ} \mathrm{C}[17]$.

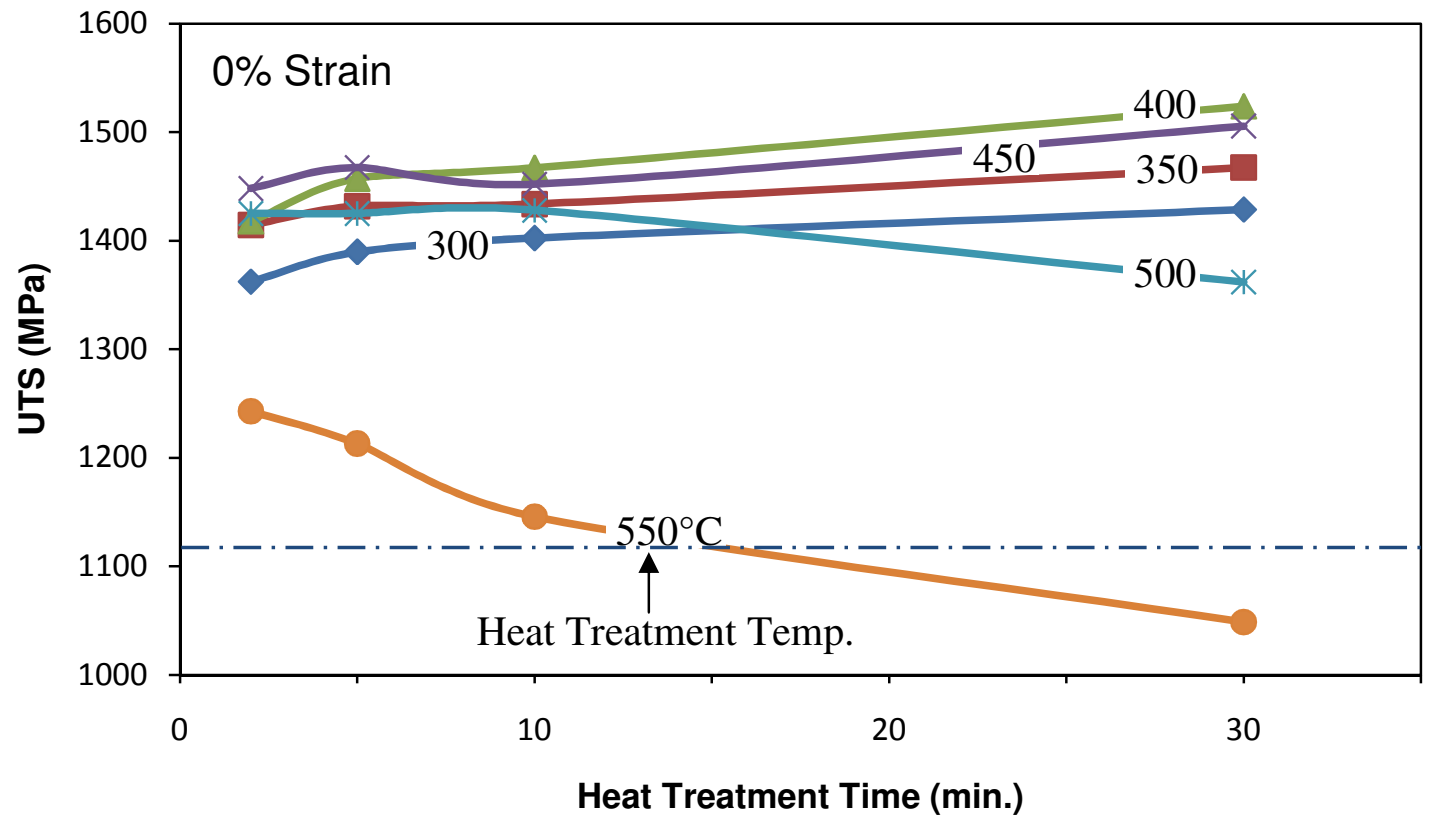

Figure 55 - Effect of time and temperature on the UTS for specimen heat treated at $0 \%$ strain. Heat treatment at $300^{\circ} \mathrm{C}$ does not significantly increase the UTS. The blue dash line at $1116 \mathrm{MPa}$ represents the UTS of the as-received wire. Heat treatments between $350-4500^{\circ} \mathrm{C}$ tend to increase UTS; heat treatments at $500^{\circ} \mathrm{C}$ and above tend to decrease UTS. 


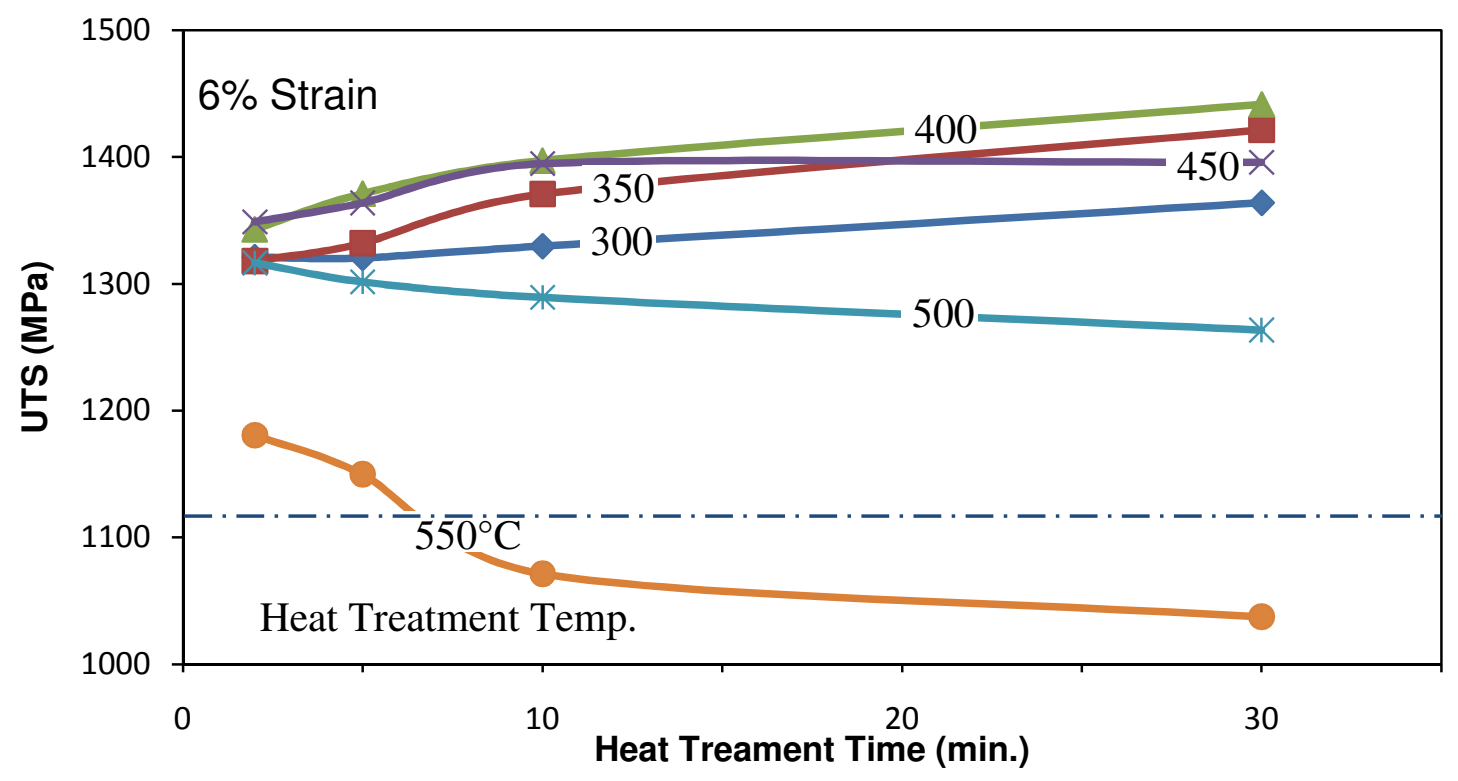

Figure 56 - Effects of time and temperature on the UTS for specimen heat treated at $6 \%$ strain. The blue dash line at 1116 MPa represents the UTS of the as-received wire. An increase in UTS is observed for heat treatments between $350-450^{\circ} \mathrm{C}$. Note heat treatments at $6 \%$ strain results in lower overall UTS as compared to a sample heat treated at lower levels of applied strain.

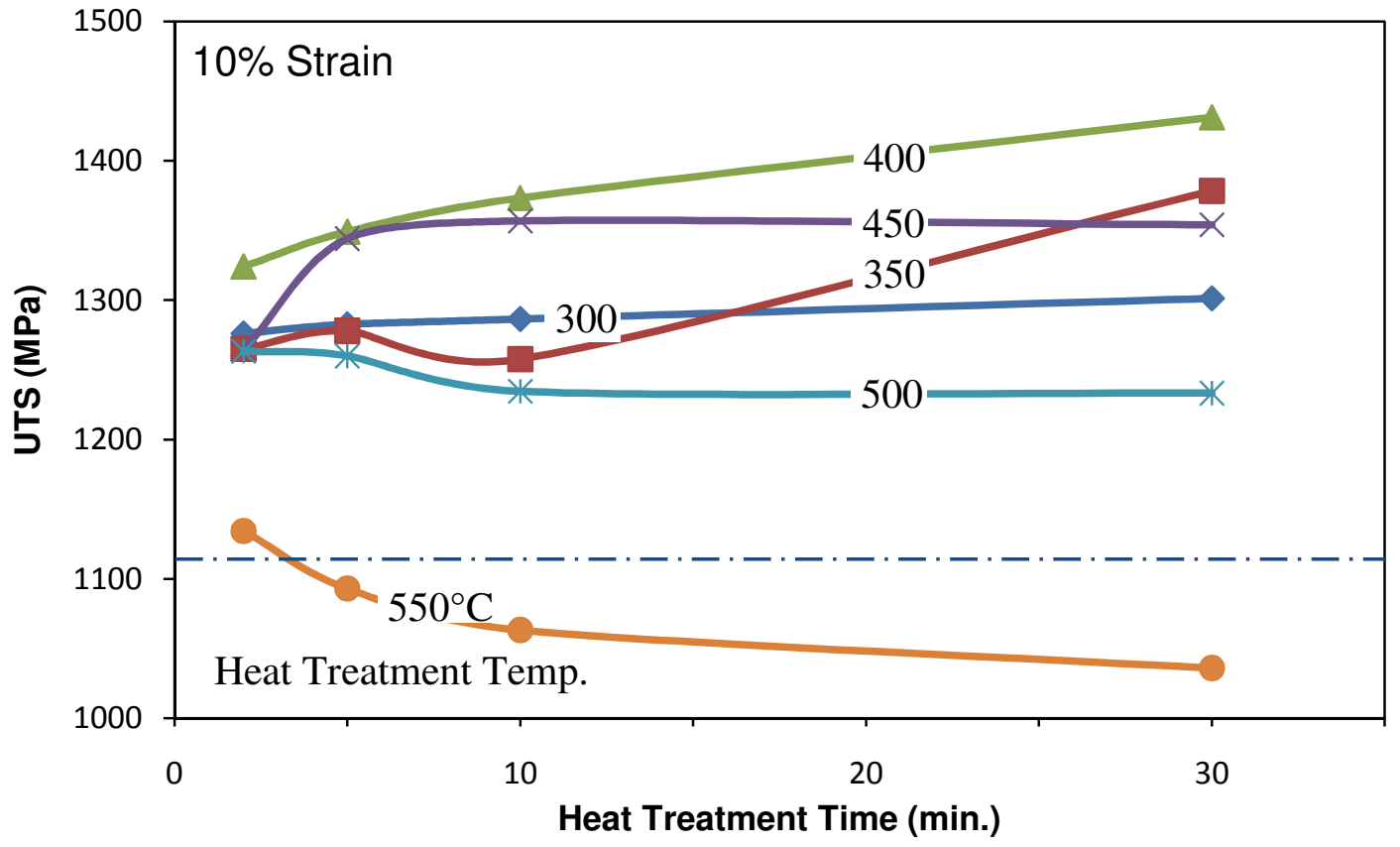

Figure 57 -Effects of time and temperature on the UTS of specimen heat treated at $10 \%$ strain. The blue dash line at 1116 MPa represents the UTS of the as-received wire. Heat treatments between 350$4500^{\circ} \mathrm{C}$ tend to increase UTS; note the significant decrease in UTS following a heat treatment at $550^{\circ} \mathbf{C}$. 
The correlation between UTS and $\mathrm{A}_{\mathrm{f}}$ were investigated by generating graphs of UTS versus $A_{f}$ for each heat treatment temperature. Plots of UTS versus $A_{f}$ for specimens heat treated at 350 and $400^{\circ} \mathrm{C}$ are shown in Figures 58 and 59, respectively. Graphs of UTS versus $A_{f}$ for specimens heat treated at 500 and $550^{\circ} \mathrm{C}$ are provided in Appendix VIII. For a given strain level, the UTS increases, due to the formation of Ni-rich precipitates, with increasing transformation temperature following a heat treatment between 300$450^{\circ} \mathrm{C}$. Heat treatments above $450^{\circ} \mathrm{C}$ tend to result in a decrease in UTS with increasing transformation temperature due to the dominant effects of annealing for a given level of applied strain. Also note that the set of UTS values within each strain level drops considerately with increasing level of applied strain.

Following the general trend of increasing $\mathrm{A}_{\mathrm{f}}$ with increased level of applied strain, the UTS was theorized to increase with higher levels of applied strain during heat treatment due to precipitation strengthening. However as the wires were uncoiled and mounted on the capstan grips, pre-straining of the specimens caused the UTS to decrease with increased level of applied strain. No general correlation exists within each level of applied strain between UTS and $\mathrm{A}_{\mathrm{f}}$ at $550^{\circ} \mathrm{C}$. A plot illustrating the spread in $\mathrm{A}_{\mathrm{f}}$ versus UTS for all levels of applied strain and heat treatment temperatures is shown in Figure 60. Note that the maximum UTS is obtained through heat treatments between $400-450^{\circ} \mathrm{C}$. The smallest spread in $\mathrm{A}_{\mathrm{f}}$, where annealing dominates, occurs at $500^{\circ} \mathrm{C}$. 


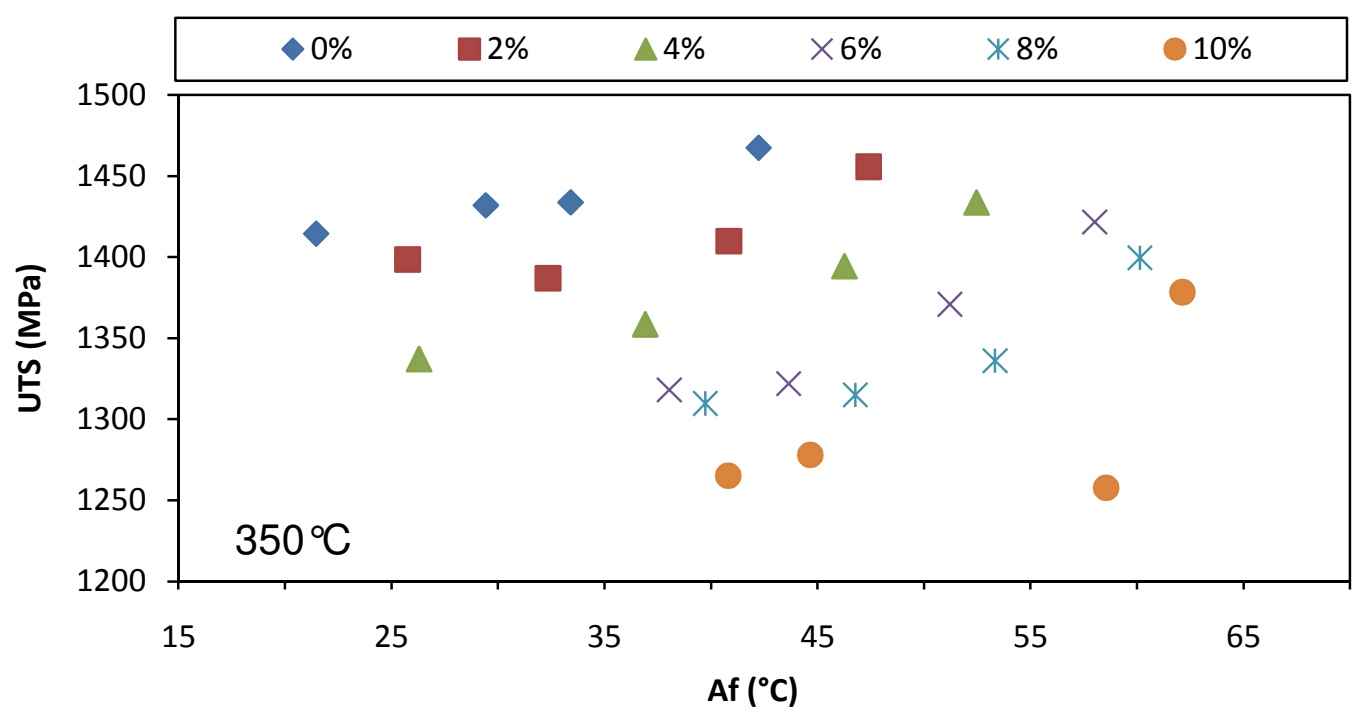

Figure 58 - Effect of transformation temperature on the ultimate tensile strength for all levels of applied strain at $350^{\circ} \mathrm{C}$. An increase in $A_{f}$ results in a decrease in UTS. Also note that higher levels of applied strain result in lower UTS values. Compared to the as-received wire, all treatments at $350^{\circ} \mathrm{C}$ have resulted in a decrease in UTS.

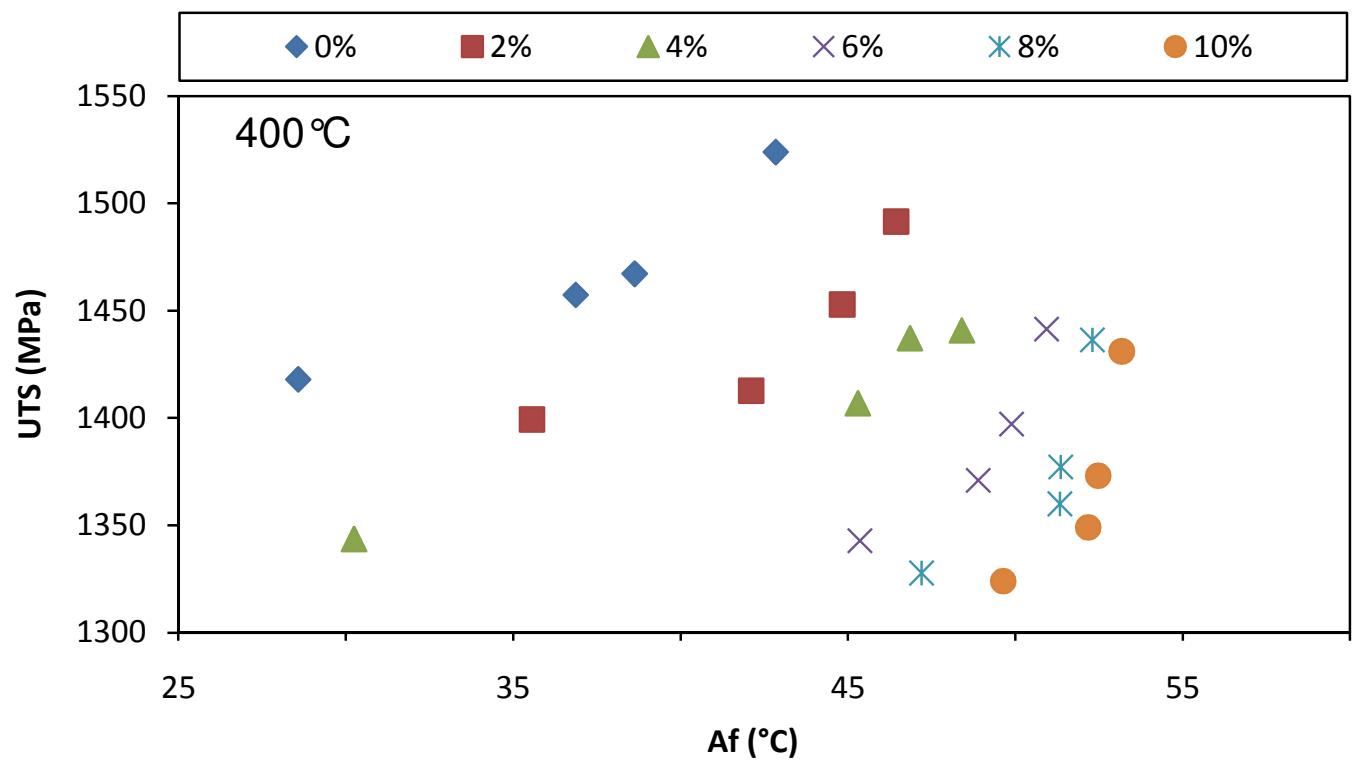

Figure 59 - Effect of transformation temperature on the ultimate tensile strength for all levels of applied strain at $400^{\circ} \mathrm{C}$. Higher UTS are obtained at lower $A_{f}$ values. Compared to the as-received wire, all treatments at $400^{\circ} \mathrm{C}$ have resulted in an increase in UTS. 


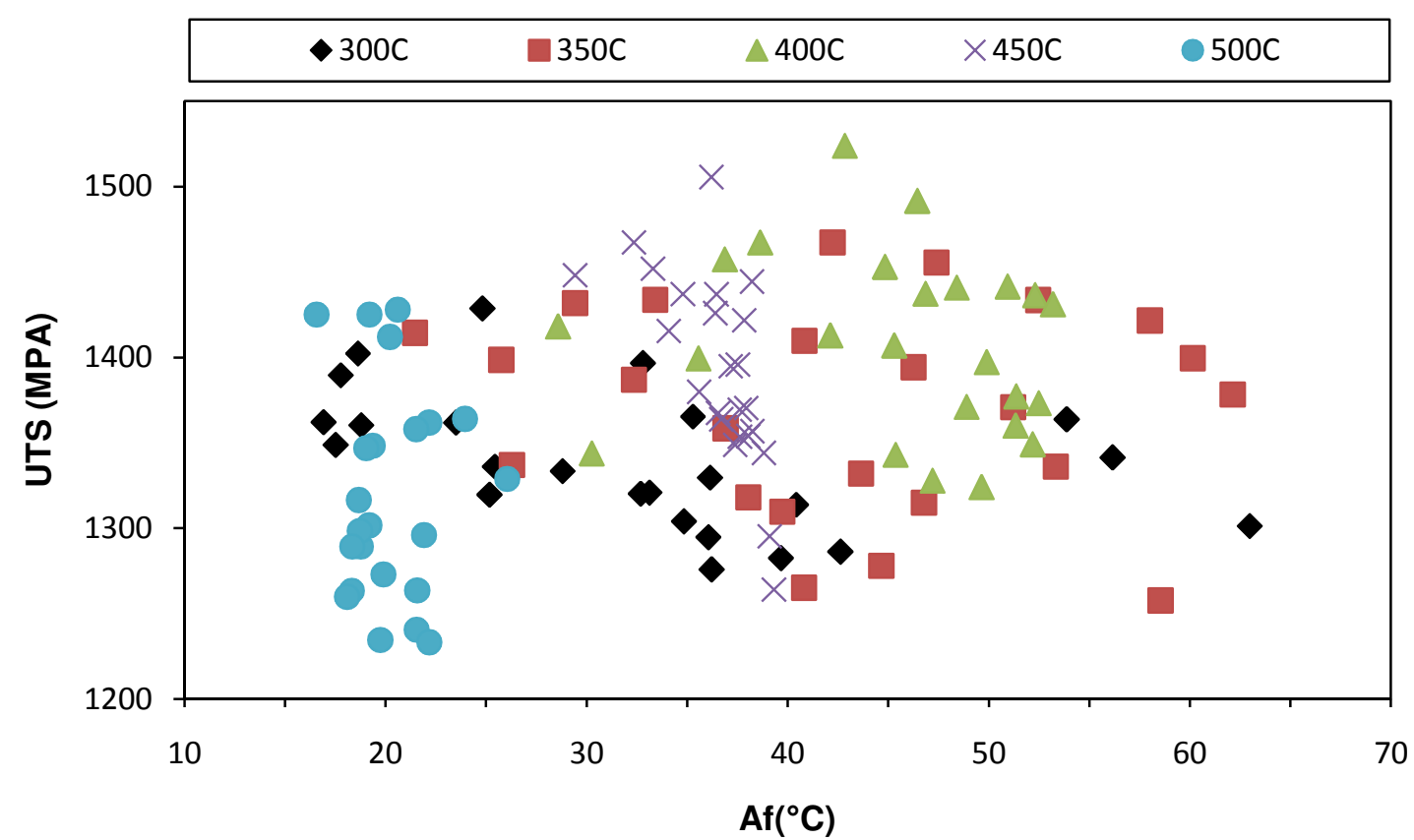

Figure 60 - Correlation between UTS and $A_{f}$ for all levels of applied strain and heat treatment temperature. The maximum UTS is obtained through heat treatments between $400-450^{\circ} \mathrm{C}$. The smallest spread in $\mathbf{A}_{\mathrm{f}}$ is obtained at $5_{00}^{\circ} \mathrm{C}$.

Graphs of elastic modulus versus heat treatment temperature were generated for each heat treatment time. The graphs of elastic modulus versus heat treatment temperatures for specimens heat treated for 2 and 30 minutes are shown in Figures 61 and 62, respectively. Graphs of elastic modulus versus heat treatment temperature for specimens heat treated for 5 and 10 minutes are provided in Appendix IX. The blue dash line at $66 \mathrm{GPa}$ represents the elastic modulus of the as-received wire. The maximum value for elastic modulus is generally obtained at temperatures between $300-350^{\circ} \mathrm{C}$ and low levels of applied strain; higher levels of applied strain tend to decrease elastic modulus with increasing heat treatment temperature. This trend is highly inconsistent at temperatures above $450^{\circ} \mathrm{C}$. 


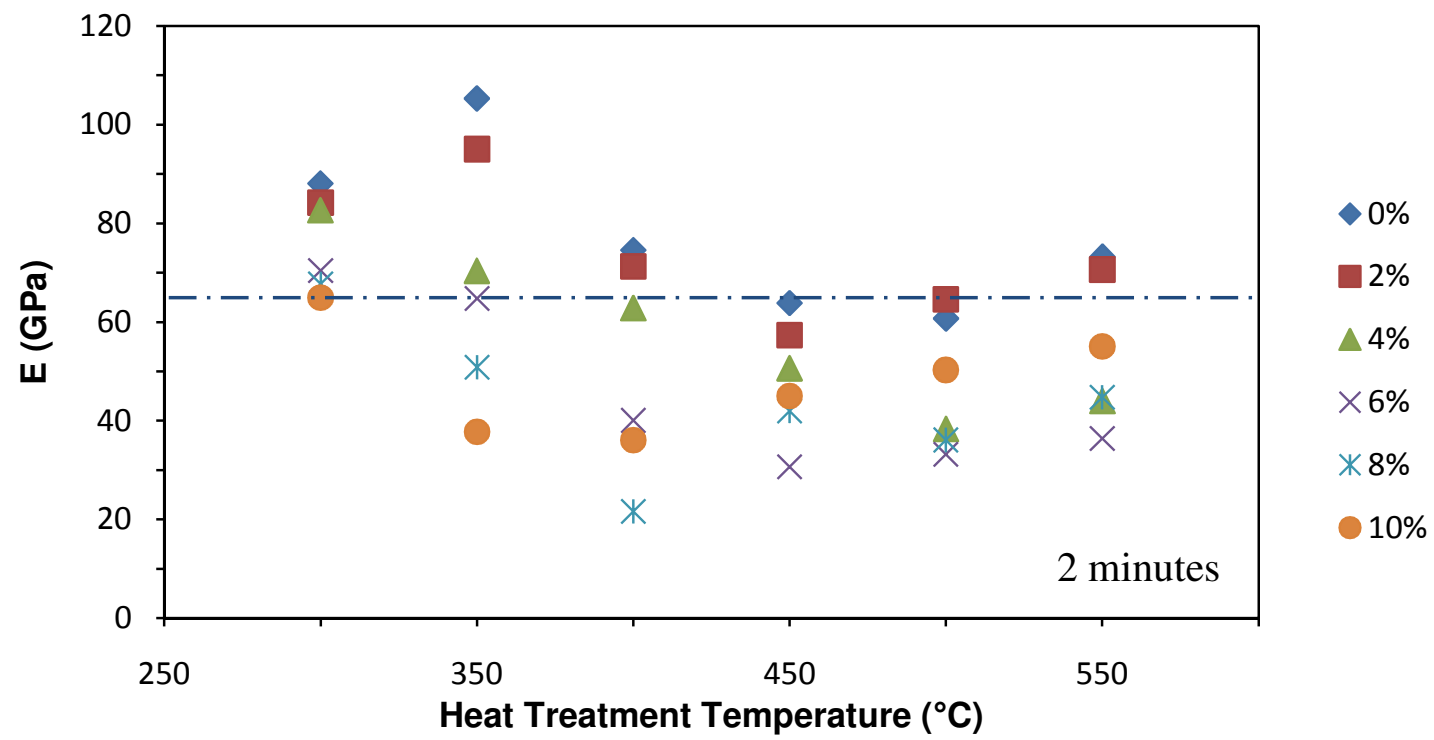

Figure 61 - Effect of applied strain and heat treatment temperature on the elastic modulus of specimen heat treated for $\mathbf{2}$ minutes. Higher levels of applied strain during heat treatment tend to decrease the elastic modulus; this trend is not consistent between heat treatment temperatures of 400-550 ${ }^{\circ} \mathrm{C}$.

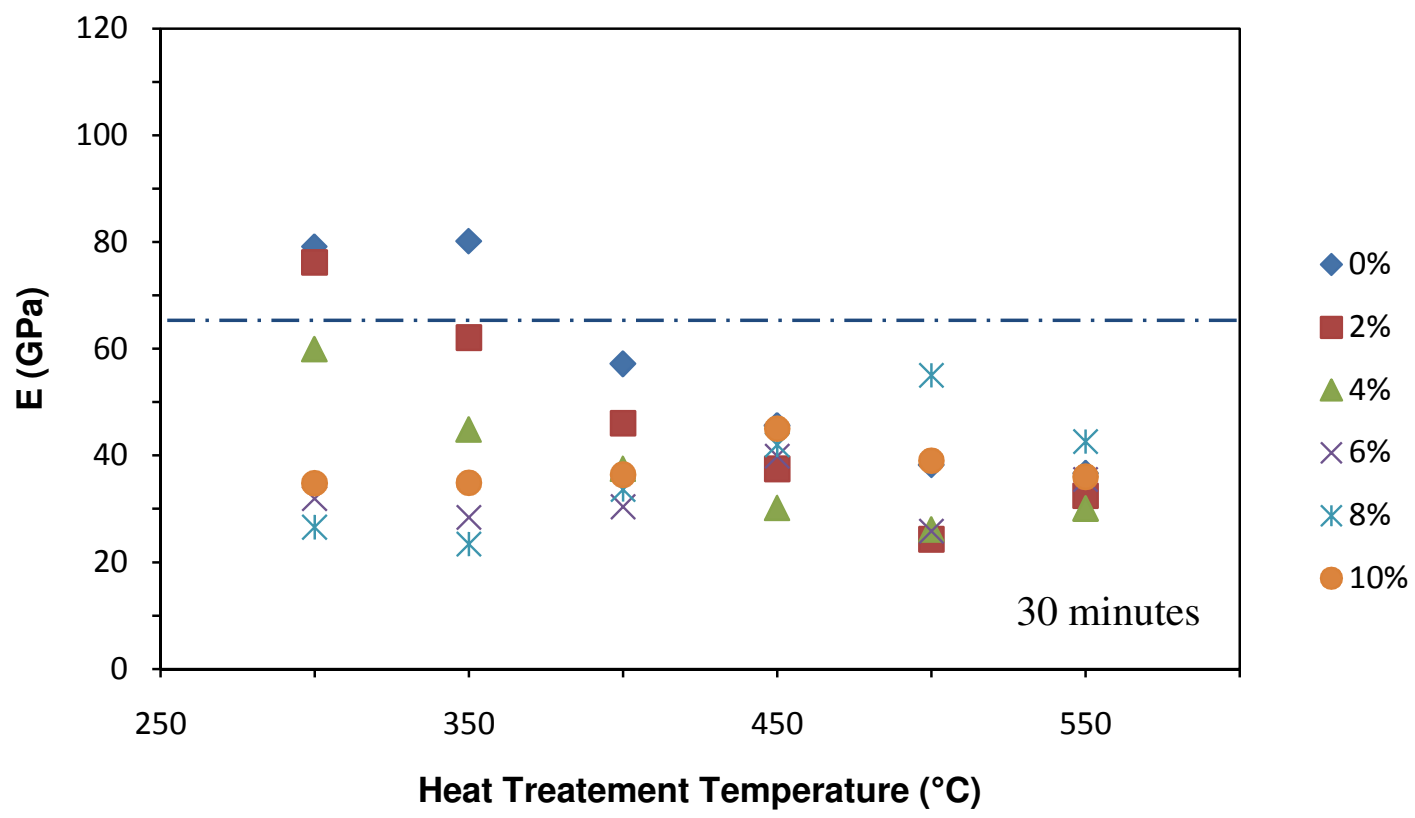

Figure 62 - Effect of applied strain and heat treatment temperature on the elastic modulus for specimen heat treated for 30 minutes. High levels of applied strain during heat treatment tend to decrease elastic modulus: note that this trend is not observed between heat treatment temperatures of $400-550{ }^{\circ} \mathrm{C}$. 
Graphs of elastic modulus versus heat treatment time were generated for each level of applied strain. Figures 63, 64, and 65 are diagrams of elastic modulus versus heat treatment time for specimens heat treated with 0,6 , and $10 \%$ applied strain, respectively. The diagrams illustrating the trends at 2, 4, and $8 \%$ are provided in Appendix X. A rapid increase in elastic modulus at short heat treatment times followed by a systematic decrease at longer times occurs between applied strains of 0-4\%, as shown in Figures 6365. Heat treatments above 6\% applied strain result in a rapid increase between 2-10 minutes for specimen heat treated between $450-550^{\circ} \mathrm{C}$. A rapid decrease occurs between $300-400^{\circ} \mathrm{C}$ for specimen heat treated at an applied strain of $6 \%$ or higher, illustrated in Figures 64 and 65 . The trends in elastic modulus are highly inconsistent primarily due to the test method used in this study. Uncoiling the wires caused pre-straining of the specimens. Therefore, the trends in mechanical properties should be interpreted as data for pre-strained wires rather than data for wire heat treated under an applied strain. 


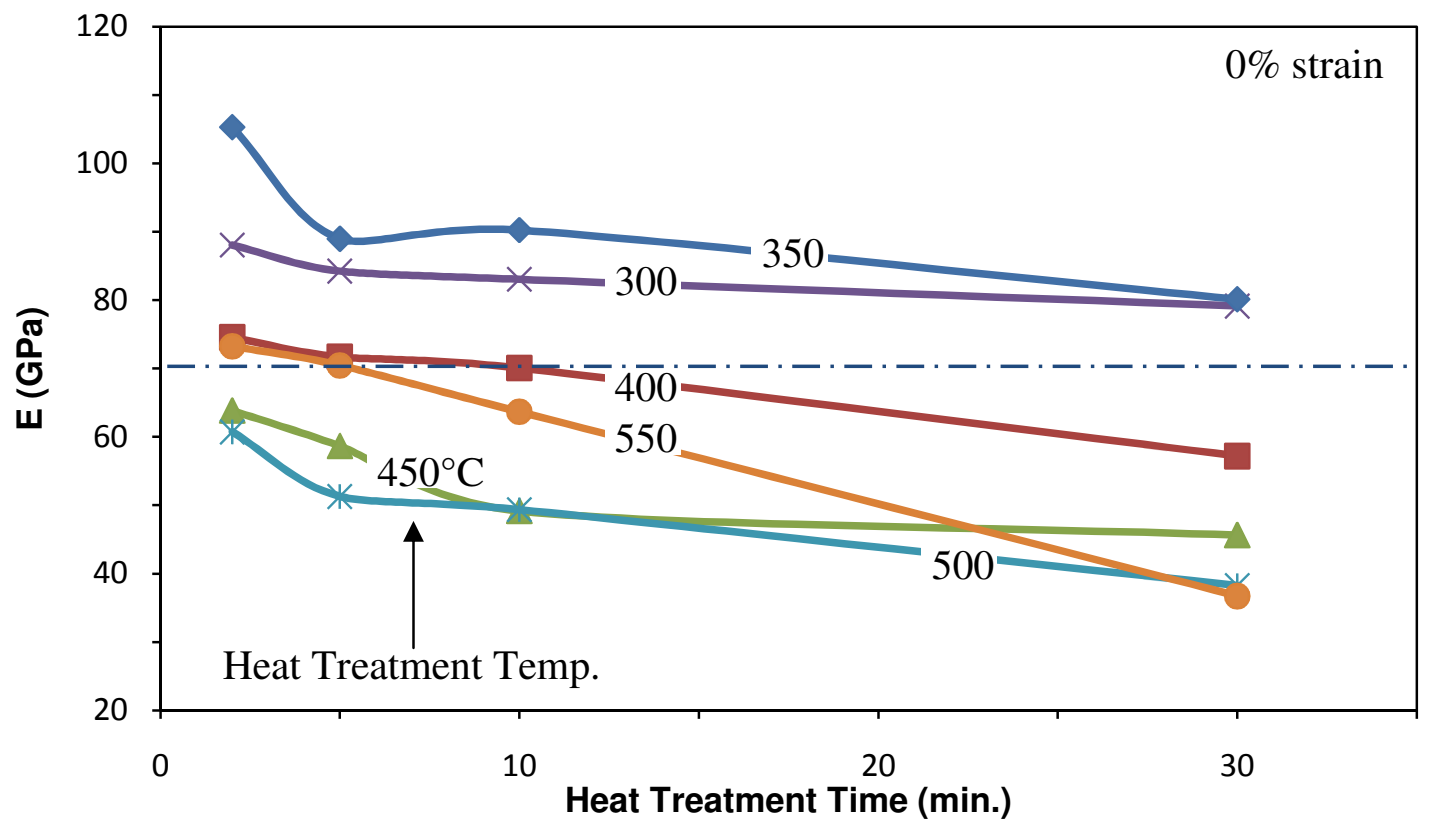

Figure 63 - Effect of heat treatment time and temperature on the elastic modulus for specimen heat treated at $0 \%$ applied strain. The blue dash line at $66 \mathrm{GPa}$ represents the elastic modulus of the asreceived wire. After a rapid increase in $\mathbf{E}$ at short times, all heat treatment temperatures tend to decrease elastic modulus with increasing heat treatment time.

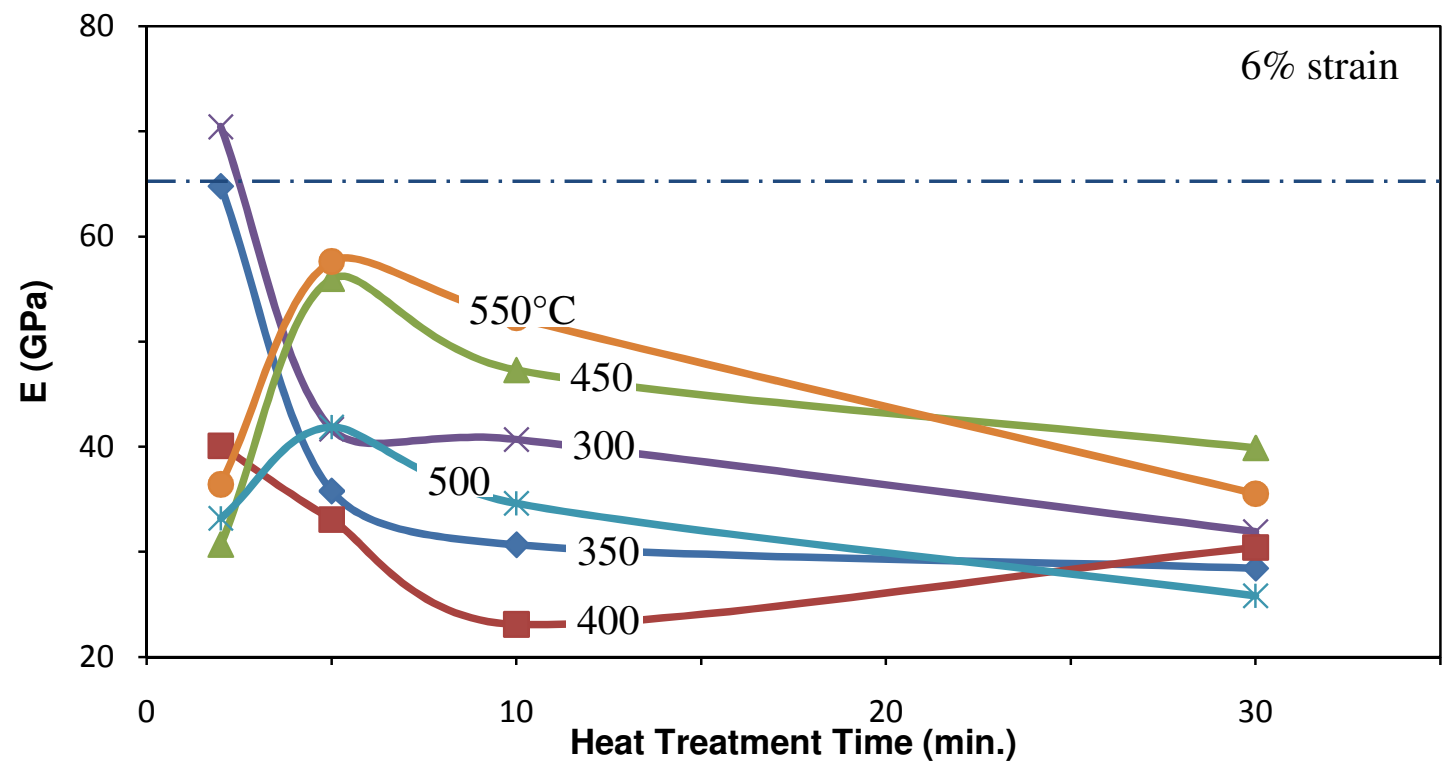

Figure 64 - Effect of heat treatment time and temperature on the elastic modulus of specimen heat treated at $6 \%$ applied strain. The blue dash line at 66 GPa represents the elastic modulus of the asreceived wire. A rapid decrease at short times followed by a rapid increase between 2-10 minutes occurs between $450-550^{\circ} \mathrm{C}$. A rapid decrease in elastic modulus occurs between $300-400^{\circ} \mathrm{C}$. 


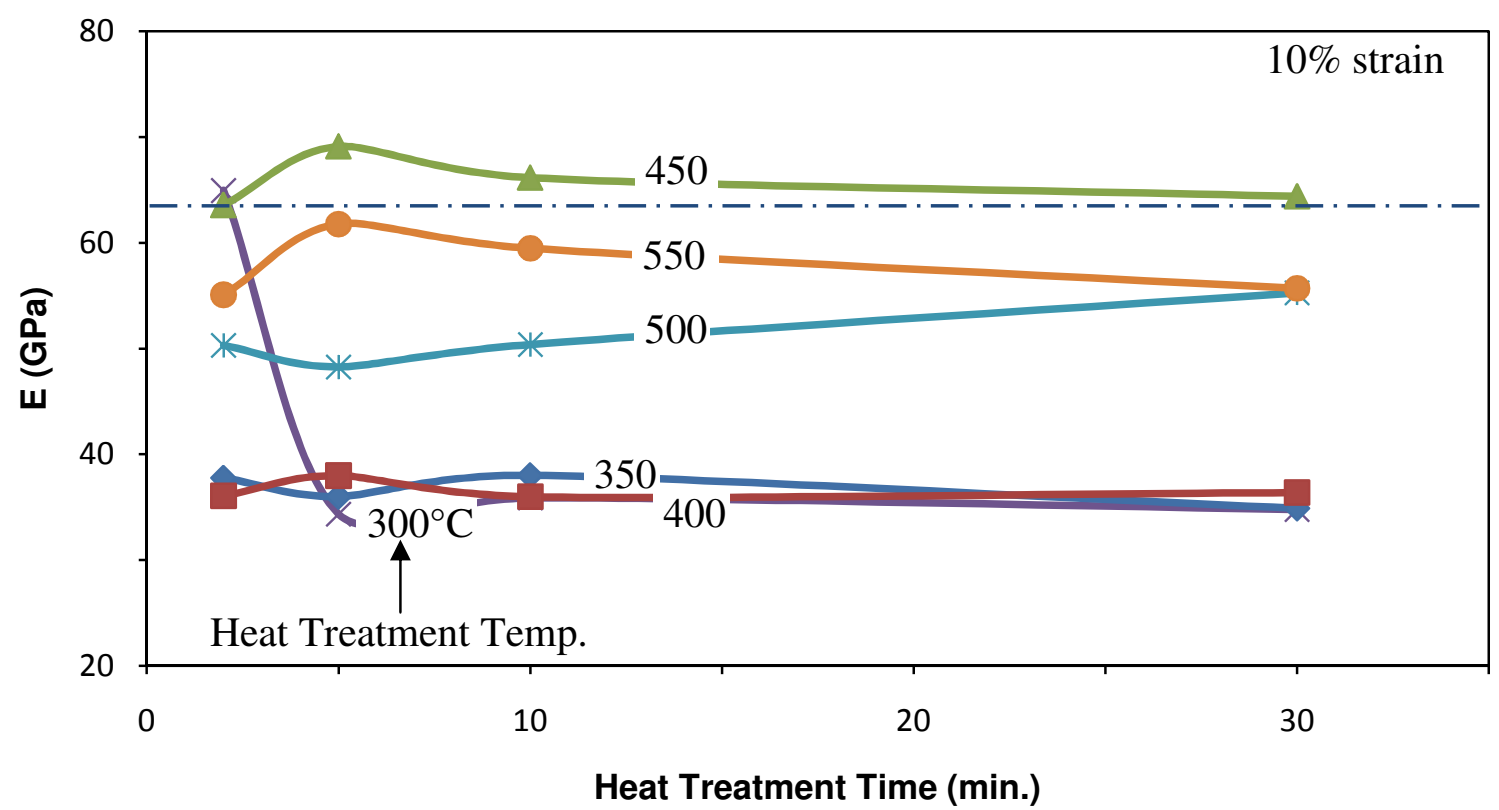

Figure 65 - Effect of time and temperature on the elastic modulus of specimen heat treated at $10 \%$ applied strain. The blue dash line at $66 \mathrm{GPa}$ represents the elastic modulus of the as-received wire. A rapid decrease in elastic modulus occurs at temperature between $300-400^{\circ} \mathrm{C}$. 


\subsection{Transformation Properties}

This section will discuss the trends in transformation properties due to applied strain and heat treatment. It will be separated into two sub-sections: Changes in $\mathrm{A}_{\mathrm{f}}$ and annealing effects. The goal of this discussion is to explain the interplay be tween the thermally activated processes of annealing and precipitation on NiTi wire heat treated under levels of applied strain.

\subsubsection{Changes in $\mathrm{A}_{\mathrm{f}}$}

The precipitation process observed in NiTi resulting in an increase in $\mathrm{A}_{\mathrm{f}}$ is well documented and commonly used in $A_{\mathrm{f}}$ tuning processes [17]. Heat treatments under no applied strain result in an increase in $\mathrm{A}_{\mathrm{f}}$ between temperatures of $300-450^{\circ} \mathrm{C}$ with increasing heat treatment time; $\mathrm{A}_{\mathrm{f}}$ does not significantly change at $300^{\circ} \mathrm{C}$. The maximum precipitation rate, indicating the temperature where the highest density of $\mathrm{Ni}_{4} \mathrm{Ti}_{3}$ precipitates is obtained, lies at approximately $400^{\circ} \mathrm{C}$. These results for specimen heat treated under $0 \%$ applied strain support previous studies conducted by Pelton et al. [7], who found the maximum precipitation rate in Ti-50.8 at.\% $\mathrm{Ni}$ wire to be centered near $450^{\circ} \mathrm{C}$.

All specimen heat treated with $0 \%$ strain resulted in the appearance of the R-phase, as illustrated by the endothermic DSC curves in Figures 30 and 31; at temperatures above 
$400^{\circ} \mathrm{C}$, a more defined presence of the R-phase is observed at longer heat treatment times. This is in agreement with Otsuka et al. [29, 30], who have reported R-phase stabilization for alloys of Ti-50.8 at.\% $\mathrm{Ni}$ aged at $400-500^{\circ} \mathrm{C}$. In this temperature regime, fine $\mathrm{Ni}_{3} \mathrm{Ti}_{2}$ precipitates are introduced during the aging process. These precipitates tend to introduce a stress within the lattice at longer heat treatment times, thereby suppressing the austenite to martensite transformation [31]. Between $300-400^{\circ} \mathrm{C}$, an increase in $\mathrm{A}_{\mathrm{f}}$ due to the formation of $\mathrm{Ni}_{4} \mathrm{Ti}_{3}$ precipitates tends to destabilize the martensite to austenite transformation and allows the R-phase transformation to occur [41].

As seen in Figures 32 and 33 between $300-450^{\circ} \mathrm{C}$, an increase in $A_{f}$ due to the formation of Ni-rich precipitates with increasing level of applied strain is observed throughout the samples. The effect of applied strain during heat treatment increases $\mathrm{A}_{\mathrm{f}}$ significantly at heat treatment temperatures between $300-350^{\circ} \mathrm{C}$. This trend of increased aging kinetics due to applied strain between heat treatment temperatures of $300-350^{\circ} \mathrm{C}$ was more visible at longer times. Applied strain has less of an effect at longer heat treatment times on the transformation temperature between $400-450^{\circ} \mathrm{C}$. The maximum precipitation rate for all levels of applied strain is found to be centered near $400^{\circ} \mathrm{C}$. As illustrated by the threedimensional TTT-like diagram in Figure 43, the reaction rates to achieve a particular $\mathrm{A}_{\mathrm{f}}$ occur faster for specimens under an applied strain during heat treatment. For instance, an $\mathrm{A}_{\mathrm{f}}$ of $40^{\circ} \mathrm{C}$ is achieved at approximately 15 minutes following a heat treatment at $400^{\circ} \mathrm{C}$ with no applied strain during heat treatment; that same $40^{\circ} \mathrm{C} \mathrm{A}_{\mathrm{f}}$ is achieved after aging for only 2 minutes at $10 \%$ applied strain. A significant increase in aging kinetics is observed with increasing level of applied strain. 
These results are consistent with previous studies by Poncin et al. [21], who attributed the increase in aging kinetics at temperatures between $300-450{ }^{\circ} \mathrm{C}$ to the formation of $\mathrm{Ni}_{3} \mathrm{Ti}_{2}$ and $\mathrm{Ni}_{4} \mathrm{Ti}_{3}$ precipitates preferentially aligned perpendicular to the applied stress. Coiling wire around a mandrel creates a tensile strain on the outer diameter of the coil, along with a compressive strain on the inner diameter of the coil. $\mathrm{Ni}_{3} \mathrm{Ti}_{2}$ precipitates form in coherent, lenticular shapes with the matrix [24], exerting an anisotropic stress field within its vicinity [27]. As a result, a compressive stress develops in the normal direction of the lenticular precipitates, as illustrated by the schematic in Figure 66. An applied stress during heat treatment has been shown to encourage the formation of $\mathrm{Ni}_{4} \mathrm{Ti}_{3}$ and $\mathrm{Ni}_{3} \mathrm{Ti}_{2}$ precipitates $[18,22,23]$. As the density of these precipitates increase during the precipitation process, a larger amount of stress is introduced to the lattice. This tends to increase the aging kinetics, as illustrated by the TTT-like diagrams in Figure 41 and 42, due to lattice expansion [18] to relax the internal stresses created by the anisotropic stress fields of the lenticular precipitates. An external stress has also been shown to affect the morphology and shape of these lenticular precipitates [27], increasing the driving force for aging kinetics. 


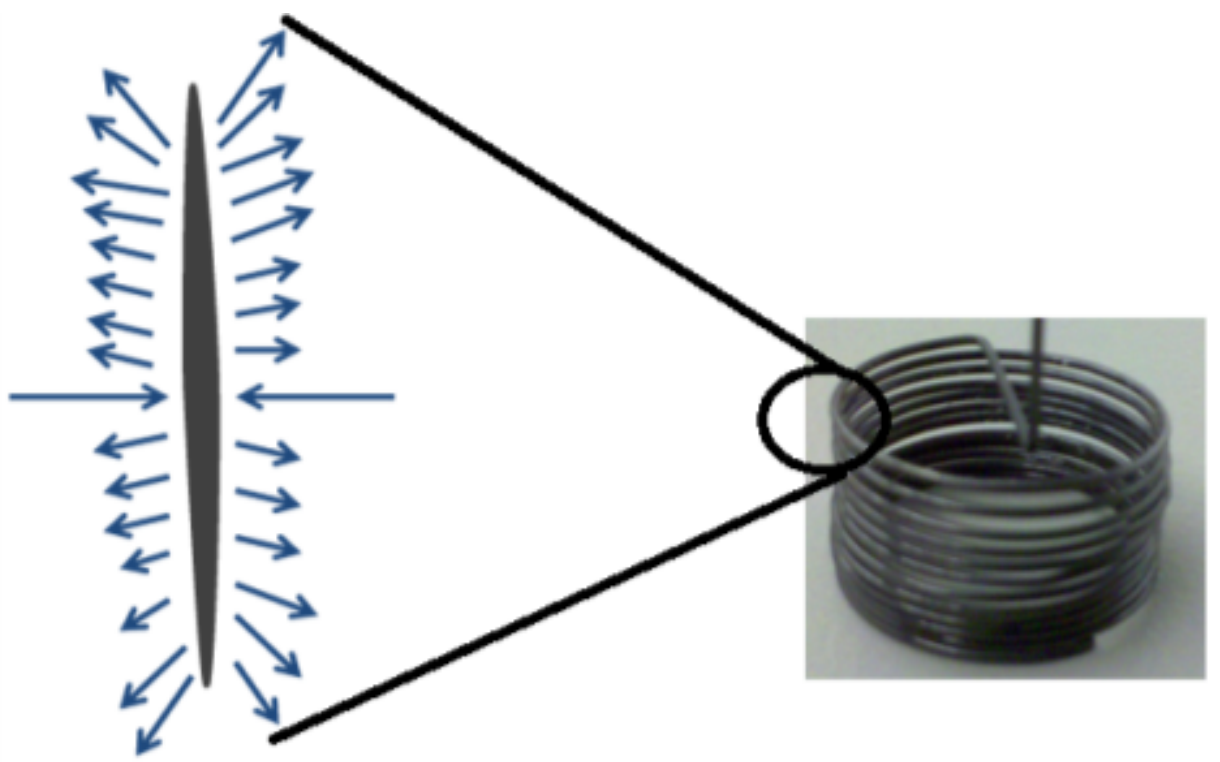

Figure 66 - Schematic of a lenticular precipitate, including an anisotropic stress field with a compressive stress in the normal direction, formed during stress-assisted aging. These lenticular precipitates form preferentially aligned to the external tensile stress and perpendicular to the external compressive stress. As the anisotropic stress field increases due to formation of $\mathrm{Ni}_{4} \mathbf{T i}_{3}$ precipitates, an increase in aging kinetics occurs to relax the internal stresses.

\subsubsection{Annealing Effects}

Annealing processes can be divided into three stages: recovery, recrystallization and grain growth. The recovery stage in annealing is primarily a low temperature process, where the main purpose is to relieve internal strains due to cold work or shape-setting [42]. In shape-setting, the recovery stage serves to relieve the tensile and compressive strains caused by coiling the wire around the mandrel. As the temperatures increases past the recovery stage, nucleation and growth of new strain-free grains occur [43]. In shapesetting, recrystallization of new strain-free grains replaces the elastically strained grains and allows the wire to conform to the corresponding mandrel. If annealing is allowed to continue once recrystallization has been completed, grain growth will occur, in which the microstructure begins to coarsen. Grain growth in annealing is primarily a high 
temperature process, where mechanical properties such as tensile strength and hardness generally decrease [44].

As illustrated by Figure 27, applied strain tends to encourage shape-setting behavior between heat treatment temperatures of $300-450^{\circ} \mathrm{C}$. Following heat treatments below $450^{\circ} \mathrm{C}$, shape-setting occurs for wires heat treated with applied strains above $4 \%$. According to Himmel, a larger amount of prior cold work, or internal strain, tends to decrease the recrystallization temperature. Higher levels of applied strain during heat treatment lower the recrystallization temperature and promote shape-setting, as illustrated in Figure 27. Wires heat treated below $450^{\circ} \mathrm{C}$ tend to conform less to the shape of the corresponding mandrel, indicating that the onset of recrystallization occurs at higher temperatures. Heat treatment above $500^{\circ} \mathrm{C}$ tends to encourage shape-setting behavior, while rapidly decreasing mechanical properties. This suggests that the onset on recrystallization, indicating the temperature range that new strain-free grains begin to nucleate and replace elastically deformed grains, must be between $450-500^{\circ} \mathrm{C}$. This is in agreement with previous studies conducted Drexel [3], who determined that the onset of recrystallization occurs between $450-475^{\circ} \mathrm{C}$.

A more defined presence of the R-phase, indicating the suppression of the austenite to martensite transformation, was observed at heat treatment temperatures above $500^{\circ} \mathrm{C}$ as illustrated in Figure 31. Also, the overall shape of the DSC curve does not significantly change with increasing heat treatment time or level of applied strain, indicating a smaller spread in $A_{f}$. A decrease in reaction rates occurs with increase in heat treatment 
temperature, due to the dominant effects of annealing. As illustrated in Figure 33, applied strain has no significant effect on $A_{f}$ increase between $500-550^{\circ} \mathrm{C}$. Since annealing effects dominate at higher temperatures, a significant decrease in the spread of $A_{f}$ values occurs. Heat treatments are typically conducted at approximately $500^{\circ} \mathrm{C}$ for short heat treatment times, where consistent transformation temperatures are obtained.

The appearance of the R-phase is also evident by the trends in $A_{f}$ seen between 500$550^{\circ} \mathrm{C}$. At $500^{\circ} \mathrm{C}$, applied strain has no significant effect on $\mathrm{A}_{\mathrm{f}}$ increase; heat treatment at $550^{\circ} \mathrm{C}$ results in an initial decrease in $\mathrm{A}_{\mathrm{f}}$ followed by a gradual increase as heat treatment time increases. This trend of an initial decrease at higher temperature is in agreement with previous studies by Pelton et al. [7], who established the initial drop in $A_{f}$ results from the dissolution of the $\mathrm{Ti}_{3} \mathrm{Ni}_{4}$ precipitates followed by the eventual formation of the $\mathrm{Ni}_{3} \mathrm{Ti}_{2}$ and $\mathrm{Ni}_{3} \mathrm{Ti}$ precipitates at longer times. Stabilization of the R-phase through heat treatments between $400-500^{\circ} \mathrm{C}$ have been investigated in greater detail by the work of Ren et al.[31]. According to Ren, the fine dispersion of $\mathrm{Ni}_{3} \mathrm{Ti}_{2}$ precipitates at higher heat treatment temperatures introduces stress to the lattice. As a result, this suppresses the austenite to martensite transformation, thereby exposing the intermediate R-phase. Between $500-550^{\circ} \mathrm{C}$, the trend of increasing $\mathrm{A}_{\mathrm{f}}$ with increased time or applied strain is not observed due to annealing effects and relaxation of stresses within the constrained sample. This results in a significant decrease in the spread of $A_{f}$ values, as illustrated in Figure 33-37. 


\subsection{Mechanical Properties}

To reiterate, the mechanical properties from this study should be interpreted as data for pre-strained wires, rather than data for wires heat treated with an applied strain. The goal of this study was to characterize the effects of applied strain and heat treatment on the mechanical properties of NiTi wire during shape-setting. However, the test method used in this study to characterize the mechanical properties of coiled wires is not ideal; tensile testing of coiled wires pre-strains the samples upon loading the specimen on the capstan grips. The wires were uncoiled and characterized using a tensile test, causing the samples that were heat treated with higher strain levels to fracture prematurely. In effect, this test method may lead to incorrect correlations between applied strain during shape-setting and the resulting mechanical properties. The following sections will explain the changes in tensile response, including UTS and elastic modulus, due to applied strain and heat treatment for pre-strained wires. It will be divided into two sub-sections: precipitation strengthening and annealing.

\subsubsection{Precipitation Strengthening}

The increase in UTS, as illustrated in Figures 55-57 for all levels of applied strain with increasing heat treatment time between $300-450^{\circ} \mathrm{C}$, results from precipitation strengthening. Since Ni-rich precipitates are coherent with the matrix, they act as effective dislocation barriers and thereby increase the strength of the wire. At lower temperatures, where annealing processes are not dominant, precipitation strengthening occurs more effectively. The maximum UTS, corresponding to the maximum 
precipitation of $\mathrm{Ni}_{4} \mathrm{Ti}_{3}$ and thereby the highest density of dislocation barriers, is observed between $400-450^{\circ} \mathrm{C}$ for all levels of applied strain as shown in Figure 52 and 53.

Precipitation strengthening, occurring between $300-450^{\circ} \mathrm{C}$, is not clearly illustrated by the stress-strain curves in Figures 45 and 46. The stress-strain curves illustrate a systematic decrease in UTS with increased level of applied strain. Admittedly, these trends of heat treatment and applied strain on the UTS appear to contradict the trend seen of increasing $\mathrm{A}_{\mathrm{f}}$ with increasing level of applied strain. Following the trends observed in Figures 32 and 33, an applied strain during heat treatment between temperatures of 300$450^{\circ} \mathrm{C}$ tends to increase the reaction rates and thereby the density of precipitates with increasing level of applied strain. In theory, an increase in UTS due to precipitation strengthening is expected with increasing level of applied strain. However, a decrease in UTS with increasing level of applied strain is observed. This is best explained by analyzing the test method used to characterize the mechanical properties. As applied strain during heat treatment increases, the wires are shape-set onto smaller mandrels. In effect, the spring constant (stored energy) of each coiled wire increases as the diameter of the mandrel decreases. As each wire was uncoiled and mounted onto the capstan grips during tensile testing, the wires that were shape-set on smaller mandrels (higher levels of applied strain) were pre-strained and fractured at a lower tensile stress.

The correlation between UTS and $\mathrm{A}_{\mathrm{f}}$ was investigated to illustrate how pre-straining the wires during tensile testing may have led to incorrect correlations between applied strain during heat treatment and the resulting UTS. As illustrated in Figures 58 and 59, for a 
given strain level the UTS increases, due to precipitation strengthening, with increasing transformation temperature following a heat treatment between $300-450^{\circ} \mathrm{C}$. Within each strain level between heat treatments of $300-450^{\circ} \mathrm{C}$, the amount of precipitates increases with increased heat treatment time. As demonstrated by Favier et al. [18], an applied stress during heat treatment increases the ageing kinetics. In theory, the UTS is expected to increase with increasing level of applied strain during shape-setting due to the formation of Ni-rich precipitates and precipitation strengthening. However, testing coiled wires using a uniaxial tensile test caused pre-straining and led to the wires fracturing at a lower tensile stress.

A decrease in elastic modulus with increasing level of applied strain and heat treatment time is observed between $300-400^{\circ} \mathrm{C}$; this trend is highly inconsistent with increasing heat treatment temperature. Within each level of applied strain, higher $A_{f}$ values tend to correlate to larger UTS values. These results are indeed counterintuitive, suggesting that an increase in $A_{f}$ results in a higher elastic modulus. The correlation between UTS and $A_{f}$ is highly inconsistent between $500-550^{\circ} \mathrm{C}$ for all levels of applied strain, further adding to the discrepancy of the data obtained for the elastic modulus. Pre-straining of the wires may have caused such large inconsistencies in elastic modulus during the tensile tests. The devised SOP was based on a coiled wire with an $\mathrm{A}_{\mathrm{f}}$ in the austenite phase at room temperature heat treated at $550^{\circ} \mathrm{C}$ with an applied strain of $10 \%$. Each coil was subjected to a pre-load of $30 \mathrm{~N}$ in order to keep the wire in tension during the tensile test. Wires that were heat treated with higher levels of applied strain have a higher spring constant (stored 
energy). As a result, the wires that were heat treated with higher levels of applied strain tend to have a lower elastic modulus due to the initial $30 \mathrm{~N}$ load.

\subsubsection{Annealing}

Annealing processes are not clearly illustrated by the stress-strain curves in Figures 42-

47. Tensile curves for specimen heat treated between $500-550^{\circ} \mathrm{C}$ illustrate that superelastic behavior is not exhibited; in actuality, all specimen heat treated between 500$550^{\circ} \mathrm{C}$ are primarily in the austenite phase with an average $\mathrm{A}_{\mathrm{f}}$ of $15^{\circ} \mathrm{C}$. The stress induced phase transformation is observed at applied strains of $0-4 \%$ following a heat treatment of $500-550^{\circ} \mathrm{C}$. Note that the lower plateau upon unloading is not observed, a characteristic seen for specimens in the martensite phase. However, this observation is not a valid interpretation of the stress hysteresis. Investigating the SOP used in this study helps to validate and assess this observation. The standard operating procedure, based on preliminary tensile tests of wire heat treated at $550^{\circ} \mathrm{C}$ for 30 minutes, dictates that an unloading stress of $60 \mathrm{MPa}$ is required to prevent the wire from losing tension during the unloading cycle. However, an unloading stress of $60 \mathrm{MPa}$ is high enough to prevent the reversible phase transformation from martensite to austenite in superelastic NiTi. This explains why a complete stress hysteresis was not observed for specimen in the austenite phase. 


\section{CHAPTER SEVEN \\ CONCLUSION}

The goal of this study was to investigate effects of applied strain and heat treatment on the properties of NiTi wire during shape setting. An increase in aging kinetics has been observed with increasing levels of applied strain between heat treatment temperatures of $300-450^{\circ} \mathrm{C}$. A three-dimensional TTT-like diagram illustrates a systematic shift to the left, indicating faster reaction times with increased level of applied strain. The effects of applied strain are more significant at low temperatures and are less significant at temperatures above $500^{\circ} \mathrm{C}$ due to annealing effects.

A standard operating procedure and custom capstan grips were developed in an attempt to characterize the mechanical properties of NiTi wire using crosshead displacement, rather than an extensometer, to measure engineering strain. Due to precipitation strengthening, an increase in UTS with increased heat treatment time was observed between $300-450^{\circ} \mathrm{C}$; annealing processes dominate at higher temperatures, resulting in a decrease in UTS above $500^{\circ} \mathrm{C}$. A positive correlation between UTS and $\mathrm{A}_{\mathrm{f}}$ was found between $300-450^{\circ} \mathrm{C}$ within each level of applied strain. A decrease in UTS with increased level of applied strain was observed; after further investigation, it was theorized that the test method used in this study contributed to the misleading correlations between applied strain during shape-setting and the resulting mechanical properties. As the samples are uncoiled and mounted on the capstan grips the wires are pre-strained, causing the wire to fracture at a lower tensile stress with increased level of applied strain during shapesetting. Elastic modulus was difficult to measure and obtain any reliable trends; 
inconsistencies were observed throughout all samples. Heat treatments at $500^{\circ} \mathrm{C}$ and short times result in the least variability in transformation and mechanical properties. In the medical device industry, precise control of the mechanical and thermal properties of NiTi is necessary. In this study, the $\mathrm{A}_{\mathrm{f}}$ and UTS have been shown to vary significantly between $300-450^{\circ} \mathrm{C}$ following heat treatments at short times. Depending on the composition and the desired $\mathrm{A}_{\mathrm{f}}$, process engineers can apply a heat treatment at approximately $500^{\circ} \mathrm{C}$ to obtain reproducible properties.

The results in this study were successful in characterizing the general trends in the properties of NiTi wire due to an applied strain during heat treatment; this study does not necessarily provide a processing guide prescribing optimal strain levels. An increase in aging kinetics was observed, indicating that the reaction rates to achieve a particular $\mathrm{A}_{\mathrm{f}}$ might be faster than expected if the sample is under strain during the shape-setting process. All factors, including changes in composition, levels of initial cold work and the addition of an applied stress, must all be considered when processing and applying a heat treatment to NiTi wire. Ultimately it is the understanding of the interplay between annealing and precipitation processes that will assist in $\mathrm{A}_{\mathrm{f}}$ and mechanical properties tuning. 


\section{CHAPTER EIGHT \\ RECOMMENDATIONS FOR FUTURE WORK}

This study successfully characterized the trends in $\mathrm{A}_{\mathrm{f}}$ due to an applied strain and heat treatment during the shape-setting of NiTi wire. However, due to the test method used in this study, the trends in mechanical properties due to an applied strain and heat treatment during shape-setting were not successfully characterized. Since the wires were shape-set into coils, measuring the spring constant of each heat treated wire would have been a better method to characterize the trends in mechanical properties. Each wire can be mounted on a tensile tester equipped with a load cell of approximately $50 \mathrm{~N}$. By measuring the displacement due to an applied load, the spring constant and shear modulus can be calculated.

However, as discussed in Chapter 6, section 1.2 of this report, wires that were heat treated below $450^{\circ} \mathrm{C}$ for short times shape-set less to the corresponding mandrel size, resulting in coils that were shape-set on the same size mandrel to have different diameters. This adds variability and difficulty in relating the spring constant of each coil to the shear modulus based on heat treatment and applied strain. Future studies may investigate the effects of applied strain at a narrower heat treatment temperature range, such as $475-550^{\circ} \mathrm{C}$, where recrystallization occurs. NiTi components are typically heat treated at approximately $500^{\circ} \mathrm{C}$ for short times. Therefore, future studies can select small heat treatment time and temperature intervals to investigate the effects of applied strain during shape-setting on the mechanical properties of NiTi wire in a range that is typically used in industry. 
This study investigated the effects of applied strain during heat treatment for times of 2 , 5, 10 and 30 minutes. As demonstrated in Chapter 6, an applied strain during heat treatment increases the ageing kinetics considerably following a heat treatment time of only 2 minutes. In this study, it was difficult to capture the rapid increase in $A_{f}$ due applied strain at short times. Smaller heat treatment time intervals, such as increments of 30 seconds, may be investigated to better characterize the rapid increase in $\mathrm{A}_{\mathrm{f}}$ due to applied strain. 


\section{REFERENCES}

[1] Isaac Mayo and George B. Kauffman, "The Story of Nitinol: The Serendipitous Discovery of the Memory Metal and Its Applications," The Chemical Educator, vol. 2, pp. 1-21, 1997.

[2] D. Stockel, A.R. Pelton, and T.W. Duerig, "Medical Uses of Nitinol," Materials Science Forum, vol. 327, pp. 63-70, 2000.

[3] D.J. Masao and A.R. Pelton, "The Effects of Cold Work and Heat Treatment on the Properties of Nitinol Wire," Proceedings of the International Conference on Shape Memory and Superelastic Technologies, pp. 447-454, 2006.

[4] A.R. Pelton, T.W. Duerig, and D. Stockel, "An Overview of Nitinol Medical Applications," Materials Science and Engineering, pp. 149-160, 1999.

[5] R. Zadno and T.W. Duerig, "An Engineer's Perspective of Psuedoelasticity," Engineering Aspects of Shape Memory Alloysm, pp. 369-393, 1990.

[6] RGB-154N, "Smart Materials: A Technology and Market Assessment," vol. 35, 2006.

[7] S.M. Russell, A.R. Pelton, and J. DiCello, "The Physical Metalllurgy of Nitinol for Medical Applications," pp. 21-35, 2003.

[8] M.H. Wu, R.J. Biermann, and D.E. Hodgson, "Shape Memory Alloys," ASM Handbook, vol. A2, pp. 897-902, 2000.

[9] A.J. Graeme and P. Udomsilp, "How Do Martensite Twins Move," University of Edinburgh Department of Physics and Astronomy, 2002.

[10] W.J. Buehler, F.E. Wang, and S.J. Pickart, "Crystal Structure and a Unique "Martensitic" Transition of TiNi," vol. 36, pp. 3232-3239, 1965.

[11] C. Pfeiffer, M. Mosley, and C. Mavrodis, "Conventional Actuators, Shape Memory Alloys, and Electroheological Fluids," 1998.

[12] C.M. Wayman, "Shape Memory Alloys," vol. 18, pp. 49-56, 1993.

[13] K.N. Melton, "Ni-Ti Based Shape Memory Alloys," pp. 21-35, 1990.

[14] S.M. Russell, "Nitinol Melting and Fabrication," pp. 1-10, 2001. 
[15] C.M. Wayman, T. Honma, and M. Nishida, "Precipitation Processes in NearEquiatomic TiNi Shape Memory Alloys," vol. 17A, pp. 1505-1515, 1986.

[16] "Equilibrium Phase Diagram for Nickel Titanium," 2009.

[17] A.R. Pelton, "Optimization of Processing and Properties of Medical Grade Nitinol Wire," vol. 9, pp. 107-118, 2000.

[18] Y. Liu, D. Favier, L. Orgeas, A. Sandel, L. Debove and P. Comte-Gaz, "Influence of Thermomechancial Processing on the Superelastic Properties of a Ni-rich Nitinol Shape Memory Alloy," vol. A 429, pp. 130-136, 2006.

[19] L. Orgeas, D. Favier, D. Ferrier, P. Poncin and Y. Liu, "Influence of Manufacturing Methods on the Homogeneity and Properties of Nitinol Tubular Stents," vol. 11, pp. 541-546, 2001.

[20] A.R. Pelton, X.Y. Gong, T.W. Duerig, N. Rebelo and K. Perry, "Finite Element Analysis and Experimental Evaluation of Superelastic Nitinol Stent."

[21] D. Favier, P. Poncin, L. Orgeas and Y. Liu, "Nitinol Self-expanding Tubular Devices," pp. 477-486, 2000.

[22] M.C. Carroll, J. Michutta, A. Yawny, C. Somsen, K. Neuking and G. Eggeler, "Martensitic Phase Transformation in Ni-rich NiTi single Crystals with One Family of Ni4Ti3 Precipitates," vol. A 378, pp. 152-156, 2004.

[23] J.E. Bidaux, R. Gotthardt, and L. Bataillard, "Interaction between Microstructure and Multi-step Transformation in Binary NiTi alloys using in-situ Transmission and Electron Microscopy Observations," vol. 78, pp. 327-344, 1998.

[24] K. Otsuka, K. Shimizu, and T. Tadaki, "Shape Memory Alloys," vol. 18, pp. 2545, 1998.

[25] R. Kainuma, M. Matsumoto, and T. Honma, "The Mechanism of the all-round Shape Memory Effect in a Ni-rich TiNi Alloy," pp. 717-722, 1987.

[26] G. Eggeler, O. Bojda, and A. Dloughy, "Precipitation of $\mathrm{Ni}_{4} \mathrm{Ti}_{3}$-variants in a polycrystalline Ni-rich NiTi Shape Memory Alloy," vol. 53, pp. 99-104, 2005.

[27] D.Y. Li, "Morphological Evolution of Coherent $\mathrm{Ti}_{11} \mathrm{Ni}_{14}$ Precipitates under Inhomogeneous Stresses," vol. 79, pp. 2603-2616, 1999.

[28] Y. Wang, X. Liu, D. Yang, and M. Qi, "The Effect of Ageing Treatment on Shape-setting and Superelasticity of a Nitinol Stent," vol. 59, pp. 402-406, 2008. 
[29] Y. Liu, S. Miyazaki, and J.I. Kim, "Ageing-induced Two-stage R-phase Transformation in Ti-50.8at.\%Ni," vol. 52, pp. 487-499, 2004.

[30] K. Otsuka, "Introduction of the R-Phase Transition," pp. 36-45, 1990.

[31] N. Miura, X. Ren, J. Zhang, K. Otsuka, K. Tanaka, M. Koiwa, T. Suzuki, Y. Chumlykov and J. Asai, "A Comparative Study of Elastic Constraints of Ti-Ni based Alloys Prior to Martensitic Transformation," pp. 196-206, 2001.

[32] "www.jmmedical.com," in Johnson Matthey Medical - Nitinol Technical Properties, ed.

[33] EFunda: Engineering Fundamentals. (5 June 2009). Thermal Expansion of Tool Steel W1.

[34] G.E. Dieter, Handbook of Workability and Process Design: ASM International, 2003.

[35] Q.D. Mehrkam, "An Introduction to Salt Bath Heat Treating," 1997.

[36] "ASTM F 2004-05 Standard Test Method for Transformation Temperature of Nickel-Titanium Alloys by Thermal Analysis."

[37] ASTM, "Standard Test Method for Tension Testing of Nickel-Titanium Superelastic Materials," 2007.

[38] Instron, "Cord Capstan Grips," in Instron Materials Testing, ed.

[39] Wyoming Test Fixtures Inc., "Capstan Grips," in Wyoming Test Fixtures Inc., ed.

[40] NDC, "Nitinol SE508 Wire - Material Data Sheet."

[41] A. R. Pelton, Private Communication June 2010.

[42] L. Himmel, "Recovery and Recrystallization of Metals," Gordon and Breach N.Y., 1963.

[43] William Callister, Ed., Material Science and Engineering: An Introduction. p.^pp. Pages.

[44] Nix and Tetelman Barrett, "The Principles of Engineering Materials," PrenticeHall, N.Y., 1972. 


\section{APPENDIX I \\ MATERIAL DATA SHEET}

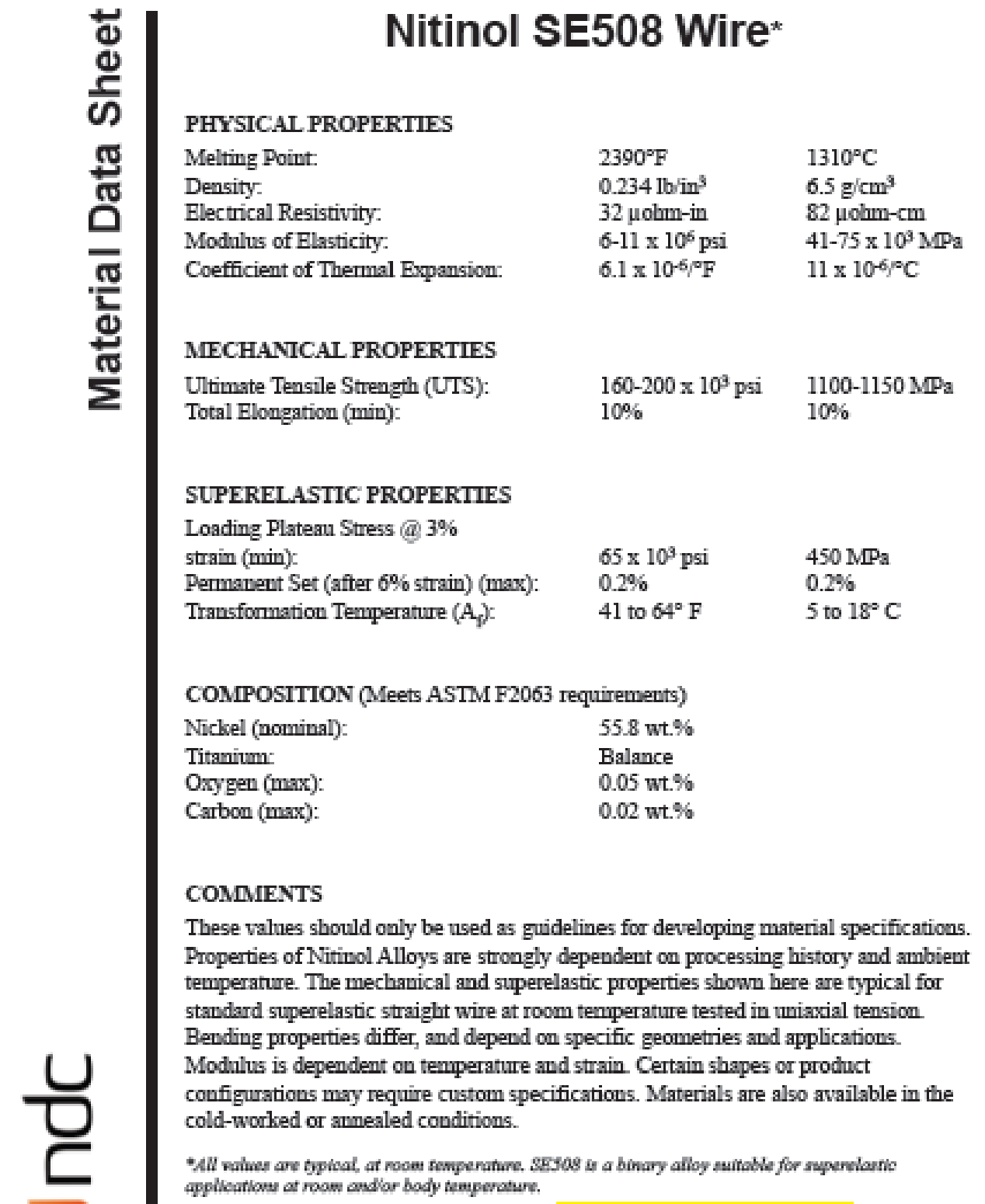

lot \#: 106771-B1A1

Nitinol Devices s Components * 47533 Westinghouse Drive * Fremont, Calfornla 94539 (510) 683-2000 - Fax: (510) 683-2100 * sales Qhitinol.com * wwwitinal.com 


\section{APPENDIX II \\ EFFECT OF APPLIED STRAIN AND HEAT TREATMENT ON Af AT 300 AND $500^{\circ} \mathrm{C}$}

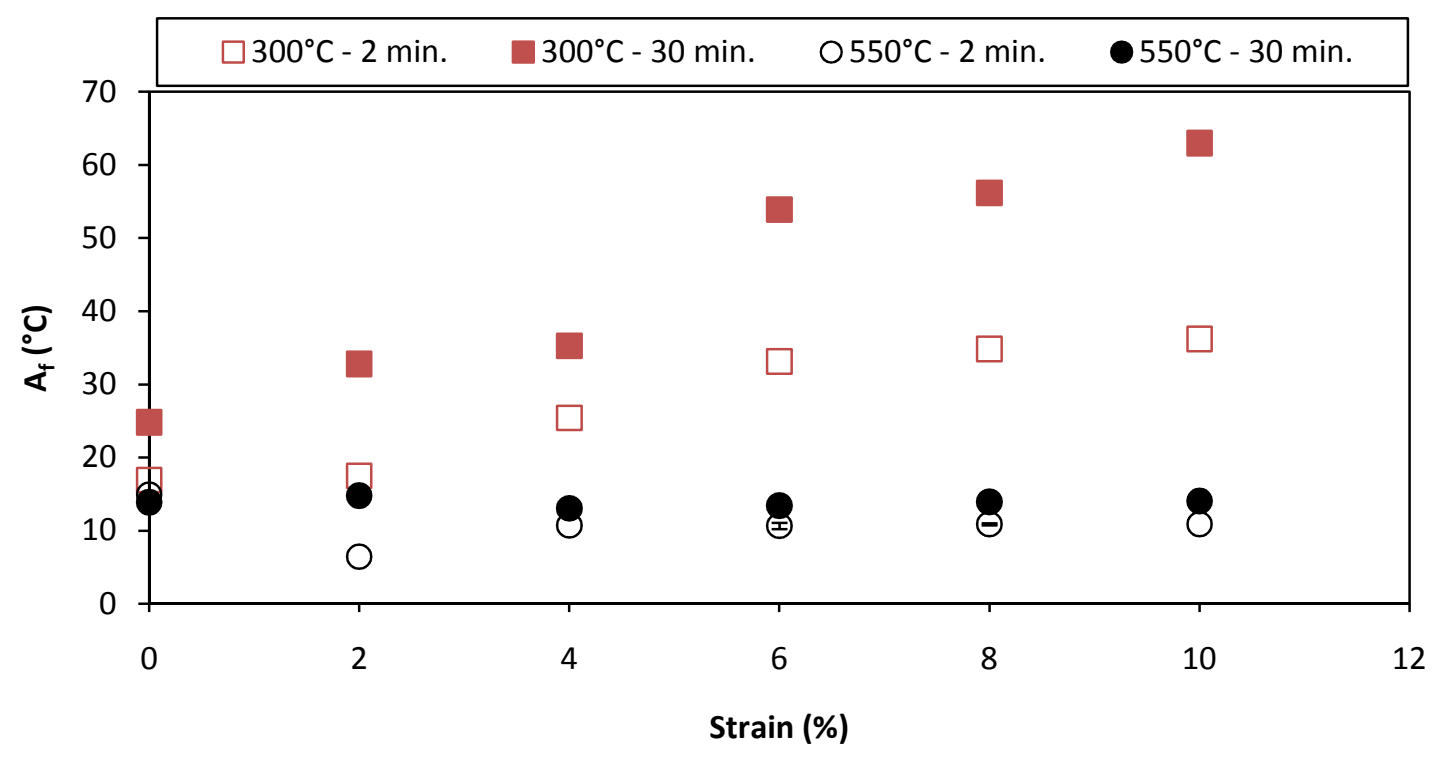

Figure 67 - Effect of applied strain and heat treatment $300550^{\circ} \mathrm{C}$ for 2 and 30 minutes. A systematic increase in $A_{f}$ with increased level of applied strain and heat treatment time occurs at $350^{\circ} \mathrm{C}$. Applied strain and heat treatment time have no significant effect on $A_{f}$ increase at $550^{\circ} \mathrm{C}$. 


\section{EFFECT OF HEAT TREATMENT ON AF AT APPLIED STRAINS OF 2-8\%}

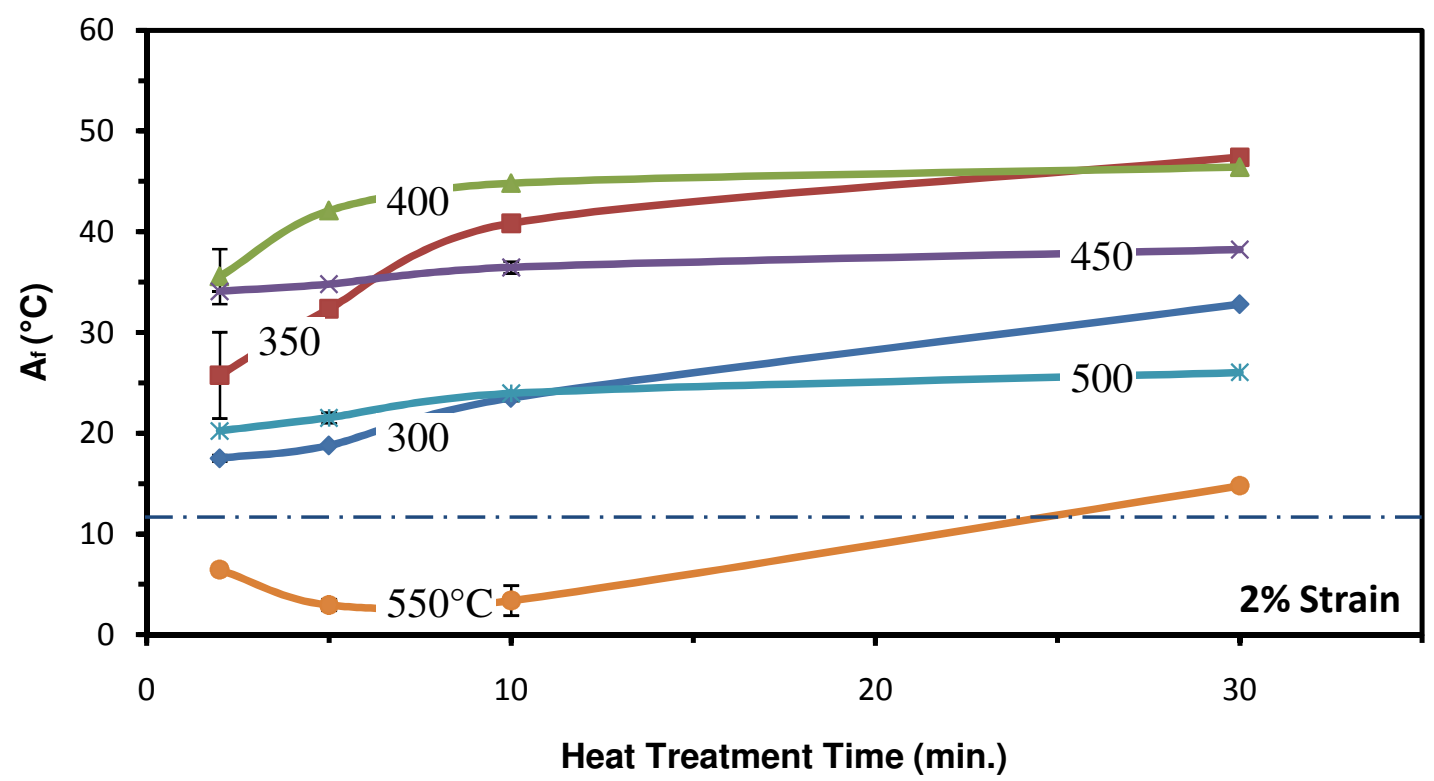

Figure 68 - Effect of heat treatment temperature and time on the transformation temperature of NiTi wire under a strain of $2 \%$ with a starting $A_{f}$ of $11{ }^{\circ} \mathrm{C}$. Note that all heat treatment temperatures tend to increase the $\mathbf{A}_{\mathrm{f}}$ with increasing time.

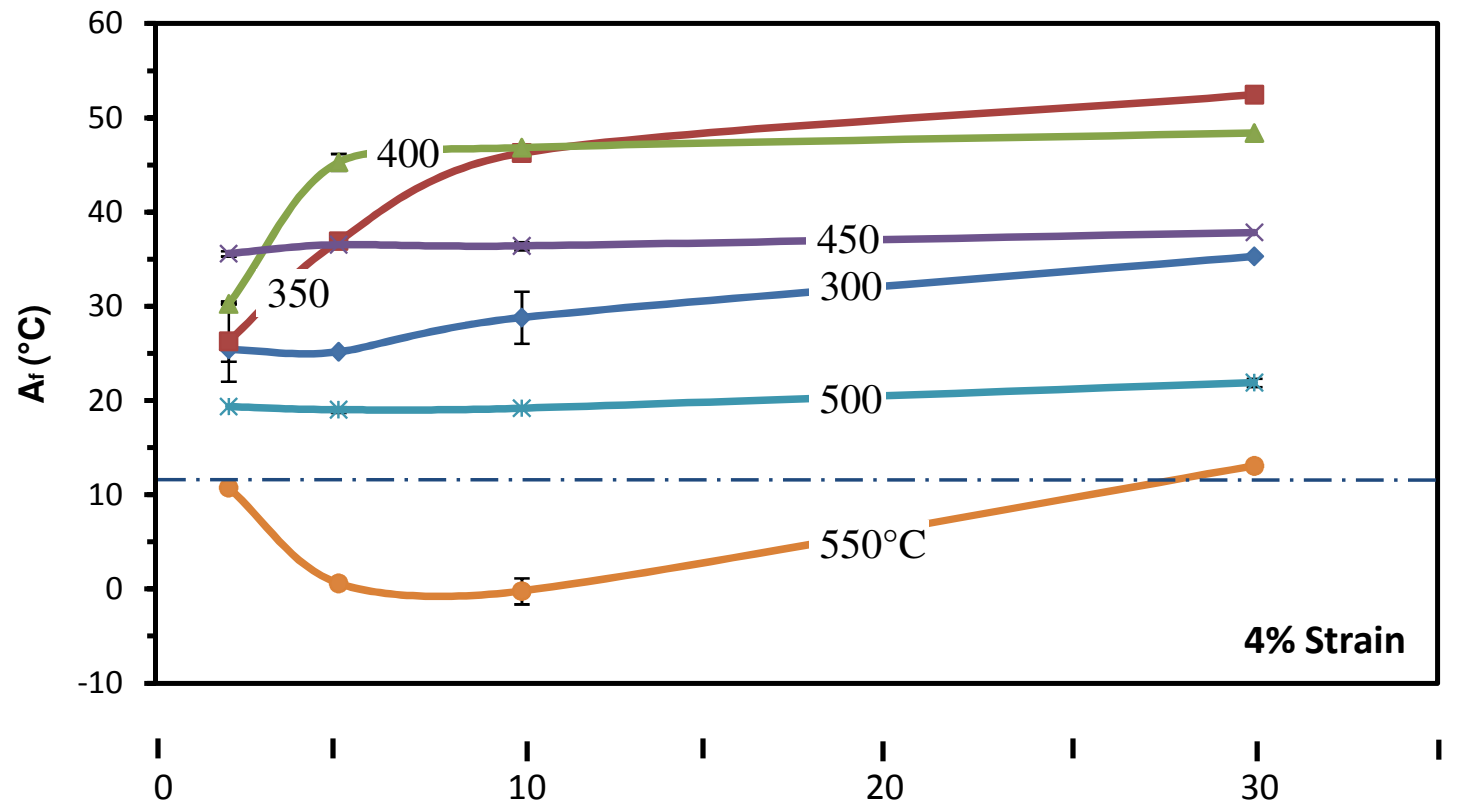

Figure 69 - Effect of heat treatment temperature and time on the transformation temperature of NiTi wire under a strain of $4 \%$ with a starting $A f$ of $11^{\circ} \mathrm{C}$. 


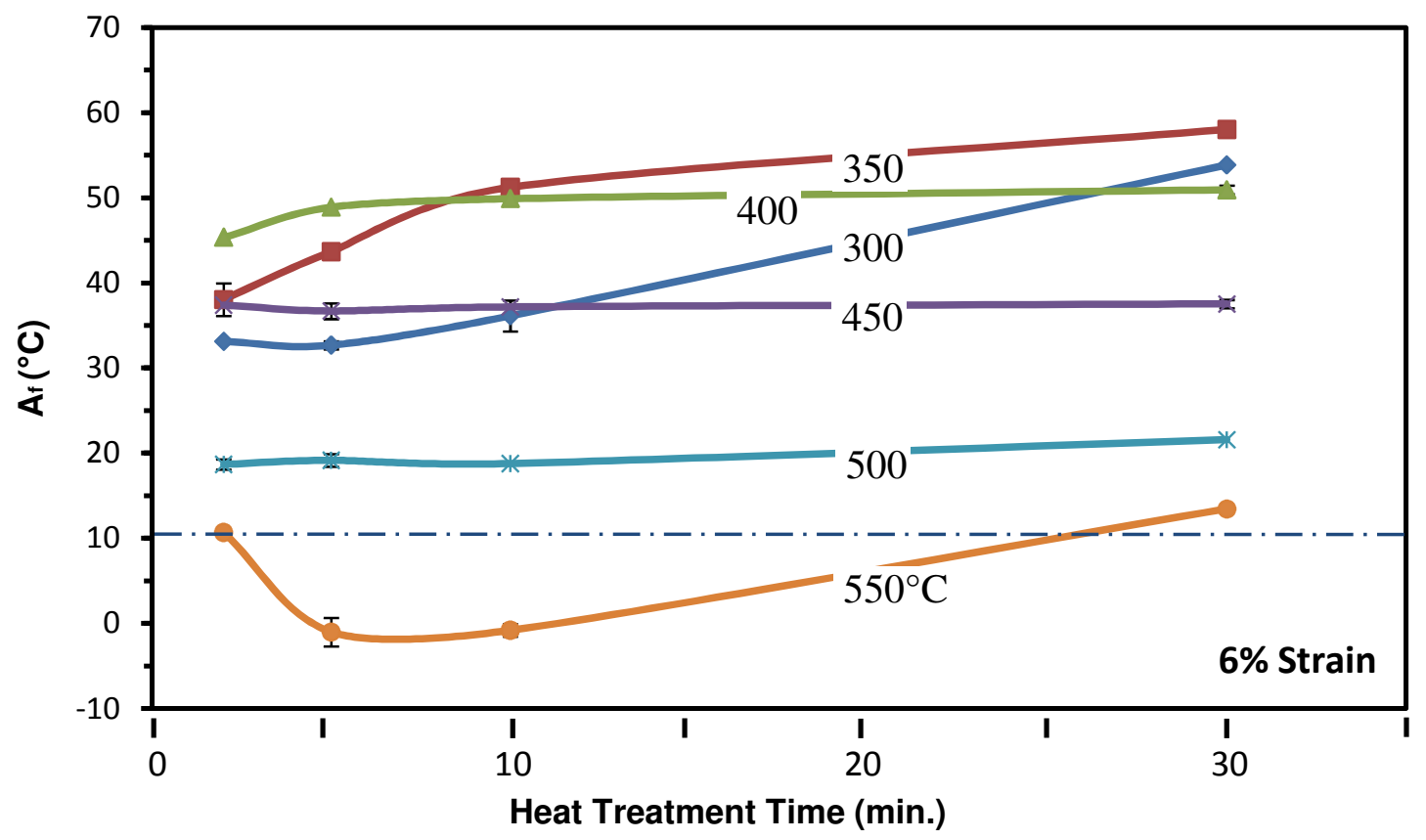

Figure 70 - Effect of heat treatment temperature and time on the transformation temperature of NiTi wire under a strain of $6 \%$ with a starting $\mathrm{Af}$ of $11^{\circ} \mathrm{C}$.

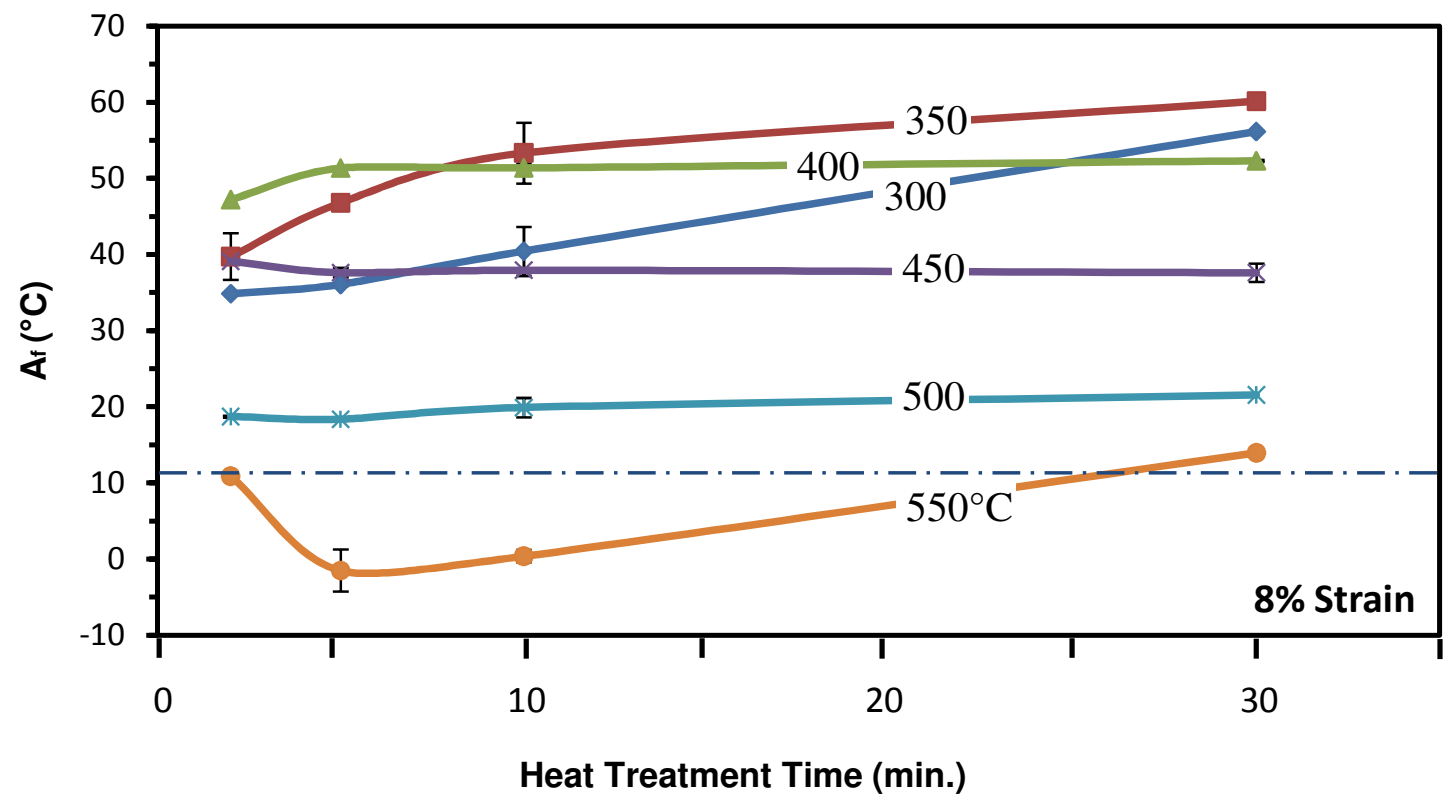

Figure 71 - Effect of heat treatment temperature and time on the transformation temperature of NiTi wire under a strain of $8 \%$ with a starting $\mathrm{Af}$ of $11^{\circ} \mathrm{C}$. Note that all heat treatment temperatures tend to increase the Af with increasing time. 
TTT-LIKE DIAGRAMS FOR APPLIED STRAINS OF 2-8\%

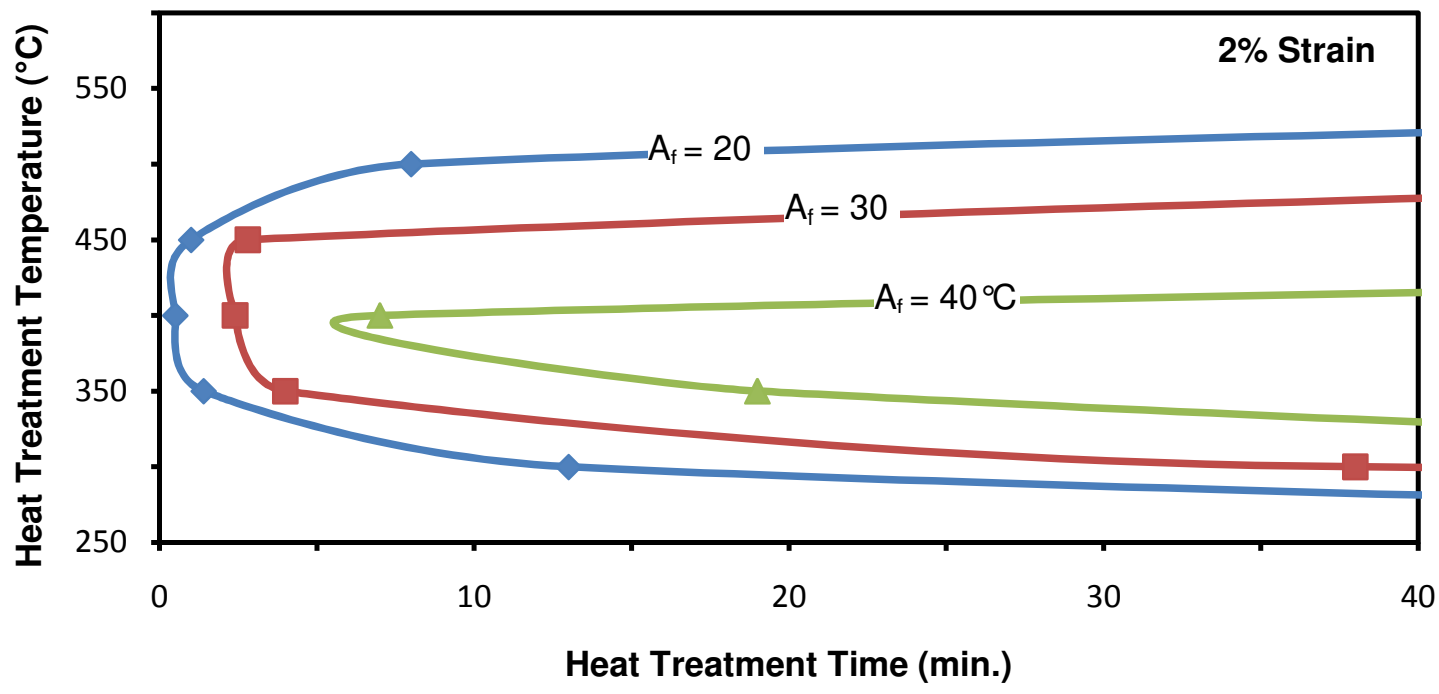

Figure 72 - TTT-like diagram illustrating the effects of heat treatment temperature and time for specimen heat treated at $2 \%$ strain. The maximum precipitation rate occurs at approximately $400^{\circ} \mathrm{C}$. A systematic shift to the left, indicating faster reaction times, is observed as compared to a specimen heat treated at $0 \%$ applied strain.

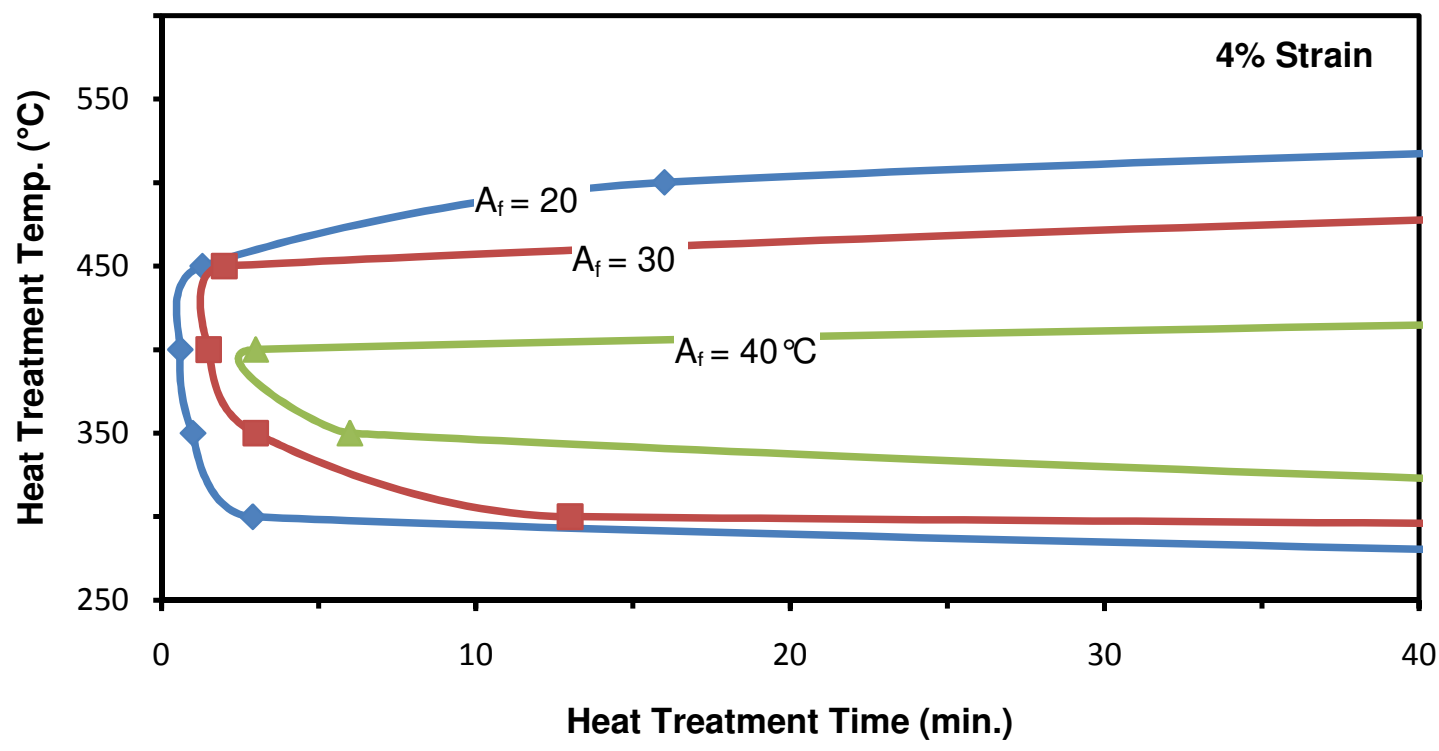

Figure 73 - TTT-like diagram illustrating the effects of heat treatment temperature and time for specimen heat treated at $4 \%$ strain. The maximum precipitation rate occurs at approximately $400^{\circ} \mathrm{C}$. Faster reaction times are observed to achieve an $A_{f}$ of $40^{\circ} \mathrm{C}$. 


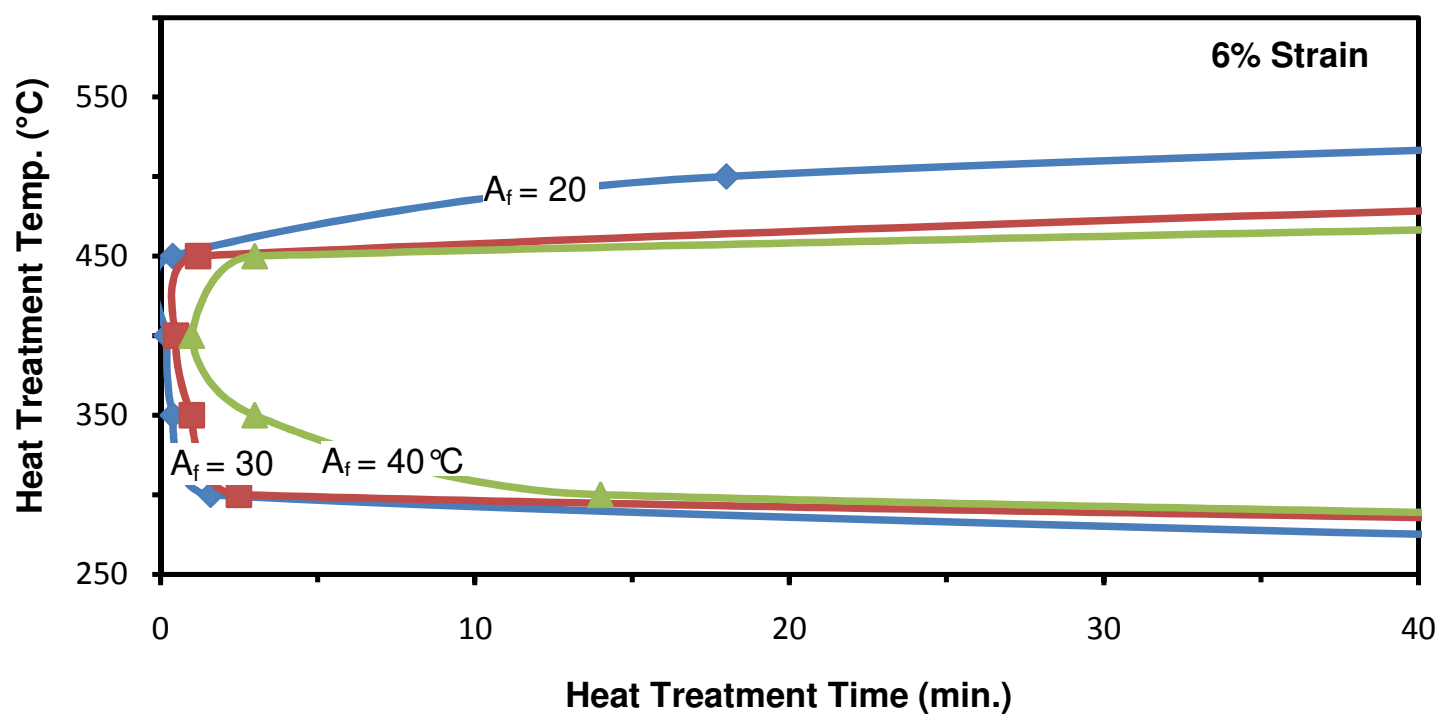

Figure 74 - TTT-like diagram illustrating the effects of heat treatment temperature and time for specimen heat treated at $6 \%$ strain. The maximum precipitation rate occurs at approximately $400^{\circ} \mathrm{C}$. All three c-curves has significantly shifted to the left, indication increased kinetics during heat treatment under an applied strain.

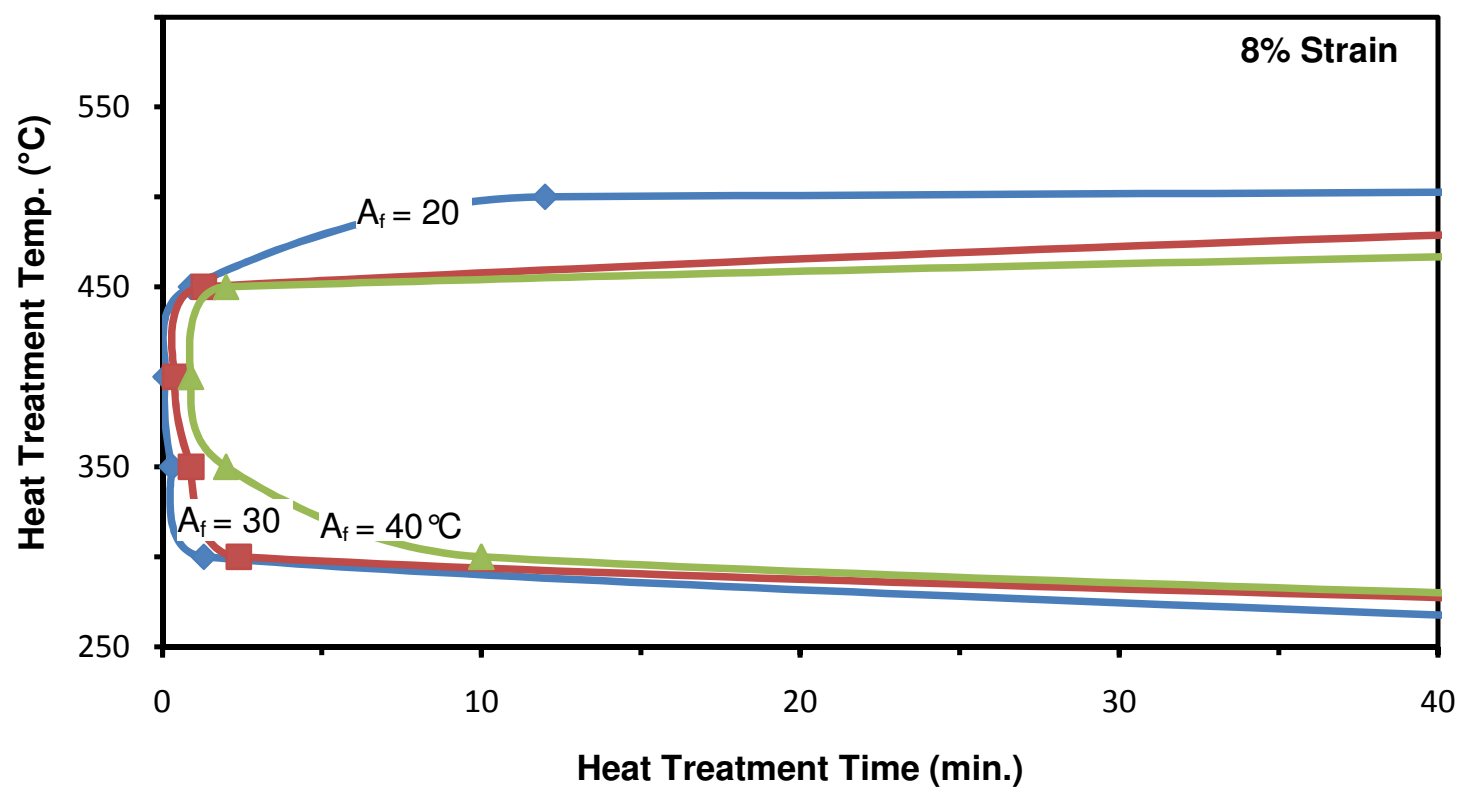

Figure 75 - TTT-like diagram illustrating the effects of heat treatment temperature and time for specimen heat treated at $8 \%$ strain. The maximum precipitation rate occurs at approximately $400^{\circ} \mathrm{C}$. 
TENSILE RESPONSE AT $400^{\circ} \mathrm{C}$ FOR 2 AND 30 MINUTES

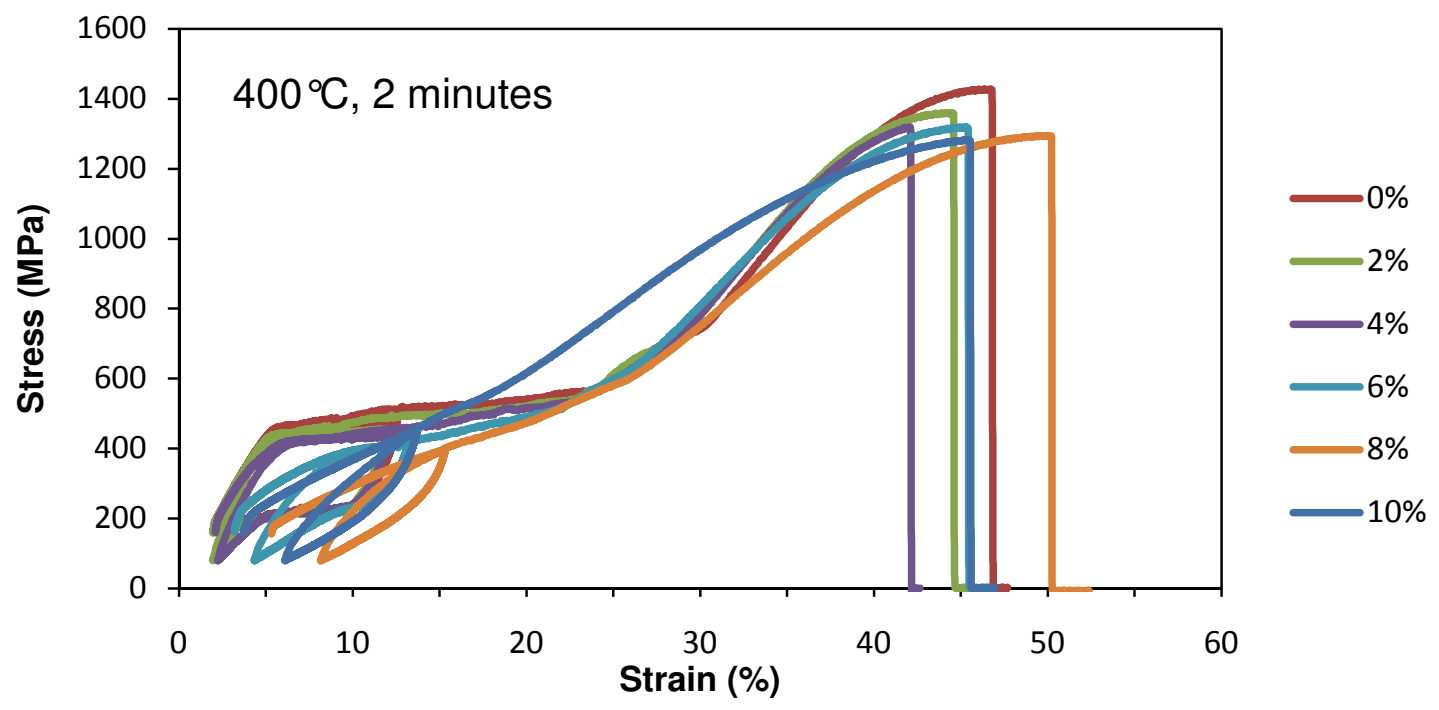

Figure 76 - Tensile response of specimen heat treated at $400^{\circ} \mathrm{C}$ for 2 minutes illustrated for all levels of applied strain. A superelastic flag is observed for specimen heat treated at strain levels of 0-4\%; higher strain levels tend to distort the superelastic flag. Also note a systematic decrease in UTS as applied strain increases.

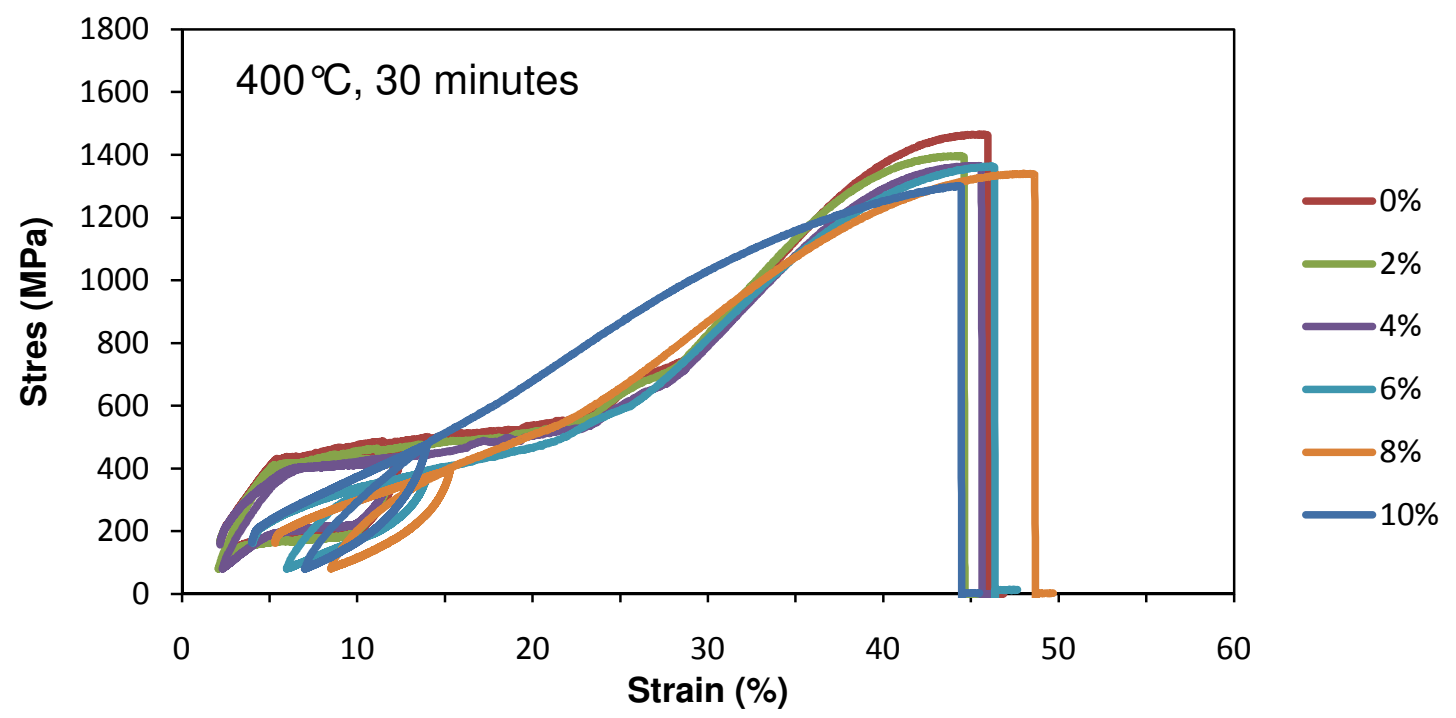

Figure 77 - Tensile response of specimen heat treated at $400^{\circ} \mathrm{C}$ for 30 minutes illustrated for all levels of applied strain. A superelastic flag is observed for specimen heat treated at strain levels of 0-4\%; higher strain levels tend to distort the superelastic flag. A decrease in UTS is observed with increasing level of applied strain. 


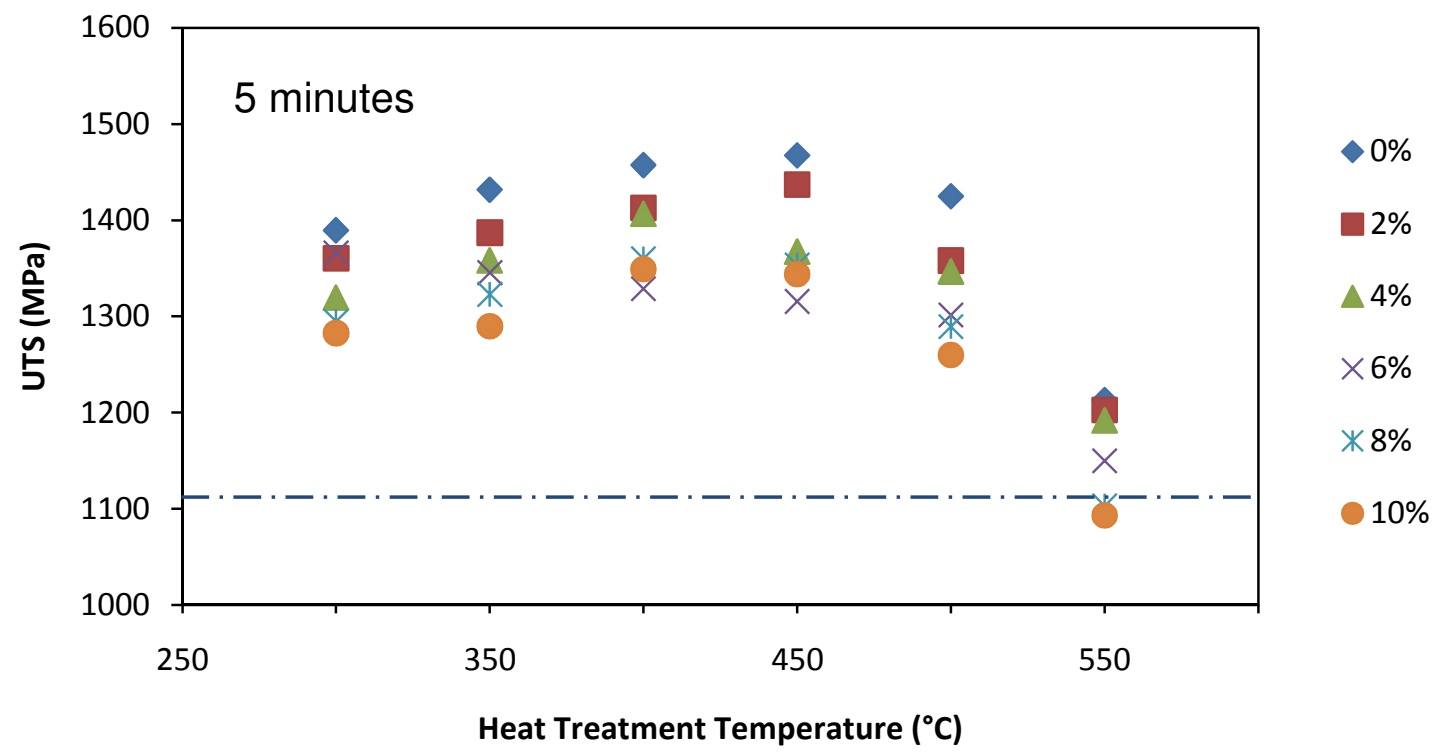

Figure 78 - Effect of applied strain and heat treatment temperature for specimen heat treated for 5 minutes. The blue dash line at 1116 MPa represents the UTS of the as-received wire. The maximum UTS is obtained between heat treatments temperatures of $400-450^{\circ} \mathrm{C}$;

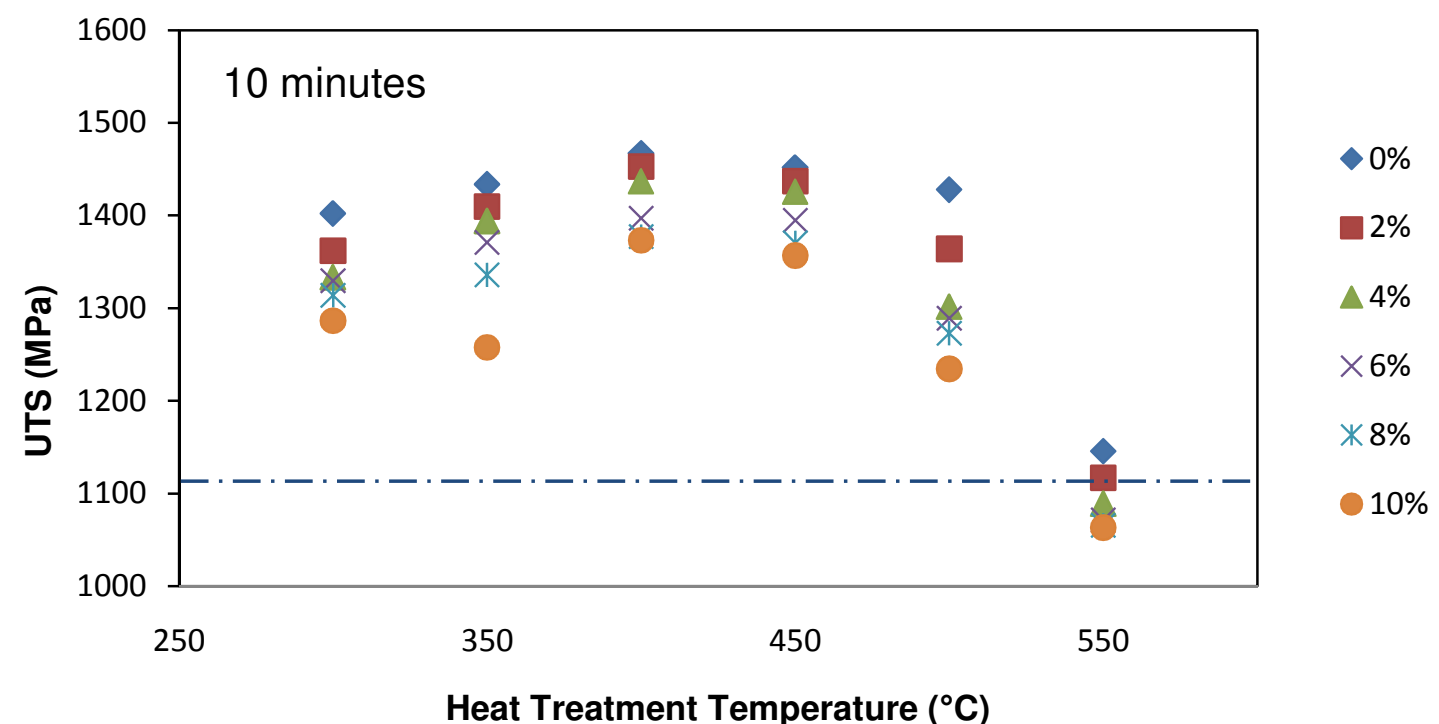

Figure 79 - Effects of applied strain and heat treatment temperature for specimen heat treated for 10 minutes. The blue dash line at 1116 MPa represents the UTS of the as-received wire. The maximum UTS is obtained between heat treatments temperatures of $400-450^{\circ} \mathrm{C}$. 
EFFECT OF HEAT TREATMENT TIME AT APPLIED STRAINS OF 2-8\%

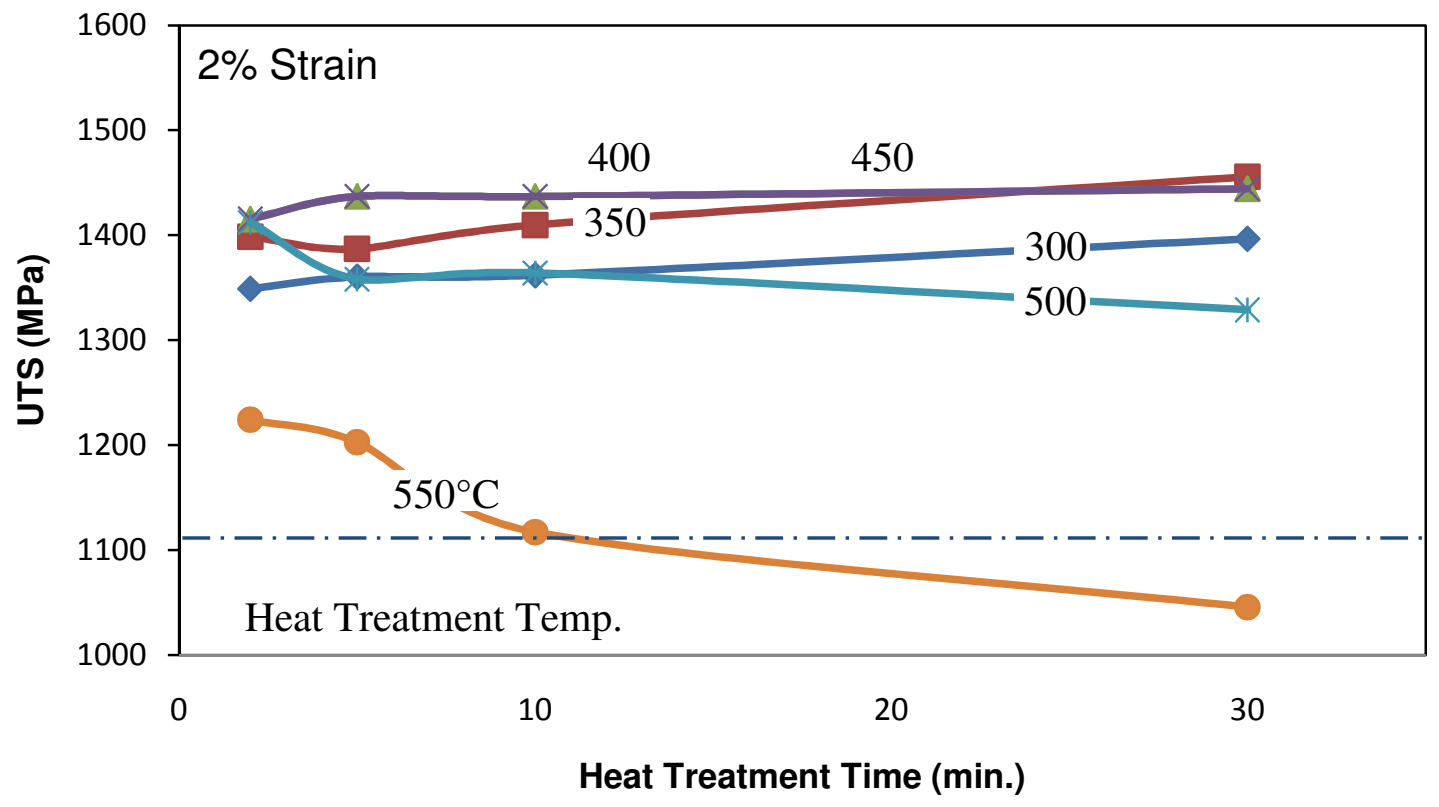

Figure 80 - Effect of time and temperature on the UTS for specimen heat treated at $2 \%$ strain. Heat treatment at $300^{\circ} \mathrm{C}$ does not significantly increase the UTS. Heat treatments between $350-450{ }^{\circ} \mathrm{C}$ tend to increase UTS; heat treatments at $500^{\circ} \mathrm{C}$ and above tend to decrease UTS.

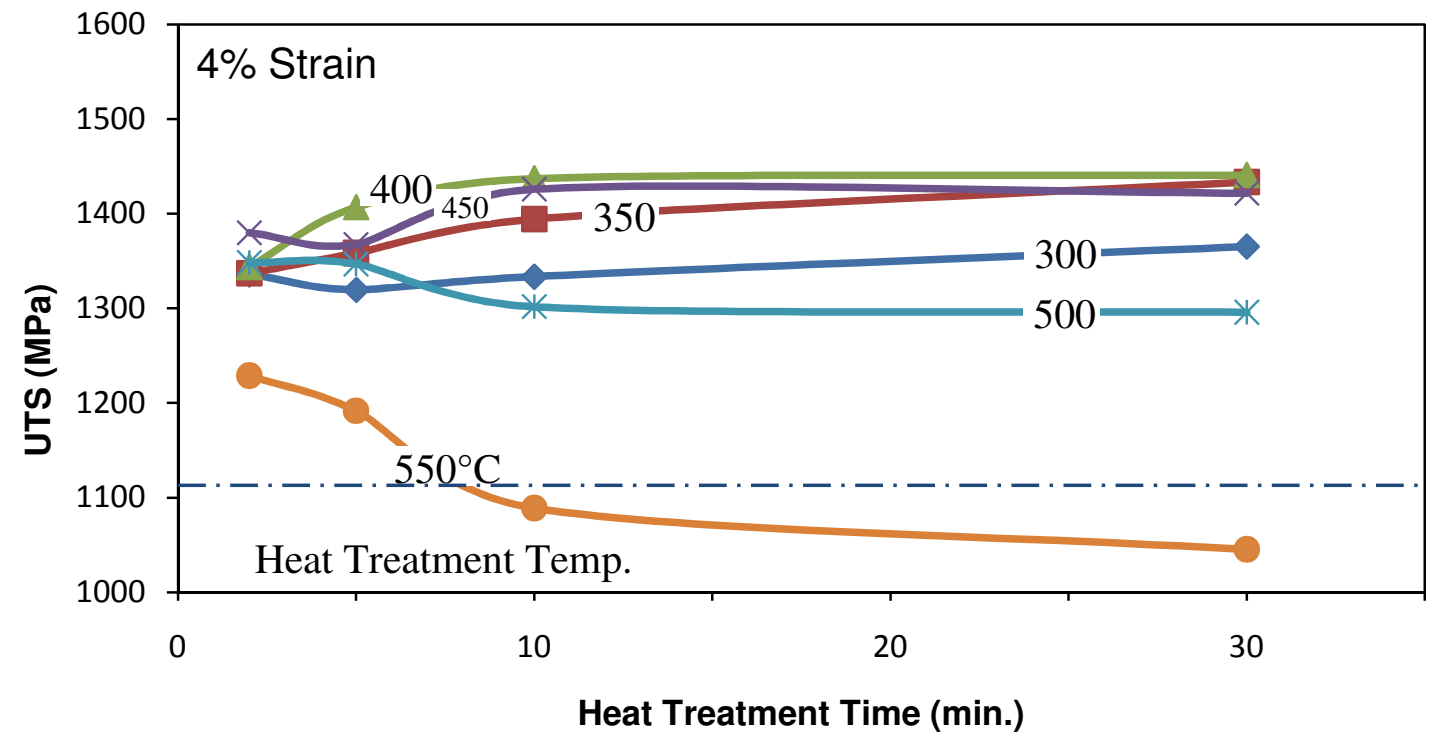

Figure 81 -Effect of time and temperature on the UTS for specimen heat treated at $4 \%$ strain. Heat treatment at $300^{\circ} \mathrm{C}$ does not significantly increase the UTS. A rapid increase in UTS at short times followed by a slower increase at longer times is observed between $300-500^{\circ} \mathrm{C}$. 


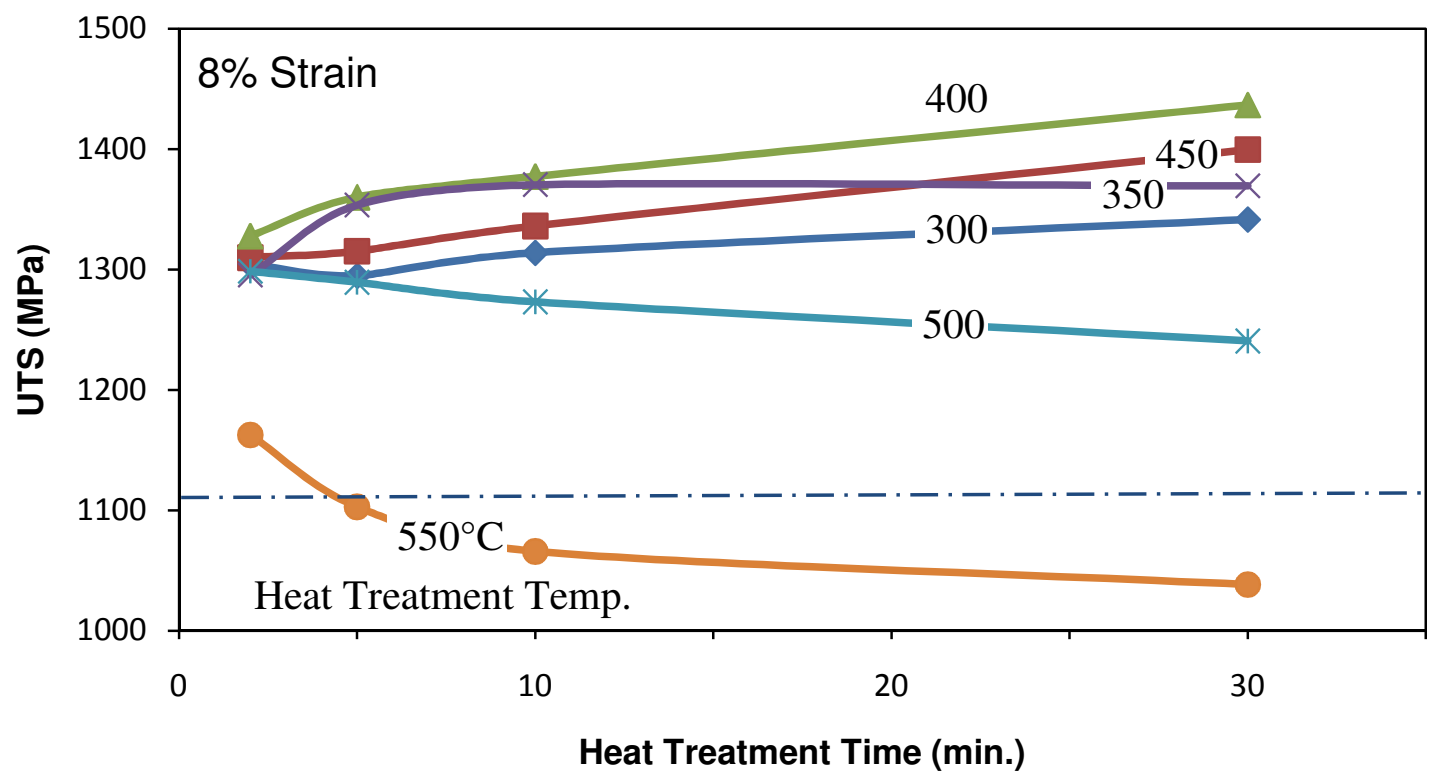

Figure 82 - Effects of time and temperature on the UTS for specimen heat treated at $8 \%$ strain. An increase in UTS is observed for heat treatments between $350-450{ }^{\circ} \mathrm{C}$. Note, heat treatments at $8 \%$ strain results in lower overall UTS as compared to a sample heat treated at lower levels of applied strain. 
CORRELATION OF UTS AND A AT 500 AND $550^{\circ} \mathrm{C}$

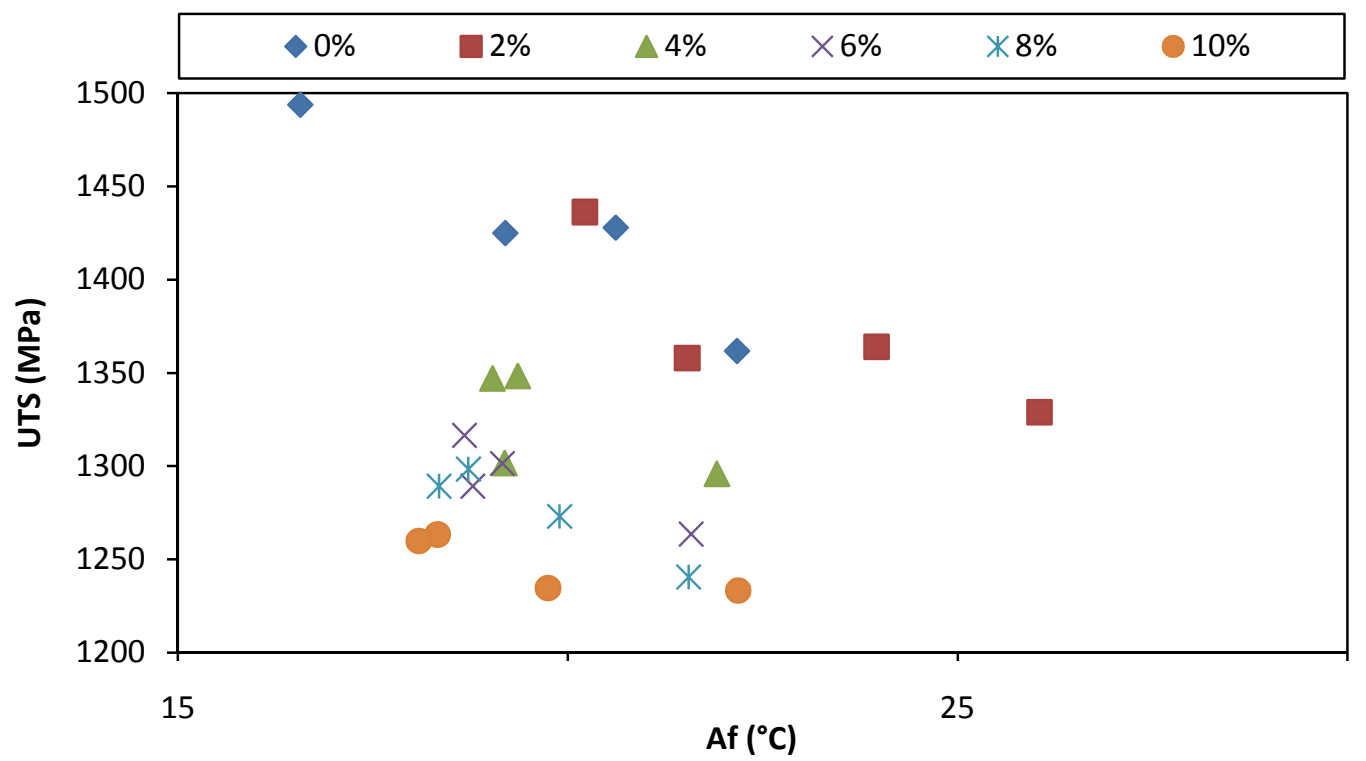

Figure 83 - Effect of transformation temperature on the ultimate tensile strength for all levels of applied strain at $500^{\circ} \mathrm{C}$. The spread in $\mathrm{A}_{\mathrm{f}}$ values decreases at $500^{\circ} \mathrm{C}$. Compared to the as-received wire, all treatments at $400^{\circ} \mathrm{C}$ have resulted in an increase in UTS.

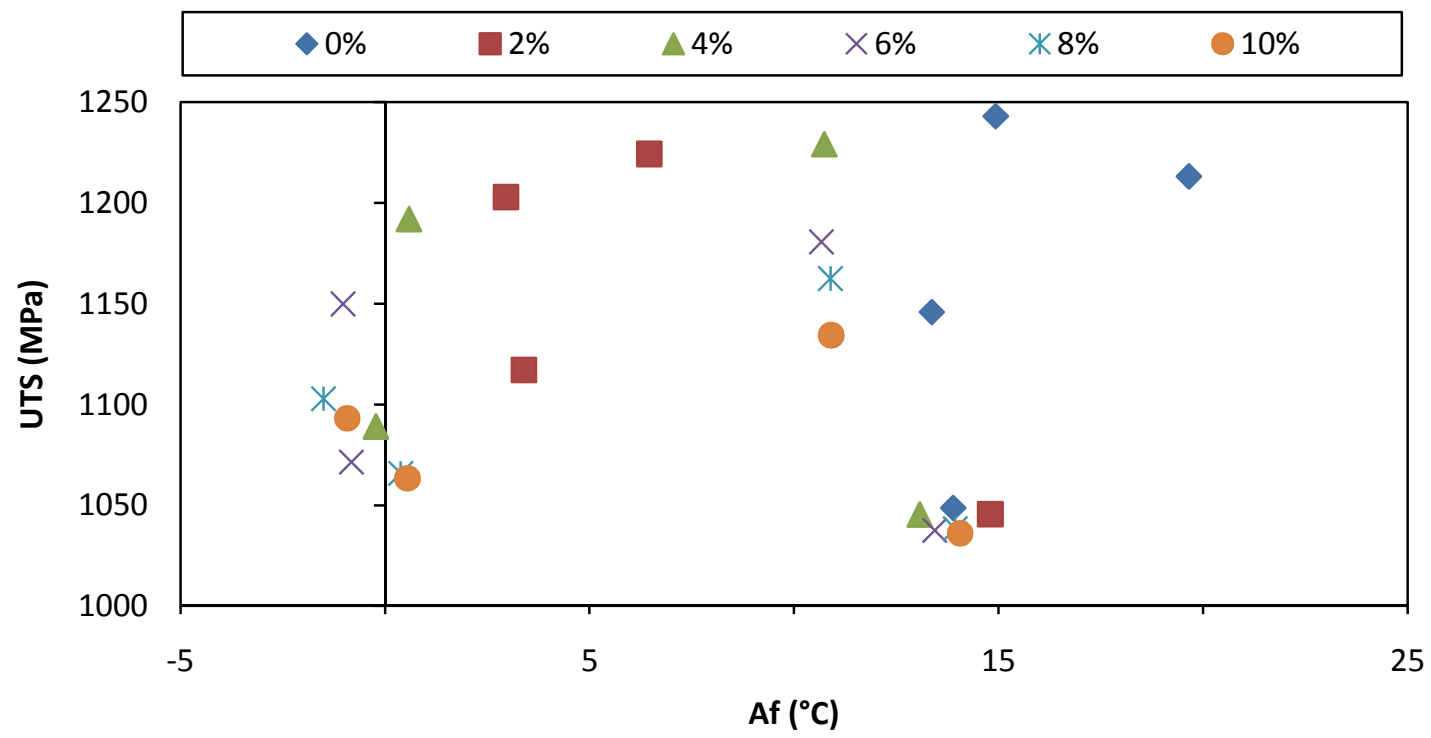

Figure 84 - Effect of transformation temperature on the ultimate tensile strength for all levels of applied strain at $550^{\circ} \mathrm{C}$. No general correlation exists between UTS and $A_{\mathrm{f}}$ at $550^{\circ} \mathrm{C}$. 


\section{APPENDIX IX \\ EFFECT OF TEMEPRATURE ON ELASTIC MODULUS AT 5 AND 10 MIN}

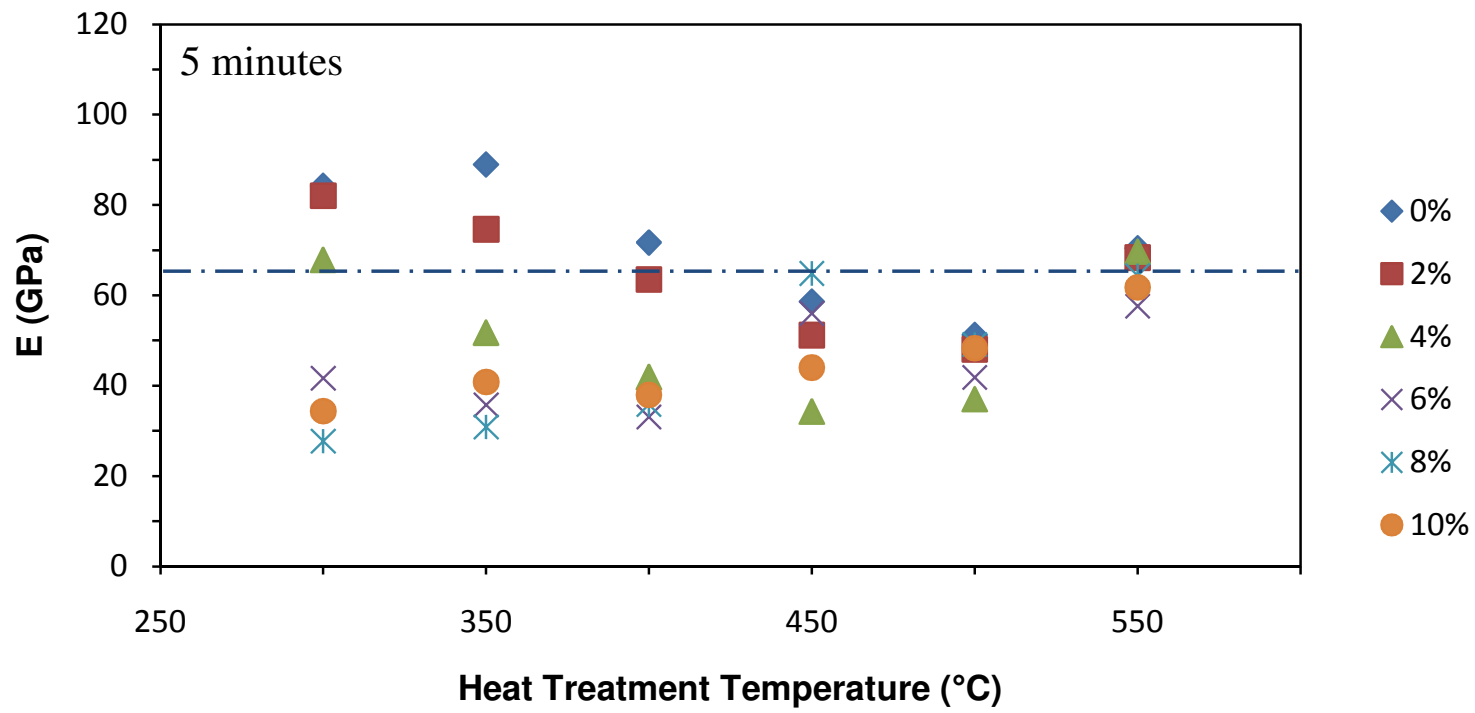

Figure 85 -Effect of applied strain and heat treatment temperature on the elastic modulus of specimen heat treated for 5 minutes. Higher levels of applied strain during heat treatment tend to decrease the elastic modulus; this trend is not consistent between heat treatment temperatures of $400-550{ }^{\circ} \mathrm{C}$

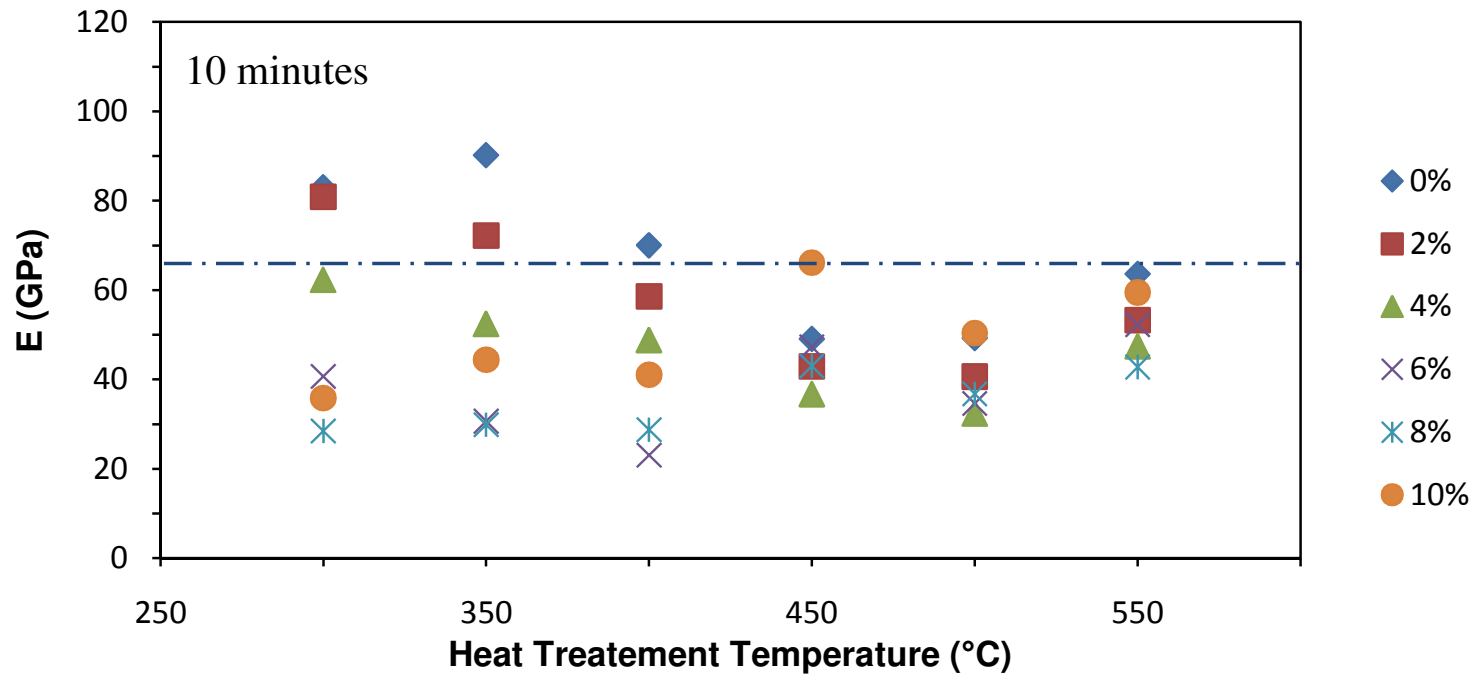

Figure 86 - Effect of applied strain and heat treatment temperature on the elastic modulus of specimen heat treated for 10 minutes. Higher levels of applied strain during heat treatment tend to decrease the elastic modulus; this trend is not consistent between heat treatment temperatures of 400-550 ${ }^{\circ} \mathrm{C}$. 
APPENDIX X

\section{EFFECT OF HEAT TREATMENT ON ELASTIC MODULUS APPLIED STRAINS OF \\ $2-8 \%$}

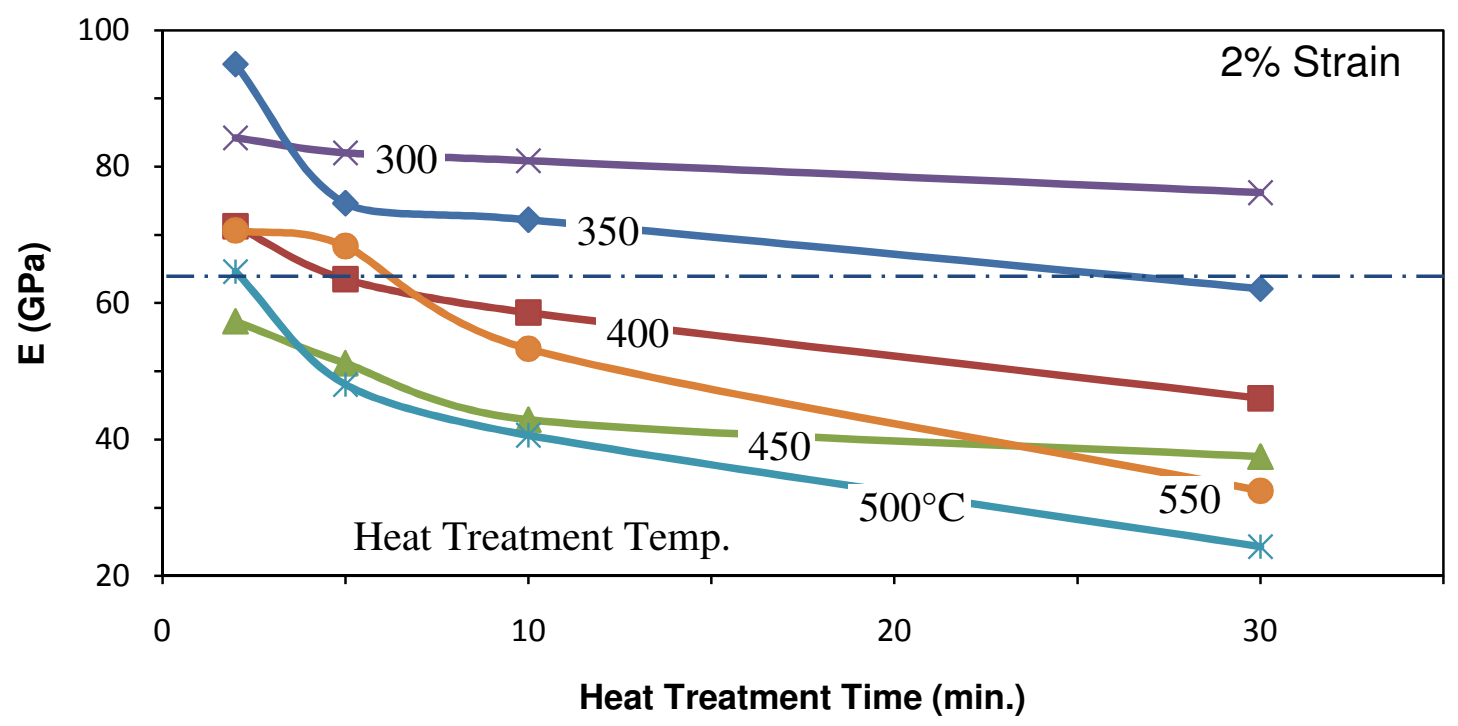

Figure 87 - Effect of heat treatment time and temperature on the elastic modulus for specimen heat treated at $2 \%$ applied strain. After a rapid increase in $\mathrm{E}$ at short times, all heat treatment temperatures tend to decrease $E$ with increasing heat treatment time.

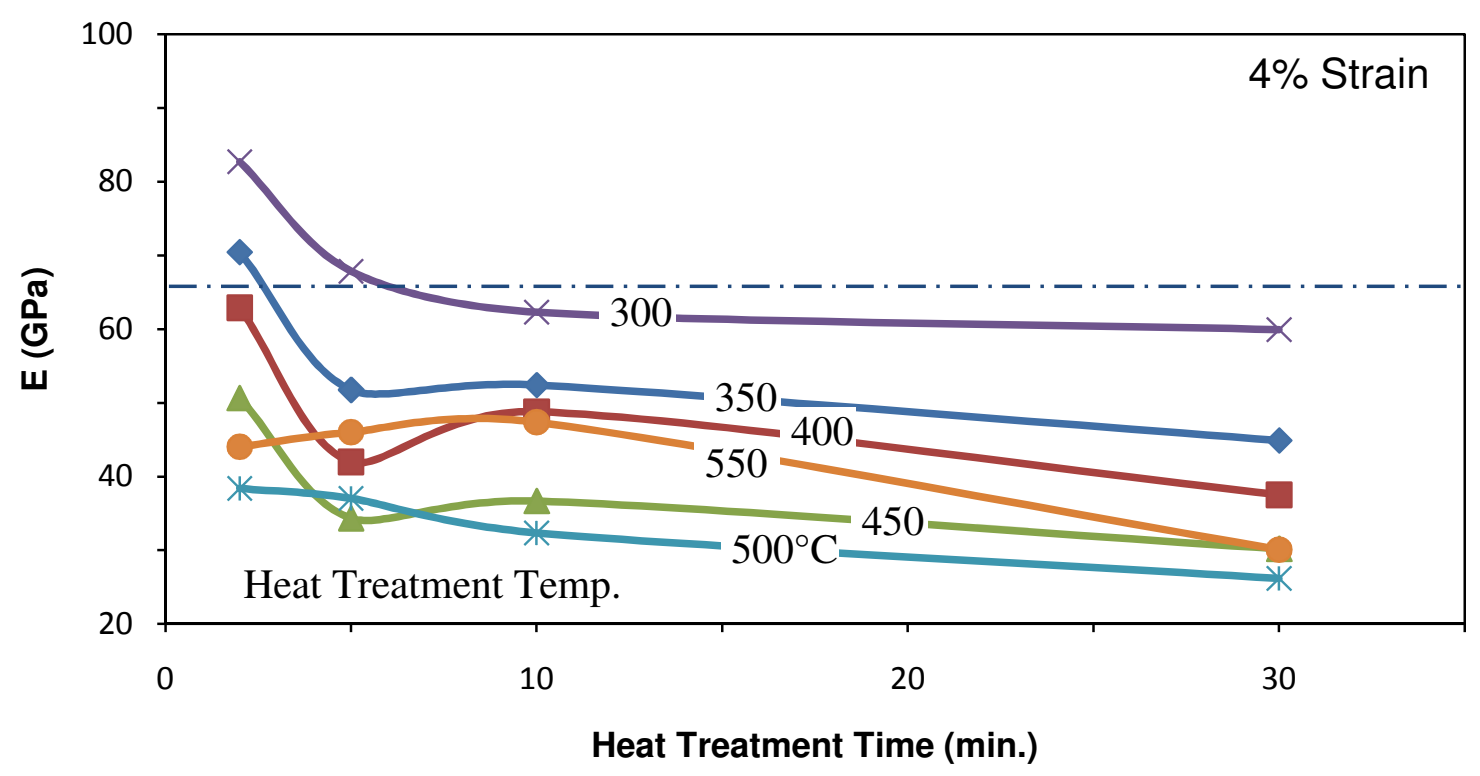

Figure 88 - Effect of heat treatment time and temperature on the elastic modulus for specimen heat treated at $4 \%$ applied strain. After a rapid increase in $E$ at short heat treatment times, all heat treatment temperatures tend to decrease $E$ with increasing heat treatment time. 


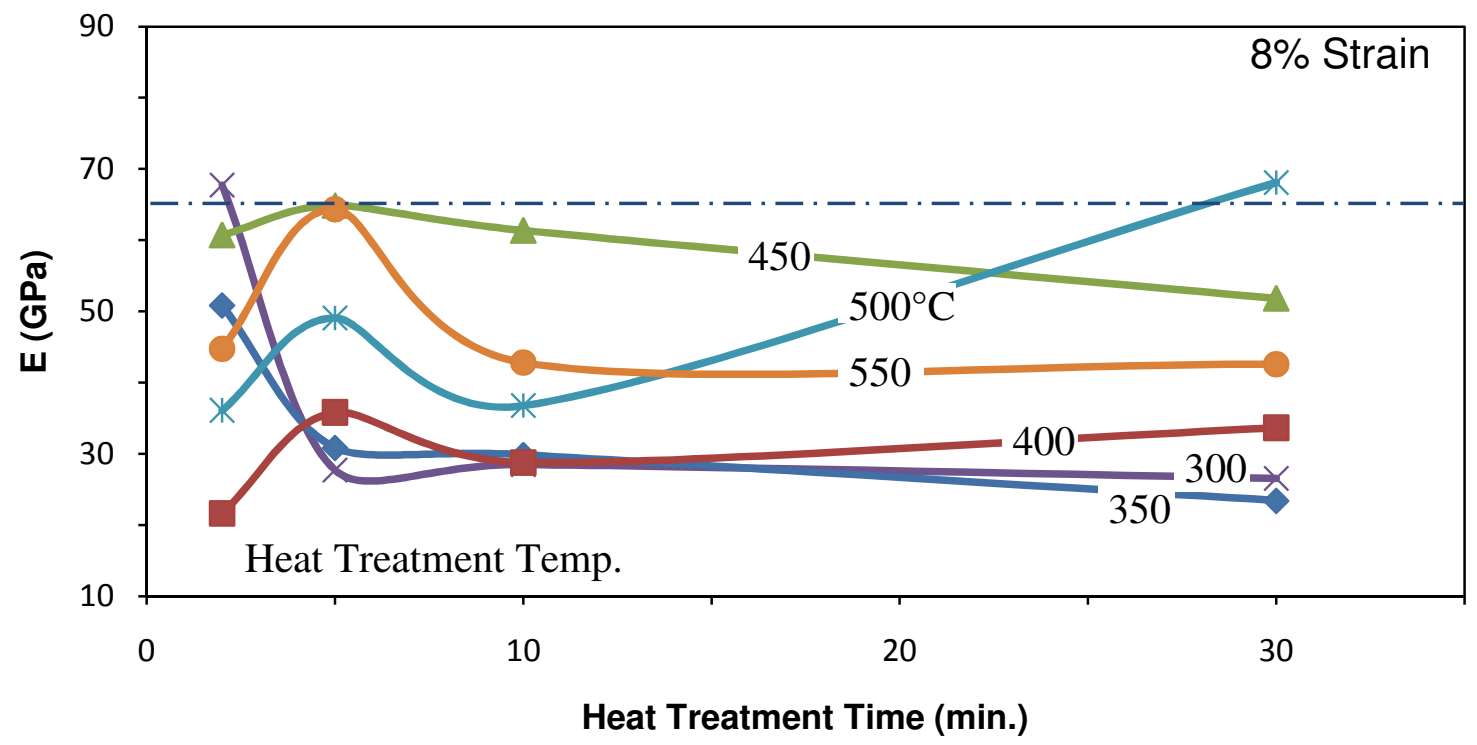

Figure 89 - Effect of heat treatment time and temperature on the elastic modulus of specimen heat treated at 8\% applied strain. A decrease at short times followed by a rapid increase between 2-10 minutes occurs between $450-550^{\circ} \mathrm{C}$. A rapid decrease occurs between $300-400^{\circ} \mathrm{C}$. 